\title{
UNIVERSITIES \\ AND REGIONAL \\ ENGAGEMENT
}

\section{FROM THE EXCEPTIONAL TO THE EVERYDAY}

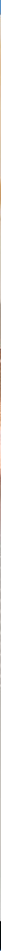

A leading \& impactful community

REGIONS AND CITIES

EDITED BY TATIANA IAKOVLEVA, ELISA THOMAS,

LAILA NORDSTRAND BERG, RÓMULO PINHEIRO, AND

PAUL BENNEWORTH

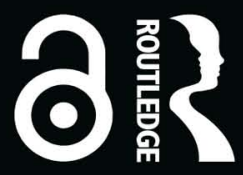


"The growth and significance of universities, and education more widely, has become ever more important in stimulating innovation and economic developments across nations and regions. This edited book provides a perspective into how higher education institutions and other agents operate by using a unique three tier macro, meso, and micro lens to view such relationships and the interplay of universities and educational providers with their external environment. This book is both timely and rewarding to the reader in providing such a rich conceptual framework and it covers a wide and diverse set of case studies across the globe."

Jeremy Howells, Professor and Dean of the Faculty of Business and Law, University of Portsmouth

"For too long, the academic and practitioner debate on the role of universities has focused on a narrow view of commercialization and knowledge exchange, drawing from a limited number of "best practice" cases. This edited book offers a necessary and timely counterview to this idealized picture. It focuses instead on the "mundaneness" of universities' regional engagement, unpacking their complex and context-specific institutional arrangements, practices, and interactions. It is a must-read for scholars and practitioners interested in understanding regional development, innovation, and higher education in real places."

\section{Elvira Uyarra, Professor of Innovation Studies,} University of Manchester

"This is a very welcome book which expands the discussion of universities' regional engagement both thematically and geographically by going beyond the well-known cases to explore the mundane, but important, regional engagement activities of a wide range of universities. Universities and their academics engage with regional actors in a myriad of ways, most of which go under the radar both in policy-making and in research. This book is a step towards redressing this imbalance."

\section{Rune Dahl Fitjar, Pro-rector for Innovation and Society and Professor of Innovation Studies, University of Stavanger}

"This book is important because it conceptualizes and provides examples of the broad range of mundane activities that makes up the majority of linkages between a university and its region. These everyday engagements connecting universities with their region are often neglected, while the attention has been on extraordinary cases of highly innovative regions and the commercialization of research with high economic impact. The chapters in this book are of great value for understanding how typical universities can engage with their region in a profound way."

Einar Rasmussen, Professor of Technology Management, Nord University 

$\because$ Taylor \& Francis http://taylorandfrancis.com 


\section{Universities and Regional Engagement}

The study of universities' role in regional engagement has traditionally been focusing on exceptional cases. This book presents a reconceptualization which embraces its underlying complexity and proposes a roadmap for a renewed research agenda. Starting from the grassroots level of universities' "everyday" engagements, the book delves into the manifold ways in which university knowledge agents build connections with regional partners.

Through 11 empirical chapters, the authors not only chart the diversity among case institutions, engagement mechanisms, and regional contexts but also use that diversity to advance a novel conceptual framework, centered on the process of mundaneness, for unpacking university-regions' everyday activities, taking into account the dynamic, complex, and co-evolving interplay between (a) key social agents and institutions, (b) the contexts in which they are embedded, as well as (c) the historical trajectories and strategic ambitions underpinning context-specific social arrangements and interactions that are mediated by temporal and spatial dimensions.

Drawing on evolutionary economic geography, innovation studies, management and organization studies, and historical perspectives, the volume advances a new mode of understanding university-regional engagement as a form of extendable temporary coupling, which also helps to address perennial policy and managerial questions alike of what to do with universities that do not serve local labour market needs and/or are located in regions suffering from brain drain. The book illustrates such dynamics from diverse national contexts and three continents: Brazil, Caribbean, China, Italy, Norway, and Poland.

This book will be valuable reading for advanced students, researchers, and policymakers working in economic geography, regional development, innovation, and higher education management.

Tatiana Iakovleva is Professor of Entrepreneurship at the Business School, University of Stavanger, Norway.

Elisa Thomas is Associate Professor at Nord University and Adjunct Associate Professor at the University of Stavanger, Norway.

Laila Nordstrand Berg is Associate Professor at Western Norway University of Applied Sciences, Norway.

Rómulo Pinheiro is Professor of Public Policy and Administration at the University of Agder, Norway.

Paul Benneworth was Professor of Innovation and Regional Development at Western Norway University of Applied Sciences, Norway. 


\section{RSA \\ Regional Studies Association}

A leading \& impactful community

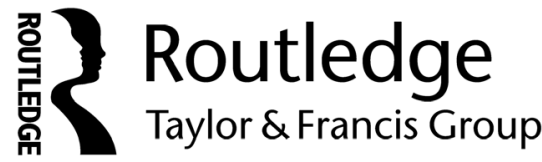

\author{
Regions and Cities \\ Series Editor in Chief: \\ Joan Fitzgerald, Northeastern University, USA \\ Editors: \\ Roberta Capello, Politecnico di Milano, Italy \\ Rob Kitchin, Maynooth University, Ireland \\ Jörg Knieling, HafenCity University Hamburg, Germany \\ Nichola Lowe, University of North Carolina at Chapel Hill, USA
}

In today's globalised, knowledge-driven and networked world, regions and cities have assumed heightened significance as the interconnected nodes of economic, social and cultural production, and as sites of new modes of economic and territorial governance and policy experimentation. This book series brings together incisive and critically engaged international and interdisciplinary research on this resurgence of regions and cities, and should be of interest to geographers, economists, sociologists, political scientists and cultural scholars, as well as to policy-makers involved in regional and urban development.

\title{
About the Regional Studies Association (RSA)
}

The Regions and Cities Book Series is a series of the Regional Studies Association (RSA). The RSA is a global and interdisciplinary network for regional and urban research, policy and development. The RSA is a registered not-for-profit organization, a learned society and membership body that aims to advance regional studies and science. The RSA's publishing portfolio includes five academic journals, two book series, a Blog and an online magazine. For more information on the Regional Studies Association, visit www.regionalstudies.org

There is a $\mathbf{3 0} \%$ discount available to RSA members on books in the Regions and Cities series, and other subject-related Taylor and Francis books and e-books including Routledge titles. To order, simply email Luke McNicholas (Luke.McNicholas@tandf.co.uk), or phone on +44 (0)20 70177545 and declare your RSA membership. You can also visit the series page at www.routledge.com/Regions-and-Cities/book-series/RSA and use the discount code: RSA225

\section{Metropolitan Governance in Latin} America

Edited by Alejandra Trejo-Nieto and José L. Niño-Amézquita

\section{Governance and City Regions \\ Policy and Planning in Europe \\ Karsten Zimmermann and Patricia Feiertag}

\section{Universities and Regional Engagement}

From the Exceptional to the Everyday Edited by Tatiana Iakovleva, Elisa

Thomas, Laila Nordstrand Berg, Rómulo

Pinheiro, and Paul Benneworth

For more information about this series, please visit: www.routledge.com/Regions-and-Cities/ book-series/RSA 


\section{Universities and Regional Engagement}

From the Exceptional to the Everyday

Edited by Tatiana Iakovleva, Elisa Thomas, Laila Nordstrand Berg, Rómulo Pinheiro, and Paul Benneworth 
Cover Image: (C) Phawat Topaisan / Getty Images

First published 2022

by Routledge

4 Park Square, Milton Park, Abingdon, Oxon OX14 4RN

and by Routledge

605 Third Avenue, New York, NY 10158

Routledge is an imprint of the Taylor \& Francis Group, an informa business

(C) 2022 selection and editorial matter, Tatiana Iakovleva, Elisa Thomas,

Laila Nordstrand Berg, Rómulo Pinheiro, and Paul Benneworth; individual chapters, the contributors

The right of Tatiana Iakovleva, Elisa Thomas, Laila Nordstrand Berg, Rómulo Pinheiro, and Paul Benneworth to be identified as the authors of the editorial material, and of the authors for their individual chapters, has been asserted in accordance with sections 77 and 78 of the Copyright, Designs and Patents Act 1988.

The Open Access version of this book, available at www.taylorfrancis.com, has been made available under a Creative Commons Attribution-Non Commercial-No Derivatives 4.0 license.

Trademark notice: Product or corporate names may be trademarks or registered trademarks, and are used only for identification and explanation without intent to infringe.

British Library Cataloguing-in-Publication Data

A catalogue record for this book is available from the British Library

Library of Congress Cataloging-in-Publication Data

Names: Iakovleva, Tatiana, editor.

Title: Universities and regional engagement: from the exceptional to the everyday / edited by Tatiana Iakovleva, Elisa Thomas, Laila Nordstrand Berg, Rómulo Pinheiro and Paul Benneworth.

Description: Abingdon, Oxon; New York, NY: Routledge, 2022. Series: Regions and cities RSA | Includes bibliographical references and index.

Identifiers: LCCN 2021052714 (print) | LCCN 2021052715 (ebook) | ISBN 9780367713072 (hardback) | ISBN 9780367713072 (paperback) | ISBN 9781003150299 (ebook)

Subjects: LCSH: Community and college. | Academic-industrial collaboration. | Regional planning. | Universities and colleges-Social aspects.

Classification: LCC LC237 .U4943 2022 (print) | LCC LC237 (ebook) | DDC 378.1/03—dc23/eng/20211103

LC record available at https://lccn.loc.gov/2021052714

LC ebook record available at https://lccn.loc.gov/2021052715

ISBN: 978-0-367-71307-2 (hbk)

ISBN: 978-0-367-71319-5 (pbk)

ISBN: 978-1-003-15029-9 (ebk)

DOI: $10.4324 / 9781003150299$

Typeset in Bembo

by Apex CoVantage, LLC 


\section{Contents}

List of figures $\quad$ ix

List of tables $\quad \mathrm{x}$

List of contributors $\quad$ xi

Acknowledgments xvi

Editorial foreword $\quad$ xvii

Preface xix

1 Universities' Mundaneness and Regional Engagement: Setting the Stage

ELISA THOMAS, PAUL BENNEWORTH, LAILA NORDSTRAND BERG,

TATIANA IAKOVLEVA, AND RÓMULO PINHEIRO

2 Unpacking Mundaneness: A Novel Conceptual Framework for Universities and Regional Engagement

RÓMULO PINHEIRO, LAILA NORDSTRAND BERG, TATIANA

IAKOVLEVA, ELISA THOMAS, AND PAUL BENNEWORTH

3 Changes and Continuities in the Development of Rural Teacher Education in the Fjords of Western Norway

LAILA NORDSTRAND BERG AND GUNNAR YTTRI

4 University Dynamic Capabilities to Boost Innovation Ecosystems: The Case of a University Alliance in Brazil

KADÍGIA FACCIN, ELISA THOMAS, AND CAROLINE KRETSCHMER

5 Exploring the Role of the University in the Creation of Knowledge Networks in the Aso Valley, a Rural Area in Marche Region (Italy) 
viii Contents

6 The Third Mission: Enhancing Academic Engagement with Industry

TATIANA IAKOVLEVA AND METTE ERIKSEN ADKINS

7 Student Entrepreneurship Programmes in Higher Education Institutions: Multi-scalar Embeddedness and Heterogeneous Regional Responses

ØYVIND MIDTBØ BERGE, ØYSTEIN STAVØ HØVIG, AND SVEIN GUNNAR SJØTUN

8 Student Incubators in China: The Cases in Shanghai and Wuhan

DIAN LIU

9 Aligning University Roles and Strategic Orientations: When Local Mandates and Global Aspirations Meet

IYAD ABUALRUB AND RÓMULO PINHEIRO

10 Emergent Strategies and Tensions Between Decoupled University Structures and Management Initiatives: A Case Study of a Strategy Process

JAMES KARLSEN AND RÓMULO PINHEIRO

11 Towards The Strategic Cooperation Of "Two Worlds": University-Local Government Relationships in Warsaw ANNA DĄBROWSKA, WOJCIECH DZIEMIANOWICZ, AND MAGDALENA CYBULSKA

12 Keeping Talents in the Region?: Educational Internships and Their Impact on Regional Development LAILA NORDSTRAND BERG AND KRISTIN LOFTHUS HOPE

13 Activist Leadership in the Caribbean: The Case of the University of the West Indies

ELIN M. OFTEDAL, EMILY DICK-FORDE, AND LUZ LONGSWORTH

14 Universities and Regions: New Insights and Emerging Developments

LAILA NORDSTRAND BERG, ELISA TOMAS, TATIANA IAKOVLEVA, RÓMULO PINHEIRO, AND PAUL BENNEWORTH 


\section{Figures}

2.1 Mundaneness as process 20

3.1 Critical junctures in the development and modes of change 36

4.1 Stages of innovation ecosystem 53

10.1 Timeline of UiA's strategy process 145

13.1 UWI's organizational structure: integrated third mission 197 


\section{Tables}

4.1 Universities' practices and the clusters of dynamic capabilities $\quad 50$

4.2 Dynamic capabilities to boost innovation ecosystems 52

5.1 The rural buzz dimensions adapted to the $\begin{array}{ll}\text { Agritur-Aso case study } & 65\end{array}$

6.1 Summary of hypotheses 81

6.2 Descriptive sample statistics 82

6.3 Involvement in entrepreneurial activities and in industry

6.4 Linear regression analysis of the effect of the university context on entrepreneurial intentions 83

6.5 Linear regression analysis of the university context on industry collaboration $\quad 83$

7.1 HEIs' entrepreneurship activities, strategies, and embeddedness 107

$\begin{array}{lll}8.1 & \text { Stakeholder groups } & 119\end{array}$

10.1 Competing logics within universities 144

10.2 Empirical manifestation of competing logics at UiA 151

$\begin{array}{lll}12.1 & \text { Examples of regional internship placements } & 179\end{array}$

13.1 The elements of the entrepreneurial architecture 192

13.2 Data sources for third-mission activities and the entrepreneurial architecture $\quad 195$

14.1 Mapping the volume's empirical contributions 206

Appendix 6.1 Constructs used in the study 94 


\section{Contributors}

\section{Editors}

Tatiana Iakovleva is Professor of Entrepreneurship at the Business School, University of Stavanger (UiS), Norway. She has researched topics related to entrepreneurial intentions, innovative working behaviour, factors that affect firm growth and performance as well as regional innovation systems, and their effects on new path creation and path development. Recently her research focus was stakeholder inclusion and responsible innovation.

Elisa Thomas is Associate Professor at Nord University Business School and Adjunct Associate Professor at the University of Stavanger, Norway. She is a leader of the Academic Division in Competences, Behaviour, and Culture for Innovation at the Brazilian Academy of Management (ANPAD), and a leader of the Special Interest Group on Responsible Innovation at the International Society for Professional Innovation Management (ISPIM).Her research interests include entrepreneurship and innovation ecosystems, the role of universities in regional development, start-up incubators and technology parks, and open innovation intermediaries. Recently she has been involved in research on stakeholder inclusion and responsible innovation.

Laila Nordstrand Berg has a PhD in Public Policy and Administration from University of Bergen, Norway. She is Associate Professor at Western Norway University of Applied Sciences (HVL). There she is leading the research group, Innovation and Governance in Public Sector, and is co-leading the research pillar, Public Sector Innovation. She is also an associate member of the GOLEP research group at the University of Agder (UiA). Laila's research interest is related to the intersection between public policy and administration, organizational studies, reforms, the influence of the market on management of hospitals and higher education and the effect of higher education on regional development.

Rómulo Pinheiro is Professor of Public Policy and Administration at the University of Agder (UiA), Norway, where he is Deputy Head of Department for Political Science and Management and member of the research group 
on Public Governance and Leadership (GOLEP). He is also a member of the Centers for Digital Transformation (CeDiT), for Advanced Studies in Regional Innovation Strategies (RIS), and the Jean Monet's Center of Excellence "Laboratories of Differentiated Integration in a Post-Brexit Europe", all based at UiA. Rómulo's research interests are located at the intersection of public policy and administration, organizational theory, economic geography, innovation, and higher education studies. His recent work encompasses two co-edited volumes on organisational resilience (Palgrave, 2022) and the Governance of Complexity in Turbulent Times (Edgar Elgar, 2022).

Paul Benneworth (1974-2020) was Professor in Innovation and Regional Development at the Western Norway University of Applied Sciences, Norway. Previously, he was a senior researcher at the Center for Higher Education Policy Studies (CHEPS) at the University of Twente (Netherlands). Benneworth's research focused on the dynamics of innovation and societal change in peripheral regions.

\section{Authors}

Iyad Abualrub is Associated Research Fellow at the Department of Education, University of Oslo ( $\mathrm{UiO})$, Norway. Research interests in the higher education area include institutional dynamics, learning environments and student experience, quality and change management.

Mette Eriksen Adkins currently works as global product marketing manager for Laerdal Medical AS in Stavanger, Norway. Mette has more than 15 years of experience of surveying consumers in tech markets. Her interests are in survey methodology and design that drive consumer insights that support good business decisions.

Chiara Aleffi has an industrial $\mathrm{PhD}$ in human sciences. Currently she is a postdoctoral researcher on the topic "University and self-reflection tools for regional action" at the Department of Education, Cultural Heritage and Tourism at the University of Macerata. In recent years she gained experience in European projects, stakeholder's engagement, and innovation brokering. Her main fields of studies are tourism, agribusiness, rural development, and place branding in the framework of RIS3.

Øyvind Midtbø Berge is Associate Professor in working life, innovation, and regional development at Western Norway University of Applied Sciences (HVL). He is the deputy centre manager for the Mohn Centre for Innovation and Regional Development and has been responsible for HVLs student entrepreneurship programme, HVL Skape.

Giovanna Bertella received her $\mathrm{PhD}$ about learning and networking in tourism from the Department of Sociology, Political Science and Community Planning at the Arctic University of Norway (UiT). Currently she 
is Associate Professor at the School of Business and Economics, at UiT. Her main research interests are management, marketing, innovation, entrepreneurship, tourism and leisure studies, and food studies.

Alessio Cavicchi is Full Professor at the Department of Education, Cultural Heritage and Tourism at the University of Macerata. His main fields of interest and research are consumer food choice, economics of food quality and safety, sustainable tourism, and innovation in the agri-food sector.

Magdalena Cybulska is a $\mathrm{PhD}$ student and assistant (in teaching staff) at the Faculty of Geography and Regional Studies at the University of Warsaw, Poland. Her research interests are regional and local development (in particular the development paths of municipalities), development strategies, and territorial foresight.

Anna Dąbrowska is Assistant Professor at the Faculty of Geography and Regional Studies at the University of Warsaw, Poland. She has a PhD degree in earth sciences (geography) from the University of Warsaw, and her dissertation was related to the knowledge transfer process. Her research interests are the role of universities in regional development, innovation systems, and local-level public policies. She has experience in national and international research projects and consultancy projects for central and local government in Poland.

Emily Dick-Forde works at the University of the West Indies (UWI) as a manager for special initiatives. Dr Dick-Forde obtained her PhD in accounting (corporate social and environmental reporting) from the University of Dundee, Scotland, in 2000. She was appointed a Senator in December 2007, at which time she was also appointed Minister of Planning, Housing and the Environment. Her research interests are sustainable development, accounting, and management.

Wojciech Dziemianowicz is Associate Professor at the Faculty of Geography and Regional Studies at the University of Warsaw, Poland. He is Head of Chair of Urban Geography and Spatial Planning. His research interests are strategical planning and management in public sector, regional and local development, and territorial marketing.

Concetta Ferrara is an industrial $\mathrm{PhD}$ student in human sciences at the Department of Education, Cultural Heritage and Tourism at the University of Macerata. In the last years, she gained experience in stakeholder's engagement through participatory approaches and European and regional projects on rural development and place branding. Her main fields of interest and research are university-business collaboration for local development and experiential and relational tourism in rural and inner areas.

Kristin Lofthus Hope is Associated Professor at the Department of Business Administration at the Western Norway University of Applied Science s (HVL). 
She has a $\mathrm{PhD}$ degree in science and technology studies. Her research experience and interests cover the study of organization and technology, knowledge production, cultural studies, reforms, and institutional change in higher education. In addition, she has also investigated how policy measures are governed, managed, and organised, especially regarding dropout in upper secondary school.

Øystein Stavø Høvig is an associate professor at the Mohn Centre for Innovation and Regional Development at Western Norway University of Applied Sciences (HVL). He is experienced with research, teaching, and facilitation efforts related to innovation and entrepreneurship. His research interests include entrepreneurship, entrepreneurship education, academic entrepreneurship, technology transfer, and geography of innovation.

James Karlsen is Professor at the University of Agder (UiA), Norway. He is Head of Department of Working Life and Innovation at the School of Business and Law. Karlsen's research interests include industrial development and regional innovation, action research for territorial development, higher education institutions, and regional development.

Caroline Kretschmer has a $\mathrm{PhD}$ in Business from UNISINOS University in Brazil. Her research interests include entrepreneurship and innovation ecosystems, strategic management, and international business.

Dian Liu is currently Associate Professor at the University of Stavanger (UiS), Norway. After completing her $\mathrm{PhD}$ at the University of Hong Kong on personal advancement of university graduates in job search, she is working on graduate entrepreneurship and regional innovation, as well as internationalization of higher education. At UiS, she is leading the research group on "Education, Work and Social Cohesion" with international colleagues from diverse scientific disciplines.

Luz Longsworth is the former Pro Vice-Chancellor and Principal of the University of the West Indies (UWI) Open Campus. She is also a certified trainer in leadership courses for the internationally renowned John Maxwell Company and has participated in various consulting projects in the Caribbean and the UK. Dr Longsworth's research includes leadership development, change management, and organizational development and transformation.

Elin M. Oftedal is Professor in change management and innovation at the University of Stavanger (UiS). Oftedal's research interests include responsible innovation, sustainable innovation and business models, student entrepreneurship, and the entrepreneurial university.

Gigliola Paviotti holds a $\mathrm{PhD}$ degree in education and works as a research fellow at the University of Macerata, Italy. She has worked more than 20 years in the education and training field, focusing on the employability topic and 
transitions from education to work. In recent years, her research work has focused on place-based approaches to support graduates' employment in local labour markets.

Svein Gunnar Sjøtun is Associate Professor at the Mohn Center for Innovation and Regional Development at the Western Norway University of Applied Sciences (HVL). Sjøtun has a background from economic geography and innovation studies and is also interested in studies of sustainability transitions and responsible innovation. He has also worked as an innovation advisor with regard to student entrepreneurship at HVL.

Sabrina Tomasi has an industrial $\mathrm{PhD}$ in human sciences. Currently she is a postdoctoral researcher at the Department of Education, Cultural Heritage and Tourism at the University of Macerata, Italy. Her main current research topic is the universities' contribution in the regional innovation ecosystem. In recent years she investigated tourism-related topics and took part in several European and regional projects on rural development and place branding and also in the framework of RIS3, and she has also gained experience in stakeholder's engagement and innovation brokerage approaches.

Gunnar Yttri has a Dr. Philos. degree in history from the University of Oslo $(\mathrm{UiO})$, Norway. He has worked as a researcher and historian at $\mathrm{UiO}$ and at the Western Norway University of Applied Sciences (HVL) and has published works on contemporary technological, economic, intellectual, and regional history. On 1 January 2021 he was appointed HVL's new Rector. 


\section{Acknowledgments}

The idea for this book emerged from our research project: "The role of higher educational institutions in regional development - connected or disconnected?".

Our first thanks are directed to the University and College Network for Western Norway for funding the project. This work has transformed the way we look at university-regional engagements.

We are also grateful to all contributors, including our authors and informants from cases and surveys. Furthermore, it would not be possible to write this book without inputs from all stakeholders of the regional university-industry ecosystem, including industry actors, academics, entrepreneurs, students, municipality, and cluster representatives who share their viewpoints with us. There are too many to mention by name, but we are grateful to all of them.

Thanks also go to Leanne Benneworth for being supportive regarding Paul Benneworth's legacy.

Special thanks are due to the team at Routledge Publishing for their support during the writing and publication process. 


\section{Editorial foreword}

This edited volume was initiated in late 2019 as a part of the project "The role of higher educational institutions in regional development - connected or disconnected?", funded by the University and College Network for Western Norway. From the beginning, it was meant to be a collaborative effort between researchers from three Norwegian universities: the University of Stavanger, the University of Agder, and the Western University of Applied Sciences. The idea of the volume emerged as we met to discuss the project in a series of workshops held during 2019 and 2020. One of the key figures in those discussions was our dear friend and colleague, Prof. Paul Benneworth, unquestionably one of the brightest minds of our days in the field of regional science and innovation studies. Paul was adamant about the need to move beyond "happy family stories" and, instead, pay close attention to the more mundane aspects, including tensions and dilemmas, associated with everyday engagement between universities and multiple societal actors. It was around this central idea of mundaneness and everyday activities and building on key work in the area, including Paul's seminal contributions, that the volume took shape and evolved. It was then decided that we would need to mobilize several colleagues from the Nordics and elsewhere to shed light on this somewhat neglected aspect of universities' societal engagement. Paul unexpectedly passed away in May 2020, leaving behind a beautiful family and numerous happy memories among colleagues and friends all over the globe. The shocking news of Paul's passing was a big loss for all of us who knew him well and worked with him closely, including many of the authors and co-editors of this volume. Given that we already had the commitment from both the publisher and the chapters' authors, in addition to permission from Paul's wife to continue, we then decided to complete the volume both to bring out the main message of the importance of unpacking the more mundane aspects, but also in memory of our dear friend and colleague whose life was cut way too short. We have tried our best to keep Paul's original vision for this volume, following the path left from brainstorming and designing the volume with him. Nevertheless, books are organic entities, and as with institutions, they tend to gain "a life of their own" as we go about sharing thoughts and ideas and collecting empirical data to either prove or disprove them. The first two chapters and the volume's conclusion were primarily 
developed following Paul's passing, expanding on the original idea as sketched out by Paul in the book proposal. We have done our best to keep the volume truthful to its original spirit, and we trust that Paul would have agreed with most of our core arguments, as well as the research, policy, and managerial implications going forward. It is our collective hope that this volume, which pays tribute to Paul's remarkable contributions to the field, will provoke new and insightful academic, policy, and managerial debates regarding the role of universities and other types of higher education institutions in the broader socio-economic and cultural development of the societies in which they are embedded, at the local, regional, national, and global levels. In times of increasing change and global turbulence, like the ones we are currently experiencing, it has never been so critical to gain a better understanding of the various roles that key social institutions, like universities, play in tackling the great challenges facing humanity in the $21^{\text {st }}$ century.

Tatiana Iakovleva, Elisa Thomas, Laila Nordstrand Berg, and Rómulo Pinheiro

September 2022

Stavanger, Bodø, Sogndal, and Kristiansand 


\section{Preface}

The early 21 st century seems in some ways to be the time of the university. Universities have seen massive growth in the later years of the previous century, as being a graduate is needed for more and more occupations, and with the increasing importance in our lives of science-based industries in information and communication technologies and biosciences much of which has emerged from universities. So, policymakers look to universities to help solve many of the great challenges facing society. Yet the focus is often placed on the exceptional and transformative, on internet unicorn spin-offs, vaccines for global pandemics and novel, exotic materials. The typical university is however involved in a multitude of external engagements which are less dramatic than this but also more pervasive. Whether at a local and regional scale, or working through international collaborations, universities can be characterized by their universalism, their ability to bring together a wide range of disciplines and forms of knowledge to address problems, large and small, and to train up the next generation of problem-solvers and knowledge workers.

This book focuses on the mundane aspects of university-regional engagement across a range of ordinary regions, and it is right to do so. From a perspective of a university leader or a local policymaker it is the ongoing everyday engagements that absorb time and effort. Once in a while something sexier comes along, in the form of a technological breakthrough that forms the basis of a spin-off, although for most universities this is an unlikely event. For most, engagement is mundane, often routine, but no less important for that, and often can be transformative for the individuals and communities involved.

We have become accustomed in the academic and policy literature to seeing a focus on those exceptional occurrences such as patents or spin-off companies, because they are notable and measurable. They make for good stories and can be counted and valued and hence are ideal for researchers wishing to test hypotheses or politicians wanting to make the case for universities working more closely with business. An industry is being built up around metrics, indicators and rankings, which focus primarily on research outputs but when needed can incorporate patent numbers, licence income and returns on spin-off firms. In this way those universities which are good 
at such commercialization, usually because of huge research incomes, are presented as "best practice" and we see the promulgation of the MIT model or the Cambridge model as the way forward, even though such exceptional universities are impossible to replicate. Yet while good at commercialization, the global research leaders may not be so well placed in delivering a wider range of more mundane engagement. Universities are not all the same, and it is the mix of institutions of different types that constitute a higher education system, and regions need a combination of forms of higher education and forms of engagement. Across the system there is a proliferation of approaches to engagement, and much is almost invisible to policymakers at the national level and hence mostly ignored. Our focus on commercialization blinds us to the wider mix of engagement and, as a result, policymakers design policies focused on the narrow form of commercialization. We need to uncover the breadth of engagement, make it visible and try to indicate its importance even if we can't apply neat metrics such as the number of patents granted. This book is an important step in that direction.

The book explores depth of engagement through a detailed examination of the Norwegian case with several chapters examining different aspects of engagement from strategic relations between a university and its region to teacher training in rural areas and student entrepreneurship. This depth provides guidance to other regions on some of the issues to be examined in everyday university links. It also looks internationally though to Poland, Brazil, China and the West Indies, examining the nature of university engagement in very different local contexts from the megacities of China to the islands of the Caribbean. Local context is important, and local arrangements may not be duplicated in other contexts where institutional arrangements differ, but understanding where to look to find engagement and the range of possibilities for productive engagement, however mundane, is a vital lesson for academics and policymakers, so we can shift our perspective from the limitations of looking only for unicorns.

This book is also a tribute to one of its authors who has not been able to see its completion. Paul Benneworth passed away unexpectedly while the book was in its early stages, but the book reflects many of the concerns he had about the need to look beyond emblematic "happy family" stories as he put it and to look to the everyday life of the university and its community relations. I had the good fortune to work with Paul for around 24 years on and off, mostly on, and watched him carve out an important place in the literature on universityregional engagement. He would be pleased with the way the book has been brought to fruition. The absorption of its messages and the appreciation of the benefits to society of mundane engagement would be a suitable tribute to his contribution to the literature and the debate.

David Charles,

Professor of Enterprise and Innovation and Director of the Northumbria Centre for Innovation, Regional Transformation and Entrepreneurship (iNCITE), Newcastle Business School, Northumbria University, United Kingdom 


\title{
1 Universities' Mundaneness and Regional Engagement
}

\author{
Setting the Stage
}

\author{
Elisa Thomas, Paul Benneworth, Laila Nordstrand \\ Berg, Tatiana Iakovleva, and Rómulo Pinheiro
}

\begin{abstract}
This chapter introduces the main logic of this volume, which starts from the grassroots level of universities' "everyday" engagements, looking at the manifold ways in which university knowledge agents build connections with multiple regional partners across the public and private sectors, and civic society more generally. Roles, functions and normative orientations of universities in the context of their surrounding regions have, in many cases, been taken for granted and, thus, have not been systematically addressed and/or still lack theorizing, due to the focus being on extraordinary, largescale and eye-catching activities, and financially impressive transactions such as patents and spin-offs, embedded in "happy family stories" of ambitious regional development projects and coalitions.
\end{abstract}

There is an extensive academic and policy literature regarding the various ways in which universities contribute to society through their teaching and research activities, as well as what has been termed the "third mission" (cf. Pinheiro et al., 2015). Much attention has been given to universities' formal relationships with multiple stakeholders, in the context of making their knowledge externally available in different ways as a means of supporting national and local economic development, as well as innovation (Perkmann et al., 2013).

However, there is a growing recognition that this set of easily measured activities is only a very limited subset of what universities do (Laredo, 2007), and that tasks associated with broader regional engagement are often located at the fringes of universities' core purposes (Benneworth, 2013). Nonetheless, these restrictive conceptions have dominated policy and academic debates because of their easy measurability (OECD, 2007; Charles \& Wilson, 2012). There has been a tendency within the literature to treat universities' societal contributions in a very reductive way, regarding them as strategic actors contributing mainly to innovation, and with a limited number of best practices which can optimize these knowledge transfer activities. 


\section{Elisa Thomas et al.}

This reduction has created a situation in which we are often studying and making policy for the small and the exceptional, forming university policies for counting measurable outcomes such as numbers of spin-offs and/or patents. This ignores the larger contexts - local, regional, national and global - within which universities and other types of higher education institutions (HEIs) operate and are deeply embedded (Krücken et al., 2007; Marginson \& Rhoades, 2002) and, specifically, the variety of ways in which their everyday teaching, research and engagement activities - what we term here as "mundaneness" can create wider and more sustainable societal impacts.

This edited volume comprises 11 empirical chapters from different geographical and cultural contexts. Through these chapters, we not only chart the diversity among case institutions, engagement mechanisms and regional contexts, but also use that diversity to advance a novel conceptual/analytical framework for unpacking university-regions' everyday activities, taking into account the dynamic, complex and co-evolving interplay between (a) key social agents and institutions, (b) the contexts in which they are embedded, as well as (c) the historical trajectories and strategic ambitions underpinning context-specific social arrangements and interactions that are mediated by temporal and spatial dimensions.

For the last 50 years, universities' contributions to society in general and their regions in particular have become a thorny issue for policymakers, practitioners and researchers alike (Charles \& Benneworth, 2001; World Bank, 2008). In the last two decades, and particularly since the enactment of the European Union's 2000 Lisbon Agenda, universities have emerged as key actors in driving the knowledge economy (Harding et al., 2007; Pinheiro, 2015; Oftedal et al., 2018). Yet, as a handful of studies show, policy prioritization through catchy but often ill-defined concepts such as the triple-helix, science parks, research excellence, smart specialization and entrepreneurialism has been found to have had mixed results. For example, a recent study encompassing 266 European regions concluded that, despite the policy and managerial attention devoted to research excellence or rankings, and its apparent positive effect on regional competitiveness, in terms of its contribution to regional development, research excellence was found to be a valuable but not a crucial factor per se and always required contextualization (Garcia-Alvarez-Coque et al., 2021).

The existing state-of-the-art literature on the topic often regards universities as strategic actors, contributing through infrastructures and focused methods to the fostering of trajectories for regional change, and is overseen by strategic managers who coordinate their organizations to deliver effectively for regional needs (cf. Benneworth et al., 2017). In this edited volume, we contend that the failure to solve the aforementioned thorny issue has been driven by the fact that there has been a focus on extraordinary regional engagement, large-scale and eye-catching activities, and financially impressive transactions such as patents and spin-offs, embedded in "happy family stories" of ambitious regional development projects and coalitions. These "happy" stories have had a tendency not only to focus on individual cases ("my country" or "my university") but also 
to glorify formalized arrangements, like policies, strategies and leadership discourses, instead of shedding critical light on how these affect the daily lives of university actors across the board, including the tensions and volitions that arise as a result of making strategic intentions an everyday reality. We are not here arguing that we are the first to raise these critical queries or to provide an alternative path for unpacking the complexities associated with university-region interactions (cf. Uyarra, 2010; Perry, 2012 Lattu \& Cai, 2020). We are simply stating that certain assumptions as regards the roles, functions and normative orientations of universities in the context of their surrounding regions have, in many cases, been taken for granted and, thus, have not been systematically addressed and/or still lack theorizing.

Nonetheless, this extraordinary engagement does not explain what we know matters about universities' societal contributions, embedded in their core tasks of teaching and research. Therefore, the approach taken in this volume is to start from the grassroots level of universities" "everyday" engagements, looking at the manifold ways in which university knowledge agents, most often academics and students, build connections with multiple regional partners across the public and private sectors, and civic society more generally. This agenda is, in part, a reflection of the attention given in recent years to the interplay between place-based (formal) structures and (informal) social interactions in shaping dynamics that are conducive (or not) to sustained regional engagement and development over the long run (cf. Sotarauta, 2015; Kolehmainen et al., 2022). The empirical chapters comprising the heart of this volume both identify and describe a range of repertoires by which universities couple and become coupled to their regional surroundings, creating external, regional benefits but also remaking internal structures (formal and informal ones) for supporting and empowering university staff and students to use their knowledge to make a local difference. This in turn allows us to reconceptualize the very notion of university-regional engagement, embracing its underlying complexity and proposing a roadmap for a renewed research agenda that brings together social science scholars within the sub-fields of regional science, higher education, management, and innovation and entrepreneurship studies, among others.

The volume's starting point is to consider the various processes by which university knowledge is made available and actionable for regional development, by being taken up by and shaped in concert with regional actors. The framework sets out the pathways which universities, as organizations and institutions (Pinheiro, 2012), create in their regions and the ways in which universities couple their knowledge to regional actors, systems and institutions. The primary focus of analysis is the micro-scale of individual agency (knowledge actor) and the ways in which university interactions with societal partners shape local contexts for actionable knowledge (Karlsen, 2005).

This in turn motivates the volume's main theme, namely the fact that cocreation with different stakeholders results in a new set of tensions, volitions and unintended outcomes. The main contributions come through a rich set of empirical chapters, each focusing on micro-practices of knowledge interactions 
by academics, students, citizens, policymakers and businesses. These chapters explore the different ways in which these actors help shape knowledge exchange and co-creation networks and the long-lasting effects (both intended and unintended) these have on those institutions and the geographies in which they are embedded.

Drawing on evolutionary economic geography, innovation studies, management and organization studies, and informed by historical perspectives, the volume creates a new mode of understanding university-regional engagement as a form of extendable temporary coupling, which also helps to address perennial policy questions of what to do with universities that do not serve local labour market needs and/or are in regions suffering from brain drain or "institutional thinness". The book illustrates such dynamics by drawing upon examples from a wide range of regions in diverse national contexts: Brazil, Caribbean, China, Italy, Norway and Poland. Through practical examples and by observing the phenomena in different contextual situations, this edited volume addresses several research queries that are associated with the following (four) key elements composing the analytical framework advanced in Chapter 2:

1. Who are the key, internal and external, actors (or agents) involved in regional engagement? What are their strategic intentions and roles, and what types of tensions and volitions occur as a result of normative and strategic clashes?

2. How does HEIs' embeddedness in global, national, regional and local contexts and institutions affect patterns, structures and mechanisms of academic engagement across the board?

3. To what extent do the everyday affairs of HEIs both contribute and reflect the nature, scope and strategic commitment towards external engagement?

4. How do past experiences, materialized in the form of local norms, traditions and identities, help determine current and future engagement patterns and strategic aspirations?

\section{The Volume and Its Key Contributions}

This volume consists of 14 chapters, including 11 empirical chapters. In the second chapter, "Unpacking mundaneness: a novel conceptual framework for universities and regional engagement”, editors Rómulo Pinheiro, Laila Nordstrand Berg, Tatiana Iakovleva, Elisa Thomas, and Paul Benneworth debate the current view on university-regional engagements and suggest a renewed theoretical framework based on four main elements - macro, meso, micro dimensions, as well as temporality - that are further explored in the volume in different contexts. The starting point for the analysis relates to the fact that actors motivations and actions do not exist in a vacuum, and thus are greatly influenced by the context in which they operate. Too often, context - in its manifold manifestations (from macro to micro) - is taken for granted, and its influence is under-reported, although, we content, it offers deeper insights into 
how actors within and beyond the university interact with situations and how these, in turn, influence the behaviours of individuals involved with processes of regional engagement.

Our empirical section opens in Chapter 3 with Laila Nordstrand Berg and Gunnar Yttri's "Changes and continuities in the development of rural teacher education in the fjords of Western Norway". This chapter looks at the development of teacher education in Sogndal, a Norwegian rural village, through the lens of historical institutionalism. The authors review key events and critical junctures over six decades from the early 1960s to the present. Developments and changes are understood within the historically determined and changing framework of institutional strategies, regional needs, and national policies. The study is illuminated by a story from a rural Norwegian teacher-training institution, which was quite successful in supplying teachers for the region until the 2010s. Nonetheless, this regional success offered no guarantee of satisfying higher academic requirements following national reforms.

Chapter 4, authored by Kadígia Faccin, Elisa Thomas, and Caroline Kretschmer and titled "University dynamic capabilities to boost innovation ecosystems: the case of a university alliance in Brazil", examines how universities' dynamic capabilities are mobilized to take on the role of fostering and orchestrating regional innovation ecosystems. Increasingly, universities are applying strategic and entrepreneurial management practices to be able to expand themselves into governance structures to deal with dynamic and changing environments. Different phases of an innovation ecosystem (initial stage, development, and renewal) require different key dynamic capabilities. The authors find that there is a fourth phase, the boost stage, in which an existing but declining innovation ecosystem requires an agent to be the propellant and revitalizer so that its development cycle can be resumed and expanded. We address this issue with a unique Brazilian case study concerning an alliance founded by three universities to develop the region into an environment conducive to innovation and entrepreneurship. This case study reveals the role of universities as an orchestrating agent when there is a need to boost an ecosystem that is experiencing difficulties, by organizing, motivating, and supporting a network of stakeholders to drive the regional ecosystem. The research found that universities in declining ecosystems need to combine three dynamic capabilities at the same intensity in several activities to lead the local initiative.

Chapter 5, "Exploring the role of the university in the creation of knowledge networks in the Aso Valley, a rural area in Marche Region (Italy)", authored by Sabrina Tomasi, Concetta Ferrara, Gigliola Paviotti, Chiara Aleffi, Alessio Cavicchi, and Giovanna Bertella, questions how and to what extent universities can stimulate knowledge networks to valorize regional cultural capital in remote rural regions. Rural areas are often disadvantaged by their peripheral position, depopulation, and the scarcity of primary services, but they also have specific characteristics, especially in terms of cultural capital, that can make them attractive as tourism destinations. Sustainable tourism paths can be developed through collaboration between various actors with complementary skills 
and areas of expertise, especially local cooperatives and associations. In this context, universities can play a crucial role in creating knowledge networks and enhancing "rural buzz", that is, the flow of information and knowledge among the individuals, organizations, and businesses in a rural area through face-toface interaction. This chapter is based on an Italian case study from the Marche Region: the collaboration between the University of Macerata (UNIMC) and a local association, Agritur-Aso, has been chosen as an example of a network for the co-valorization of regional cultural capital.

Chapter 6, authored by Tatiana Iakovleva and Mette Eriksen Adkins and titled "The third mission - enhancing academic engagement with industry", explores what types of knowledge spillover are preferable for academics and how universities can support them. There is an ongoing debate in the literature about a "third mission" for universities. Examples of successful academic spinoffs have led to a widespread policy of encouraging collaboration between the academic and commercial worlds. However, the commercialization of researchbased innovation often suggests a conflict of interest to academics. Analysing a survey of 226 academics in a medium-sized university in Norway, the authors found that supporting the entrepreneurial knowledge and skills of academics might cause a modest increase in their entrepreneurial intentions. At the same time, incentives for joint research projects with industrial partners enhance academics' desire to take part in such collaborations. The authors conclude by questioning the well-publicized policy efforts focused on boosting academic start-ups and argue that more knowledge about starting and running a business would be helpful, but only for a small number of academics who are already interested in such activities. To enhance broader academic involvement in the "third mission", policies should encourage a wider range of activities and focus on providing incentives, such as tax regimes or co-funding possibilities, for other types of research-industry collaboration such as joint research projects.

Chapter 7, "Student entrepreneurship programmes in higher education institutions: multi-scalar embeddedness and heterogeneous regional responses", authored by Øyvind Midtbø Berge, Øystein Stavø Høvig, and Svein Gunnar Sjøtun, investigates how different HEIs interact with the region regarding student entrepreneurship. Since the 2000s there has been an increasing prevalence of student entrepreneurship programmes in HEIs. Even though the HEIs have different institutional and regional preconditions for student entrepreneurship, the concrete activities and strategies are often shaped by best-practice models derived from successful and well-performing organizations. With empirical examples, this chapter shows how the embeddedness of HEIs in a regional context influences strategies for student entrepreneurship. The authors discuss the activities and strategies at three different HEIs in the Bergen region with regard to how they have been influenced by the dynamic interaction between the HEIs and the regional context.

Chapter 8, by Dian Liu, "Student incubators in China: the cases in Shanghai and Wuhan", focuses on the impact of environmental contextual characteristics on incubator practice. "Environmental contextual characteristics" refers 
to both the organizational character of the host university and the regional features where the university incubator is located, which intertwine and jointly shape the current profile of university incubators. Drawing upon two case studies of incubators in two universities with varying disciplinary strength (science and engineering, and teacher education) in two different cities (Shanghai and Wuhan), this chapter examines the management policies and practices of the two student incubators and how such incubator profiles are framed by environmental contextual perspectives. This chapter first demonstrates the entrepreneurship initiative and student entrepreneurship development as the background of the generation of university incubators, followed by an introduction to the two cases of university incubators. It then compares the varied incubation policies, structures, and practices in the two cases, underpinned by regional characteristics and organizational institutions and supplies empirical evidence for further policy recommendations regarding student incubators and entrepreneurship in China.

Chapter 9, by Iyad Abualrub and Rómulo Pinheiro, is titled "Aligning university roles and strategic orientations: when local mandates and global aspirations meet". HEIs are increasingly under pressure to make societal contributions, for example, in the form of job creation, technology transfers, local economic development, and so on, which result in tensions and dilemmas at multiple levels, not least as regards strategic management. In this chapter, the authors investigate how universities align education and research on the one hand and how they navigate the tensions between local demands for relevance and global aspirations towards excellence on the other. Firstly, the chapter identifies these tensions and dilemmas, and secondly, it investigates how they are being handled with regard to strategic planning (including resource allocation) at both the central (university) and sub-unit (faculty) levels. The study adopts a qualitative case study design and compares developments at two distinct HEIs in Norway. The findings suggest that relevance and excellence are intertwined dimensions associated with the multiple pressures facing HEIs. These findings provide critical insights into how the strategies and daily practices of actors at different levels within HEIs address the demands posed by a dynamic and increasingly complex and turbulent environment.

Chapter 10, by James Karlsen and Rómulo Pinheiro, titled "Emergent strategies and tensions between decoupled university structures and strategic management initiatives: a case study of a strategy process", investigates the ways in which a Norwegian university located in a region facing a series of socio-economic challenges devised and implemented a new strategy centred on the co-creation of knowledge as a vision. More specifically, the authors examine the dilemmas and tensions faced by university actors in articulating a shared strategic platform bridging internal (university) aspirations with external (regional actors and ministry) demands and expectations. The chapter adopts a historical institutionalist perspective using institutional logics as the conceptual lens through which the case data are interpreted. The findings provide fresh evidence of the complexity associated with strategic processes within highly 
institutionalized organizations such as universities. Strategic orientations were found to adopt emergent rather than deliberative patterns. Challenges associated with the institutionalization of the co-creation of knowledge vision resulted from the clashes between the different logics and behavioural postures associated with the main actors involved in the strategy process.

Chapter 11, by Anna Dąbrowska, Wojciech Dziemianowicz and Magdalena Cybulska, is titled "Towards the strategic cooperation of "two worlds": universitylocal government relationships in Warsaw". In this chapter, the authors address the issue of the relationships between universities and local governments by asking the research question: (How) can universities contribute to the design and implementation of public policies at the local level? Based on the case of the city of Warsaw (Poland), this study provides a comparison of the role of university stakeholders in the process of design and implementation of the city's development strategy. The study provides a comparison of two strategic plans for two time periods and concludes that the role of academic stakeholders has changed from formal involvement towards guiding the process of decisionmaking. The authors identify factors hindering the involvement of universities within the policy process, namely a lack of systemic solutions for cooperation, a lack of incentives for academics to put special focus on activities not related to publication results, low understanding of the third mission among the academic community and limited trust between the representatives of the "two worlds".

Chapter 12, authored by Laila Nordstrand Berg and Kristin Lofthus Hope, titled "Keeping talents in the region? Educational internships and their impact on regional development", highlights how internships within higher education contribute to place-shaping and regional development. It addresses how employees and students engage with regional partners to develop education by co-creating internship projects. Strategies concerning regional development are set into play when HEIs and the private and public sectors collaborate to provide education. The focus is on academic disciplines in Norway that have quite recently established student practice through internships, namely sociology, history, and business administration. The authors are following up on this practice element by analysing the perspective of educational fields and different public and private actors within a regional setting to provide internships for students.

The last empirical chapter of this volume, Chapter 13, by Elin M. Oftedal, Emily Dick Ford, and Luz Longsworth, titled "Activist leadership in the Caribbean: the case of the University of the West Indies", investigates how a crossnational university in a transitional region such as the Caribbean implements its third mission, defined broadly as engagement in society, including entrepreneurial and innovative efforts. Conceptually, the chapter uses the entrepreneurial architecture framework and discusses how systems, structures, strategy, leadership, and culture form a unique mandate to engage in national, regional but also international challenges.

The book concludes with Chapter 14, "Universities and regions: new insights and emerging developments", authored by editors Laila Nordstrand 
Berg, Elisa Tomas, Tatiana Iakovleva, Rómulo Pinheiro, and Paul Benneworth. This final chapter summarizes the findings of the volume across the four dimensions mentioned earlier: macro, meso, micro, and temporality. In doing so, the editors propose a refined framework to address the role these dimensions play in addressing HEI-regional interactions, and sketch out a roadmap for future studies in the area.

In a nutshell, this edited volume offers fresh evidence and compelling examples of how the macro environment, composed of political, economic, and sociocultural value, affects HEI-regional relationships; how the everyday engagement of core agents within HEIs and the region forms and shapes those interactions; and how these activities can be seen in a historical perspective over time. These phenomena are observed in different situations and varieties and within different international contexts. The volume's take home message is that mundaneness, or the everyday activities of agents involved with regional engagement, serves as a key tool for unpacking and better understanding HEIs and their regional engagement.

\section{References}

Benneworth, P. (2013). University engagement with socially excluded communities. Dordrecht: Springer.

Benneworth, P., Pinheiro, R., \& Karlsen, J. (2017). Strategic agency and institutional change: Investigating the role of universities in regional innovation systems (RISs). Regional Studies, 51(2), 235-248. https://doi.org/10.1080/00343404.2016.1215599

Charles, D., \& Benneworth, P. (2001). Are we realizing our potential? Joining up science and technology policy in the English regions. Regional Studies, 35(1), 73-79.

Charles, D., \& Wilson, B. (2012). Managing regional engagement: The role of benchmarking. In R. Pinheiro, P. Benneworth, \& G. A. Jones (Eds.), Universities and Regional Development: A critical assessment of tensions and contradiction (pp. 219-238). Milton Park and New York: Routledge.

Garcia-Alvarez-Coque, J.-M., Mas-Verdú, F., \& Roig-Tierno, N. (2021). Life below excellence: Exploring the links between top-ranked universities and regional competitiveness. Studies in Higher Education, 46(2), 369-384. https://doi.org/10.1080/03075079.2019.16 37843

Harding, A., Scott, A., Laske, A., \& Burtscher, C. (Eds.). (2007). Bright satanic mills: Universities, regional development and the knowledge economy. Aldershot: Ashgate.

Karlsen, J. (2005). When regional development becomes an institutional responsibility for universities: The need for a discussion about knowledge construction in relation to universities' third role. AI \& Society, 19(4), 500-510. https://doi.org/10.1007/ s00146-005-0330-9

Kolehmainen, J., Kurikka, H., Keerberg, A., \& Raagmaa, G. (2022). Being resilient between the region and the higher education system? Views on regional higher education institutions in Estonia, and Finland. In R. Pinheiro, L. Frigotto, \& M. Young (Eds.), Towards resilient organizations and societies: A cross-sectoral and multi-disciplinary perspective (pp. 249276). Cham: Springer International Publishing.

Krücken, G., Kosmützky, A., \& Torka, M. (Eds.). (2007). Towards a multiversity? Universities between global trends and national traditions. Bielefeld: Transaction Publisher. 


\section{Elisa Thomas et al.}

Laredo, P. (2007). Revisiting the third mission of universities: Toward a renewed categorization of university activities? Higher Education Policy, 20(4), 441-456.

Lattu, A., \& Cai, Y. (2020). Tensions in the sustainability of higher education - The case of Finnish universities. Sustainability, 12(5), 1941.

Marginson, S., \& Rhoades, G. (2002). Beyond national states, markets, and systems of higher education: A glonacal agency heuristic. Higher Education, 43(3), 281-309. https:// doi.org/10.1023/a:1014699605875

OECD. (2007). Higher education and regions: Globally competitive, locally engaged. Paris: Organisation for Economic Co-operation and Development.

Oftedal, E. M., Iakovleva, T. A., \& Foss, L. (2018). University context matter: An institutional perspective on entrepreneurial intentions of students, Education + Training, 60(7/8), 873-890. https://doi.org/10.1108/ET-06-2016-0098

Perkmann, M., Tartari, V., McKelvey, M., Autio, E., Broström, A., D’Este, P., . . Sobrero, M. (2013). Academic engagement and commercialisation: A review of the literature on university - industry relations. Research Policy, 42(2), 423-442. https://doi.org/10.1016/j. respol.2012.09.007

Perry, B. (2012). Excellence, relevance and the construction of regional science policy: Science frictions and fictions in the North West of England. In R. Pinheiro, P. Benneworth, \& G. A. Jones (Eds.), Universities and regional development: A critical assessment of tensions and contradictions (pp. 105-123). Milton Park and New York: Routledge.

Pinheiro, R. (2012). University ambiguity and institutionalization: A tale of three regions. In R. Pinheiro, P. Benneworth, \& G. A. Jones (Eds.), Universities and regional development: A critical assessment of tensions and contradictions (pp. 35-55). Milton Park and New York: Routledge.

Pinheiro, R. (2015). Citius, Altius, Fortius: Mobilising the university for the "Europe of knowledge". In B. Culum, F. Robeiro, \& Y. Politis (Eds.), New voices in higher education research and scholarship (pp. 1-17). Hershey, PA: IGI-Global.

Pinheiro, R., Langa, P., \& Pausits, A. (2015). One and two equals three? The third mission of higher education institutions. European Journal of Higher Education, 5(3), 233-249. https://doi.org/10.1080/21568235.2015.1044552

Sotarauta, M. (2015). Leadership and the city: Power, strategy and networks in the making of knowledge cities. London: Taylor \& Francis.

Uyarra, E. (2010). Conceptualizing the regional roles of universities, implications and contradictions. European Planning Studies, 18(8), 1227-1246.

World Bank. (2008). Higher education and development: Annual Conference on Developmental Economics - Regional. Washington, DC: World Bank. 


\title{
2 Unpacking Mundaneness
}

\section{A Novel Conceptual Framework for Universities and Regional Engagement}

\author{
Rómulo Pinheiro, Laila Nordstrand Berg, Tatiana \\ Iakovleva, Elisa Thomas, and Paul Benneworth
}

\begin{abstract}
In this chapter, we debate the current view on university-regional engagements and suggest a renewed theoretical framework based on four main elements - macro, meso, micro dimensions, as well as a meta-dimension of temporality that cuts across all levels. The macro environment is typically defined as pertaining to public policies, culture, laws, and economy, while the meso environment includes links between the macro (societal) forces and the micro (agents) level through intermediate institutions and structures and is characterized by the processes and mechanisms of interaction of different actors. The micro level is about agency - organizations or individuals/groups within organizations - and agents' intentions and behaviours. Finally, the interactions between actors and their macro and meso environments occur throughout a timeline and are subject to temporality and "loop" effects.
\end{abstract}

\section{Introduction}

The conceptual/analytical framework advanced in this chapter, and operationalized throughout the volume albeit differently across chapters, builds on seminal contributions from organizational and management studies, in addition to key insights from the extant literature on the topic of universities' regional engagement. This edited volume focuses on the "everyday" engagements of universities and other types of higher education institutions (HEIs) across different geographies, investigating the manifold ways in which university knowledge agents build connections with regional partners. Their motivations and actions do not exist in a vacuum. Rather, actors' behaviours are greatly influenced by the context in which they operate. By "context" we refer to the circumstances, conditions, situations, or environments that are external to a phenomenon and either enable or constrain it (Welter \& Smallbone, 2011). Too often, context is taken for granted, and its influence is under-reported, although it offers deeper insights into how individuals interact with situations and how situations influence the behaviours of individuals (Johns, 2001). We 


\section{Rómulo Pinheiro et al.}

use the term "mundaneness" to characterize the dynamic interplay between contextual factors and actors' strategic intentions and behaviours, in the context of the (daily) routinized tasks and social relationships within and beyond the university campus.

It is possible to conceive of the engagement of HEIs with regional actors as composed of four key elements, to a large extent corresponding to the macro, meso, and micro levels, in addition to a meta-dimension that cuts across all levels: temporality. The macro environment is typically defined as pertaining to public policies, culture, laws, and economy (Pitelis, 2005). It is exogenous, since agents often have limited power to change it. Social, cultural, and institutional arrangements define how the "gatekeepers" of resources, as well as the power-holders, have an impact on agents and their behaviours (Brush et al., 2009). At the same time, the meso environment includes links between the macro (societal) forces and the micro (agents) level through intermediate institutions and structures and is characterized by the processes and mechanisms of interaction of different actors. The micro level is about agency - organizations or individuals/groups within organizations - and agents' intentions and behaviours. Finally, the interactions between actors and their macro and meso environments occur throughout a timeline and are subject to temporality and "loop" effects.

In the next section, we provide a succinct description of each of the four dimensions composing the framework and elaborate on their relationships in the context of university-region interactions and engagement.

\section{The socio-cultural context}

HEIs of all types and sizes are embedded into the geographical as well as the socio-cultural contexts surrounding their operations. Institutional scholars acknowledge that such sociocultural contexts, comprising political systems and regulations, and a collective understanding of society and norms of behaviour, can be considered as primary factors in forcing organizations to conform (Pfeffer \& Salancik, 2003). When it comes to how embeddedness affects the activities of HEIs, these are, for the most part, regulated and funded nationally by governmental agencies. The latter are, on behalf of the government, tasked with providing oversight in relation to the governance and operations of the entire higher education (HE) system. Not only are the activities of HEIs embedded in national and increasingly supra-national (European Union) science and research sub-systems (cf. Maassen \& Olsen, 2007), but the scope and legitimacy of their tasks and roles are also embedded in other (macro-level) societal structures such as the academic profession and the disciplinary fields into which academics are socialized and from which they derive their normative allegiances and professional identities (Becher \& Trowler, 2001).

Marginson and Rhoades (2002) show how the dynamic interplay between local, national, and global dimensions supporting HE policy and practice, including increasing global competition for talent and funding, underpins the 
local activities of individual academics and their respective organizations. In a similar vein, Hüther and Krücken (2016) refer to the notion of "nested organisational fields" - a specific manifestation of embeddedness at the sector level to explain patterns of convergence (isomorphism) and differentiation among HEIs. Following this line of thought, Pekkola et al. (2021) contend that the increasing hybridity of policies and practices across European HE systems is a function of the degree of nestedness among key sub-systems - sociopolitical, institutional, organizational, and psychological - in which HEIs and key actors are deeply embedded.

While discussing the tensions and dilemmas faced by the HE systems and HEIs, Pinheiro et al. (2014) shed light on the complex interplay between a set of "nested tensions" and different types of internal (e.g., goal conflict, renewal versus continuity, governance) and external pressures such as the rise of competitive funding regimes. Regional science scholars have shown how HEIs are deeply embedded in local and regional economic/innovation systems, in addition to national and supra-national ones (Benneworth \& Sanderson, 2009; Benneworth et al., 2017). What is more, studies show that key actors within HEIs play a critical role in connecting or bridging these different spheres (cf. Benneworth \& Hospers, 2007). As a result, HEIs face pressure to actively engage with, and contribute towards, the broader development of their surrounding geographies, even if that may not necessarily be reflected in their primary functions of teaching and knowledge production (Benneworth, 2012) or be tightly aligned with their strategic interests and (world-class) aspirations (Ramirez et al., 2016).

It is important to note, however, that, as alluded to earlier, degrees of societal embeddedness among HEIs differ, depending on historical conditions and contextual circumstances (Krücken, 2003; Geiger, 2009). Although these days it is almost impossible for HEIs of any size or type to disengage from active participation in societal issues, as was recently demonstrated across the Nordic countries regarding the notion of the "responsible university" (Sørensen et al., 2019), this does not necessarily imply that a tight coupling exists between such activities and core/traditional tasks within teaching and research. Indeed, there is evidence from several contexts showing that actors within HEIs often engage in processes of "loose coupling" to protect core tasks from being co-opted by external interests and agendas (Pinheiro, 2012; Benneworth, 2018; Pinheiro et al., 2018) and/or prevent mission drift or overload (Enders \& Boer, 2009). Furthermore, a handful of studies reveal that proper incentive and rewards structures (collectively and individually) for promoting academic engagement across the board are, in most cases, still rather inadequate (Nyden, 2003; Balbachevsky, 2008).

Thus, the opportunities that HEIs perceive and the actions of key agents within them (individuals or groups of individuals) are strongly influenced by their embeddedness within their context. It is possible to use context as a "lens", drawing attention to questions of when, where, and why (Griffin, 2007; Johns, 2001; Oftedal et al., 2018). Such contextual understanding employs 


\section{Rómulo Pinheiro et al.}

several dimensions: given the remit and ambition of this volume, we limit the scope of analysis to such dimensions as culture and society, as well as political and economic systems. The empirical cases presented in the volume emanate from different countries. Grasping the specificities associated with the cultural, political, and economic systems of each of the cases is helpful in explaining certain trends as regards universities' interactions with regional actors.

\section{Unpacking mundaneness: an institutional lens}

It is important to note that, to describe the phenomenon of university-regional engagement and understand its influence on social participants, a broader (systemic) picture of the macro and meso environments is required for defining and unpacking what is termed as "the mundane". The latter is defined here as pertaining to the routine behaviour of everyday life within both HEIs (as organizations and institutions) and regions (as socio-economic, cultural, and political entities), as social agents or participants go about their daily tasks and activities. As alluded to earlier (see Chapter 1), in this volume the primary focus of analysis is not on the extraordinary, that is, striving for excellence, becoming a new Silicon Valley, and so on, as is the case with earlier studies, but rather on the mundane aspect underpinning the interplay between university and societal actors in the context of academic engagement and the broader processes of regional development and regional renewal.

One of the many possible ways of unpacking mundaneness is through the theoretical lens of institutional work (Lawrence et al., 20119), a sub-stream within the broader neo-institutional tradition within organizational studies (Greenwood et al., 2017). Aligned with the earlier criticism that too much attention had been paid to the role of structural arrangements in conditioning actors' behaviours at the expense of aspects such as power (Lawrence, 2008) and social standing (Battilana, 2006), proponents of institutional work lend credence to the critical role that key agents within organizations play in creating, upholding, developing, and/or disrupting institutional arrangements (Lawrence et al., 2011). Institutional work manifests itself not only in the form of purposive and intentional actions, but also in regard to the widespread adoption of daily routines and institutionalized behaviours without much fuss or consideration by the actors involved. Such mundane behaviours are often invisible or "natural" (Scott, 2003), with actors being largely unaware of them. Still, they often contribute to incremental adjustments which are necessary for maintaining the organization and the sets of formal and informal rules underpinning social life (cf. March et al., 2000). On the more visible side, some actions are more intentional, as is the case with entrepreneurial-related efforts either to change existing structural arrangements or to establish new ones (Beckert, 1999) with differing degrees of internal resistance and external support (Mahoney \& Thelen, 2010).

All types of organizations, independently of their legal status, size, and age, are not simply production machines or economic actors designed to achieve 
certain ends but are also infused with an array of cultural symbols, ceremonies, and traditions, reflecting institutionalized norms, practices, and belief systems that define what is worth dealing with, how, when and by whom (Meyer \& Rowan, 1977; March \& Olsen, 2006). Yet, as open systems, organizations do not exist in a vacuum and are an integral part of the regulative and technical environments in which they operate (Scott, 2003), as sketched out earlier in the discussion on embeddedness. External environments help shape individuals' preferences and exert influence on collective and individual behaviour alike (Meyer \& Scott, 1992; Geschwind et al., 2022).

Mundane work around institutional maintenance relies on social activities that are performed in a rather automatic or routine-like fashion, without much reflection. Nonetheless, to arrive at that stage, some form of institutionalization is needed before daily organizational (shared) practices and behaviours are performed, repeated, and taken for granted (Berger \& Luckmann, 1966; DiMaggio \& Powell, 1983). Still, the actions of organizational members are guided or mediated by a set of values, norms, beliefs, and identities that are associated with broader (macro-level) institutional orders and logics (Thornton et al., 2012) in addition to the meso- and micro-level dimensions underpinning organizational life (Brint \& Karabel, 1991).

To unpack the roles of macro-, meso-, and micro-level dimensions, as well as the interplay among them, in institutionalization processes that result in the establishment of practices and daily routines that are taken for granted, we refer to Scott's $(2003,2008)$ seminal work on the importance of three institutional pillars underpinning organizational (social) life: the regulative, normative, and cultural-cognitive.

The regulative pillar refers to regulatory arrangements and legal frameworks at the macro (societal or sector) level. Once enacted by governmental agencies, these regulations must first be interpreted and second be implemented by the members of the organization to become part of so-called mundane work. Non-compliance with official rules and regulations often results in punishment, which can take legal, financial, or other forms (e.g., non-certification). As a result, most organizations, particularly publicly funded ones such as HEIs, will tend to comply. Organizational members, most saliently leaders, as well as others tasked with enforcing external regulations, tend to act in an instrumentalist fashion to avoid legal or financial punishment (Pfeffer \& Salancik, 2003), as well as to avoid losing legitimacy or external support for organizational tasks and goals (Deephouse \& Suchman, 2008).

The normative pillar reflects the dominant norms and values which influence the social behaviour of actors going about their daily tasks and activities. Such values often originate in the professional and/or organizational fields in which organizational participants have been socialized and to which they belong (cf. Welch, 2005), and consist of (informal) instructions on how to behave in each situation, through the matching of predefined and widely shared (and cherished) rules to emerging circumstances (March \& Olsen, 2006). Over time, such norms and values have a tendency to become deeply institutionalized or 
taken for granted and are often infused with a value beyond the task at hand (Selznick, 1996).

The last pillar, the cultural-cognitive pillar, is based on how organizational members cognitively perceive their local or immediate surroundings and how this perception is interpreted and integrated culturally within the entire organization, or parts of it, in ways that provide meaning to local participants (Scott, 2003, 2008). Thus, the local culture becomes an integral part of the identity of the organizational members (Clark, 1972), being influenced by traditions and common perceptions on how to act and how to perceive the social reality. From this perspective, mundane activities are regulated following a "logic of orthodoxy": "this is who we are and how we always have been doing things".

To further unpack mundaneness at the meso and micro levels, aspects such as materiality, spatiality, practices, and leadership or power structures should be given some attention as well. Mundane activities are often made visible through materiality. This is typically explored in sectors or organizational fields such as health care, where the interrelations of material and actions (care, in this setting) are explored (Buse et al., 2018). Mundane work is also influenced by material practices related to "things" pertaining to the technical environment, such as computers and software programmes. Such technical "things" can be conceived of as actors that influence or mediate the actions of organizational participants through daily interactions (Czarniawska \& Hernes, 2005). Materiality also encompasses the realm of the immaterial, expressed through "things" and artefacts that are artificially made (e.g., academic groups or research units), reflecting cultural scripts and atmosphere (Buse et al., 2018). As for material artefacts, such as buildings, libraries or science parks, these are shared between the actors and play an active part in mundane activities and in what it is possible (or not possible) to perform.

Turning to spatiality, this pertains to the ways in which organizations design and physically organise work, with direct influence on how mundane activities are undertaken, when, and by whom. The locations can vary from the physical buildings (campuses in the case of HEIs) to informal spaces in and between organizations and social participants (e.g., annual academic conferences). Organizational sub-units (e.g., academic departments) placed close to one other influence the development of social networks, determining the types of working and informal relationships among social participants both within (intra) and across (inter) organizations. Likewise, organizations that are clustered together (such as science parks) and/or are located in more central areas, such as large urban settings, are easier to access by others than those in more remote locations.

Practice encompasses a relationship between actors' competencies, ongoing dynamics, and processes in addition to the material aspects of social/organizational life that are embodied in tacit knowledge and routinized activities (Buse et al., 2018). As part and parcel of the repository of organizational skills and capabilities, individuals' "know-how" and "craft knowledge" enable or hinder the types of mundane (daily) activities that social participants can pursue. 
Finally, hierarchies and power relations have been found to regulate practice and influence the mundane (Buse et al., 2018). The managerial side of organizations not only allocates roles, responsibilities, and resources but also signals to participants which preferences (goals, solutions, partners, and so on) are to be given priority (Thompson, 2008). That said, mundane activities have, for the most part, been rather neglected in management and leadership studies. Nevertheless, performing administrative tasks, chatting with employees, gossiping, and creating a good working atmosphere are considered important mundane tasks by formal leaders or managers (Buse et al., 2018). The significance of such informal activities in respect of mundaneness may be more salient when compared to, formal, strategic and change processes.

\section{Agency and agents in regional engagement}

Although macro and meso environments are important in shaping interactions with regions, it is always individuals or groups of individuals as organizations (agents) who perform certain activities in pursuit of opportunities they find attractive. Neffke et al. (2018) specifically discusses the role of entrepreneurs and existing firms in structural change in regional economies, a role that can also be attributed to the university as a change agent. According to Neffke et al. (2018), local agents have ties with social and economic networks in their home regions which allow them to understand and draw from the region's capabilities to develop engagement activities contributing to regional development. Agents in this book can be either universities as organizations or agents within universities, including the university's leadership and employees: academics, researchers, administrative staff, and students. We also relate agents to individuals or organizations in the regional environment such as firms, entrepreneurs, political institutions, policymakers, non-government organizations, and so on. As university agents have access to different regional capabilities, this affects their capacity (or willingness) to induce change in a region and create economic activities (Neffke et al., 2018).

By drawing on the concept of entrepreneurial agency, Garud and Karnøe (2003) have shown that agency is distributed across actors because each actor dominates incomplete areas of knowledge. The same can be said about the agency for regional development, where the university and external partners contribute specific, different, and complementary forms of knowledge. Steen (2016) adds that the path creation in a region is the result of collective rather than individual agency and that the development of some sense of collective expectation is important. The actors shape paths and become embedded in these paths; "in turn, these paths begin shaping actors over time" (Garud \& Karnøe, 2003, p. 278).

Universities' engagement is context-specific and contingent on agency. It is the agents who "mindfully deviate" from existing paths to establish new practices that will, with time, turn into new routines (Garud \& Karnøe, 2003; Steen, 2016). "To understand why particular paths emerge instead of others therefore 
requires more attention to agency and how actors respond to changes in (but also influence) the contexts in which they operate" (Steen, 2016, p. 1608). The 11 empirical chapters of this volume provide numerous illustrations of the role that agents at multiple levels, both internal and external to HEIs, play in processes of regional engagement.

\section{Temporality as a key dimension of regional engagement}

The processes underlying regional change and path creation/evolution due to universities' engagement include a temporal dimension of agency: this is simultaneously past- and future-oriented (Steen, 2016). Emirbayer and Mische (1998) emphasized the agency as a temporally embedded process of social engagement, in which the past contributes with habits, the future predicts and imagines alternative possibilities, and the present contextualizes how past habits may become future projects according to the contingencies of the moment. The temporally oriented definition of agency reinforces the notion that actors adjust their actions in relation to changing circumstances or specific contexts, and "they selectively engage with routines and habits from the past, evaluate present possibilities and project hypothetical new paths into the future" (Araujo \& Harrison, 2002, p. 8). When agents are aware of their ability to change the course of events and that the efficacy of their choices is temporally dependent, that is, when path dependence gets disentangled from determinism (Araujo \& Harrison, 2002), there arises a useful discussion regarding universities' engagement in regional development. University agents may, according to their engagement activities, create new paths or reinforce existing paths in their region.

As an integral part of institutional work, the intentionality of actors (i.e., the actions taken in given circumstances and linked to a predefined outcome) can be studied in relation to temporality (Lawrence et al., 2011). Tacit rhythms and rituals constitute and support social participants' sense of security (Buse et al., 2018), but such rituals and habits do have a starting point. Firstly, habits that are taken for granted are based both on past experiences (Bucheli \& Wadhwani, 2013) and what actions are considered appropriate or legitimate in each situation (March \& Olsen, 2006). Tacit knowledge and habitual or routinized behaviour can be understood as intentional, since actors can often choose from a range of suitable alternatives (cf. March \& Olsen, 1979). Secondly, the present context and social experience are thought to influence intentionality (Buse et al., 2018). Actors engage in self-reflexive actions to handle emerging situations in either a pragmatic fashion or a normative fashion. Thirdly, future expectations influence intentionality. This can best be seen in relation to goal-oriented actions and an orientation towards what is to be achieved, strategically, over time (cf. Chandler, 1990). In short, past, present, and future expectations are part and parcel of the ways in which actors within and across organizations choose from a course of possible actions as they undertake their mundane or daily activities. 
The embeddedness of actors in their context often results in a "loop effect", leading to path dependencies (Welter \& Smallbone, 2010) whereby future trajectories and dynamics are to a large extent determined ex ante as a function of earlier events and situations (e.g., past decisions affect future decisions, and so on, in a pattern of incremental change). Multiple studies have pointed to the historical nature of universities' functions, structures, and outlooks (cf. Krücken, 2003). Similarly, regional science scholars have demonstrated the role of path dependencies as important constraining and enabling factors in processes of regional change and adaptation or the lack thereof (Isaksen et al., 2019). Hence, the temporality dimension is an important element in understanding how macro and meso environments reflect contextual embeddedness and mundane activities.

\section{Towards an integrative mundaneness framework}

This book's starting point is to consider the various processes by which university knowledge is made available and transferred into regions through everyday actions. Keeping focus on practices and processes, we want to shed light on how university interactions with societal partners shape and modify the development of HEIs as well as the regions in which they are embedded. In this chapter, we have reviewed four dimensions - embeddedness in sociocultural arrangements, mundaneness, agency, and temporality - to integrate them into a new framework for understanding the coupling of universities with places and the ways in which universities as institutions can allow their everyday activities to contribute strongly and positively to regional prosperity.

So far, we have paid attention to structures and processes that might affect agents' behaviours. We mentioned earlier that regulative, normative, and cognitive dimensions within organizations should be considered, as well as external processes and structures, such as materiality, spatiality, practices, and leadership. However, over time, structure and agency become mutually constituted. Structuration theory holds that an actor or agent is a knowledgeable individual who has a capacity for actions (Giddens, 1984). The actors are seen as independent, creative, free, and sensible and are able to perform agency; that is, they have the "capacity to do otherwise: to follow one system of practices and to refuse another" (Whittington, 2010, p. 147). Through structuration theory, Giddens attempts to build a bridge between actors and structures with the latter providing opportunities (enabling and/or constraining) for actions (Giddens, 1984).

The structuration process is characterized by three distinct dimensions ranging, in order of strength, from iterative to projective to practical-evaluative (Emirbayer \& Mische, 1998). The most prevalent at the start of the structuration process is the iterative agent. This refers to the selective reactivation, by actors, of past patterns of thought and action. These are routinely incorporated into practical activity, giving stability and order to social universes, and helping sustaining identities, interactions, and institutions over time. The next 
stage of the process is projectivity, which is the imaginative generation by actors of possible future trajectories of action that are creatively reconfigured, considering actors' hopes, fears, and desires for the future. The final stage of the process is practical evaluation, which is based on the capacity of actors to make practical and normative judgements regarding alternative trajectories of action in response to emerging demands and dilemmas alongside the ambiguities of evolving situations.

While the iterative agent may develop intentions and attitudes for future behaviour, as the phases of structuration proceed, the projective agent is likely to test the context by choosing a behavioural posture fitting one's intentions. Practical-evaluative agents may, in turn, influence existing structural arrangements by communicating their judgement of them. In other words, agents are affected by, but may also influence (help shape), structural conditions through their actions and experiences, a process recognized in the literature as pertaining to phenomenon of "embedded agency" (cf. Battilana \& D'aunno, 2009). This in turn poses the perennial dilemma of how, and under what circumstances, agents who are deeply embedded in a given structure or sets of structures, and socialized to accept them as "natural", exercise agency to change these same structures.

Following the conceptual and analytical elements sketched out earlier, our framework suggests that mundaneness processes take place in each of the aforementioned pillars. Universities as organizations or university agents - students, academics, administrators, and so on - are therefore exposed to formal or informal rules derived from the regulative, normative, and cognitive pillars and/or to new knowledge which then forms the basis for the agents' awareness of contextual circumstances. Those pillars impact agents through such mechanisms as materiality, spatiality, practices, and leadership structures. Agents, in turn, might behave in iterative, projective, or practical-evaluative ways. Over time, their behaviours also modify the context in which they operate. This dynamic and non-linear process is illustrated in Figure 2.1.

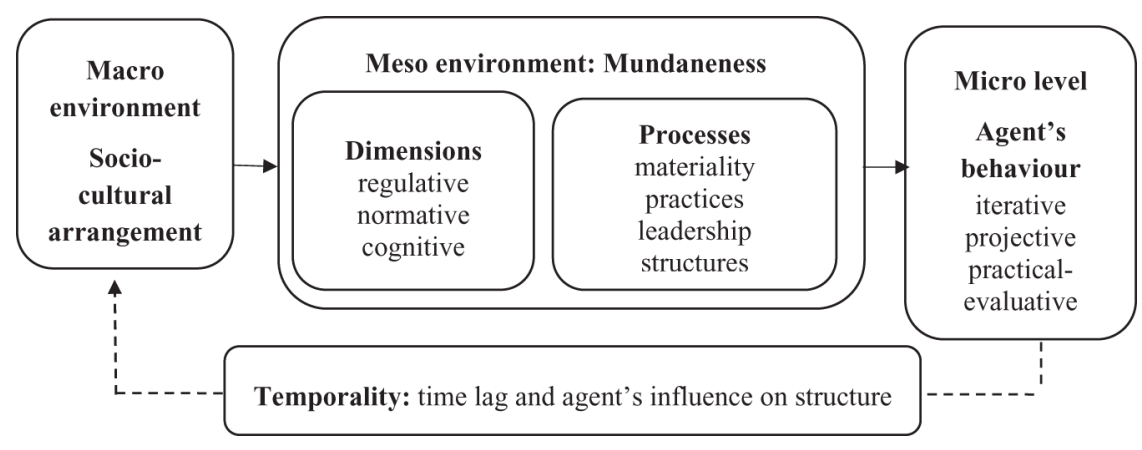

Figure 2.1 Mundaneness as process 
We accept, in this theoretical framework, a time lag between reaction, stimuli, and action. A time lag also exists between the agent's stimulation by the structure and the agent's influencing that same structure. In certain cases, for example, students or temporary staff spend limited periods of time at universities, in contrast to permanent academic and administrative staff. In such situations, it is therefore necessary to consider the influence of structure upon the agent to be greater than that of the agent upon the structure. On the other hand, when it comes to permanent staff, and in particular senior academics, the reverse holds true. Senior academics have a considerable degree of professional autonomy and discretion in going about their teaching, research, and engagement activities (Kehm \& Teichler, 2013). This creates a high degree of "loose-coupling" between structural arrangements at the central and sub-unit levels (Pinheiro \& Young, 2017).

We assert, on the basis of Giddens's (1984) interpretivist view of structure, that perception of the regional and organizational context guides agentic behaviour, related to structural maintenance, change, or both. This view is aligned with the notion of the university as an institution, composed of a set of institutionalized (formal and informal) structures determining the behaviour of social actors; more specifically as encompassing

a relatively enduring collection of rules and organized practices, embedded in structures of meaning and resources that are relatively invariant in the face of turnover of individuals and relatively resilient to the idiosyncratic preferences and expectations of individuals and changing external circumstances.

(March \& Olsen, 2006, p. 3)

This view contrasts with a more instrumentalist account, held by rationalchoice scholars and most managers and policymakers, which treats the university as a tool or instrument for reaching certain policy-defined or managerially induced strategic agendas (Gornitzka \& Maassen, 2007; Pinheiro \& Stensaker, 2014).

This book focuses on the formal and informal roles and everyday activities played by different agents in universities' engagement with the regions where universities are located. The university and its role in regional development have been discussed from different approaches, that is, the triple helix, regional innovation systems, and the entrepreneurial university (Etzkowitz \& Leydesdorff, 1997; Asheim et al., 2011; Audretsch, 2014). However, for the most part, these studies fail to address how "university agents" perform their ordinary activities when engaging with "regional agents".

Hence, the analytical framework described here and visualized in Figure 2.1 aims at unpacking the everyday interactions of university agents with their environment, whether within their core organization or at the regional and national levels. Thus, the main focus is not on exceptional performance by HEIs, measured in terms of patents, licences, or publications. Rather, our framework 


\section{Rómulo Pinheiro et al.}

focuses on the micro scale of individual knowledge actor agency and the way that the interactions of HEIs with societal (regional) partners shape local contexts for actionable knowledge.

\section{References}

Araujo, L., \& Harrison, D. (2002). Path dependence, agency and technological evolution. Technology Analysis \& Strategic Management, 14(1), 5-19. https://doi.org/10.1080/ 09537320220125856

Asheim, B. T., Smith, H. L., \& Oughton, C. (2011). Regional innovation systems: Theory, empirics and policy. Regional Studies, 45(7), 875-891.

Audretsch, D (2014). From the entrepreneurial university to the university for the entrepreneurial society. Journal of Technology Transfer, 39(3), 313-321.

Balbachevsky, E. (2008). Incentives and obstacles to academic entrepreneurship. In S. Schwartzman (Ed.), University and development in Latin America: Successful experiences of research centre (pp. 23-42). Rotterdam: Sense.

Battilana, J. (2006). Agency and institutions: The enabling role of individuals' social position. Organization, 13(5), 653-676.

Battilana, J., \& D'aunno, T. (2009). Institutional work and the paradox of embedded agency. In T. Lawrence, R. Suddaby, \& B. Leca (Eds.), Institutional work: Actors and agency in institutional studies of organizations (Vol. 31, pp. 31-58). Cambridge: Cambridge University Press.

Becher, T., \& Trowler, P. (2001). Academic tribes and territories: Intellectual enquiry and the culture of disciplines. Buckingham: Society for Research into Higher Education \& Open University Press.

Beckert, J. (1999). Agency, entrepreneurs, and institutional change. The role of strategic choice and institutionalized practices in organizations. Organization Studies, 20(5), 777-799.

Benneworth, P. (2012). The relationship of regional engagement to universities' core purposes: Reflections from engagement efforts with socially excluded communities. In R. Pinheiro, P. Benneworth, \& G. A. Jones (Eds.), Universities and regional development: A critical assessment of tensions and contradictions (pp. 199-218). Milton Park and New York: Routledge.

Benneworth, P. (2018). Universities and regional economic development: Engaging with the periphery. London: Taylor \& Francis.

Benneworth, P., \& Hospers, G. J. (2007). The new economic geography of old industrial regions: Universities as global-local pipelines. Environment and Planning C: Government and Policy, 25(6), 779-802.

Benneworth, P., Pinheiro, R., \& Karlsen, J. (2017). Strategic agency and institutional change: Investigating the role of universities in regional innovation systems (RISs). Regional Studies, 51(2), 235-248.

Benneworth, P., \& Sanderson, A. (2009). The regional engagement of universities: Building capacity in a sparse innovation environment. Higher Education Management and Policy, 21(1), 1-18.

Berger, P. L., \& Luckmann, T. (1966). The social construction of reality. London: Penguin Books.

Brint, S. B., \& Karabel, J. (1991). Institutional origins and transformations: The case of American community colleges. In W. Powell \& P. DiMaggio (Eds.), The new institutionalism in organizational analysis (pp. 337-360). Chicago: University Chicago Press. 
Brush, C., de Bruin, A., \& Welter, F. (2009). A gender-aware framework for female entrepreneurship. International Journal of Gender and Entrepreneurship, 1(1), 8-24.

Bucheli, M., \& Wadhwani, R. D. (2013). Organizations in time: History, theory, methods. Oxford: Oxford University Press.

Buse, C., Martin, D., \& Nettleton, S. (2018). Conceptualising "materialities of care": Making visible mundane material culture in health and social care contexts. Sociology of Health \& Illness, 40(2), 243-255.

Chandler, J. A. D. (1990). Strategy and structure: Chapters in the history of the American industrial enterprise. Boston, MA: MIT Press.

Clark, B. (1972). The organizational saga in higher education. Administrative Science Quarterly, 17(1), 178-184.

Czarniawska, B., \& Hernes, T. (2005). Actor-network theory and organizing. Copenhagen: Liber \& Copenhagen Business School Press.

Deephouse, D., \& Suchman, M. (2008). Legitimacy in organizational institutionalism. In R. Greenwood, C. Oliver, K. Sahlin, \& R. Suddaby (Eds.), The Sage handbook of organizational institutionalism (pp. 49-77). London and Thousand Oaks: Sage.

DiMaggio, P., \& Powell, W. (1983). The iron cage revisited: Institutional isomorphism and collective rationality in organizational fields. American Sociological Review, 48(2), 147-160.

Emirbayer, M., \& Mische, A. (1998). What is agency? American Journal of Sociology, 103(4), 962-1023.

Enders, J., \& Boer, H. (2009). The mission impossible of the European university: Institutional confusion and institutional diversity. In A. Amaral, G. Neave, C. Musselin, \& P. Maassen (Eds.), European integration and the governance of higher education and research (Vol. 26, pp. 159-178). Dordrecht: Springer.

Etzkowitz, H., \& Leydesdorff, L. (1997). Introduction to special issue on science policy dimensions of the Triple Helix of university-industry-government relations. Science and Public Policy, 24(1), 2-5.

Garud, R., \& Karnøe, P. (2003). Bricolage versus breakthrough: Distributed and embedded agency in technology entrepreneurship. Research Policy, 32(2), 277-300.

Geiger, R. L. (2009). Research \& relevant knowledge: American research universities since World War II. New Jersey: Transaction Publishers.

Geschwind, L., Pinheiro, R., \& Stensaker, B. (2022). Organizational persistence in highly institutionalized environments: Unpacking the relation between identity and resilience. In R. Pinheiro, L. Frigotto, \& M. Young (Eds.), Towards resilient organizations and societies: A cross-sectoral and multi-disciplinary perspective (pp. 195-221). Cham: Springer International Publishing.

Giddens, A. (1984). The constitution of society. Outline of the theory of structuration. Cambridge: Polity Press

Gornitzka, Å., \& Maassen, P. (2007). An instrument for national political agendas: The hierarchical vision. In P. Maassen \& J. P. Olsen (Eds.), University dynamics and European integration (pp. 81-98). Dordrecht: Springer

Greenwood, R., Oliver, C., Lawrence, T. B., \& Meyer, R. E. (2017). The SAGE handbook of organizational institutionalism. London and New York: SAGE Publications.

Griffin, M. (2007). Specifying organizational contexts: Systematic links between contexts and processes in organizational behaviour. Journal of Organizational Behaviour, 28(7), 859-863.

Hüther, O., \& Krücken, G. (2016). Nested organizational fields: Isomorphism and differentiation among European universities. In E. Berman \& C. Paradeise (Eds.), The university under pressure (pp. 53-83). Bingley: Emerald Group Publishing Limited. 


\section{Rómulo Pinheiro et al.}

Isaksen, A., Jakobsen, S. E., Njøs, R., \& Normann, R. (2019). Regional industrial restructuring resulting from individual and system agency. Innovation: The European Journal of Social Science Research, 32(1), 48-65.

Johns, G. (2001). In praise of context. Journal of Organizational Behaviour, 22(1), 31-42.

Kehm, B. M., \& Teichler, U. (2013). The academic profession in Europe: New tasks and new challenges. Dordrecht: Springer.

Krücken, G. (2003). Learning the "New, New Thing": On the role of path dependency in university structures. Higher Education, 46(3), 315-339.

Lawrence, T. (2008). Power, institutions and organizations. In R. Greenwood, C. Oliver, K. Sahlin, \& R. Suddaby (Eds.), The Sage handbook of organizational institutionalism (pp. 170-197). London: Sage Publishers.

Lawrence, T., Suddaby, R., \& Leca, B. (2011). Institutional work: Refocusing institutional studies of organization. Journal of Management Inquiry, 20(1), 52-58.

Maassen, P., \& Olsen, J. P. (2007). University dynamics and European integration. Dordrecht: Springer.

Mahoney, J., \& Thelen, K. (2010). Explaining institutional change: Ambiguity, agency, and power. Cambridge: Cambridge University Press.

March, J. G., \& Olsen, J. P. (1979). Ambiguity and choice in organizations. Bergen: Universitetsforlaget.

March, J. G., \& Olsen, J. P. (2006). Elaborating the "New Institutionalism". In R. A. Rhodes, S. A. Binder, \& R. B. A. (Eds.), The Oxford handbook of political institutions (pp. 3-22). Oxford: Oxford University Press.

March, J. G., Schulz, M., \& Zhou, X. (2000). The dynamics of rules: Change in written organizational codes. Stanford: Stanford University Press.

Marginson, S., \& Rhoades, G. (2002). Beyond national states, markets, and systems of higher education: A glonacal agency heuristic. Higher Education, 43(3), 281-309.

Meyer, J. W., \& Rowan, B. (1977). Institutionalized organizations: Formal structure as myth and ceremony American Journal of Sociology, 83(2), 340-363.

Meyer, J. W., \& Scott, W. R. (1992). Organizational environments: Ritual and rationality. Beverly Hills, CA.: Sage Publications.

Neffke, F., Hartog, M., Boschma, R., \& Henning, M. (2018). Agents of structural change: The role of firms and entrepreneurs in regional diversification. Economic Geography, 94(1), 23-48.

Nyden, P. (2003). Academic incentives for faculty participation in community-based participatory research. Journal of General Internal Medicine, 18(7), 576-585.

Oftedal, E. M., Iakovleva, T. A., \& Foss, L. (2018). University context matter. Education+ Training, 873-890

Pekkola, E., Pinheiro, R., Geschwind, L., Siekkinen, T., Carvalho, T., \& Pulkkinen, K. (2021). Nested hybridity and value definition in public higher education. In J. Vakkuri \& J.-E. Johanson (Eds.), Hybrid governance, organisations and society: Value creation perspectives (pp. 59-80). London: Routledge.

Pfeffer, J., \& Salancik, G. (2003). The external control of organisations: A resource-dependence perspective. Stanford, CA: Stanford Business Books.

Pinheiro, R. (2012). In the region, for the region? A comparative study of the institutionalisation of the regional mission of universities ( $\mathrm{PhD}$ dissertation). Oslo: University of Oslo.

Pinheiro, R., Geschwind, L., \& Aarrevaara, T. (2014). Nested tensions and interwoven dilemmas in higher education: The view from the Nordic countries. Cambridge Journal of Regions, Economy and Society, 7(2), 233-250. 
Pinheiro, R., \& Stensaker, B. (2014). Strategic actor-hood and internal transformation: The rise of the quadruple-helix university? In J. Brankovik, M. Klemencik, P. Lazetic, \& P. Zgaga (Eds.), Global challenges, local responses in higher education. The contemporary issues in national and comparative perspective. (pp. 171-189). Rotterdam: Sense.

Pinheiro, R., \& Young, M. (2017). The university as an adaptive resilient organization: A complex systems perspective. In J. Huisman \& M. Tight (Eds.), Theory and method in higher education research (pp. 119-136). Bingley: Emerald.

Pinheiro, R., Young, M., \& Sima, K. (2018). Higher education and regional development: Tales from Northern and Central Europe. Cham: Palgrave.

Pitelis, C. N. (2005). On globalisation and governance; some issues. Contributions to Political Economy, 24(1), 1-12.

Ramirez, F., Byrkjeflot, H., \& Pinheiro, R. (2016). Higher education and health organizational fields in the age of "world class" and "best practices". In R. Pinheiro, L. Geschwind, F. Ramirez, \& K. Vrangbæk (Eds.), Towards a comparative institutionalism: Forms, dynamics and logics across health care and higher education fields (pp. 35-57). Bingley: Emerald.

Scott, W. R. (2003). Organizations: Rational, natural, and open systems. New York: Prentice Hall.

Scott, W. R. (2008). Institutions and organizations: Ideas and interests. London: Sage Publications.

Selznick, P. (1996). Institutionalism “old” and "new". Administrative Science Quarterly, 41(2), 270-277.

Sørensen, M. P., Geschwind, L., Kekäle, J., \& Pinheiro, R. (2019). The responsible university: Exploring the Nordic context and beyond. Cham: Springer Nature.

Steen, M. (2016). Reconsidering path creation in economic geography: Aspects of agency, temporality and methods. European Planning Studies, 24(9), 1605-1622.

Thompson, J. D. (2008). Organizations in action: Social science bases of administrative theory (5th ed.). New Brunswick, NJ: Transaction Publishers.

Thornton, P. H., Ocasio, W., \& Lounsbury, M. (2012). The institutional logics perspective: A new approach to culture, structure, and process. Oxford: Oxford University Press.

Welch, A. R. (2005). The professoriate: Profile of a profession. Dordrecht: Springer.

Welter, F., \& Smallbone, D. (2010). The embeddedness of women's entrepreneurship in a transition context. In C. Brush, A. Bruin, E. Gatewood, \& C. Henry (Eds.)., Women entrepreneurs and the global environment for growth: A research perspective (pp. 96-117). Cheltenham Edward Elgar: Publisher.

Welter, F., \& Smallbone, D. (2011). Institutional perspectives on entrepreneurial behaviour in challenging environments. Journal of Small Business Management, 49(1), 107-125.

Whittington, R. (2010). Giddens, structuration theory and strategy as practice. In D. Golsorkhi, L. Rouleau, D. Seidl, \& E. Vaara (Eds.), Cambridge handbook of strategy as practice (pp. 145-164). Cambridge: Cambridge University Press. 


\title{
3 Changes and Continuities in the Development of Rural Teacher Education in the Fjords of Western Norway
}

\author{
Laila Nordstrand Berg and Gunnar Yttri
}

\begin{abstract}
In this chapter, we apply historical institutionalism to study the development of teacher education in Sogndal, a Norwegian rural village, from the early 1960 s to the present. The rationale for establishing teacher training within the county boundaries sprang from two interconnected needs: to have access to sufficient qualified teachers for primary schools and to stop the brain drain. In the analysis of the evolution of teacher education in a rural setting, key events and critical junctures over six decades are identified and highlighted. Developments and changes are understood within the historically determined and changing framework of institutional strategies, regional needs, and national policies. The study illuminates a story from a rural Norwegian teacher education, which was quite successful in supplying teachers for the region by the 2010s. Nonetheless, the regional success was no guarantee of satisfying higher academic requirements following national reforms. When the Sogn og Fjordane University College merged into the new Western Norway University of Applied Sciences in 2017, proven lack of academic qualifications in teacher education was a major reason for joining forces with other institutions.
\end{abstract}

\section{Introduction}

Besides being a fundamental human right, education enables people to acquire knowledge, achieve and develop important skills and techniques, and become independent. Education provides a foundation towards achieving a good life, and it is considered as a prerequisite for the development of society by enabling them to know their rights and duties towards their family, society, and the nation. In addition, universities and higher education institutions (HEIs) are often seen as important factors that facilitate regional socio-economic developments and connect to global competitiveness (Lester \& Sotarauta, 2007).

Providing good-quality primary education is a basic necessity for every society, which will enable students in pursuing higher education, and to deliver 
this, effective teachers, enabled by effective teaching, are crucial. In this chapter, we focus on the development of teacher education in a Norwegian rural region. Equity and equality of access to public goods, such as education, are core values in the egalitarian Norwegian society (Esping-Andersen, 1990) and the central tenets of the development of the higher education sector. In general, providing teachers and educators to rural areas in such a sparsely populated country has been challenging; therefore, to determine the contributing factors to this important issue, we focus on one of the most sparsely populated counties in Norway, Sogn og Fjordane.

We chose this region to study how easy it is to forget that regional education is embedded in the larger educational system, a system that is highly influenced by the development in international and global currents. This chapter provides a historical institutionalist (HI) perspective on the development of teacher education in this region. The history of teacher education in the municipality of Sogndal is described and analysed in the context of national education policy and regional expectations from 1960 to 2020. Hence, our research question is this: What characterizes the development of the teacher school and how is this coherent with the development of the HEI sector?

The fundamental role of higher education in the development of society is gaining increasing recognition since the post-war period, resulting in various educational reforms in Western countries, particularly since the 1960s (Kyvik, 2004). As societies are getting more complex, there is a consensus in the literature that although considering the characteristics following dynamic and technical environments is important, considering the structural and cultural complexity when focusing on the sustainability of HEIs regional mandate is equally important (Goddard et al., 2016). Regional development is not detached from national development, but national focus and policy arrangements directed towards efficiency and global excellence can be considered as barriers to regional engagement (Benneworth et al., 2017).

The study of rural teacher education is of interest to the questions raised in this edited volume for at least three reasons. Firstly, it gives us the chance to better understand the embeddedness between higher education policy at the national level and how an organization adapts to and develops at the regional and local levels. Secondly, throughout the period, 1960-2020, teacher education in Norway has been at the forefront of the government's policies, including major reforms in higher education. By directing our focus on this development, we can follow up on how individuals and organizations influence development within a sector. Thirdly, the rural experience over time is particularly interesting because the new higher education architecture, which was designed at the beginning of the 1970s, aimed to contribute to regional development. The chapter highlights this adaption in the light of temporality and studies concerning how past events connected to development in the light of HI.

In the continuation of this chapter, we first introduce the fjord context where our case is selected from. Central elements of HI are thereafter elaborated. The presentation of national context and development of the HE sector 
and the tale of Sogn og Fjordane teacher education is thereafter described, and this is considered our empirical base. The empirics are then analysed according to HI, and the chapter ends with a concluding discussion.

\section{The fjord context}

Sogn og Fjordane county is geographically located on the west coast of Norway, with high mountains, coastal islands, and deep and long fjords. Sognefjorden and Nærøyfjorden are the most famous ones. The county is sparsely populated, with weaker population growth than the rest of Norway from 1900 to 2000. The county was inhabited by almost 90,000 inhabitants in 1900 , and if developments in this county had been the same as the rest of the country, the numbers would have increased to 190,000 in 2010 (Urtegaard, 2005). Instead, the county recorded 110,000 inhabitants in 2019 (Statistisk sentralbyrå, 2019). This weak population growth can be attributed to the rural settlement pattern, lacking a unifying larger city centre. Cities with varied business structures and large service sectors became the engines of growth driving the modern Norwegian economy. As a result, regions without such cities did not witness the new growth to the same degree (Bukve et al., 2006).

Sogn og Fjordane is divided into small municipalities with scattered villages providing services from the public sector such as education, health, and social services. The long Norwegian coastline provides natural resources to the fishing industry; the long fjords have a climate that is suitable for growing apples as well as other fruit-related industries; and the mountains provide hydropower resources, and large industrial facilities were built post-World War II (in Høyanger, Årdal, and Bremanger).

\section{Historical institutionalism}

In this chapter, we apply HI to study the development of teacher education in Sogndal, a rural Norwegian village. HI is neither a theoretical framework nor a specific method (Steinmo, 2008); rather it is an approach that in its historical orientation pays close attention to real-world empirical questions and to how institutions structure and shape social behaviour and policy and strategic outcomes. Steinmo (2008) characterizes this as an approach to study real historical events, politics, and social change, but the approach provides a theoretical vocabulary for the analysis on how institutions change over time by social and political actors (Capoccia, 2016b).

Society and higher education have undergone extensive changes in the last few decades, especially in technology and communication. Perspectives and key concepts from HI are helpful to narrow and conduct our empirical investigation. In conclusion, HI teaches us that history matters (Pierson, 2000; Skockpol \& Pierson, 2002; Thelen, 1999). Political events are taking place within specific historical contexts that influence the output. In addition, the 
actors involved can learn from their experiences and political, cultural, social, or economic events, and lastly, expectations of future events are rooted in the past (Steinmo, 2008).

Institutional changes, that is, shifts in formal and informal rules regulating the behaviour of social actors, are, to a large degree, incremental and evolutionary, thus dependent on historical paths and trajectories. Contemporary changes are dependent on a series of previous events, and even small events can result in large consequences that can be difficult to reverse (Pierson, 2000). Such moments can be viewed as "critical junctures" where the uncertainty of future development allows political agencies to influence the way forward, and this path can be persistent over time (Capoccia, 2016a). Critical junctures can be a synonym of "crisis" or "turning points" and refers to something that has occurred earlier, which influences later outcomes. These critical junctures are normally concentrated in a specific and short period. In this chapter, the critical junctures are identified through a teacher education study in Sogndal and various national reforms. Another central term is "path dependency", which implies that development within a field depends on prior events and arrangements. Critical junctures can create new conditions or institutions that may result in path dependency (Capoccia, 2016b). The study of path dependencies, therefore, includes tracing back to the events that were of importance for future outcome (Mahoney, 2000).

As a way to study continuity or institutional change, we apply four modes of change: displacement, layering, drift, and conversion (Mahoney \& Thelen, 2010; Streeck \& Thelen, 2005). Displacement refers to comprehensive changes where existing rules are removed and new ones are introduced, which can be either a fast or slow process. As such, the introduction of reforms can be viewed as a mode of change. Layering refers to changes where new rules are established in addition to the existing ones. This can also lead to considerable changes over time or stabilize and reproduce core features of the organization, such as new routines or curriculum. Drift refers to gradual changes where existing rules are losing impact due to changes in external conditions. For example, an educational system that persists to remain due to its local appropriateness may lose impact over time if not responding adequately to crossing trends in society. Conversion relates to internal changes within an organization while the external core appears to be unchanged. The formal rules are interpreted in new ways as strategic redeployment. For example, the school retains its name while merging with other organizations. Here, although there may be large organizational changes and altered formal rules internally, the school appears to remain the same to an outsider.

To ensure that our analysis of the evolution of teacher education in a rural setting remains relevant, key events and critical junctures in the formation of teacher education will be highlighted. The study is based on a large range of historical documents, decisions, central reports, and literature that stems from internal correspondence between the Ministry of Education, Sogn og Fjordane county, and interest organizations in the 1960s and the teacher training college 
and university college board from the 1970s until 2020. For further elaborations, refer to studies conducted by Yttri $(2008,2016)$.

In this continuation, we will first elaborate on the development of higher education in Norway, followed by the development of the teacher school in Sogn og Fjordane.

\section{Development of higher education in Norway}

Teacher education has roots back to the start of higher education in Norway. The first teacher education was established in the 1820s, shortly after the first university was founded in 1811, the University of Oslo. The university sector was inspired by Humboldtian values and a German university model where research-based teaching and freedom for the individual professor were emphasized (Vabø, 2011). This contrast in the development of teacher education, since their establishment under the county's educational system, is due to strict regulations (Garm \& Karlsen, 2004).

The Norwegian educational sector is dominated by public providers at all levels; the provision for the sector is tax-based, and education at all levels is tuition-free. Stipends and affordable state loans have been made available to students for expenses since 1946 (Bjelle, 2019). This acts as a remedy to support young people to pursue education without being dependent on their families for financial support.

Since the 1950s, to maintain the population in dispersedly populated districts of Norway, the government has made a conscious effort to ensure that their policies are designed to emphasize the importance of education and increase access to education (Pinheiro et al., 2016). Furthermore, there was a growing political awareness of the use of established district colleges in rural communities as a means to serve districts with professionals to public and private sectors and to maintain population within the districts (Kvil, 2004). This concept was introduced in Norway at the end of the 1960s (Yttri, 2016, pp. 29-32). As a result, a dual model of education was introduced. The universities were placed in the largest cities, while occupationally oriented district colleges expanded to the regions throughout the 1970s. The parliament decided that some of these should be in rural communities. While the focus of universities has been on research, the mission of district colleges was on providing central educations to districts, such as teacher education.

From 1970 to 2020, higher education in Norway, as in many other European countries, was characterized by significant and tremendous growth in the number of students and types of education. Furthermore, the number of students increased from almost 50,000 to 300,000 approximately (Yttri, 2016; Statistisk sentralbyrå, 2019). In the 1970s, there was a myriad of different professional schools, such as engineering, types of health education, social work, and teacher education. These specialized schools were upgraded to higher educational institutions during the 1970s to the 1980s (Kyvik, 2008). Schools for teacher training were upgraded to colleges of higher education in 1975. 
Regional college boards were established to enable coordination of the new educational system.

This disperse model, however, was expensive, fragmented, and difficult to coordinate (ibid.). Hence, in 1987, the Hernes Commission was established to draw guidelines for future educational policy (Kvil, 2004). On the basis of this, in 1993, the government merged a variety of independent colleges within the regions through the college reform (KUF, 1993-1994; Kyvik, 2008). Many small and specialized providers belonging to the college sector were regionally integrated through large-scale mergers of geographically close university colleges in 1994. In this process, 98 district and vocational colleges merged into 26 state colleges in 1994 (in a top-down process) (Kyvik, 2002). In addition, through the mergers, the dual model of district colleges and universities was replaced by the establishment of a binary system of universities and state colleges ("høyskoler").

Another goal of the reform (Kyvik, 2002) was to prevent large regional colleges to apply for university status. The pressure continued as many large colleges pursued their ambition to become universities, and by the turn of the millennium, there was a discussion concerning abolishing the binary system.

In 1998, the Mjøs Commission was established to develop Norwegian higher education after 2000 (Kvil, 2004). Their comprehensive suggestions culminated in the Quality Reform (ME, 2001), which contributed to higher academic requirements for both the institutions and the employees. The central elements from this reform were to prepare the HEIs to develop towards the international degree systems, aligned with the Bologna intergovernmental process as part of the aims of creating a common European higher education area. In August 2003, the international degree systems with bachelor and master programmes were established, along with the use of the European Credit Transfer System (commonly referred to as ECTS) (ibid.).

In 2004, in efforts to further develop the sector, the government decided that state colleges could apply for full university status if they could fulfil certain standards (Kyvik, 2005). This resulted in numerous initiatives, and a new "wave" of mergers began (in a bottom-up manner). The mergers in 2005-2007 resulted in 7 universities, 7 specialized universities, 25 state colleges, and 25 smaller, private institutions (Kyvik, 2008).

In 2007, the Stjernø Commission was set up by the government to investigate the development of the sector for the following decade. Furthermore, the commission recommended that the binary system should be abolished and a unified higher education system should be established instead in line with international developments (Regjeringen, 2008). This could probably be materialized by granting university status to large colleges and integrating small colleges and specialized university institutions into existing universities. However, the government rejected the proposal (Kyvik, 2008), and the arrangement that each college could qualify for university status was continued and clarified.

In the 2010s, several more institutions merged, and some of these mergers joined together without pressure from national authorities; however, regional 
authorities also played an active role. For example, Telemark was supportive of a merger with the University in Agder, whereas the Agder region was against it (Stensaker et al., 2016). For the remaining institutions, the government-led structural reform in higher education, in association with the government's parliamentary report approved by the parliament in 2015, was decisive. In addition, during this period, there was a shift in the political landscape that resulted in a government that was very pro-mergers and had a focus on reforming the sector into a more unified, competitive and efficient sector. By 2017, the number of universities and colleges was reduced from 33 to 21 (Regjeringen, 2016).

Currently, most tertiary education providers are universities, with only a handful of university colleges remaining, of whom, several have stated their ambitions to become fully fledged universities in the near future. All the mergers were motivated by a desire to achieve greater strategic strength, not only within the respective region but also nationally and internationally. For several of the colleges, especially the larger ones, achieving university status was an important part of this strategic strength and a special motivation for the mergers. For others, often smaller ones, considerations for participating in a merger were greatly influenced by the government's introduction of higher academic requirements to be allowed to offer new 5-year teacher education from the autumn of 2017 (Regjeringen, 2016; Yttri, 2016, pp. 71-72).

\section{Sogn og Fjordane teacher education: regional needs and national policies}

Local and regional interests in the county of Sogn og Fjordane raised the demand for teachers' schools in the early 1960s. For a county consisting of some rural municipalities scattered along fjords and mountains, therefore, making communication difficult, it was not sufficient to have these schools in neighbouring counties. By the beginning of 1960, Sogn og Fjordane county had the least number of qualified teachers working in a primary school in southern Norway (Yttri, 2008, p. 37). A paradox in this respect was the fact that in national surveys (Strømnes, 2006, pp. 128-140; Yttri, 2008, p. 37, 2015, pp. 24-25), Sogn og Fjordane was the county that recruited the very best for teacher education and teaching profession for decades. However, most of the local youths who pursued teacher education in the other parts of the country did not return to their counties after completing their studies, which was a major issue. The rationale for establishing a teacher training college within the county boundaries thus sprang from two interconnected regional needs: to have access to sufficient qualified teachers for primary schools and to stop the brain drain. This was a strong rationale that remained over the years. It was the raison d'être of the rural teacher education.

Initially, the demand for new teacher education was met with sympathy by the government's Labour Party (Yttri, 2008, pp. 37-45), but all teacher schools established in Norway post-World War II were located in cities and urban areas. 
A central government advisor on education, Eva Nordland (Yttri, 2008, pp. 37-49), strongly opposed the idea of new teacher education in rural counties and succeeded in stopping the initiative. At the beginning of the 1960s, the government, therefore, decided not to establish a teaching school in Sogn og Fjordane county. The arguments from the advisor were that the rural areas neither have the population and infrastructure to conduct a modern teacher education nor could it match urban areas in recruiting competent teachers and staff for the school. In addition, the adviser strongly opposed that the location of new teacher education in Sogn og Fjordane could contribute to more qualified teachers in the county's scattered rural municipalities. The measure was considered too weak to stop the ongoing process of brain drain from the periphery to more central areas (ibid.).

Nonetheless, the proven needs of teacher education in Sogn og Fjordane were later acknowledged in 1962. In the process that followed, the Ministry of Education determined that a teacher school serving Sogn og Fjordane should be located in the south-eastern part of the county in Sogndal municipality (Yttri, 2008, pp. 40-42). To ensure that the school was accessible, as much as possible, to the county's various municipalities, the regional authorities had proposed a location in the middle of the county in the municipality of Førde. However, the central authorities did not share this reasoning. The size of Sogn og Fjordane's population was not sufficient to secure a new teacher school and fill up the required number of students. If a new educational organization had to have the right to exist, it should have a location that made it possible to recruit students from neighbouring counties, including the east and the south. The ministry, therefore, in 1962, decided to locate the new school in Sogndal, a village at the inner part of the Sognefjord. Comparatively, this location was closer to eastern Norway and counties to the north and the south. The recruitment of students from the surrounding counties became a feature of the teacher education in Sogndal in the following decades: the ability to recruit a relatively high proportion of students outside the county of Sogn og Fjordane. The Sogndal Teacher School opened in 1972.

Although teacher education in Sogndal followed national guidelines and thus educated teachers for the whole country, regional needs were very much in focus (Yttri, 2008, pp. 86-87). During the first few years, measures that specifically aimed at educating teachers for small rural municipalities were developed. For instance, teachers at the rural school accepted assignments and provided part-time training in various parts of the county. More importantly, specialized on-campus courses were developed to qualify teachers for small schools wherein teaching students of different ages at the same time and in the same classroom was the norm. Despite these developments, at the tenth anniversary in 1982, the county's school director pointed out that several schools across the county still lacked qualified teachers (ibid.).

Initially, the teacher school was separated from the district colleges, but following the development of the HE sector, the post-secondary teacher training was upgraded to colleges of higher education in 1975, and Sogndal Teacher 
School was given the responsibility to lead and develop the new district college, the Sogn og Fjordane District College. However, the process involved in developing this district college was not without tensions because two different academic cultures were involved in this merger. The teacher education came from the rule-based vocational training tradition, while the district college was more oriented towards the university sector, regarding both the background of employees and academic focus. Since 1975, this became the basis for turbulence, conflicts, and inadequate cooperation. In 1981, the ministry finally decided to establish two independent institutions under their own leadership, the Sogndal Teacher School and the Sogn og Fjordane District College (Yttri, 2008, pp. 64-73).

The second half of the 1980s was a time of crisis for Norwegian teacher education. Few young people wanted to become teachers, and in Sogndal, several desks were empty. The recruitment of students became significantly better in the early years, and Sogndal also recruited a high proportion of students from outside the county. However, during a period of low interest in teacher education nationally, the student base was not sufficient. Yet, in consultation with the Ministry of Education, the teacher college was allowed to re-allocate resources (Yttri, 2008, pp. 89-91). These resources were used to initiate the sports education in Sogndal from 1986, as well as part-time education, with decentralized teaching at various places across the county. This provided teachers in the whole county a new foundation to pursue education. Eventually, Sogndal Teacher School also offered education outside the county. This activity became a trademark of the rural teacher college, and it was highly appreciated beyond the county's boundaries (Yttri, 2008, p. 204). During various political regimes in the 1990s and 2000s, the extensive decentralized educational activities were continued, as it compensated for the lack of sufficient numbers of on-campus students.

During the waves of mergers after the college reform in 1994, changes were also observed in Sogn og Fjordane where the HEIs that had been established in the county in the 1970s and 1980s were gathered. The Sogn og Fjordane University College was a merge between the Sogndal Teacher School, Sogn og Fjordane District College, the Nursing Education in Sogn og Fjordane, Sogn og Fjordane Engineering College, and the College at Sandane. However, the Sogndal Teacher School continued as a separate department in the university college.

In the latter half of the 1990s, teacher training in Sogndal began to adopt a more systematic and long-term competence programme for the teaching staff in all municipalities throughout Sogn og Fjordane. This was executed in close cooperation with regional state school authorities, municipalities, and employers, as well as teachers' organizations. The teaching methodology and results won national praise, and the good results were reflected in the testing of the pupils. At the national tests that were introduced to Norwegian primary schools from 2004 in reading, maths, and English, pupils across Sogn og Fjordane topped the national tests in the 2000s and 2010s 
(Langfeldt, 2015). The close collaboration between the university college and the municipalities received much of the credit for these results (Glosvik, 2015; Yttri, 2016).

In 2012, a recruitment study comparing several colleges documented that teacher training in Sogndal for decades had played a particularly important role in providing qualified teachers to the region (Gythfeldt \& Heggen, 2012). Combined with the strong school results, this helped strengthen both the legitimacy of the education and the regional and national reputation.

Although the Sogn og Fjordane University College established in 1994 had a wide range of education, the teacher education had a high internal and external prestige during the first few decades or the 2000s. This probably contributed to the moderate academic ambitions that were found for the entire college (Yttri, 2015, pp. 56-57). While other university colleges across the country established master's and doctoral degrees, Sogn og Fjordane University College profiled itself as a bachelor's or first cycle college. In a regional context, this was probably a great strength because occupational relevance then was the most important criterion. To compensate for the small number of teacher students on campus, the focus on decentralized education was increased. However, at the national level, the university college's academic development was too weak. Neither the college reform in 1994 nor the quality reform in 2003 led to any significant changes in the competence profile of teacher education. The research activity increased slightly, and some employees completed their doctoral studies. However, in addition to the closely related sports education, the research activity was insignificant. The typical career path remains in the line of vocational tradition, which is lecturer and docent, rather than following university tradition: associate and full professor. In 2014, the Ministry of Education required the colleges to offer a 5-year programme in teacher education from 2017 (ME, 2014). The teacher training in Sogndal was far from satisfying the academic requirements, and it appeared that the focus that had earlier reckoned strength became their major weakness.

In 2016, the board of Sogn og Fjordane University College chose to merge with Bergen University College and Stord/Haugesund University College, and Western Norway University of Applied Sciences was established in 2017. The colleges from these neighbouring regions had teacher education that was a part of the merger. The consideration of the future status for teacher education in Sogndal was crucial to the final decision (Pedersen, 2017).

\section{Analysis, critical junctures, and modes of change}

In our attempt to analyse the development of teacher education in Sogn og Fjordane from the early 1960s until 2020, we applied the HI approach and used it to highlight the developments according to the development in the sector otherwise, as described in the contextual chapter. Firstly, we focus on critical junctures as turning points, which has influenced the development in the later 


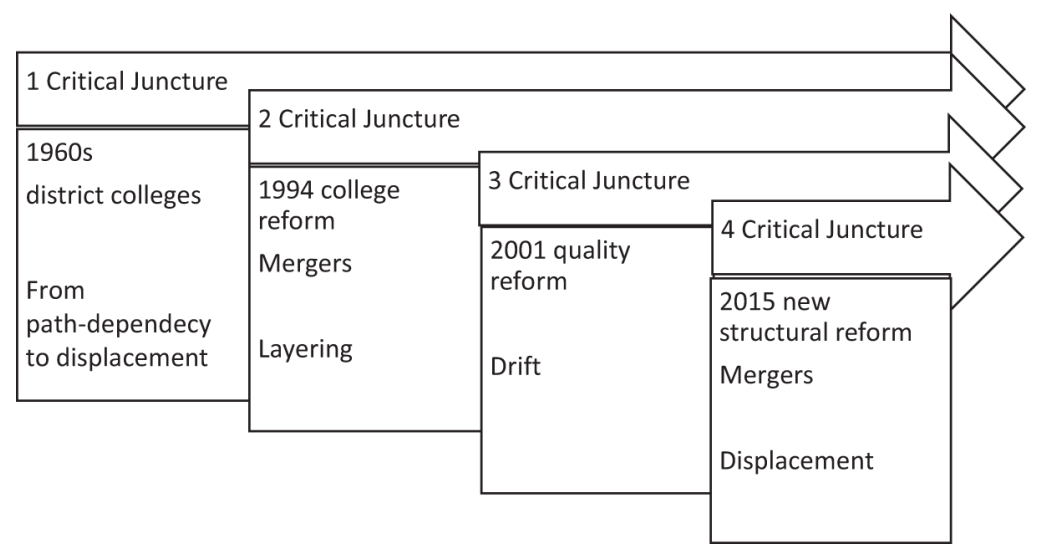

Figure 3.1 Critical junctures in the development and modes of change

stages (Capoccia, 2016a). The critical moments are listed in Figure 3.1, which will be discussed in relation to the development in the teacher education after the figure.

Critical junctures create an uncertainty that makes it possible for political agency to manoeuvre and influence the way forward (Capoccia, 2016a). In the 1960s, the actors from Sogn og Fjordane fought for establishing a teacher education and were rejected by the government initially (Yttri, 2008, pp. 37-49). This can be seen as the first critical juncture. Parallel to this, we focus on the political trends from society regarding the development of the districts (Kvil, 2004). This can be interpreted as the critical juncture provided a room for the ongoing political process, and this paved the way for establishing teacher education in Sogn og Fjordane in 1972. The first period can be seen as pathdependent (Mahoney, 2000), wherein the development of higher education followed the path that educational institutions should be established in urban areas. The critical juncture led to a change in this path and can be seen as a displacement (Mahoney \& Thelen, 2010), wherein the old model was abolished and prepared the ground for the new development of the sector.

The second turning point and critical juncture with the severe influence of the development of the sector came with the structural college reform initiated by Hernes in 1993-1994. The top-down restructuring of the sector that resulted in mergers all over the country did not appear to influence the development of teacher education in Sogndal, despite the mergers and formation of Sogn og Fjordane University College. No drastic changes were introduced in this wave of mergers for teacher education in Sogn. During the 1990s, which were turbulent times for the rest of the sectors in Norway, they continued to develop what appeared to become their brand, decentralized education. While displacement (Mahoney \& Thelen, 2010) and establishment of new HE 
constellations characterized the sector in other places, layering (Mahoney \& Thelen, 2010) can be a way to analyse the development in the teacher education at Sogn og Fjordane University College during this period. In addition to the existing rules, new rules were introduced, that is, with further development of the decentralized model of teacher education by introducing systematic and long-term programmes for improving competencies for teachers across the municipalities in the county.

The third critical juncture in the sector can be highlighted according to the quality reform in 2001, where the whole sector had to change their degree systems to align with the European education (Kvil, 2004). State colleges across the country took on this displacement mode (Mahoney \& Thelen, 2010) and replaced the old educational structure with new rules and ways to organize education. This became a critical time for teacher education in Sogndal. In Sogndal, the teachers' education pride was in delivering relevant education to meet regional needs but was now met with more challenges that would continue through to the next decade. They decoupled the push towards a higher focus on research and academic achievements. This can be seen as a period of drift (ibid.) where their inner core of existing rules was losing impact due to external demands from society and government.

As the fourth critical juncture appeared in 2015 with the new structural reform (KD, 2014-2015), teacher education remains in a critical place. Because the focus had been towards meeting regional needs, the academic development was too weak. Very few of the lecturers fulfilled the demands with a $\mathrm{PhD}$ and research competencies, and measures had to be taken to be able to keep the teacher education. The board of Sogn og Fjordane University College initiated the merger with neighbouring state colleges across the region to secure the status for teacher education in Sogndal. With the new merger in 2017 and the establishment of Western Norway University of Applied Sciences, the mode of change can once more be characterized by displacement (Mahoney \& Thelen, 2010) with radical changes regarding organizing, teaching. and research, and by merging different types of education at large distances. As a part of a larger university college, the teacher education in Sogndal finally established a 5-year master's degree in teaching. Nonetheless, the development of Western Norway University of Applied Sciences is in progress and this is also fuelled by the application for full university status. Could this be viewed as a new critical juncture?

\section{Conclusion}

This chapter aims to study the development of teacher education in a rural county within the Norwegian education system in light of HI. The development of an educational organization depends on history, geography, and governmental policy. For the teacher education in Sogndal, it was clear since the beginning of the 1960s that the population in the county was too small to establish a teacher school, and recruiting students from other counties was of 
high importance. A characteristic feature of teacher education in this county was the regional push to be active with different types of decentralized education throughout the county. In periods when on-campus recruitment was weak, this was crucial to maintain the number of students. This decentralized activity was growing through the decades. The collaboration with municipalities and counties was developed and followed quite advanced methodologies in the 2000s and 2010s. This increased the popularity of teacher education in the region, and the educational model received some of the credit for the strong results of regional primary school pupils in national tests. The cooperation with municipalities and counties was highlighted as a model for other organizations. Nonetheless, in the same period as this collaboration was characterized by success, the same teacher education slowed down in terms of research, academic merit, and internationalization. When new national academic standards were introduced regarding offering a 5-year teacher education from 2017, the same teacher education was not able to keep pace with the academic developments and expectations in the sector. A new merger became the solution.

In this chapter, we described four critical junctures of significance for teacher education in the county. The first critical juncture provided the base to initiate teacher education in Sogndal. During the turbulences after the college reform in 1994 and critical juncture number 2, the teacher school was not significantly affected, but the problems started to materialize after critical juncture number 3 (quality reform) and number 4 (structural reform). The latter two displayed that the focus on regional relevance, which was so successful for the teacher education in Sogndal, also became a trap. The education was lagging in academic development and was at risk for closing down. The mergers with other teacher educations in the Western Norway University of Applied Sciences rescued the teacher education in Sogn og Fjordane, and Sogndal could finally provide a 5-year master's programme in teaching.

Our study illuminates a story from a Norwegian region that successfully built an education system that provided teachers for their county, and through the model they had developed, the pupils in this scattered, rural region delivered top results in national rankings. However, this embeddedness in regional need also became a trap regarding embeddedness in the national programme of education (which again reflects international and global influences). Teacher education in Norway has always been highly regulated, and by losing focus on the current trends in the sector otherwise, they drifted away from national requirements for education. Another aspect is that the trap also can be viewed as a lock-in mechanism. Such lock-ins not only depend on path dependencies but can also relate to geographical features and, in that way, can also be placedependent (Martin \& Sunley, 2006). Such dependencies make it difficult to explore new developmental paths. Central actors here have been politicians at a national and regional level, the HEIs and municipalities. Through the HI perspective, we have also highlighted the importance of temporality and how past events are providing patterns for path dependency and layering and that critical junctures pave the way for displacement and new directions. 


\section{References}

Benneworth, P., Pinheiro, R., \& Karlsen, J. (2017). Strategic agency and institutional change: Investigating the role of universities in regional innovation systems (RISs). Regional Studies, 51(2), 235-248. https://doi.org/10.1080/00343404.2016.1215599

Bjelle, T. E. (2019). Om tre små studiestadar $i$ Norge. Sogndal: Høgskulen på Vestlandet.

Bukve, O., Farsund, A. A., \& Amdam, J. (2006). Næringsliv og sysselsetting i vår tid. In K. Hjelle (Ed.), Natur og naring (Vestlandets historie, B 1). Bergen: Vigmostad \& Bjørke.

Capoccia, G. (2016a). Critical junctures. In K. O. Fioretos, T. G. Falleti, \& A. D. Sheingate (Eds.), The Oxford handbook of historical institutionalism (pp. 89-106). Oxford: Oxford University Press.

Capoccia, G. (2016b). When do institutions "bite"? Historical institutionalism and the politics of institutional change. Comparative Political Studies, 49(8), 1095-1127. https://doi. org/10.1177/0010414015626449

Esping-Andersen, G. (1990). The three worlds of welfare capitalism. Cambridge: Polity Press.

Garm, N., \& Karlsen, G. E. (2004). Teacher education reform in Europe: The case of Norway; trends and tensions in global perspective. Teaching and Teacher Education, 20, 731-744.

Glosvik, Ø. (2015). Lærande utdanningssystem? Tilfellet Sogn og Fjordane i lys av erfaringar frå andre fylke. In G. Langfeldt (Ed.), Skolens kvalitet skapes lokalt: Presentasjon av funn fra forskningsprosjektet "Larande regioner" (pp. 121-143). Bergen: Fagbokforlaget.

Goddard, J., Hazelkorn, E., \& Vallance, P. (Eds.). (2016). The civic university: The policy and leadership challenges. Cheltenham, UK and Northampton, MA, USA: Edward Elgar Publishing.

Gythfeldt, K., \& Heggen, K. (2012). Er hogskolene regionale kvalifiseringsinstitusjoner? Likheter og ulikheter mellom hogskolene på Vestlandet og $i$ hovedstadsregionen. Oslo: Høgskolen i Oslo og Akershus.

KD. (2014-2015). Strukturreformen. Konsentrasjon for kvalitet - Strukturreformen $i$ universitets- og hoyskolesektoren, Meld.St.18(2014-2015). www.regjeringen.no/no/dokumenter/ meld.-st.-18-2014-2015/id2402377/

KUF. (1993-1994). Lov om høgare utdanning i Norge. Ot.prp.nr. 85 (1993-1994). www. stortinget.no/no/Saker-og-publikasjoner/Saker/Sak/?p=3591

Kvil, T. (2004). The Norwegian Quality Reform - Will governance make a difference in higher education? In I. Fägerlind \& G. Stömquist (Eds.), New trends in higher education. Reforming higher education in the Nordic countries - studies of change in Denmark, Finland, Iceland, Norway and Sweden (pp. 189-216). Paris: International Institute for Educational Planning.

Kyvik, S. (2002). The merger of non-university colleges in Norway. Higher Education, 44(1), 53-72. https://doi.org/10.1023/A:1015561027230

Kyvik, S. (2004). Structural changes in higher education systems in Western Europe. Higher Education in Europe, 29(3), 393-409. https://doi.org/10.1080/0379772042000331679

Kyvik, S. (2005). The implementation of the Norwegian college reform. In A. Gornitzka, M. Kogan, \& A. Amaral (Eds.), Reform and change in higher education (pp. 69-82). Dordrecht: Springer.

Kyvik, S. (2008). The dynamics of change in higher education: Expansion and contraction in an organisational field. Dordrecht: Springer.

Langfeldt, G. (2015). Skolens kvalitet skapes lokalt: Presentasjon av funn fra forskningsprosjekt "Larandre regioner". Bergen: Fagbokforlaget.

Lester, R., \& Sotarauta, M. (Eds.). (2007). Innovation, universities, and the competitiveness of regions. Helsinki: Tekes. 
Mahoney, J. (2000). Path dependence in historical sociology. Theory and Society, 29(4), 507548. www.jstor.org/stable/3108585?seq=1\#metadata_info_tab_contents

Mahoney, J., \& Thelen, K. A. (Eds.). (2010). Explaining institutional change: Ambiguity, agency, and power. Cambridge: Cambridge University Press.

Martin, R., \& Sunley, P. (2006). Path dependence and regional economic evolution. Journal of Economic Geography, 6(4), 395-437. https://doi.org/10.1093/jeg/lbl012

ME. (2001). Quality reform. Do your duty - demand your rights. (St.meld. nr. 27(2000-2001)). Oslo: Ministry of Education.

ME. (2014). Concentration for quality - Structural reform in the university and college sector. (Meld. St. 18. (2014-2015)). Oslo: Ministry of Education.

Pedersen, N. (2017). Det ukjente dramaet om høgskulen i vest. NRK.

Pierson, P. (2000). Increasing returns, path dependence, and the study of politics. American Political Science Review, 94(2), 251-267. https://doi.org/10.2307/2586011

Pinheiro, R., Geschwind, L., \& Aarrevaara, T. (Eds.). (2016). Mergers in higher education: The experiences from Northern Europe. Dordrecht: Springer.

Regjeringen. (2008, January 22). NOU 2008: 3. Sett under ett - Ny struktur i høyere utdanning. www.regjeringen.no/no/dokumenter/NOU-2008-3/id497182/

Regjeringen. (2016, October 14). Fra 33 til 21 statlige universiteter og hoyskoler. www. regjeringen.no/no/aktuelt/fra-33-til-21-statlige-universiteter-og-hoyskoler/id2515995/

Skockpol, T., \& Pierson, P. (2002). Historical institutionalism in contemporary political science. In I. Katznelson \& H. Milner (Eds.), Political science: State of the discipline (pp. 693721). New York: WW Norton.

Statistisk sentralbyrå. (2019, February 22). Population, 1 January 2019. www.ssb.no/en/ befolkning/statistikker/folkemengde/aar-per-1-januar/2019-02-22

Steinmo, S. (2008). Historical institutionalism. In D. D. Porta \& M. Keating (Eds.), Approaches and methodologies in the social sciences. A pluralist perspective (pp. 118-138). Cambridge: Cambridge University Press.

Stensaker, B., Persson, M., \& Pinheiro, R. (2016). When mergers fail: A case study on the critical role of external stakeholders in merger initiatives. European Journal of Higher Education, 6(1), 56-70. https://doi.org/10.1080/21568235.2015.1099456

Streeck, W., \& Thelen, K. (2005). Beyond continuity: Institutional change in advanced political economies. New York, USA: Oxford University Press.

Strømnes, Å. (2006). Folkeskulelararar i fattig-Noreg: ein studie frå forste halvdel av det tjuande hundreåret. Trondheim: Tapir Akademisk Forlag.

Thelen, K. (1999). Historical institutionalism in comparative politics. Annual Review Political Science, 2, 369-404. www.annualreviews.org/doi/pdf/10.1146/annurev.polisci.2.1.369

Urtegaard, G. (2005). 1905 - Folketalsutvikling i Sogn og Fjordane dei siste 100 åra. Fylkeskarkivet i Sogn og Fjordane, Kulturhistorisk leksikon.

Vabø, A. (2011). Norway: Between Humboldtian values and strategic management. In W. Locke, W. Cummings, \& D. Fisher (Eds.), Changing government and management in higher education: The perspectives of the academy. Dordrecht: Springer Netherlands.

Yttri, G. (2008). Frå skuletun til campus: soga om Hogskulen $i$ Sogn og Fjordane. Leikanger: Skald.

Yttri, G. (2015). Læraren som bygdehøvding. In G. Langfeldt (Ed.), Skolens kvalitet skapes lokalt: presentasjon av funn fra forskningsprosjektet "Larende regioner" (pp. 66-96). Bergen: Fagbokforlaget.

Yttri, G. (2016). Gjennombrot og kjenneteikn: liner i soga om hogare utdanning i Sogn og Fjordane. Oslo: Universitetet i Oslo. 


\title{
4 University Dynamic Capabilities to Boost Innovation Ecosystems
}

\author{
The Case of a University Alliance in Brazil
}

Kadígia Faccin, Elisa Thomas, and Caroline Kretschmer

\begin{abstract}
This chapter unpacks how universities' dynamic capabilities are mobilized to take on the role of fostering and orchestrating regional innovation ecosystems. Increasingly, universities are applying strategic and entrepreneurial management practices to be able to expand themselves into governance structures to deal with dynamic and changing environments. Different phases of an innovation ecosystem (initial stage, development, and renewal) require different key dynamic capabilities. We found that there is a fourth phase, the boost stage, in which an existing but declining innovation ecosystem requires an agent to be the propellant and revitalizer for its development cycle to be resumed and expanded. We address this issue with a unique Brazilian case study, an Alliance founded by three universities to develop the region into an environment conducive to innovation and entrepreneurship. This case study shows the role of universities as an orchestrator agent when there is a need to boost an ecosystem that is experiencing difficulties, by organizing, motivating, and supporting a network of stakeholders to drive the regional ecosystem. The research found that universities in declining ecosystems need to combine three dynamic capabilities at the same intensities in several actions to lead the local initiative.
\end{abstract}

\section{Introduction}

A common feature in Latin America is the lack of society's trust in their governments due to the history of corruption cases, public policies discontinuities, and lack of preparation for public management, which have occurred over the past decades (Altenburg, 2009; World Bank, 2020). This is further accentuated by the need to deal with the accelerated pace of technological advance and the reduction of globalization barriers. In this scenario, universities take roles that can go far beyond the classic (research and teaching) becoming fundamental actors in the economic development of regions. The concept of an "engaged 
university" (Trippl et al., 2015; Uyarra, 2010) considers the university's participation in a broader vision of regional development, with social and political contribution expressed by the formal integration of regional needs into university priorities, coordination of regional networks, and policy advice.

Among several regional outreach activities, universities can lead innovation ecosystems towards becoming an environment conducive to the development and transfer of disruptive knowledge and technologies (León, 2013; Thomas et al., 2020). However, universities are still "finding their feet" in these highly dynamic activities. Heaton, Siegel et al. (2019) suggest that universities, in order to contribute to the development of local innovation ecosystems, should evolve different dynamic capabilities compared to the capabilities enabling the missions of teaching and researching or even of collaborating with the industry to generate applied technologies. Dynamic capabilities are "the firm's ability to integrate, build, and reconfigure internal and external competences to address rapidly changing environments" (Teece et al., 1997, p. 516). These capabilities enable organizations to identify asset configurations and valuable skills to orchestrate them in an agile and innovative way (Schoemaker et al., 2018). Although the study by Heaton et al. (2019) presents an important advance in this theme, the results are driven from developed countries and emphasize the functions of the university in each stage of ecosystem development without discussing universities' capabilities when the ecosystem needs to be recovered or boosted, as in places where the ecosystem already exists, but it needs to be recreated because it is in a complete decline. This is the lacuna our chapter contributes to, looking into universities' dynamic capabilities that allow them to build governance structures to foster the recovery of regional innovation ecosystems, by asking, "How do universities mobilize dynamic capabilities and what are dynamic capabilities needed to allow universities to orchestrate the recovery of regional innovation ecosystems?"

In this context, we chose a unique case study that exemplifies how universities have been using capabilities to take on the role of fostering and orchestrating regional innovation ecosystems. The case studied is in the south of Brazil, where an alliance formed by three universities was founded to recreate an innovation ecosystem that is in decline. The city of Porto Alegre, capital of the state of Rio Grande do Sul, has always been one of the most thriving and developed regions in Brazil. Even today it is one of the urban centres with the highest numbers of human resources' training and is home to the most recognized and awarded structures and environments for the promotion of innovation in Brazil (Zen et al., 2018). However, despite these characteristics, in recent years it has been difficult to retain talents trained in the ecosystem, entrepreneurs have rare interactions, the number of start-ups does not advance as in other regions, and the local stories told by people about public safety and the ability to innovate are very negative (Zen et al., 2018). It is in this scenario that we unpacked the critical role played by dynamic capabilities of the alliance of universities, based on the practices employed to boost the regional innovation ecosystem. 


\section{Dynamic Capabilities Applied to Universities and Innovation Ecosystems}

The management process of companies can inspire the management of universities due to the complexity and multiple roles that universities are currently playing. Changes taken place internally to respond to externalities show the importance of strategic management for these organizations (Benneworth et al., 2016). That is why the management of universities is increasingly closer to the management of other types of organizations; however, universities have a different operating logic, being mainly public and non-profit. Therefore, management concepts need to be adjusted to universities' logic.

Currently, universities play an increasingly important role in regional economic development and in supporting innovation (O'Reilly et al., 2019). Universities are key players in the production and dissemination of knowledge, considering the new challenges of the knowledge-based economy (Bejinaru, 2017). They operate within an innovation system in which knowledge transfer activities are positioned within a triple helix of relations between universities, government, and industry (Yuan et al., 2018). Thus, many academic leaders came to understand modern universities as the nucleus of an innovation ecosystem, including public and private actors (Heaton, Lewin, et al., 2019).

Universities, as part of a continually changing innovation system, need to remain flexible to deal with changes and fluid boundaries between public and private domains (Yuan et al., 2018). They undergo intense transformation processes and are questioned about their ability to face the challenges of technological development, rapid business, and social change (Bejinaru, 2017). Universities can become a central actor for the growth of their ecosystems by applying their intellectual, financial, and reputation capital in a strategic way to establish and maintain a robust environment (Heaton, Siegel, et al., 2019). However, the context in which universities are inserted and the characteristics of the university in terms of resources, recognition, and research skills vary and must be considered when analysing universities' engagement with the regional ecosystem (Benneworth et al., 2016).

Innovation ecosystems are considered environments with dynamic and changing characteristics over time. Ecosystems evolve and are successful when they can adapt to the conditions of regulatory and business environments (Heaton, Siegel, et al., 2019). An innovation ecosystem is the "evolving set of actors, activities, and artifacts, and the institutions and relations, including complementary and substitute relations, that are important for the innovative performance of an actor or a population of actors" (Granstrand \& Holgersson, 2020, p. 3). The foundation of ecosystem thinking can be characterized as expanding an actor's capabilities beyond its own limits and transferring knowledge for the purpose of innovating in collaboration with others (Adner, 2006). The main classes of actors evidenced in ecosystem studies are close to the definitions of triple helix from the studies of Etzkowitz and Leydesdorff (2000): university, industry, government. Recently, researchers pointed out to the civil society as a new class of actors involved (Carayannis \& Campbell, 2009). 


\section{Kadígia Faccin et al.}

When considering different economic contexts, the role of actors in the ecosystem may differ. Thomas et al. (2020) argue that universities in emerging economies, due to many social challenges, must go beyond their missions of teaching, research, and collaboration with industry for innovation. Their study demonstrates that the role of universities as place leaders could be linked to ecosystem orchestration. The concept of ecosystem orchestration applied to universities comes from the perspective of dynamic capabilities (asset orchestration) and is also related to the concept of network orchestration.

The asset orchestration refers to managerial research, selection, configuration, and coordination of resources and capabilities, especially in dynamic scenarios (Helfat et al., 2009). In the context of innovation ecosystems, asset orchestration includes the notion of building consensus between the parties and persuasion so that actions and investments are channelled towards a growth set (Heaton, Siegel, et al., 2019). Such actions occur, for example, through meetings with interested parties, conferences to create initial impulses, and joint efforts to obtain necessary legislation. This approach combines with the network theory literature, which conceptualizes network orchestration as several actions carried out by a central organization in an intentional and determined way to achieve a common objective to create and extract value from the network (Dhanaraj \& Parkhe, 2006; Paquin \& Howard-Grenville, 2013; Faccin et al., 2020).

The theoretical lens from dynamic capabilities allows an appropriate understanding of universities' administration by offering a structure developed for strategic management (Teece, 2018) assisting in the analysis of universities' activities in their complex scenario (Heaton, Siegel, et al., 2019). In ecosystems' orchestration carried out by universities, the framework contemplated by dynamic capabilities helps in framing problems and prioritizing the diverse competing demands for resources within universities (Heaton, Siegel, et al., 2019).

Universities that develop dynamic capabilities are placed in an appropriate position to exercise strategic leadership in the innovation ecosystem, allowing innovations generated by the interactions between academia, industry, and government to move from laboratories to the world (Heaton, Siegel, et al., 2019). In this respect, the most relevant dynamic capabilities are contemplated in three clusters that co-occur throughout the organization and constitute continuous processes that support institutional renewal: sensing and shaping opportunities, seizing opportunities, and reconfiguring internal assets in order to maintain competitiveness (Teece, 2018).

In the sensing dimension, universities' abilities to discover opportunities are located (Yuan et al., 2018). Universities have a complex and fragmented structure, with diverse elements and interactive units and regulated by structural and social control (Hölttä \& Nuotio, 1995), with which they can develop these skills. These capabilities are present in the initial period of the innovation ecosystem, characterized by few connections, a limited identity (the ecosystem does not yet have a well-developed identity and legitimized by the actors 
and stakeholders) and marked by the beginning of cooperation between the actors (Heaton, Lewin, et al., 2019). At this stage, universities can contribute to producing and attracting the human capital required for innovation, generating new knowledge within the ecosystem, and creating the preconditions to guarantee the presence of research and dissemination in regional technological fields (Heaton, Lewin, et al., 2019). University formal and informal leaders play an essential role in sensing activities, by detecting opportunities, threats, and soliciting new ideas on and off campus to produce a continuous learning process (Heaton, Lewin, et al., 2019). Leaders can engage partners and teachers to identify promising medium and long-term technologies, allowing the university to take a direct role in orchestrating assets to attract partners to the ecosystem (Heaton, Siegel, et al., 2019).

After identifying opportunities and advancing the innovation ecosystem to the development stage, in which a number of connections, start-ups, and jobs increases, universities start to assist in the activities of the seizing dimension (Heaton, Siegel, et al., 2019). Seizing capabilities seek to convert opportunities into actions and involve harnessing the resources of internal and external stakeholders to meet different objectives (Heaton, Lewin, et al., 2019). Adequate seizing requires a systemic view of the university's complexity and its environment, as well as top-down decision-making to ensure the timely selection of alternatives (Teece, 2018). Universities are inserted in a complex and dynamic political environment that exerts pressure and affects university dynamics, requiring resilience to adapt and diversify its mission (Pinheiro \& Young, 2017). In this sense, the university can orchestrate the flow of information across the innovation ecosystem, establish connections between the actors, and develop outreach activities (Heaton, Siegel, et al., 2019).

Thus, universities can promote entrepreneurship with training programmes, accelerators, and incubators; assist in accessing tangible and intangible resources; and foster the fluidity of knowledge in several directions within the innovation ecosystem (Heaton, Siegel, et al., 2019). The way universities foster entrepreneurship varies according to the context and to the different roles played in the development of regional innovation ecosystems (Gunasekara, 2006). These roles are shaped according to several factors linked to the university's own history and characteristics such as those related to regional specificities (political economic and industrial conditions).

Finally, the reconfiguring dimension includes the ability to recombine and reconfigure organizational resources as markets, technologies, and the size of firms change, that is, its evolutionary fitness (Teece, 2007). In the context of innovation ecosystems, evolution and transformation are necessary. An ecosystem can have high performance over time if it manages to evolve with markets and technologies, renewing its resources and capabilities to face new innovation waves (Heaton, Siegel, et al., 2019). Thus, universities can help transform the ecosystem, leading the process of organizational and institutional change (Heaton, Siegel, et al., 2019). On the other hand, the dynamism of innovation ecosystems can put pressure on universities to change and adapt. So the 
development of dynamic capabilities can also help universities to adapt more quickly to address the mutation of innovation ecosystems.

These movements require new leadership in relationships with different stakeholder groups (Leih \& Teece, 2016). Place leadership plays an essential role so that different regions can reinvent themselves and branch out on a new path with balanced and sustainable regional development (Sotarauta et al., 2012). Considering the conjuncture of innovation ecosystems and the place leadership role that universities can play in this context, the strategic tools applied to organizations are relevant. Thus, we analyse the dynamic capabilities of universities in the dimensions of sensing, seizing, and reconfiguring and their respective practices to recover an ecosystem that needs to be recreated.

\section{Method}

To discuss how universities use dynamic capabilities to take on the role of fostering and orchestrating the recovery of regional innovation ecosystems, we chose a unique case study (Stake, 1995). Three universities in the city of Porto Alegre, in the south of Brazil, are taking a new role in their region: they are organizing, motivating, and supporting a network of stakeholders to drive the regional ecosystem. The project called "Alliance for Innovation" had its official launch in 2019, following discussions initiated in 2017. The project's core aim is to recreate and boost the region into an environment conducive to innovation and entrepreneurship.

The three universities are research-oriented and have a large experience in projects with the industry and government. All of them host technology parks and start-up incubators. Universidade Federal do Rio Grande do Sul (UFRGS) is a public university founded in 1934. Pontifical Catholic University of Rio Grande do Sul (PUCRS) is a private non-for-profit university founded by Marist Brothers (religious congregation) in 1948. And Universidade do Vale do Rio dos Sinos (UNISINOS) is a private non-for-profit university founded by the Jesuit Network (religious congregation) in 1969.

The data collection included interviews, participant observation, and secondary data such as websites, newspaper, and magazine reports during 2019 and 2020. We interviewed 41 people in two distinct stages. The interviewees are divided into four stakeholder groups, made up of (a) university staff (pro-rectors, managers, students, and professors - 11 respondents); (b) local government (7 respondents); (c) local entrepreneurs (12 respondents); and (d) representatives of civil society (industry associations, NGOs, and so on, - 11 respondents). There are over 20 hours of recorded interviews and a total of over 100 pages of transcripts. In addition, one of the authors spent approximately 100 hours involved in the planning steps of the Alliance's actions (an average of 4 hours per week for the first 6 months of the project), gathering important details to ensure the triangulation of the research. In addition, the researchers built an inventory of more than 100 web links with reports and interviews about the case. 
Data were analysed using the content analysis technique (Hsieh \& Shannon, 2005) and was developed around a framework of dynamic capabilities using the following categories, according to Teece (2007, 2018): sensing and shaping opportunities, seizing opportunities, and reconfiguring.

\section{Findings and Analysis: The Case of Alliance for Innovation from the Perspective of Dynamic Capabilities}

Porto Alegre is the capital of Rio Grande do Sul, the southernmost state in Brazil. Porto Alegre is among the top three cities in the country with the greatest impact on the formation of qualified human resources, being home to the best science parks in Brazil, in addition to a set of start-up incubators (Zen et al., 2018). Yet, despite its apparent economic condition, Porto Alegre has been suffering a series of recurring problems linked to public safety, quality of life, talent retention, and creation of start-ups (Zen et al., 2018). These characteristics present a very particular situation related to the process of development of innovation ecosystems: in Porto Alegre, the efforts committed by universities are largely linked to the process of recreating the ecosystem, reflected in the development of start-ups, retention of talents, increased interactions between the members of the ecosystem, boosting established sectors through collaboration with start-ups, creation of a new local identity and the stimulation of an environment that encourages talents to think in creative ways.

\section{Sensing DC to Boost the Innovation Ecosystem}

In January 2017, the mandate of a new city government in Porto Alegre started with the plan for the future of the region. Discussions were expanded among other regional actors such as firms, industry associations, start-up incubators, universities, and civil society organizations. All actors agreed that Porto Alegre and its metropolitan area needed not only to solve long-lasting social issues, such as unemployment, inequality, and crime, but also to develop an ecosystem towards innovation and entrepreneurship based on the already recognized characteristics from the past.

Firstly, the three universities actively contributed to identify opportunities and initiate the cooperation among the few actors present in mid-2017. The previous involvement of universities in innovation projects allowed the identification of needs and opportunities to be addressed within the scope of an innovation ecosystem. It became the force for the establishment of the "Alliance for Innovation". This initial scenario already shows us the presence of dynamic capabilities in universities, as according to Schoemaker et al. (2018), these capabilities assist in the identification and orchestration of skills and configuration of assets to act in an agile and innovative way.

At the beginning of 2018, large local entrepreneurs and industry associations came together and stated that they would financially support a project for the development of the region. However, they did not wish the project 
to be coordinated by the government (for several reasons that go beyond the scope of this chapter, mainly the reputation and long-term compromise). Proactively taking that role, the universities signed the agreement titled "Alliance for Innovation" on April 9, 2018. Then, with the mayor of the city, the Alliance signed its first large project, titled "Pacto Alegre", nominating 16 people, from 3 universities and government, to run and support the activities. A Spanish consultant with large experience in developing innovation ecosystems in Brazil and in other countries was hired, and the universities started to engage local stakeholders into the movement.

Between July and November 2018, the universities' pro-rectors held more than 80 meetings with local entrepreneurs to present the Alliance's aim and the project Pacto Alegre. Also, a major media company joined the project and started publishing a weekly chronicle in the newspaper highlighting the importance of a functioning ecosystem where several stakeholder groups are actively engaged. The purpose was to raise awareness in the region and actively engage with key actors from industry and from civil society.

Three banks joined the project and provided funds to pay the consultant. Around the same time, Alliance representatives joined visiting missions to the United States and Colombia, to learn about ecosystem development and to identify opportunities for the city of Porto Alegre. According to the some of the Alliance representatives they "asked each institution to dedicate time to work for the Pacto and to put good people in it" (I5).

The initial public movement was represented by a seminar with the involvement of the government, companies, and universities and the maturation of the ideas that emerged in this meeting. Based on that, at the beginning of the following year, it became possible to establish the union of these different parts to structure the Pacto Alegre with the management of the universities. This shows how universities become central players in fostering a robust innovation ecosystem and asset orchestration, by building consensus for an action strategy to boost initial activities (Heaton, Siegel, et al., 2019), as pointed out by the interviewers: "[W]e received extraordinary support from the universities, it was fundamental to face challenges" (I1). This movement shows the ability of universities to sense the opportunities, identifying possibilities for action in line with the needs and developments that occurred in their socio-economic environment (Teece, 2007).

The next step was to formalize a Board of Directors with the main stakeholders from the movement. Representatives from the universities visited each of the organizations, from November 2018 to March 2019, to discuss roles and responsibilities. The Board of Directors is composed of 75 organizations: 6 universities, 5 other educational organizations, 1 start-up incubator, 5 start-ups, 15 large companies, 33 business associations, 1 non-governmental organization, and public administration agencies. Based on an ecosystem mapping made by the Alliance members, regional needs were catalogued into six "grand challenges": city identity, public administration modernization, talents and knowledge, business environment, urban transformation, and quality of life. 
In this initial stage of ecosystem boost, we also perceive other processes of dynamic capabilities in the dimension of the sensing of universities regarding the ability of their leaders to engage and attract partners and teachers to identify technologies and solutions (Heaton, Siegel, et al., 2019). The three universities, after establishing the Alliance for Innovation agreement, signed the broader Pacto Alegre project, engaging consultants, financial organizations to provide funds for the project, several entrepreneurs, and a large media company. During the interviews, some people highlighted that "some people are very important in the governance board, like the rectors, because they have very broad relationships with many actors and they trust them. So, we were able to access these people very quickly" (I13). Thus, universities began the regional coalition building (Normann, 2013) in the innovation ecosystem and allowed interaction between academia, industry, and government as referred by Heaton, Siegel, et al. (2019) as the sense dimension.

\section{Seizing DC to Boost the Innovation Ecosystem}

In order to plan how to solve the six grand challenges and improve the innovation ecosystem, the executive group of the Board of Directors invited people from civil society, universities, government, and companies for workshops that took place at one of the universities in 2018. From the workshops, the participants created 29 projects. Each project has a different coordinator organization and time span, and the groups are self-organized. According to one of our interviewees, "from the workshops, a series of projects emerged, which were filtered, and the Table meetings were reached" (I10). From these initial movements, we realized that universities developed processes to take advantage of the opportunities and challenges identified in the region. With the formalization of the Board of Directors, universities visited the different organizations that became part of the project to discuss and establish roles and responsibilities. This movement shows that the university, as a strategic actor in the ecosystem, orchestrates the flow of information, activities, and connections between the actors, linked to what Heaton, Siegel, et al. (2019) term "capabilities of seizing opportunities". Thus, with these universityoriented movements, it was possible to bring together 75 organizations, define the 6 most prominent challenges, and create a total of 23 separate projects "bringing together 75 entities to debate innovation projects, with a focus on innovative entrepreneurship, is the first major achievement of this university project" (I8). All the 75 organizations involved have the same power of decisions and actions and represent universities, industries, different levels of government (state, city), and civil society. It shows the universities' ability to build trust and commitment together with external actors, which is in line with the capability to seize opportunities (Teece, 2007).

Members of the executive group from the Pacto Alegre project act as project managers, helping project coordinators to achieve partial milestones and to present them to the community. 
Table 4.1 Universities' practices and the clusters of dynamic capabilities

\begin{tabular}{ll}
\hline Practice employed by universities & Associated dynamic capability \\
\hline $\begin{array}{l}\text { Speeches for mobilizing regional stakeholders and } \\
\text { consultant speeches }\end{array}$ & SENSE \\
$\begin{array}{l}\text { Creation of a Board of Directors } \\
\text { Ecosystem mapping workshops }\end{array}$ & \\
$\begin{array}{l}\text { Missions to other regions and abroad } \\
\text { Documenting official actors' commitment to participate }\end{array}$ & SEIZE \\
$\begin{array}{l}\text { Mobilization meetings by pro-rectors } \\
\text { Document officializing actors' commitment to participate }\end{array}$ & \\
$\begin{array}{l}\text { Projects' co-creation workshops } \\
\text { Voting to approve projects and partners involved in each } \\
\text { project }\end{array}$ & \\
Universities named people to facilitate activities with the & RECONFIGURING \\
network of stakeholders & \\
$\begin{array}{l}\text { Each of the } 29 \text { projects has one coordinator } \\
\text { Universities transferred responsibilities to the community } \\
\text { to boost the ecosystem }\end{array}$ \\
\hline
\end{tabular}

\section{Reconfiguring DC to Boost the Innovation Ecosystem}

Based on the projects created by the community, the Alliance was able to organize a set of initial actions to promote the restart of the ecosystem. The reconfiguring dimension includes the ability to recombine and reconfigure organizational resources as markets, technologies, and the firms change over time. The universities can help transform the ecosystem, leading the process of organizations' change that is active in the ecosystem. In order for the transformation to be possible, the university appointed a leader for each of the cocreated projects. One of the project leaders highlighted that "the strategy was to always appoint a member to monitor and facilitate these projects . . . volunteers from the universities and the city hall" (I4). This leader is responsible for managing the project, maintaining the objectives, and achieving the planned activities. The responsibility for the results is shared with the entire local community. It is at this stage that the transformation of the territory begins. The Pacto projects "are developing over the years . . . in my perception, some are still immature and some projects are long-term . . . they are not expected to happen in the short term" (I8).

The identification of universities' practices in the Alliance of Innovation and their relationship with each of the three clusters of dynamic capabilities (the processes of sensing, seizing, and transforming) are summarized at Table 4.1.

\section{Discussion and Conclusions}

Universities can lead the transformation of the innovation ecosystem; however, this change does not always occur through technological renewal, as suggested by Heaton, Siegel, et al. (2019). The evidence from the Alliance for Innovation case presents a different logic, in which the ecosystem has been renewed 
through universities' orchestration of a stakeholders' network. The local ecosystem has characteristics such as few start-ups, rare interactions between the members of the ecosystem, stagnation of established sectors, and negative environments. Thus, in order to carry out these processes, universities were configured as orchestrator agents in the innovation ecosystem and needed the combination of the three key clusters of dynamic capabilities (sensing, seizing, and transforming). With that, universities acted to lead local initiatives to revitalize its neighbourhoods; to enhance communication and cooperation among ecosystem participants; and to organize, motivate, and support a network of stakeholders to drive the ecosystem boost. Universities use the reconfiguration capability to make these key decisions and transform the city's innovation ecosystem.

In this sense, we have discovered a new stage of development for innovation ecosystems, expanding the phases proposed by Heaton, Siegel, et al. (2019). The boost stage is a phase in which an existing innovation ecosystem requires an agent to be the propellant and revitalizer for its development cycle to be resumed and expanded. Thus, as shown in Table 4.2, on the boost stage, the three key dynamic capabilities need to be combined to enable universities to foster and orchestrate the innovation ecosystem.

As demonstrated in the study by Heaton, Siegel, et al. (2019), different stages of development and evolution of an innovation ecosystem require different key dynamic capabilities. In this study, we propose to expand these steps, including an additional stage for the innovation ecosystem, as shown in Figure 4.1. When an existing innovation ecosystem needs to be leveraged to reconnect the different parts, to revitalize the region (after the decline), and to allow the creation of new companies, the three key dynamic capabilities need to be present. With this, the orchestrating agent will be able to manage the different actors and needs, reconfiguring the ecosystem and allowing the resumption of its development and growth.

The case of the Alliance for Innovation provides an interesting example of how universities can become central players in the regional change, discussing the dynamic capabilities that enable them to orchestrate relationships to boost an innovation ecosystem. Figure 4.1 shows the representation of the contribution of this chapter. It is possible to find the three stages of ecosystem development pointed out by Heaton, Siegel, et al. (2019), with the appropriate capabilities that are mobilized in each stage. Heaton, Siegel, et al. (2019) demonstrate that in the early stages of the ecosystem, the university acts as an attractor of companies, talents, and resources and in the formation of the necessary structure to foster innovation, where sensing is the essential dynamic capability; while in the stages of ecosystem development, the university functions as a consolidator, where seizing is essential. Besides, the authors emphasize that the capacity "transforming" is essential to promote changes in the activities developed in an ecosystem, when there is stagnation, and it is necessary to explore new areas - what they call the "renewal stage". 


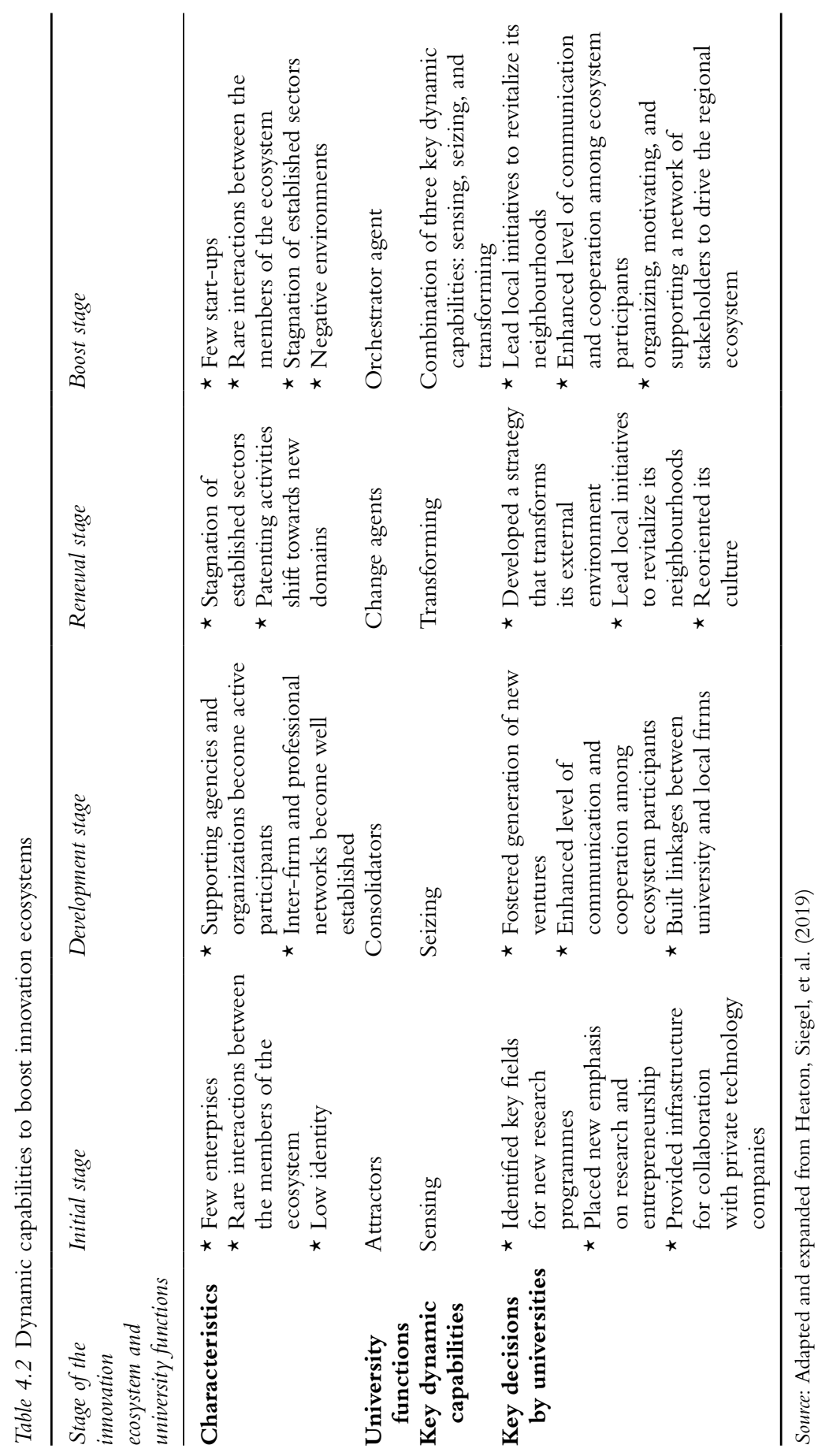




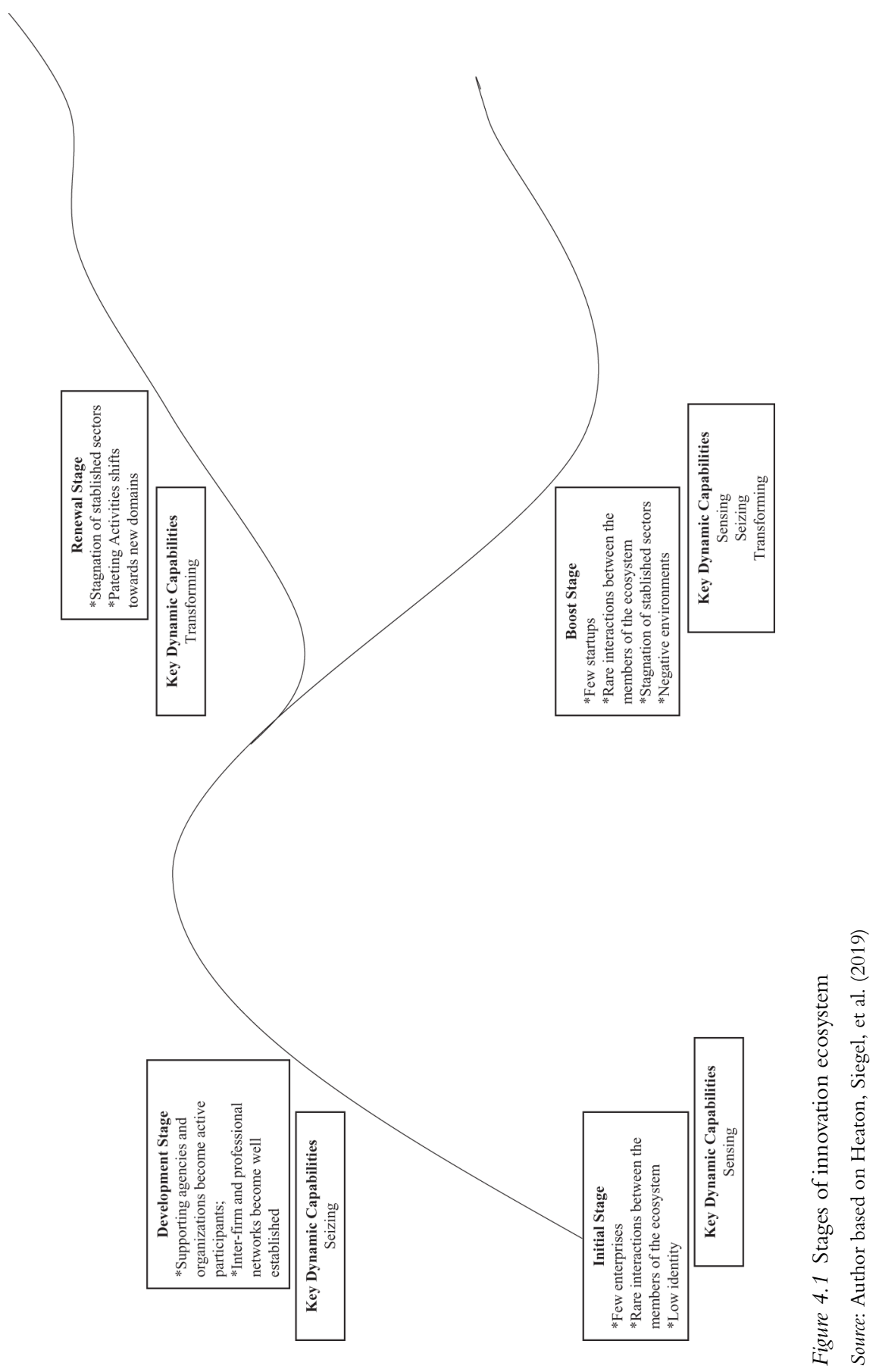




\section{Kadígia Faccin et al.}

What we are proposing is a new stage (which you can see in Figure 4.1), which is not linked to the renewal provided by the stagnation of traditional sectors where the role of the university is focused on supporting the exploration of new domains. The Brazilian case allowed us to identify a new stage of ecosystem development, very common in countries of the Global South. This new stage is linked to a situation of economic decline (not stagnation), where it is necessary to recover the links of the regional social capital for a new proposal to emerge together with the actors. For this reason, we demonstrated in our research that to "boost" the ecosystem requires an effort and the mobilization of the three dynamic capabilities. And when ecosystems are in declining stages, universities can act as agents of transformation and lead the ecosystem transformation.

We can summarize the main findings of this study in three points: (a) when studying a Latin American context, we found that there is a stage of ecosystems "development" that was not contemplated by the studies by Heaton, Siegel, et al. (2019) - the boost stage when ecosystems are in a complete decline; (b) in contexts where boosting the ecosystem is necessary, the university assumes an important role - that of orchestrator; (c) as an orchestrator (which implies collaboration and not isolation), the university needs to mobilize its sensing, seizing, and transforming capabilities at different times, given the complexity in which the scenario presents itself. This is different from the finding by Heaton, Siegel, et al. (2019) for the earlier stages where one or another dynamic capacity was more mobilized.

Although the objective of the chapter was to analyse the university, this does not mean that it is possible for an isolated actor to be able to transform the ecosystem. However, the adopted framework allows us to see the potential that this actor has to transform the realities in the territories in which it operates. This consideration is essentially important for scenarios in emerging countries, where confidence in governments and institutions is somewhat eroded by the constant episodes of corruption, for example. That is, it was only possible for the Alliance of Universities to orchestrate the recovery of the ecosystem (boost the ecosystem) because it is part and is embedded in the ecosystem (as a necessary but not sufficient condition) where university's efforts are only leveraged by the presence of other exogenous factors and actors.

The case analysis of the Alliance for Innovation showed us the importance of universities taking on a prominent role in boosting the innovation ecosystem and developing dynamic capabilities to orchestrate this ecosystem. It is aligned with Heaton, Siegel, et al. (2019) argument that when there are elements to form an ecosystem, but they cannot come together, a strong participant can take the lead and orchestrate that ecosystem's resources. In this regard, we found that the study by Heaton, Siegel, et al. (2019) presents the idea that the asset orchestration in the context of the innovation ecosystem already encompasses the notion of network orchestration. That is, universities, in addition to managing resources and assets, also have the role of persuading and creating a consensus among different actors, so that actions and investments are in favour of a common and joint objective. Thus, we suggest that future studies can integrate 
the literature of dynamic capabilities and asset orchestration with the concepts and elements of network orchestration more deeply. This will generate greater details in the analysis of innovation ecosystems' movements and evolution, as well as present strategies for the development of these ecosystems based on a broader range of elements that must be considered.

The case of the Alliance for Innovation is a recent initiative that is still structuring many activities. Thus, in the reconfiguring dimension, we are still unable to visualize results from the actions that provide the recombination and reconfiguration of resources. Reconfiguration competence would help avoid unfavourable trajectories as routines are developed, which guarantee the effectiveness in the orchestration of the ecosystem. Over the years of this innovation ecosystem's development, we will be able to analyse its evolution and transformation according to internal and external changes.

It is important to highlight that when deciding to use some practices to boost the ecosystem of the city of Porto Alegre, the university alliance suffered tensions and many challenges were presented. These challenges and tensions certainly also influenced decisions about the adoption of each practice. For example, the mobilization meetings held personally by the prorectors demonstrate that "power" and "hierarchical levels" matter in this society. However, given that the objective was to understand how they were mobilized and what are the dynamic capacities that "matter" in this activity, questions were not inserted to allow exploring why certain actions were adopted or even what challenges were faced. In this sense, a new opportunity for research emerges.

\section{References}

Adner, R. (2006). Match your innovation strategy to your innovation ecosystem. Harvard Business Review, 84(4), 98-107.

Altenburg, T. (2009). Building inclusive innovation systems in developing countries: Challenges for IS research. In B. Lundvall, K. Joseph, C. Chaminade, \& J. Vang (Eds.), Handbook of innovation systems and developing countries: Building domestic capabilities in a global setting (pp. 33-56). Cheltenham: Edward Elgar.

Bejinaru, R. (2017). Dynamic capabilities of universities in the knowledge economy. Management Dynamics in the Knowledge Economy, 5(4), 577-595.

Benneworth, P., Pinheiro, R., \& Sánchez-Barrioluengo, M. (2016). One size does not fit all! New perspectives on the university in the social knowledge economy. Science and Public Policy, 43(6), 731-735. https://doi.org/10.1093/scipol/scw018

Carayannis, E. G., \& Campbell, D. F. J. (2009). "Mode 3" and "quadruple helix": Toward a 21 st century fractal innovation ecosystem. International Journal of Technology Management, 46(3-4), 201-234. https://doi.org/10.1504/IJTM.2009.023374

Dhanaraj, C., \& Parkhe, A. (2006). Orchestrating innovation networks. Academy of Management Review, 31(3), 659-669. https://doi.org/10.5465/amr.2006.21318923

Etzkowitz, H., \& Leydesdorff, L. (2000). The dynamics of innovation: From national systems and "mode 2" to a triple helix of university - industry - government relations. Research Policy, 29(2), 109-123. https://doi.org/10.1016/S0048-7333(99)00055-4 


\section{Kadígia Faccin et al.}

Faccin, K., Wegner, D., \& Balestrin, A. (2020). How to orchestrate R\&D networks? The role of orchestration subprocess and collaborative practices over time. Creativity and Innovation Management, 29(1), 161-177. https://doi.org/10.1111/caim.12355

Granstrand, O., \& Holgersson, M. (2020). Innovation ecosystems: A conceptual review and a new definition. Technovation, 90-91, 1-12. https://doi.org/10.1016/j.technovation. 2019.102098

Gunasekara, C. (2006). The generative and developmental roles of universities in regional innovation systems. Science and Public Policy, 33(2), 137-150. https://doi.org/10.3152/ 147154306781779118

Heaton, S., Lewin, D., \& Teece, D. J. (2019). Managing campus entrepreneurship: Dynamic capabilities and university leadership. Managerial and Decision Economics, 41(6), 1126-1140. https://doi.org/10.1002/mde.3015

Heaton, S., Siegel, D. S., \& Teece, D. J. (2019). Universities and innovation ecosystems: A dynamic capabilities perspective. Industrial and Corporate Change, 28(4), 921-939. https://doi.org/10.1093/icc/dtz038

Helfat, C. E., Finkelstein, S., Mitchell, W., Peteraf, M., Singh, H., Teece, D., \& Winter, S. G. (2009). Dynamic capabilities: Understanding strategic change in organizations. Oxford: John Wiley \& Sons.

Hölttä, S., \& Nuotio, J. (1995). Academic leadership in a self-regulative environment. Tertiary Education and Management, 1(1), 12-20. https://doi.org/10.1007/BF02354090

Hsieh, H. F., \& Shannon, S. E. (2005). Three approaches to qualitative content analysis. Qualitative Health Research, 15(9), 1277-1288. https://doi.org/10.1177/1049732305276687

Leih, S., \& Teece, D. (2016). Campus leadership and the entrepreneurial university: A dynamic capabilities perspective. Academy of Management Perspectives, 30(2), 182-210. https://doi.org/10.5465/amp.2015.0022

León, G. (2013). Analysis of university-driven open innovation ecosystems: The UPM case study. www.upm.es/sfs/Montegancedo/documentos, 202013.

Normann, R. (2013). Regional leadership: A systemic view. Systemic Practice and Action Research, 26(1), 23-38. https://doi.org/10.1007/s11213-012-9268-2

O'Reilly, N. M., Robbins, P., \& Scanlan, J. (2019). Dynamic capabilities and the entrepreneurial university: A perspective on the knowledge transfer capabilities of universities. Journal of Small Business \& Entrepreneurship, 31(3), 243-263. https://doi.org/10.1080/ 08276331.2018.1490510

Paquin, R. L., \& Howard-Grenville, J. (2013). Blind dates and arranged marriages: Longitudinal processes of network orchestration. Organization Studies, 34(11), 1623-1653. https://doi.org/10.1177/0170840612470230

Pinheiro, R., \& Young, M. (2017). The university as an adaptive resilient organization: A complex systems perspective. In J. Huisman \& M. Tight (Eds.), Theory and method in higher education research (pp. 119-136). Emerald. https://doi.org/10.1108/S2056375220170000003007

Schoemaker, P. J., Heaton, S., \& Teece, D. (2018). Innovation, dynamic capabilities, and leadership. California Management Review, 61(1), 15-42. https://doi.org/10.1177/ 0008125618790246

Sotarauta, M., Horlings, I., \& Liddle, J. (Eds.). (2012). Leadership and change in sustainable regional development. Routledge. https://doi.org/10.4324/9780203107058

Stake, R. E. (1995). The art of case study research. Thousand Oaks: Sage.

Teece, D. J. (2007). Explicating dynamic capabilities: The nature and microfoundations of (sustainable) enterprise performance. Strategic Management Journal, 28(13), 1319-1350. https://doi.org/10.1002/smj.640 
Teece, D. J. (2018). Managing the university: Why "organized anarchy" is unacceptable in the age of massive open online courses. Strategic Organization, 16(1), 92-102. https://doi. org $/ 10.1177 / 1476127017732760$

Teece, D. J., Pisano, G., \& Shuen, A. (1997). Dynamic capabilities and strategic management. Strategic management journal, 18(7), 509-533. https://doi.org/10.1002/ (SICI)1097-0266(199708)18:7<509::AID-SMJ882>3.0.CO;2-Z

Thomas, E., Faccin, K., \& Asheim, B. T. (2020). Universities as orchestrators of the development of regional innovation ecosystems in emerging economies. Growth and Change, 1-20. https://doi.org/10.1111/grow.12442

Trippl, M., Sinozic, T., \& Lawton Smith, H. (2015). The role of universities in regional development: Conceptual models and policy institutions in the UK, Sweden and Austria. European Planning Studies, 23(9), 1722-1740. https://doi.org/10.1080/09654313.2015.1 052782

Uyarra, E. (2010). Conceptualizing the regional roles of universities, implications and contradictions. European Planning Studies, 18(8), 1227-1246. https://doi.org/ $10.1080 / 09654311003791275$

World Bank. (2020). Worldwide governance indicators data. Retrieved April 1, 2020, from http://info.worldbank.org/governance/wgi/.

Yuan, C., Li, Y., Vlas, C. O., \& Peng, M. W. (2018). Dynamic capabilities, subnational environment, and university technology transfer. Strategic Organization, 16(1), 35-60. https:// doi.org/10.1177/1476127016667969

Zen, A., Gazzaro, D., Faccin, K., \& Gonçalves, L. (2018). Mapeamento do Ecossistema de Porto Alegre. Porto Alegre: Aliança Pela Inovação. 


\title{
5 Exploring the Role of the University in the Creation of Knowledge Networks in the Aso Valley, a Rural Area in Marche Region (Italy)
}

\author{
Sabrina Tomasi, Concetta Ferrara, Gigliola Paviotti, \\ Chiara Aleffi, Alessio Cavicchi, and Giovanna Bertella
}

\begin{abstract}
Rural areas are often disadvantaged by their peripheral position, depopulation and the scarcity of primary services, but they also have specific characteristics, especially in terms of cultural capital, that can make them attractive as tourism destinations. Sustainable tourism paths can be developed through collaboration between various actors with complementary skills and areas of expertise, especially local cooperatives and associations. In this context, universities can have a crucial role in creating knowledge networks and enhancing "rural buzz" that is the flow of information and knowledge among the individuals, organizations, and businesses in a rural area through face-to-face interaction. This study focuses on an Italian case study from the Marche Region: the collaboration between the University of Macerata (UNIMC) and a local association, Agritur-Aso, has been chosen as an example of a network for the co-valorization of regional cultural capital.
\end{abstract}

\section{Introduction}

Rural areas are often disadvantaged by their peripheral position, depopulation, and the scarcity of primary services (Barca et al., 2014). This study argues that universities, through the creation of knowledge networks, could help their areas develop the economic and social resilience needed to counter these difficulties and to thrive.

Rural areas can be attractive tourism destinations because of their peaceful, natural beauty, made even more inviting when combined with opportunities to learn about their cultural and historical heritage, enjoy local traditional festivals, and savour their special foods and wines. This cultural capital should be exploited to develop sustainable tourism (Richards, 2002; Rinaldi, 2017) through collaboration between various actors with complementary skills and areas of expertise (Sharpley, 2002), especially local cooperatives and associations 
(Aref \& Gill, 2009; Johnson, 2010; Nair et al., 2013), which may organize activities and events featuring typical products and expressing the values and knowledge of their local historical heritage.

In this context, universities can have a crucial role in creating knowledge networks and enhancing "rural buzz" that is the flow of information and knowledge among the individuals, organizations, and businesses in a rural area through face-to-face interaction (Bathelt et al., 2004). Of particular value for both the site and the students are the university-organized opportunities for experiential learning (Kolb, 1984); student work with local actors contributes to the creation of knowledge networks for sharing and using different types of knowledge (Phelps et al., 2012) and to the enhancement of "rural buzz" (Thomas, 2016). These factors can foster innovation and rural development (Lane \& Oreszczyn, 2013).

An Italian case study from the Marche Region, the collaboration between the University of Macerata (UNIMC) and a local association, Agritur-Aso, has been chosen as an example of a network for the co-valorization of regional cultural capital. The study research question is this: How and to what extent can universities stimulate knowledge networks to valorize regional cultural capital in remote rural regions?

\section{Theory}

\section{Knowledge networks in rural areas}

In a knowledge network, the participants are the nodes, and their shared knowledge constitutes the links. While several types of knowledge networks are discussed in the literature (Jamal \& Getz, 1995; Cooper, 2006; Ngo et al., 2018), this study focuses on informal ones based on openness and reciprocity that draw together different types of knowledge in a rural region and lead to the creation and utilization of regional resources and competencies that support concrete collective and collaborative actions (Lane \& Oreszczyn, 2013; Kolehmainen et al., 2016). When existing social relations form the basis for such a network, the participants often share common values, attitudes, and interpretative schemes, and this encourages the flow of information, allowing all the members to learn and benefit as each member shares his or her knowledge (Fesenmaier \& Contractor, 2001). Temporary knowledge clusters are also formed through events that facilitate interactions among different actors (Bathelt \& Schuldt, 2008).

Regional development and innovation in remote areas can be fostered when local communities form knowledge networks. This flow of information, created face to face, in co-presence and co-location among actors and firms from the same industry, place, or region, can be defined "local buzz" (Bathelt et al., 2004). "Global pipelines" are links beyond the local level, which can have a role in knowledge creation and innovation, as they integrate information from 
other environments with potential to increase local interpretation and usage of knowledge (Bathelt et al., 2004).

An example of a rural knowledge network and "local buzz" is provided by a Welsh case study (Thomas, 2016), which observed five dimensions: (a) interaction between farmers; (b) interaction between different agricultural suppliers/ service providers; (c) interaction between the government and farmers; (d) interaction between knowledge transfer specialists and farmers; and (e) spread of knowledge throughout the community and beyond.

In the tourism sector, a similar model was applied by Bertella (2011a) to the concept of community of practice (CoP) as developed by Wenger (1998), indicating groups of people who participate together in a collective process of learning about tourism to produce a shared practice. In a CoP, members reflect on and engage to learn how to achieve an objective perceived as meaningful (Bertella, 2011a). The actors involved feel a sense of belonging to the place where they act and to the group with whom they work: a sense of reciprocal trust, of responsibility towards the community, and strong identity usually characterize a CoP (Bertella, 2011a) and distinguish it from a generic learning/ knowledge network. CoPs can be significant for promoting tourism in their area, as knowledge and identity give value to the natural and cultural resources on offer.

\section{The role of universities}

In the last decade, universities progressively involved in their local contexts. According to Goddard et al. (2016), civic universities are actively engaged with the local community through a holistic approach to impacting society beyond the academy. Characterized by a sense of purpose and a sense of place, they want to impact society by addressing societal challenges, or specific global or local problems, and view their local areas as a "living laboratory" (Goddard et al., 2016).

For civic universities, "teaching has a strong community involvement with the long-term objective of widening participation in higher education and producing well-rounded citizens as graduates" (Goddard \& Kempton, 2016, p. 13). In particular, through experiential learning (Kolb, 1984), their students connect the academic environment to local communities and, consequently, play an essential role in creating knowledge networks (Phelps et al., 2012).

Community-academic partnerships (CAPs) are collaborations between community members of rural areas and nearby universities to foster knowledge exchange (Drahota et al., 2016).

[They] are characterised by equitable control, a cause(s) that is primarily relevant to the community of interest, and specific aims to achieve a goal(s), and involve community members (representatives or agencies) that have knowledge of the cause, as well as academic researchers.

(Drahota et al., 2016, p. 192) 
The community context in which the collaboration process is formed and the relationships among the participants are significant for taking actions (Brookman-Frazee et al., 2012). Interpersonal factors that facilitate the collaboration are trust and respect, the presence of shared visions and goals, good communication (common language) and capacity to solve conflicts, and clear division of roles and functions.

\section{Benefits of knowledge networks in rural areas}

Previous research in rural areas has pointed out different types of knowledge that can be developed (Fonte, 2008; Csurgó et al., 2008; Bertella, 2011b). In terms of food, networks can foster scientific knowledge. This is a standardized form of knowledge from research, for example, in the case of food and gastronomy. Moreover, political and managerial knowledge can be enhanced: this is related to the organization of production of food that is considered a competitive tourism product. In addition to the others, local knowledge, namely "how things work", is a technical form of knowledge about how to produce and prepare local food.

CAPs can yield a variety of outcomes such as partnership synergy, knowledge exchange, tangible products (proximal outcomes), development of/ enhanced capacity to implement programmes or interventions, improved community care, creation of sustainable CAP infrastructure for collaboration, and changed community context (distal outcomes, which depend on the proximal) (Brookman-Frazee et al., 2012; Drahota et al., 2016). Students benefit from this collaboration process and active engagement in activities promoted in the local community by several local actors, as they learn new knowledge, identify employability opportunities, and are encouraged to be active citizens (Goddard \& Kempton, 2016, p. 13).

\section{Background context}

\section{The University of Macerata}

The Italian university system consists in three cycles, corresponding to the main academic degrees: bachelor (3 years), master (2 years), and $\mathrm{PhD}$ (3 years) (Bologna Process, 1999) and is aligned to the European Credit Transfer and Accumulation System (Eurybase, 2007).

UNIMC is located in the Marche Region (central Italy), populated by 1,518,400 inhabitants (Marche Region, 2019). In 1290 a School of Law run by a private master was founded under the protection of Macerata Municipality, thus having the features of a public university. In 1540, Pope Paul III reorganized it as the Studium Generale Maceratense with the classic four faculties (law, theology, philosophy, medicine) (Pomante, 2013).

UNIMC has today five departments: it is the only Italian university exclusively focused on Socio-economic Sciences and Humanities. Accordingly, its 
motto is "Innovation through Humanities": through a humanistic approach, it finds innovative interdisciplinary solutions for social and economic challenges (Compagnucci et al., 2018). In the AY 2017/2018, 10,083 students enrolled at UNIMC, 438 of them were international (USTAT, 2018).

As articulated in its 2019-2020 strategic plan, UNIMC seeks to expand its function as a public space where interactions with the city and the territory occur (UNIMC, 2018). In line with the National Strategy for Inner Areas (Barca et al., 2014), the Operational Programme for Regional Development based on the European Regional Development Fund (Marche Region, 2014) and the Regional Smart Specialisation Strategy (Marche Region, 2016), the university works with local actors to market the region, serving as a facilitator for discussions and planning working tables involving a network of various organizations to reinforce relationships among participants and foster cocreation of sustainable development.

UNIMC has coordinated or been involved in a wide range of European projects at the international level, also related to agriculture, food and wine, and tourism (Compagnucci et al., 2018).

More specifically, since 2009 a team from the Education, Cultural Heritage and Tourism Department has been working on agri-food marketing and territorial branding in rural areas, using an action research approach (Gilmore \& Carson, 1996; Grant et al., 2001) and an emphasis on mutuality and commitment. In this context, a collaboration between UNIMC and the Agritur-Aso association began.

\section{The Agritur-Aso association}

In the southern part of the Marche Region, between the Sibillini mountains and the Adriatic coast, lies the Aso valley (or Valdaso, named after the Aso River), straddling the provinces of Ascoli Piceno and Fermo. This land, populated by 29.392 inhabitants (ISTAT, 2019) living in 21 municipalities, is characterized by small hillside rural villages, surrounded by orchards, vineyards, and vegetable gardens and marked by a strong local cultural heritage, long-standing culinary traditions, and many typical local food products (Ferrara, 2015).

Agritur-Aso association was founded in 2007 by 6 rural accommodation facilities and farms and has now 22 members. The president, Roberto Ferretti, owns the B\&B La Scentella. Agritur-Aso collaborates with local tourism promoters and organizes cultural events based on local resources to foster community engagement and revitalize abandoned sites and small villages. The association offers hospitality enriched with experiential activities (Pine \& Gilmore, 1998) based on traditional, seasonal local gastronomy, natural and cultural resources, and the valorization of local traditions (Bertella \& Cavicchi, 2017), thus combining experiential tourism (Sundbo \& Sørensen, 2013), relational tourism (Grolleau, 1987), and community-based tourism (Okazaki, 2008). 
Agritur-Aso has a twofold aim and carries out initiatives mainly addressed to tourists and/or guests of its facilities, local community/stakeholders, and students.

On the one hand, the association aims at creating projects that promote a better quality of life for local communities based on solidarity and sustainability among all the actors involved in promoting the territory. The underlying philosophy of "Lu 'rajutu", reciprocal help, is deep-rooted in the rural culture. To this aim, the association designed the following events:

- The Salata (2007-2013): a rural neighbourhood dinner evoking the ritual of the pork slaughter and promoting the values of conviviality.

- Lavandaso festival (ongoing since 2012): lavender festival, including a market of local fresh products and handicrafts and cultural activities to bring abandoned villages/cultural sites back to life, by raising awareness in the local community and tourists on the importance of caring about the future of these places through an agora to discuss the future of the place (Bertella et al., 2020).

- Li Tajuli pilusi festival (ongoing since 2014): traditional home-made pasta festival that includes entertainment and cultural activities and an agora between the community and tourists to discuss the sustainability and quality of local life for the repopulation of rural villages. On the other hand, Agritur-Aso works to promote a form of hospitality based on authentic and spontaneous relationships between hosts and guests through activities and events that valorize the local culture, history, and traditions, and in doing so, to reinforce the sense of belonging of locals.

To this aim, the following events are carried on:

- Vintage festival (2009-2012): historical re-enactment of traditional winemaking and vincotto preparation, a traditional mulled wine.

- Marche in your suitcase (ongoing since 2009): Agritur-Aso members travel abroad during low tourist season to the towns of their former guests to promote Marche Region through cultural events and dinners, featuring products from small local rural firms, to attract more visitors to the region (Bertella \& Cavicchi, 2017).

\section{Methodology}

A longitudinal case study (Yin, 2003) was chosen to investigate changes in small communities, especially when there is a collaborative relationship with those being studied (Holland et al., 2006). This long-term research activity was based on the Participatory Action Research approach, mainly used in the field of rural development (Cahill, 2007): it is an umbrella term for a series of methods aimed at analysing and deepening a specific situation and cocreating solutions through active participation of researchers in collaborations 
with non-researchers (Elden \& Chisholm, 1993; Kindon et al., 2007; Bertella, 2019).

Research activities were carried out from 2014 to 2019 and included interviews, observations, and formal and informal meetings between the researchers and the association members. The data on which this specific study relies derive mainly from various documents and a series of fieldworks. Concerning the documents, two authors carried on desk research. They retrieved information by monitoring tourism promotion websites (7), blogs (7), social media pages/profiles (2), and YouTube channels (1). A review with 15 videos and 27 articles published in online magazines was also compiled.

As for field research:

- two authors conducted a semi-structured interview with the Agritur-Aso association president and a focus group with international students participating in the Lavandaso festival in 2019. These were recorded and transcribed. Other two team members operated the coding: identification of emerging aspects, categorization, summary of the main points emerged.

- all the authors practised participant observation: in the classroom and at UNIMC events and respectively during Lavandaso $(2017$; 2018) and Li Tajuli pilusi festival (2017). These activities included informal conversations with organizers and participants.

To analyse the data, a framework built on an adaptation from the "rural buzz" model described by Thomas (2016) was developed with a focus on the role of the university in fostering knowledge networks. Such framework (Table 5.1) supports the analysis of the multiple levels of knowledge exchange between UNIMC and rural actors in terms of the five dimensions (in Table 5.1 authors refer to them as D1-D5) of rural buzz and adds a sixth one (D6): the "global pipeline" (Bathelt et al., 2004). The model considers rural residents as active subjects in a network of knowledge development.

\section{Findings}

\section{Collaboration in the field}

Two UNIMC initiatives in the Fermo area involved Agritur-Aso: one is the International Student Competition on place branding and Mediterranean Diet (ISC, 2020), a short study-abroad programme organized since 2015 in collaboration with the Piceno Laboratory on Mediterranean Diet. This initiative offers international students and their professors an opportunity to spend a week in Fermo province to experience the area: learn about its culture and food traditions and compete in a contest to produce the best ideas for promoting the Mediterranean Diet territorial brand through social media and for fostering sustainable development in the area (Tomasi et al., 2019). The Agritur-Aso president, who is also one of the Piceno Lab founders, hosted some 
Table 5.1 The rural buzz dimensions adapted to the Agritur-Aso case study (authors' elaboration from Thomas, 2016; Bathelt et al., 2004)

\begin{tabular}{|c|c|c|}
\hline \multicolumn{2}{|c|}{ Rural buzz adapted dimensions } & \multirow{2}{*}{$\begin{array}{l}\text { Description } \\
\text { General interaction between tourism and } \\
\text { hospitality operators from Valdaso on an } \\
\text { informal/conversational level. } \\
\text { Horizontal but informal knowledge exchange }\end{array}$} \\
\hline D1 & $\begin{array}{l}\text { Interaction between tourism } \\
\text { and hospitality operators }\end{array}$ & \\
\hline D2 & $\begin{array}{l}\text { Interaction between tourism } \\
\text { and hospitality operators } \\
\text { and other service providers } \\
\text { from the area }\end{array}$ & $\begin{array}{l}\text { Temporary co-presence: opportunity to observe } \\
\text { and communicate with each actor contributing } \\
\text { to rural buzz. } \\
\text { Horizontal knowledge exchange } \\
\text { Temporary clustering }\end{array}$ \\
\hline D3 & $\begin{array}{l}\text { Interactions between tourism } \\
\text { and hospitality operators } \\
\text { and the government }\end{array}$ & $\begin{array}{l}\text { Government presence at events encourages trust } \\
\text { and fosters communication between different } \\
\text { rural actors. This allows operators to express their } \\
\text { views to the government and to influence policy. } \\
\text { Vertical knowledge exchange } \\
\text { Temporary clustering }\end{array}$ \\
\hline D4 & $\begin{array}{l}\text { Interaction between } \\
\text { knowledge } \\
\text { transfer facilitators and } \\
\text { tourism and hospitality } \\
\text { operators }\end{array}$ & $\begin{array}{l}\text { Tourism and hospitality operators can benefit } \\
\text { from knowledge transfer facilitators (specialists } \\
\text { providing information on innovative practice in } \\
\text { tourism, training courses, and support). } \\
\text { Vertical knowledge exchange } \\
\text { Temporary clustering }\end{array}$ \\
\hline D5 & Knowledge spreading & $\begin{array}{l}\text { The knowledge created can spread throughout } \\
\text { the region over time (through media, word of } \\
\text { mouth, events, relationships based on trust) and } \\
\text { enable complex information flows and rural } \\
\text { transformation. } \\
\text { Trust } \\
\text { Buzz }\end{array}$ \\
\hline D6 & $\begin{array}{l}\text { Global pipelines } \\
\text { (Bathelt et al., 2004) }\end{array}$ & $\begin{array}{l}\text { The links created beyond the local level can have } \\
\text { a role in knowledge creation and innovation, } \\
\text { as they integrate information from other } \\
\text { environments with the potential to increase local } \\
\text { interpretation and usage of knowledge. } \\
\text { Vertical knowledge exchange } \\
\text { Horizontal (potentially informal) knowledge } \\
\text { exchange }\end{array}$ \\
\hline
\end{tabular}

Source: Adapted from Thomas, 2016; Bathelt et al., 2004

students in his $\mathrm{B} \& \mathrm{~B}$. This direct engagement enabled him to build relationships with international participants, some of which invited the association to organize events in their own countries. Thanks to those relationships, by 2019, Marche in your suitcase had already organized three events in Belgium and two in the United States. The other initiative is the Wine Hackathon. UNIMC hosted the Agritur-Aso president as the key speaker at this 24-hour event organized in 2018 as part of the European project The Wine Lab. Generating innovation 
between practise and research (TWL, 2018). During the event, groups of students, researchers, and professionals competed to propose innovative ideas to promote the Marche Region as a food and wine destination.

Two Agritur-Aso festivals in the Valdaso have, in turn, involved UNIMC. During the first one, in 2017 UNIMC organized a participative process event (agora) to share ideas about the contribution from the population to revitalize small abandoned villages in the rural areas of Marche.

1. As for the second one, since 2017, national and international volunteering students from the master degree in International Tourism and Destination Management, supported by some $\mathrm{PhD}$ students, managed some part of the event programme (Bertella et al., 2020). In 2019, two students from Ghana, two from India, and one from Azerbaijan organized the ethnic cooking class and prepared traditional dishes from their country. The authors involved them in a focus group to evaluate the cooperation between the association and UNIMC. They expressed satisfaction for the opportunity to interact with and learn about the local community and the surrounding area. They also valued the opportunity to practise on soft skills. They suggested that in the future it could be beneficial to involve them early on in the event design and organization, to increase the visibility and enhance the reputation of the event thanks to the involvement of the university.

\section{Collaboration at the university}

Two initiatives in academia have benefitted both Agritur-Aso and UNIMC students. These are the agri-food marketing classes (problem-based learning approach, Barrows, 2002), during which, since 2015, Agritur-Aso president has presented the association's promotional activities, primarily focusing on Marche in your suitcase. Students adopting the case developed proposals coherent with the theory studied in the class. The president answered students' questions and later put into practice the most innovative and feasible ideas presented. In 2020 the students worked on the Business Model Canvas (Osterwalder, 2004) and proposed some ideas to help Agritur-Aso members during the post-COVID-19 recovery.

The other academic initiative is a UNIMC event about the recovery after the 2016 earthquakes in Central Italy (January 2017): local stakeholders from education, agriculture, tourism, and culture, discussed in groups coordinated by the UNIMC, on proposals and projects about the social and economic reconstruction of the territory. Agritur-Aso presented its initiative to raise funds to rebuild a church in a village through the donations of international contacts from Marche in your suitcase. During the event, Agritur-Aso enriched its network meeting a former high school German teacher. She put the association in contact with an association of Italians in Germany. As emerged from the interview, they then organized together Marche in your suitcase events in Obertshausen and Dudenhofen in 2017 and 2018. In turn, Agritur-Aso organized some concerts 
in the small historical theatres of Marche for a mandolin orchestra of Dudenhofen. These were planned for 2020 but postponed due to COVID-19.

UNIMC has also established an official agreement with Agritur-Aso for curricular students' internships.

\section{Collaboration in Italy and abroad}

UNIMC's national and international network has helped Agritur-Aso expand its activity.

As reported during the interview, the association established relations with the Wine Route of Tuscany, participated in Tuscan events, and shared its experiences at the post-graduate course in Wine in the Calabria Region. Moreover, in September 2019, the association presented its activities at the Summer School on Sustainable Development promoted by the University of Siena (Tuscany).

Supported by UNIMC, Agritur-Aso presented the experience of Marche in your suitcase in an application for the 2019 European Cultural Tourism Network Award for sustainable cultural tourism (ECTN, 2019). At the 12th International Conference for Cultural Tourism in Europe held in 2019 in Granada (Spain), the association was awarded first prize as a Destination of Sustainable Cultural Tourism in the "Culinary Heritage, Wine, Food \& Gastronomy Tourism” category (Europa Nostra, 2019).

Agritur-Aso also met Arizona State University students interested in sustainable agriculture, through UNIMC experiential learning activities organized for Edulingua, an Italian Language and Culture School in San Severino Marche (MC). Students visited La Scentella, attended to a presentation about AgriturAso's goals and activities, especially Marche in your suitcase, and featured the quintessence of sustainable tourism, a Ciochecio ("whatever is available") dinner prepared with seasonal products, home-grown or bought from local farmers.

\section{Discussion}

The long-term relationship between the Agritur-Aso association and UNIMC, even though mainly informal, suggests that reciprocal exchange of knowledge can emerge from an existing social tie based on trust, respect, good communication, shared goals, and a sense of belonging and identity (Wenger, 1998; Bertella, 2011a; Brookman-Frazee et al., 2012; Drahota et al., 2016). Over time, this interaction enabled the association to broaden its network locally, nationally, and internationally (Fonte, 2008; Csurgó et al., 2008; Fesenmaier \& Contractor, 2001; Lane \& Oreszczyn, 2013). This resulted in the exchange of various types of knowledge, particularly tourism knowledge about the valorization and exploitation of rural resources as experiences, and local managerial and political knowledge about the socio-cultural aspects of the specific area (Bertella, 2011b). In the following paragraphs, the relationship between UNIMC and Agritur-Aso according to the rural buzz adapted dimensions (Table 5.1, D1-D6) will be discussed. 


\section{Rural buzz in the classroom}

The UNIMC courses in Agri-food marketing and Place branding and rural development engage students in experiential learning and problem-based learning activities (Kolb, 1984; Barrows, 2002), to support their employability by experiencing real challenges in the working environments (Goddard \& Kempton, 2016). Specifically, in the Agri-food marketing course, students who did their course project on the Agritur-Aso case took part in a temporary knowledge cluster (Bathelt \& Schuldt, 2008): as they learned about it during the class presentation, they spoke with its members and other stakeholders and, in some cases, worked with them during curricular internships; they started sharing its goals and sought to support it. There is a two-way exchange of information: the students learn about the specific characteristics of the area and the associations' activities and at the same time serve as knowledge transfer facilitators (D4), providing the association with new knowledge to support its promotion of the area.

Through the participatory approach event promoted by UNIMC to discuss with local stakeholders about the post-earthquake recovery, the university also facilitated knowledge exchange with other stakeholders from the same or different fields (D1, D2).

The event was also participated by public bodies, with whom the university regularly deals. In this sense, the university supports reciprocal awareness among stakeholders that may influence policymaking (D3). Through these events, government and institutional participants understand the activities going on in the rural areas and the needs for resources.

\section{Rural buzz in the area}

UNIMC participation in Agritur-Aso events such as the Li Tajuli pilusi festival and, in exchange, Agritur-Aso operators participation in university events and learning experiences in the area, such as the International Student Competition, can be related to several dimensions of the rural buzz framework (Thomas, 2016). As a civic-engaged university, UNIMC considers the local area as a living laboratory (Goddard et al., 2016). These events foster interactions among tourism and hospitality operators (D1), other service providers (D2), and the local community and help identify the needs of the local community, providing the university with a deeper understanding of the local context, which is the subject of research of its studies, through a participatory action research approach (Cahill, 2007). This link is also applicable to the role of students working as volunteers in the frame of events such as the Lavandaso festival: by supporting organization and implementation of the events, students can apply the theoretical knowledge gained during their university courses (D4). The dimension of CAPs to enhance care for the community (Brookman-Frazee et al., 2012; Drahota et al., 2016) is retrievable in the case of the agora managed by UNIMC at the Li Tajuli pilusi festival, 
during which participants discussed the future of the abandoned villages of rural areas. The agora served to share ideas on the topic and build relationships with other participants and professionals: new relationships support the development of new opportunities for collaboration (D1, D2, D4). The $\mathrm{CoP}$ concept also comes into play here: the university students and teachers and the residents can be viewed as practitioners who possess different types of knowledge and share the same interest and concern for the local area (Wenger, 1998). As such, UNIMC contributes to horizontal rather than vertical knowledge exchange, as the transfer of knowledge is reciprocal, and the local cultural values are part of the knowledge flow (Thomas, 2016). In this collaborative inquiry, all the participants, including the university itself, invest their professional identities as part of a dynamic, forward-looking community (Wenger, 1998).

\section{Rural buzz beyond the Fermo area: a "global pipeline"}

Through the UNIMC network, Agritur-Aso could share knowledge (Thomas, 2016) throughout the region (D5) and beyond (D6), by participating in several initiatives to present and provide experiences related to its activities. Thanks to the UNIMC collaboration with Edulingua in San Severino Marche, it happened locally with the involvement of the Arizona State University students in a field trip. It also occurred outside the region, at the Wine Route in Tuscany, the Wine Master in Calabria, and the Summer School in Siena.

In a "global pipeline", links with actors abroad expand the potential for knowledge creation and innovation (Bathelt et al., 2004), as information can be transferred to other contexts but can also come from different environments, thus increasing local interpretation and usage of knowledge (Bathelt et al., 2004). In this context, UNIMC has facilitated new partnership synergies and helped actors to implement programmes or interventions beyond the local area (Brookman-Frazee et al., 2012; Drahota et al., 2016). For example, UNIMC helped Marche in your suitcase by sharing its network to meet new partners who decided to support the initiative. It is also valid for the involvement of international students in the Agritur-Aso activities, as they can promote interculturalism and place-making (e.g., ethnic cooking classes), gain local knowledge, and also provide to locals an international perspective and become "ambassadors" for the region in their countries (Wenger, 1998; Bertella, 2011a; BrookmanFrazee et al., 2012; Drahota et al., 2016) (D6).

\section{Conclusions}

This study investigated the role that universities can play in stimulating knowledge networks to valorize regional cultural capital in remote rural regions through a participatory action research approach. It explored the long-term relationship between UNIMC and Agritur-Aso, a local association of tourism and hospitality operators from a Marche region's rural area. 
The findings suggested that the reciprocity between UNIMC and AgriturAso contributed to creating the basis for temporary proximity, tacit knowledge, and situational learning; furthermore, results highlight that Agritur-Aso benefitted the expansion of its network significantly through UNIMC contacts.

Thus, universities can play a significant role in stimulating knowledge networks to valorize regional cultural capital in remote rural regions. The horizontal knowledge exchange and expansion of learning relationships beyond the local area and the significant amount of time developing reciprocal trust and mutual commitment based on a shared vision of rurality and the related challenges and potential strongly emerge. These factors were addressed in terms of the concepts of Rural Buzz, CoP, and CAP. This case presents some critical aspects: UNIMC-Agritur-Aso collaboration, based on trust and mutual commitment and related to researchers' and students' personal and informal engagement, has never been officially structured. The lack of structure prevents it from a long-term vision. For example, the relationships built in the classroom sometimes were not nurtured after the end of the course and had not a followup in practical terms.

Moreover, the association's activities are mainly based on volunteering: they depend on the free availability of human and financial resources. In this way, continuity cannot be guaranteed: this is one of the main reasons why some of the events stopped (e.g., the Salata, the Vintage festival). A more structured collaboration with the university could provide the association with more opportunities to access public funding and direct contact with local and regional public authorities. More generally, creating a sustainable CAP infrastructure for collaboration could also share the university's wider network with local stakeholders and turn these relationships into concrete collaborations from a long-term perspective.

This study presents some limitations. Firstly, it lacks precise measurements of these relationships' impact in terms of improved community care and changes the community's context. Concerning this, future studies should be dedicated to understanding the actual nature of the knowledge exchange between the actors involved and how it is translated into concrete actions. A second limitation concerns the existence of perspectives on the local development of tourism that differ from the view advocated and promoted by the investigated university and association. Such an issue can be related to possible conflicts and power relations that might have been overseen, partly due to the researchers' active role in the investigated collaboration. As a research team, we discussed this aspect and strived to gain a broad view of possible relevant topics and actors excluded from the cooperation. Nonetheless, future studies about the rural buzz and the collaboration between universities and local associations might include a seventh dimension representing the lack of interactions among potentially relevant actors. 


\section{References}

Aref, F., \& Gill, S. S. (2009). Rural tourism development through rural cooperatives. Nature and Science, 7(10), 68-73.

Barca, F., Casavola, P., \& Lucatelli, S. (2014). Strategia nazionale per le Aree interne: definizione, obiettivi, strumenti e governance. Roma: Ministero dello Sviluppo Economico, Dipartimento per lo Sviluppo e la Coesione Economica, Unità di Valutazione degli Investimenti Pubblici.

Barrows, H. (2002). Is it truly possible to have such a thing as dPBL? Distance Education, 23(1), 119-122. https://doi.org/10.1080/01587910220124026.

Bathelt, H., Malmberg, A., \& Maskell, P. (2004). Clusters and knowledge: Local buzz, global pipelines and the process of knowledge creation. Progress in Human Geography, 28(1), 31-56. https://doi.org/10.1191/0309132504ph469oa.

Bathelt, H., \& Schuldt, N. (2008). Between luminaires and meat grinders: International trade fairs as temporary clusters. Regional Studies, 42(6), 853-868. https://doi.org/10.1080/ 00343400701543298.

Bertella, G. (2011a). Communities of practice in tourism: Working and learning together. An illustrative case study from Northern Norway. Tourism Planning \& Development, 8(4), 381-397. https://doi.org/10.1080/21568316.2011.598179.

Bertella, G. (2011b). Knowledge in food tourism: The case of Lofoten and Maremma Toscana. Current issues in tourism, 14(4), 355-371. https://doi.org/10.1080/13683500.2010.489638

Bertella, G. (2019). Participatory action research and collaboration in CSR initiatives by DMOs. Journal of Ecotourism, 18(2), 165-173. https://doi.org/10.1080/14724049.2018 .1482904

Bertella, G., \& Cavicchi, A. (2017). From sharecroppers to "flying farmers": New forms of tourism entrepreneurship in rural areas. e-Review of tourism Research, 14(3/4), 133-148.

Bertella, G., Tomasi, S., Cavicchi, A., \& Paviotti, G. (2020). Community-based tourism engagement and wellbeing from a learning perspective. In P. Wiltshier \& A. Clarke (Eds.), Community-based tourism in the developing world. London: Routledge.

Brookman-Frazee, L., Stahmer, A. C., Lewis, K., Feder, J. D., \& Reed, S. (2012). Building a research-community collaborative to improve community care for infants and toddlers at-risk for autism spectrum disorders. Journal of Community Psychology, 40(6), 715-734. https://doi.org/10.1002/jcop. 21501.

Cahill, C. (2007). The personal is political: Developing new subjectivities through participatory action research. Gender, place and culture, 14(3), 267-292. https://doi.org/10.1080/ 09663690701324904

Compagnucci, L., Spigarelli, F., Passarini, P., Ferrara, C., Aleffi, C., \& Tomasi, S. (2018). Local development and innovation in a social sciences and humanities based university: The case of the University of Macerata. Agricoltura, istituzioni e mercati.

Cooper, C. (2006). Knowledge management and tourism. Annals of Tourism Research, 33(1), 47-64. https://doi.org/10.1016/j.annals.2005.04.005.

Csurgó, B., Kovách, I., \& Kučerová, E. (2008). Knowledge, power and sustainability in contemporary rural Europe. Sociologia Ruralis, 48(3), 292-312. https://doi.org/10.1111/ j.1467-9523.2008.00461.x.

Drahota, A. M. Y., Meza, R. D., Brikho, B., Naaf, M., Estabillo, J. A., Gomez, E. D., Veinoska, S. F., Dufek, S., Stahmer, A. C., \& Aarons, G. A. (2016). Communityacademic partnerships: A systematic review of the state of the literature and recommendations for future research. The Milbank Quarterly, 94(1), 163-214. https://doi. org/10.1111/1468-0009.12184. 


\section{Sabrina Tomasi et al.}

ECTN. (2019). European cultural tourism network. Awards 2019 edition overall theme: Culture and heritage for responsible innovative and sustainable tourism actions. Retrieved December 30, 2020, from www.culturaltourism-network.eu/award-2019.html\#

Elden, M., \& Chisholm, R. F. (1993). Emerging varieties of action research: Introduction to the special issue. Human relations, 46(2), 121-142. https://doi.org/10.1177/ 001872679304600201.

Europa Nostra. (2019). Winners of the destination of Sustainable Cultural Tourism Awards 2019 announce. Retrieved December 30, 2020, from www.europanostra.org/winners-of-thedestination-of-sustainable-cultural-tourism-awards-2019-announced/.

Eurybase, E. (2007). The information database on education systems in Europe, the education system in France. Directorate General for Education and Culture, European Commission. Retrieved December 28, 2020, from www.indire.it/lucabas/lkmw_file/eurydice/// Eurybase_2008_EN.pdf

Ferrara, C. (2015). Cibo, Cultura, Paesaggio. Strategie di marketing territoriale per la Valdaso. Macerata: Eum.

Fesenmaier, J., \& Contractor, N. (2001). The evolution of knowledge networks: An example for rural development. Community Development, 32(1), 160-175. https://doi.org/10.1080/ 15575330109489697.

Fonte, M. (2008). Knowledge, food and place. A way of producing, a way of knowing. Sociologia ruralis, 48(3), 200-222. https://doi.org/10.1111/j.1467-9523.2008.00462.x.

Gilmore, A., \& Carson, D. (1996). Integrative qualitative methods in a services context. Marketing Intelligence and Planning, 14(6), 21-26. https://doi.org/10.1108/02634509610131126.

Goddard, J., Hazelkorn, E., Kempton, L., \& Vallance, P. (2016). Introduction: Why the civic university?. In Goddard, J., Hazelkorn, E., \& Vallance, P. (Eds.), The Civic University: The policy and leadership challenges. Cheltenham, UK: Edward Elgar Publishing. https://doi. org/10.4337/9781784717728.

Goddard, J., \& Kempton, L. (2016). The civic university: Universities in leadership and management of place. Centre for Urban and Regional Development Studies, Newcastle University. Retrieved December 30, 2020, from www.ncl.ac.uk/media/wwwnclacuk/curds/files/ university-leadership.pdf

Grant, K., Gilmore, A., Carson, D., Laney, R., \& Pickett, B. (2001). "Experiential” research methodology: An integrated academic-practitioner "team" approach. Qualitative Market Research, 4(2), 66-75. https://doi.org/10.1108/13522750110388563

Grolleau, H. (1987). Rural tourism in the 12 member states of the European economic community. Brussels: EEC Tourism Unit, DG XXIII.

Holland, J., Thomson, R., \& Henderson, S. (2006). Qualitative longitudinal research: A discussion paper. London: London South Bank University.

ISC. (2020). Piceno laboratory on Mediterranean diet. International Student Competition. Retrieved December 22, 2020, from www.laboratoriodietamediterranea.it/it/eventi/vinternational-student-competition-place-branding-and-mediterranean-diet

ISTAT. (2019). Censimento permanente della popolazione e delle abitazioni. Anno 2019.

Jamal, T. B., \& Getz, D. (1995). Collaboration theory and community tourism planning. Annals of Tourism Research, 22(1), 186-204. https://doi.org/10.1016/0160-7383(94)00067-3.

Johnson, P. A. (2010). Realising rural community-based tourism development: Prospects for social economy enterprises. Journal of Rural and Community Development, 5(1), 150-162.

Kindon, S., Pain, R., \& Kesby, M. (2007). Participatory action research approaches and methods: Connecting people participation and place. Oxon: Routledge.

Kolb, D. (1984). Experiential learning: Experience as the source of learning and development. Englewood Cliffs, NJ: Prentice Hall. 
Kolehmainen, J., Irvine, J., Stewart, L., Karacsonyi, Z., Szabó, T., Alarinta, J., \& Norberg, A. (2016). Quadruple helix, innovation and the knowledge-based development: Lessons from remote, rural and less-favoured regions. Journal of the Knowledge Economy, 7(1), 23-42. https://doi.org/10.1007/s13132-015-0289-9

Lane, A., \& Oreszczyn, S. (2013, September 25-27). Understanding influences on farmers' practices. In Sustainable intensification: The pathway to low carbon farming? (pp. 41-43). Edinburgh: Scotland's Rural College.

Marche Region. (2014). PSR Marche 2014-2020. Retrieved December 22, 2020, from www.regione.marche.it/Entra-in-Regione/Psr-Marche

Marche Region. (2016). Regional strategy for research and innovation for smart specialisation. Retrieved December 22, 2020, from www.marcheinnovazione.it/sites/marcheinnovazione. it/files/strategia_per_la_ricerca_e_linnovazione_per_la_smart_specialisation_0.pdf

Marche Region. (2019). Report. Demografia. Marche Popolazione. Anno 2019. Retrieved December 28, 2020, from http://statistica.regione.marche.it/Portals/0/Pubblicazioni/ Popolazione/Report_Marche\%20Popolazione_2019.pdf.

Nair, V., Hussain, K., Ramachandran, S., Mohamad, N. H., \& Hamzah, A. (2013). Tourism cooperative for scaling up community-based tourism. Worldwide Hospitality and Tourism Themes, 5(4), 315-328. https://doi.org/10.1108/WHATT-03-2013-0017.

Ngo, T., Lohmann, G., \& Hales, R. (2018). Collaborative marketing for the sustainable development of community-based tourism enterprises: Voices from the field. Journal of Sustainable Tourism, 26(8), 1325-1343. https://doi.org/10.1080/09669582.2018.1443114-

Okazaki, E. (2008). A community-based tourism model: Its conception and use. Journal of Sustainable Tourism, 16(5), 511-529. https://doi.org/10.1080/09669580802159594.

Osterwalder, A. (2004). The business model ontology. A proposition in a design science approach (p. 172) (Doctoral thesis). Lausanne: Université de Lausanne.

Phelps, C., Heidl, R., \& Wadhwa, A. (2012). Knowledge, networks, and knowledge networks: A review and research agenda. Journal of Management, 38(4), 1115-1166. https:// doi.org/10.1177/0149206311432640.

Pine, B. J., \& Gilmore, J. H. (1998). The experience economy. Boston: Harvard Business School Press.

Pomante, L. (2013). Per una storia delle università minori nell'Italia contemporanea. Il caso dello Studium Generale Maceratense tra Otto e Novecento. Macerata: Eum.

Richards, G. (2002). From cultural tourism to creative tourism: European perspectives. Tourism, 50(3), 225-233.

Rinaldi, C. (2017). Food and gastronomy for sustainable place development: A multidisciplinary analysis of different theoretical approaches. Sustainability, 9(10), 1748. https://doi. org/10.3390/su9101748.

Sharpley, R. (2002). Rural tourism and the challenge of tourism diversification: The case of Cyprus. Tourism Management, 23(3), 233-244. https://doi.org/10.1016/S0261-5177 (01)00078-4.

Sundbo, J., \& Sørensen, F. (Eds.). (2013). Handbook on the experience economy. Cheltenham: Elgar.

Thomas, G. (2016). The royal Welsh show: Facilitating rural buzz. Regional Studies, Regional Science, 3(1), 428-436. https://doi.org/10.1080/21681376.2016.1239224.

Tomasi, S., Cavicchi, A., Paviotti, G., Bertella, G., \& Santini, C. (2019). Assessing the learning outcomes of food-related educational tourism events for university students: The case of the international student competition of Fermo, Italy. International Studies. Interdisciplinary Political and Cultural Journal, 24(2), 95-125. https://doi.org/10.18778/1641-4233.24.07. 
74 Sabrina Tomasi et al.

TWL. (2018). The Wine Lab. Generating innovation between practise and research. 1st TWL Winethon in Italy a great success! Retrieved December 30, 2020, from www.thewinelab.eu/ en/news/item/63-1st-twl-winethon-in-italy-a-great-success.

UNIMC. (2018). Piano strategico 2019-2022. Retrieved June 16, 2020, from www.unimc. it/it/sostenibilita/pianificazione-programmazione/documenti/ps_2019-2022.pdf

USTAT. (2018). Portale dei dati dell'Istruzione Superiore, Didattica, Università degli Studi di Macerata. Retrieved December 20, 2020, from http://ustat.miur.it/dati/didattica/italia/ atenei-statali/macerata

Wenger, E. (1998). Communities of practice: Learning as a social system. Systems Thinker, 9(5), 2-3.

Yin, R. K. (2003). Case study research: Design and methods (3rd ed.). Thousand Oaks, CA: Sage. 


\title{
6 The Third Mission

\author{
Enhancing Academic Engagement \\ with Industry
}

Tatiana Iakovleva and Mette Eriksen Adkins

\begin{abstract}
There is an ongoing debate in the literature about a "third mission" for universities. Examples of successful academic spin-offs have led to a widespread policy of encouraging collaboration between the academic and commercial worlds. However, the commercialization of researchbased innovations often suggests a conflict of interest to academics. In this study we explore what types of knowledge spillover are preferable for academics and how universities can support them. Analysing a survey of 226 academics in a medium-sized university in Norway, we found that supporting the entrepreneurial knowledge and skills of academics might cause a modest increase in their entrepreneurial intentions. At the same time, we found that incentives for joint research projects with industrial partners enhance academics' desire to take part in such collaborations. We conclude by questioning the well-publicized policy efforts focused on boosting academic start-ups. We argue that more knowledge about starting and running a business would be helpful, but only for a small number of academics who are already interested in such activities. To enhance broader academic involvement in the "third mission", policies should encourage a wider range of activities and focus on providing incentives, such as tax regimes or co-funding possibilities, for other types of research-industry collaboration, such as joint research projects.
\end{abstract}

\section{Introduction}

As this book focuses on the everyday engagements of universities and higher educational institutions with regional partners, our chapter adds to this discussion by looking at different methods for such knowledge transfer. There is an ongoing debate in the literature, started by Leydesdorff and Etzkowitz (1996), as to whether universities can and should fulfil a "third mission" in addition to education and basic research (Bruneel et al., 2010; Ankrah \& Omar, 2015; 
Kaklauskas et al., 2018; Perkmann et al., 2013). This third mission resembles the "entrepreneurial university" model, which focuses on outreach activities based upon generating technology transfer and knowledge-based start-ups, or the "engaged university" model, which involves collaborative projects with industrial and other regional actors (Sánchez-Barrioluengo \& Benneworth, 2019). Various channels are available for establishing these links, ranging from applied research and joint research projects with regional and industrial actors, to commercial efforts such as licensing, patenting, and academic spin-offs.

The Bayh-Dole Act and its European equivalents, along with other policy changes, introduced the concept of the "entrepreneurial university". An embryonic academic entrepreneurial dynamic originated in US universities during the late 19th century, when the lack of a formal research funding system made necessary individual and collective initiatives to obtain resources to support original research (Etzkowitz, 2003). The US entrepreneurial university emerged from the "bottom up", in contrast to Europe, where the introduction of academic entrepreneurship has been a recent "top-down" phenomenon, in response to the innovation gap between the United States and Europe (Soete, 1999; Lopes et al., 2018). Etzkowitz (2003) views the emergence of the university as a form of collective entrepreneurship. He argues that groups of individuals, irrespective of their cultural and social backgrounds, can be trained in entrepreneurial spirit and that modern polices can facilitate entrepreneurial thinking at university leadership level to stimulate both research and commercial activities.

The assumption among policymakers is that the entrepreneurial university will contribute to inspire more entrepreneurs among students and academics, which in turn will increase the direct contribution of universities to the local and national economy (Foss \& Gibson, 2015; D’Este \& Perkmann, 2011; Clarysse et al., 2011). At the same time, Clark $(1998,2001,2004)$ points out that this transformation is not unproblematic: he particularly notes a growing imbalance between the demands made upon universities and the universities' capacity to respond if they remain in their traditional form. The demandresponse imbalance is especially evident in public universities that are mainly supported by a national or regional ministry of education or education and science - as is often the case with universities located in Europe. In addition, he argues for three pathways that need to be present for transformation to occur:

[T] he extended developmental periphery, in all of its grand profusion of new forms and relationships; the stimulated academic heartland, with its well-rooted but quite varied departments that have to join the overall transformation or else it probably will not occur; and the integrated entrepreneurial culture, voiced with pride and passion, where a new point of view becomes characteristic of the entire university.

(Clark, 2001, p. 8)

In their recent article, Sánchez-Barrioluengo and Benneworth (2019) distinguish between the entrepreneurial university and the engaged university. The 
"entrepreneurial university" refers to commercial activities involving spin-offs, patents, and licensing, while the "engaged university model" refers to collaborative projects with industrial and regional partners. The engagement approach acknowledges the university's role in knowledge production but regards the primary contribution as coming from structural improvements to the knowledge exchange environment, organization, governance, and policy frameworks.

This chapter is intended to contribute to this debate, to highlight which channels of knowledge transfer are preferred by academics, and to show how universities can facilitate their transformation into entrepreneurial universities. In particular, we aim to investigate the role the university context plays in academics' entrepreneurial intentions and their willingness to collaborate with industry. To study how the third role of university can be fostered, we are focusing on the university context by applying Scott's (2014) institutional pillars: the regulative, normative, and cognitive pillars. The regulative dimension consists of formal support mechanisms, such as rewards and recognition, for involvement in third-mission activities. The normative aspects are the informal actions, beliefs, and attitudes of academics towards the third mission. The cognitive aspects are the knowledge and skills of academics concerning the implementation of the third mission, ranging from the commercialization of innovations through spin-offs to the broader spectrum of academic-industrial collaboration. In this chapter we are looking on University of Stavanger, located in Norway. Using a survey sample of 226 academics, we empirically test our hypothesis that a university context that is supportive towards the third mission increases academics' ability and willingness to engage in entrepreneurial activities and collaborate with industry.

The rest of this chapter is organized as follows. We first present a theoretical framework and discuss the importance of the university context in entrepreneurial university transformation. We then describe our method and analyse the findings from our study. We conclude with the discussion of the implications of this study for theory and practice.

\section{The university context as enabler and constrainer of the transformative process}

When an institution is attempting to move itself into an entrepreneurial mode, it is pertinent to consider how this implementation of entrepreneurial modes occurs. Transformation of any organization, including universities, can be seen as institutional change (Scott, 2014), consisting of the roles, norms, and conventions that society has identified for how universities are expected to perform. We view the transformation towards an entrepreneurial university as being heavily influenced by the institutional environment in which the university is embedded. Despite an increasing number of books and articles on universities' third mission (Morris et al., 2013; Fayolle \& Redford, 2014; Foss et al., 2013) scant attention has been given to the role of context in the transformative process of universities. Moreover, universities are comprised of rules, 
laws, formal and informal policies, as well as the organization of key groups or communities, which affect and form the university context (Etzkowitz, 2003; Storper, 2013, p. 8). These groups form networks with civic associations, businesses, and other neighbouring communities. In this way, the university context can both enable and constrain its groups, and it can reinforce regional and national perceptions on the role of universities in regional development (Foss \& Gibson, 2015; Valdez \& Richardson, 2013).

In this chapter we consider "the university context" as an organizational context that has a significant influence on the propensity of an organization towards innovation by affecting employee behaviour (Tidd et al., 2001; Tolbert et al., 2011; Oftedal et al., 2018). McLaughlin et al. (2005) set out the characteristics of organizational structure that supports innovation. The university context possesses many characteristics that are enablers of innovation. The university, by the nature of its primary objective of developing knowledge, has a structure that facilitates knowledge gathering. On the other hand, the university is highly institutionalized and is seen as resistant to change (Bercovitz \& Feldman, 2008). This suggests that universities have some of the important characteristics that typify organizations that are well positioned for change but equally that they display factors that inhibit change. In this way, the university context can both enable and constrain transformative change towards the fulfilment of the third mission.

This study considers the institutional context in an academic setting as consisting of regulative, normative, and cognitive structures. Scott (2014, p. 56) defines institutions as "regulative, normative and cultural-cognitive elements that, together with associated activities and resources, provide stability and meaning to social life". Applying the same logic, we study the university context through these three pillars, where "regulative" relates to formal rules and regulations, "normative" to informal norms and values, and "cognitive" to shared knowledge and interpretation.

The regulative structure implies that rules and regulations exist separately and objectively from the agent. At the same time, agents' actions are dependent upon their perceptions of the rules. Thus, formal rules affect agents' behaviour through constituting and regulating activities (Scott, 2014). Although rules and regulations can be viewed at a state level, it is their local adoption in the form of university regulations, policies, and strategies that matters for academics. A number of studies address the regulative dimension of the university context (Kraaijenbrink et al., 2009; Saeed \& Muffatto, 2012; Turker \& Selcuk, 2009; Oftedal et al., 2018). These studies indicate a positive relationship between university support for entrepreneurship in the form of competitions and monetary rewards for involvement in entrepreneurial activities (Todorovic et al., 2011), but they are mainly based on the study of student samples.

The normative dimension is based on the values and norms that prevail in the organization. Values are conceptions of the preferred or the desirable, together with the construction of standards with which existing structures or behaviour can be compared and by which they can be assessed. Norms specify how 
things should be done: they define goals or objectives, and they also designate appropriate ways to pursue these goals or objectives. The logic of appropriateness is a perspective that sees human action as driven by rules of appropriate or exemplary behaviour, organized into institutions. Rules are followed because they are seen as natural, rightful, expected, and legitimate. Actors seek to fulfil the obligations encapsulated in a role, an identity, or a membership of a political community or group, and the ethos, practices, and expectations of its institutions. Embedded in social collectivity, they do what they see as appropriate for themselves in a specific type of situation (March \& Olsen, 2006, p. 2). Some values and norms are applicable to all members of the collective, others to specific types of actors or positions (Scott, 2014).

The cognitive aspect of organizational context is concerned with acceptable behaviour based on the knowledge of what lies within a certain context. Cognitive structures can be described as the shared conception that constitutes the nature of social reality and creates the frames through which meaning is made (Scott, 2014, p. 67). The cultural-cognitive dimension reveals the cognitive structures and social information shared by the people in a given country, region, or organization. In relation to the entrepreneurial university, the cognitive aspect relates to shared knowledge, traditions, identities, and practices that have become institutionalized (taken for granted) over time among faculty and students in relation to starting and running a business or enrolling in industry collaborations. In our study, we are focusing particularly on academics.

A number of recent studies have indicated the positive relationship between a university climate supportive of entrepreneurship and entrepreneurial intentions on the part of students (Todorovic et al., 2011; Oftedal et al., 2018). Engagement in entrepreneurial activities can be explained by behavioural theories, and therefore research has evolved around entrepreneurial intention as a powerful theoretical framework (Liñán \& Fayolle, 2015). Intention in this sense is viewed as a predictor of actual behaviour (Ajzen, 1991; Liñán \& Chen, 2009; Iakovleva et al., 2011).

Thus, a university's offer of rewards in the form of monetary and nonmonetary incentives, its fostering of entrepreneurial culture, and its promotion of education programmes on entrepreneurship have proved to result in increased entrepreneurial intentions among students (Bae et al., 2014; Rauch \& Hulsink, 2015; Oosterbeek et al., 2010; Souitaris et al., 2007). Different factors, such as gender, age, and self-employment experience (Westhead \& Solesvik, 2016; Welter, 2011; Liñán et al., 2015; Gundray et al., 2014), might moderate the effects of the cognitive and normative dimensions of the university context.

However, there is a lack of studies looking at whether the same stimulus would promote the intentions and competence of academics. As we assume that behavioural theories should apply across different social groups, this argument leads us to suggest that the university context comprised the aforementioned regulative, normative, and cognitive pillars should equally affect the intention of academics to engage in entrepreneurial behaviour. Moreover, looking at 
other behaviour, such as collaboration with industry, we suggest that a university context supportive of that behaviour will lead equally to an increased desire to collaborate with industry. Academic engagement in industrial collaboration represents instances of inter-organizational collaboration, usually involving "person-to-person interactions" (Cohen et al., 2002) that link universities and other organizations, notably firms (Bonaccorsi \& Piccaluga, 1994; Meyer-Krahmer \& Schmoch, 1998; Schartinger et al., 2002). In a literature review of academic engagement, Perkmann et al. (2013) found that academic engagement is a multi-level phenomenon and that it is determined by the characteristics of individuals and the organizational and institutional context in which individuals work. Some argue that a policy (regulation) emphasis on commercialization obscures the fact that industry engagement often generates considerable benefits for academic research and that academics are motivated to engage with industry to further their own research (D'Este \& Perkmann, 2011; Perkmann et al., 2013).

On the basis of the earlier discussion, we suggest that a university context supportive of entrepreneurial activities and industry collaboration across regulative, normative, and cognitive dimensions should be positively related to the intention of academics to engage in entrepreneurial activities and their desire to engage in industrial collaboration. The following hypotheses are presented in Table 6.1.

\section{Methodology}

To test the hypotheses, we conducted a survey of academics in a mediumsized regional university located in western Norway. The University of Stavanger is one of the youngest universities in Norway, having been established in 2005, although its colleges in engineering, nursery, business, and the arts were in place for a long period before then. The university is located in a region dominated by oil exploration activities, in the city of Stavanger, which is often called the oil capital of Norway. Petroleum engineering was one of the main drivers of the establishment of Stavanger's colleges in the 1970s. Today, the university comprises five faculties and accommodates around 12,000 students. It is the workplace of around 1,600 academics, administration, and service staff. The University of Stavanger can be characterized as a regional university that mainly plays a support role for the local industries of oil and gas, engineering specialists, IT firms, the maritime industry, and a relatively large regional hospital. It also educates teachers, social workers, business managers, journalists, and other specialist occupations. The university collaborates with the technology transfer office (TTO Valide), a separate entity of which the university is a co-owner. The TTO is located in an innovation park not far from the university. The TTO plays an important role in commercializing innovations that derive from the University of Stavanger. Since 2003, Norwegian universities have been given ownership of intellectual property rights (IPR) which previously belonged 
Table 6.1 Summary of hypotheses

\begin{tabular}{ll}
\hline$N$ & Hypotheses \\
\hline $\mathrm{H} 1$ & $\begin{array}{c}\text { The regulative dimension of a university context supportive towards entrepreneurship } \\
\text { leads to stronger entrepreneurship intentions among academics. }\end{array}$ \\
$\mathrm{H} 2$ & $\begin{array}{c}\text { The normative dimension of a university context supportive towards entrepreneurship } \\
\text { leads to stronger entrepreneurship intentions among academics. }\end{array}$ \\
$\mathrm{H} 3 \quad \begin{array}{l}\text { The cognitive dimension of a university context supportive towards entrepreneurship } \\
\text { leads to stronger entrepreneurship intentions among academics. }\end{array}$ \\
$\mathrm{H} 4 \quad \begin{array}{c}\text { Aniversity context supportive of industrial collaboration leads to increased industrial } \\
\text { collaboration among academics. }\end{array}$
\end{tabular}

to individual researchers. Significant changes have also taken place at the university level, as TTOs have been established at many universities, which are actively encouraging university spin-offs. The role of the TTO is to help an inventor develop a sound business model and find partners for their prospective business. Despite the fact that TTO Valide is well equipped with competent personnel, the rate of commercialization at the University of Stavanger remains quite low, mainly occurring in technical departments and the university hospital. This research was sponsored by TTO Valide to find out more about entrepreneurial intentions within the university's faculties as well as attitudes towards other forms of industrial collaboration and the commercialization of research inventions.

To ensure validity, the survey draft was reviewed by university students from the business school, by staff from three different faculties at the university, by a professor of research methodology from another Norwegian university, and by staff belonging to the technology transfer office. Input was also sought from a professional with considerable surveying experience who was not linked to academia. A total of eight different people were involved in the reviewing process.

An online survey was emailed to all academics on behalf of the researchers by the rector of the university. The survey was conducted during December 2017 and January 2018. The survey was available in Norwegian and English. Around 10\% of responses were completed in English, while the rest were completed in Norwegian. Our population comprised all academic staff, including $\mathrm{PhD}$ students and post-doctoral researchers. The survey was distributed to 1,406 respondents. The response rate was $16 \%$. The final sample consisted of 226 completed questionnaires. The sample characteristics relative to the population are presented in Table 6.2 in the "Findings" section of this chapter.

Whenever possible we used well-developed scales for dependent variables and adapted them for the needs of the present research. Principal component analysis was used to create reliable scales for the constructs that were new, and multiple regression analysis was utilized to test the hypotheses. A summary of the constructs and control variables applied is presented in Appendix 6.1. 
Table 6.2 Descriptive sample statistics

\begin{tabular}{lll}
\hline Item & Characteristic survey sample (\%) & University as a whole (\%) \\
\hline Female & 50 & 55 \\
Male & 50 & 45 \\
Faculty of science and & 29 & 32 \\
$\quad$ technology & & \\
Faculty of health sciences & 16 & 8 \\
Faculty of social sciences & 12 & 17 \\
Faculty of arts and education & 27 & 31 \\
Business school & 11 & 6 \\
Other faculties & 5 & 9 \\
\hline
\end{tabular}

Table 6.3 Involvement in entrepreneurial activities and in industry collaboration

\begin{tabular}{ll}
\hline Item & Characteristic survey sample (\%) \\
\hline Have licensed an idea & 3 \\
Have patented an idea & 6 \\
Currently involved with a business & 8 \\
This business is based on your research & 4 \\
Collaboration projects with industry in the past 2 years & 51 \\
Worked on collaboration projects where 30\% or more of & 34 \\
$\quad$ whose financing came from industry & \\
\hline
\end{tabular}

\section{Findings}

This section will first present some descriptive statistics of the sample (Table 6.2). It will then provide some key figures in relation to two major types of knowledge transfer: that made through commercialization activities (including licensing, patenting, and business start-ups) and that made through collaboration with broader industry (collaboration projects with industry, research projects co-funded by industry partners). These figures are presented in Table 6.3. In addition, we have tested the hypotheses from Table 6.1 using linear regression analysis. The results are presented in Tables 6.4 and 6.5.

As Table 6.2 reveals, respondents from the health sciences faculty and the business school are over-represented in our sample and respondents from the faculty of social sciences are slightly under-represented, while other faculties appear in more or less representative proportions. The sample is also representative in relation to gender. In terms of age, $74 \%$ of all respondents were between 30 and 60 years old, with $7 \%$ between 20 and 30, and $18 \%$ over 60 years old.

Table 6.3 shows the actual involvement of academics in entrepreneurial activities and industrial collaboration. These data were self-reported. Our study findings indicate that only $8 \%$ of academics are involved in an entrepreneurial start-up. This is in line with overall statistics for entrepreneurial activities in Norway, which show variations from 5 to $8 \%$ over the last 10 years in the 
Table 6.4 Linear regression analysis of the effect of the university context on entrepreneurial intentions

\begin{tabular}{lcl}
\hline & Entrepreneurial intentions & Tolerance \\
\hline & Model 1 & \\
& St. Beta & \\
Controls & $.26^{\star \star \star}$ & 0.909 \\
Gender & $-.200^{\star \star}$ & 0.909 \\
Age & .031 & 0.968 \\
Department & $.374^{\star \star \star}$ & 0.928 \\
Self-employment experience & .204 & \\
Adjusted $\mathrm{R}^{2}$ & $13.409^{\star \star \star}$ & \\
F-value & -.0290 & 0.735 \\
University context regulative & -.009 & 0.692 \\
University context normative & $.204^{\star \star}$ & 0.792 \\
University context cognitive & .036 & \\
$\Delta \mathrm{R}^{2}$ & .229 & \\
Adjusted $\mathrm{R}^{2}$ & $9.209^{\star \star \star}$ & \\
F-value & $\mathrm{n}=195$ & \\
$\mathrm{n}$ &
\end{tabular}

Notes: $\dagger \mathrm{p}<0.1 ;{ }^{\star} \mathrm{p}<0.05 ;{ }^{\star \star} \mathrm{p}<0.01 ;{ }^{\star \star \star} \mathrm{p}<0.001$.

Table 6.5 Linear regression analysis of the university context on industry collaboration

\begin{tabular}{lcl}
\hline & Industry collaboration & Tolerance \\
\hline & Model 1 & \\
& St. Beta & \\
Controls & & \\
Gender & -.097 & .918 \\
Age & -.021 & .935 \\
Department & -.014 & .972 \\
Self-employment experience & -.066 & .930 \\
Adjusted R ${ }^{2}$ & -.002 & \\
F-value & .907 & \\
University context towards IC & $.320^{\star \star \star}$ & \\
$\Delta \mathrm{R}^{2}$ & $.099^{\star \star \star}$ & \\
Adjusted $\mathrm{R}^{2}$ & $.094^{\star \star \star}$ & \\
F-value & $5.079^{\star \star \star}$ & \\
$\mathrm{n}$ & $\mathrm{n}=197$ & \\
\hline
\end{tabular}

Notes: $\uparrow \mathrm{p}<0.1 ;{ }^{\star} \mathrm{p}<0.05 ;{ }^{\star \star} \mathrm{p}<0.01 ;{ }^{\star \star \star} \mathrm{p}<0.001$.

involvement of the general population in Norway in entrepreneurial start-ups (GEM study, 2014). It is also remarkable that only $4 \%$ of our sample say that the business they are involved with is related to their research.

At the same time, our study reveals that $51 \%$ of academics are involved in different kinds of collaboration with industry for research. This resembles previous research findings and confirms that academics are keener to collaborate 
with industry than engage in the commercialization of their research results via spin-offs (D’Este \& Perkmann, 2011; Perkmann et al., 2013).

To test hypotheses $\mathrm{H} 1-\mathrm{H} 3$ on whether the regulative, normative, and cognitive dimensions of the university context affect the entrepreneurial intentions of academics, we performed the linear regression analysis presented in Table 6.4.

Our control variables explain $20.4 \%$ of variance in entrepreneurial intentions among academics. Self-employment experience is in particular a strong predictor of future entrepreneurial intentions. This supports arguments in favour of entrepreneurialism being self-perpetuating. Age also has a significant impact on entrepreneurial intentions, with younger members of staff being more likely to display entrepreneurial intentions. Being male is strongly positively related to entrepreneurial intentions, as is expected and in line with previous studies (Solesvik et al., 2019; Verheul et al., 2006).

Surprisingly, departmental membership did not prove to be a significant variable in explaining entrepreneurial intentions. This contradicts the findings of previous studies (Bercovitz \& Feldman, 2008; Clarysse et al., 2011), which have shown that academics involved in engineering and sciencerelated areas have a greater inclination towards entrepreneurial activities than academics in other fields. One explanation for this could be specific to the Norwegian or even the regional context. The majority of externally financed research activities occur in cooperation with a research institute partly owned by the University of Stavanger: the International Research Institute of Stavanger (IRIS), which was recently renamed and merged with a larger research institute, Norce. This research institute encompasses most applied projects, with research and related activities in petroleum, new energy, marine environment, biotechnology, the social sciences, and business development (Oftedal \& Iakovleva, 2015).

Our findings reveal that, contrary to our expectations, the regulative and normative dimensions of the university context do not seem to influence the entrepreneurial intentions of academics. This is surprising, as the same constructs have been proven to have a strong relationship to entrepreneurial intentions among students (Oftedal et al., 2018). One explanation for this might be that academics choose their careers vocationally, and they perceive their careers as being related to scientific development rather than business development. Additionally, the technical and disciplinary environments in which Norwegian universities operate do not put pressure on academics to reach out to industry, compared with other contexts (Bercovitz \& Feldman, 2008; Bereznitz \& Feldman, 2012). However, the cognitive dimension, which instils knowledge about start-ups, licensing, and patenting processes, seems to be an important facilitator of entrepreneurial intentions among academic staff. Thus, hypotheses H1 and $\mathrm{H} 2$ are rejected, while $\mathrm{H} 3$ is supported.

We also conducted a regression analysis to test hypothesis $\mathrm{H} 4$, the impact of the university context in promoting industrial collaboration intentions. The results are presented in Table 6.5. 
None of the control variables were significant. The lower impact of the control variables in comparison with entrepreneurial intentions may indicate that the benefits of industrial collaboration appeal widely to all staff at the university. The findings revealed that a university context supportive of industry collaboration is strongly related to the perceived benefits of such collaboration among academics. Thus, hypothesis H4 is supported.

\section{Discussion}

Our study findings indicate that the university context influences the entrepreneurial and industrial collaboration intentions of academics, albeit in different degrees. Firstly, we will further discuss the factors that affect entrepreneurial intentions and thus contribute to building an entrepreneurial university. Secondly, we will examine the findings related to industrial collaboration intentions, which are crucial for building an engaged university.

\section{Building the entrepreneurial university}

The entrepreneurial university model (Clark, 2001; Etzkowitz \& Leydesdorff, 2000) focuses mainly on commercial activities (Perkmann et al., 2013), with the new university structures of TTOs confirming the importance of actively and strategically promoting commercialization of knowledge through spin-offs, patents, and licensing. Such promotion might be achieved through stimulating the regulatory environment through formal demands and rewards, enhancing the cognitive dimension by boosting knowledge among academics about such activities or even by building an entrepreneurial culture and thereby stimulating the normative organizational context. Our study tested the assumption that these dimensions are useful in stimulating entrepreneurial university.

Our analysis showed that some control variables are important for the entrepreneurial intentions of academics. The male gender was found to be strongly influential in the entrepreneurial intentions of academics. This is in line with gender research on entrepreneurship (De Bruin et al., 2006; Iakovleva \& Kickul, 2011). It is important to recognize gender differences and to put in place relevant measures that can help address these differences. For example, universities can implement programmes that enhance women's competence with regard to commercialization or involvement in industrial collaboration through various programmes. Previous start-up experience was also a strongly influential variable for entrepreneurial intentions among academic staff. This is in line with our expectations and in line with previous studies (Liñán \& Chen, 2009; Ucbasaran et al., 2006).

However, unlike earlier studies that found a positive and significant relationship between the regulative, normative, and cognitive structures in the university context and the respondents' entrepreneurial intentions (Kraaijenbrink et al., 2009; Oftedal et al., 2018; Todorovic et al., 2011), we found only limited support for this relationship. One explanation might be that previous 
studies were based on student samples, while our respondents were academics. Students have yet to make their final career choices, and their values and behavioural norms are easier to influence. Thus, institutional structures that are supportive towards entrepreneurship are helpful in forming students' entrepreneurial intentions. The only dimension found to be strongly and significantly related to academics' entrepreneurial intentions is the cognitive dimension. Scott (2014) defines the cognitive dimension as cognitive structures and social information shared by the people in a given country, region, or organization. Knowledge of the processes of licensing, patenting, and starting up a business might be very helpful in encouraging more academics to think entrepreneurially. That is something which TTOs can easily address via courses, knowledgesharing platforms, and other means for educating academics in entrepreneurial activities.

The fact that the regulative and normative dimensions are less important for encouraging entrepreneurial behaviour among academics can be explained by the fact that academics, unlike students, have made their career choice. Our research shows that values of academic research are not aligned with entrepreneurial activities, since engaging in commercial activities does not form part of socialization in this disciplinary setting, unlike teaching and research. This is in line with previous research (Rasmussen et al., 2006).

Policymakers should be mindful of this conflicted situation, where there is a clash of logic between science as an institution and the university as a tool for economic development (Olsen, 2007). Academics perceive the university's role as providing cutting-edge research and high-quality education, rather than commercialization of innovations. Our research shows that $8 \%$ of sample respondents are currently involved in start-up activities. Among those there is a slight surplus of professors and respondents aged over 60. The average of $8 \%$ is close to the national average (GEM report, 2014); however, it is atypical that seniors (people over 60) should be enrolled in such activities. Only $4 \%$ of respondents are engaged in business that relates to their main research field. We have to acknowledge that to academic staff, commercial activities suggest a conflict of interest. This was also indicated by previous studies (Gibb \& Hannon, 2006; Rasmussen et al., 2006). The advancement of academic careers depends on knowledge openness, while achieving commercial success depends on exclusive distribution of knowledge to gain financial benefit.

\section{Building the engaged university}

The engaged approach (Sánchez-Barrioluengo \& Benneworth, 2019) acknowledges the university's roles in knowledge production through formal research and development and consultancy transactions, alongside informal knowledge transmission not involving financial compensation. This model distinguishes between "soft" activities (advisory roles, consultancy, industry training, production of highly qualified graduates) that are closer to the traditional academic 
paradigm and "hard" initiatives such as patenting, licensing, and spin-off activities that form part of third-mission outputs.

Although commercial activities were not prioritized among academics, an engaged approach through collaboration with industry was practised by $51 \%$ of respondents from our academic survey. This percentage is considerably higher than could be expected on the basis of previous studies, which highlight the challenges involved in such collaboration (Gulbrandsen \& Nerdrum, 2009; Mowery \& Sampat, 2005). However, as is also pointed out by De Fuentes and Dutrénit (2012), the nature of interactions changes as the country develops, as these reflect a co-evolution of factors which depend on context, incentives, and agents' characteristics, particularly their absorptive capacities and embedded culture. Norwegian innovation policies, in particular funding resources available for firms and universities through Norwegian Research Council programmes, clearly highlight initiatives for promoting industrial collaboration. Thus, industry collaboration though applied research is seen as a natural and important activity for academics to engage in.

These findings also suggest that academics do not consider industrial collaborators' profiting from research generated by university-industry collaboration to be a barrier. The strongest motivators for industry collaboration were centred on the expansion of knowledge and the access to financing for research projects. Both factors align well with academics' core objectives of basic research and education. These findings align with previous findings that suggest that academics engage with industry in order to further their own learning or to access funds and other resources (D'Este \& Perkmann, 2011; Pinheiro et al., 2017).

Our analysis confirmed that promoting industry collaboration in the university context by means of rules, rewards, knowledge availability, and social norms would further increase industrial collaboration. Thus, promoting collaboration with industry might be a fruitful strategy that will enhance knowledge.

\section{Conclusion}

The drive to achieve entrepreneurial and engaged universities has given rise to questions about what motivates academics to engage in commercial activity or industrial collaboration. While Clark $(2001,2004)$ provides excellent illustrations of the drivers of such transformative processes, using a number of cases from well-known universities such as Harvard Business School, little is still known about the more "average", regional universities, often located on the periphery. This book argues that "one size does not fit all", and we can see that our findings support that. Commercial activities and successful spin-offs from academia are often taken as examples of how universities should contribute to regional development. However, one should acknowledge that not all universities or cities or regions have either the capacity or the drivers equal to those of universities located in major cities or in areas with high levels of technological development, such as Silicon Valley. 
In this study we have investigated the role of the university context in relation to entrepreneurial intentions and the industrial collaboration intentions of academics. The study revealed that the cognitive dimension of the university context, which includes knowledge about entrepreneurial processes, such as licensing, patenting, or start-up processes, plays a major role in forming entrepreneurial intentions. However, we did not find support for the view that the regulative or normative dimensions of the university context were associated with the entrepreneurial intentions of academics. Although we expected some differences in attitude towards commerce across disciplines or fields, in line with Becher and Trowler's (2001) debate on academic cultures, we did not find evidence for such differences. That could perhaps be explained by differences in academic and professional norms of behaviour. The comments provided to our survey gave us the sense that there is strong loyalty towards the principles of academic freedom and that some academics perceive commercial activities to be a threat to such freedom. This is in line with some "myths" that Clark (2004) argued are not necessarily true, labelling them the "collegiality defensive strategy". However, they still seem to be present in our case study.

On the other hand, we found that engaging in industry collaboration in form of joint research-industry projects and applied research dominates the collaboration landscape. Such collaboration is promoted by the government, and in addition it does allow for publication, which is one of the promotion criteria for academics (Pinheiro et al., 2017). Further, it was found that a university context supportive to such collaboration might be an enabling factor (Etzkowitz et al., 2000), both for industrial collaboration and for the perceived benefits of such collaboration.

This study adds to the discussion on entrepreneurial and engaged universities and their "third mission". While universities' engagement in entrepreneurial and commercial activities is much desired by policymakers, our findings suggest that in the case of regional, middle-sized universities on the peripheries of academia and geographically, industrial collaboration is more prevalent than pure commercialization of research-based ideas. One needs to acknowledge that regional context-embeddedness does matter, but the degree of impact seems to be dependent upon the correspondence between the activities encouraged for agents and their perceived personal goals. In case of Universities, the desire to increase commercialization of innovations from academics through start-ups or licensing might conflict with the academics' perceived personal goals such as ground research or teaching.

Social systems both constrain and enable the discovery, evaluation, and exploitation of opportunities by entrepreneurs. We have established that individuals do not exist separately from their structural context. Attempts to understand them outside of this context cannot, therefore, fully capture their nature. Thus, rather than encourage a general academic population to engage in commercial activities, we suggest that universities in Norway would benefit by directing resources effectively towards a targeted group of academics who feel positively about involvement in commercial activities. 
This strategy might increase the success rate of academic entrepreneurs and equip those who are motivated to perform better. Such a strategy would be in line with earlier findings from student surveys, which found that the entrepreneurial intentions of students enrolled in mandatory courses decreased as some of them realized how difficult and demanding entrepreneurial activity was (Oosterbeek et al., 2010). At the same time, the entrepreneurial intentions of students who were enrolled in elective courses, and who were therefore highly motivated to become entrepreneurs, actually increased (Fayolle et al., 2006; Liñán \& Fayolle, 2015). This implies that working with targeted populations would provide better results than attempting to engage a larger number of individuals who might not be interested in pursuing an entrepreneurial career.

Our findings have certain policy implications for how to view the "third mission" of regional, medium-sized universities. Understanding and valuing regional context-embeddedness seems to be the key to stimulating the building of truly functional and engaged universities. Instead of attempting to replicate Silicon Valley by raising expectations for university-based start-ups, policies should distinguish between the demands and capacities of regional universities. One evident approach is to encourage industry collaboration through providing supportive regimes, building knowledge among academics about collaboration possibilities, and enhancing collaborative culture. Engaged universities might be of great value in knowledge transfer and in contributing to regional development.

\section{Future research}

The objective of this study was to focus on the transformation of a regional, medium-sized Norwegian University into one capable of achieving thirdmission goals. This task is not without limitations, as contextual embeddedness does not allow broad generalizations from this study. Our sample was limited to one university, with a rather modest response rate. Therefore, we acknowledge that generalizability of this study is limited, and future research would have to address the same issues applying longitudinal design and in diverse contexts. For example, one might test whether the university context has a different and more distinct effect on academics in other cultures or regions. However, we hope that our results are stimulating and will bring greater attention to the agent-context research in entrepreneurship. Our study calls for more debate on the benefits of having universities encourage academics to become entrepreneurs, and for caution towards "one size fits all" policies. We would also like to see further investigation of means for stimulating an effective and much-needed collaboration with industry and for knowledge spillover from universities to the business world. Can we find ways to change academic values to include a more entrepreneurial approach by resolving conflicts of interest? These questions should be addressed in the future research. 


\section{References}

Ajzen, I. (1991). The theory of planned behaviour. Organizational Behavior and Human Decision Processes, 50(2), 179-211.

Ankrah, S., \& Omar, A. T. (2015). Universities - industry collaboration: A systematic review. Scandinavian Journal of Management, 31(3), 387-408.

Bae, T. J., Qian, S., Miao, C., \& Fiet, J. O. (2014). The relationship between entrepreneurship education and entrepreneurial intentions: A Meta-Analytic Review. Entrepreneurship Theory and Practice, 38(2), 217-254.

Becher, T., \& Trowler, P. (2001). Academic tribes and territories: Intellectual enquiry and the culture of disciplines. Buckingham: Society for Research into Higher Education \& Open University Press.

Bercovitz, J., \& Feldman, M. (2008). Academic entrepreneurs: Organizational change at the individual level. Organization Science, 19(1), 69-89. https://doi.org/10.1287/orsc.1070.0295

Bereznitz, S., \& Feldman, M. (2012). The engaged university. The Journal of Technology Transfer, 37(2), 139-157. https://doi.org/10.1007/s10961-010-9183-6

Bonaccorsi, A., \& Piccaluga, A. (1994). A theoretical framework for the evaluation of university-industry relationships. RED Management, 24(3), 229-247.

Bruneel, J., d'Este, P., \& Salter, A. (2010). Investigating the factors that diminish the barriers to university - industry collaboration. Research Policy, 39(7), 858-868.

Clark, B. (2001). The entrepreneurial university: New foundations for collegiality, autonomy, and achievement. Higher Education Management, 13(2).

Clark, B. R. (1998). The entrepreneurial university: Demand and response. Tertiary Education and Management, 4(1), 5-16.

Clark, B. R. (2004). Delineating the character of the entrepreneurial university. Higher Education Policy, 17(4), 355-370.

Clarysse, B., Tartari, V., \& Salter, A. (2011). The impact of entrepreneurial capacity, experience and organizational support on academic entrepreneurship. Research Policy, 40(8), 1084-1093.

Cohen, W. M., Nelson, R. R., \& Walsh, J. P. (2002). Links and impacts: The influence of public research on industrial R\&D. Management science, 48(1), 1-23.

De Bruin, A., Brush, C. G., \& Welter, F. (2006). Introduction to the special issue: Towards building cumulative knowledge on women's entrepreneurship. Entrepreneurship Theory and Practice, 30(5), 585-593.

De Fuentes, C., \& Dutrénit, G. (2012). Best channels of academia - industry interaction for long-term benefit. Research Policy, 41(9), 1666-1682.

D'Este, P., \& Perkmann, M. (2011). Why do academics engage with industry? The entrepreneurial university and individual motivations. Journal of Technology Transfer, 36, 316-339

Etzkowitz, H. (2003). Research groups as "quasi-firms": The invention of the entrepreneurial university. Research Policy, 32(1), 109-121.

Etzkowitz, H., \& Leydesdorff, L. (2000). The dynamics of innovation: From National Systems and "mode 2" to a Triple Helix of university - industry - government relations. Research Policy, 29(2), 109-123.

Etzkowitz, H., Webster, A., Gebhart, C., \& Terra, B. R. C. (2000). The future of the university and the university of the future: Evolution of ivory tower to entrepreneurial paradigm. Research Policy, 29, 313-330

Fayolle, A., Gailly, B., \& Lassas-Clerc, N. (2006). Assessing the impact of entrepreneurship education programmes: A new methodology. Journal of European Industrial Training, 30(9), 701-720. 
Fayolle, A., \& Redford, D. T. (2014). Introduction: Towards more entrepreneurial universities - myth or reality?. In Handbook on the entrepreneurial university. de A. Fayolle and D. T. Redford. Edward Elgar Publishing.

Foss, L., \& Gibson, D. V. (eds.). (2015). The entrepreneurial university. Context and institutional change. London: Routledge.

Foss, L., Oftedal, E., \& Iakovleva, T. (2013). Action-based education in academic entrepreneurship: A new role of the student? In Ferreira et al. (eds.), Cooperation, clusters and knowledge transfer (pp. 249-263). Berlin, Heidelberg: Springer.

GEM report. (2014). Global entrepreneurship monitor. Alsos, Clausen, Isaksen, Åmo (2014). Retrieved October 16, 2020, from www.gemconsortium.org/file/open?fileId=49497

Gibb, A., \& Hannon, P. (2006). Towards the entrepreneurial university. International Journal of Entrepreneurship Education, 4(1), 73-110.

Gulbrandsen, M., \& Nerdrum, L. (2009). University industry relations in Norway. In J. Fagerberg, D. C. Mowery, \& B. Verspagen (Eds.), Innovation, path dependency, and policy: The Norwegian case (Vol. 1, pp. 297-327). Oxford: Oxford University Press.

Gundray, L., Kickul, J., Iakovleva, T and Carsrud, A. (2014). Women-owned family businesses in transitional economies: Key Influences on Firm Innovativeness and Sustainability. Journal of Innovation and Entrepreneurship, 3(8), DOI: 10.1186/2192-5372-3-8

Iakovleva, T., \& Kickul, J. (2011). Beyond social capital: The role of perceived legitimacy and entrepreneurial intensity in achieving funding success and superior venture performance in women-led Russian SMEs. International Journal of Entrepreneurship and Small Business, 14(1), 13-38.

Iakovleva, T., \& Kolvereid, L. (2009). An integrated model of entrepreneurial intentions. International Journal of Business and Globalisation, 3(1), 66-80.

Iakovleva, T. Kolvereid, L. and Stephan, U. (2011). Entrepreneurial intentions in developing and developed countries. Education and Training, 53(5), 353-370.

Kaklauskas, A., Banaitis, A., Ferreira, F. A., Ferreira, J. J., Amaratunga, D., Lepkova, N., . . . Banaitienè, N. (2018). An evaluation system for university - Industry partnership sustainability: Enhancing options for entrepreneurial universities. Sustainability, 10(1), 119.

Kraaijenbrink, J., Bos, G., \& Groen, A. (2009). What do students think of the entrepreneurial support given by their universities?. International Journal of Entrepreneurship and Small Business, 9(1), 110-125.

Krueger, N. F., Reilly, M. D., \& Carsrud, A. L. (2000). Competing models of entrepreneurial intentions. Journal of Business Venturing, 15(5-6), 411-432.

Leydesdorff, L., \& Etzkowitz, H. (1996). Emergence of a Triple Helix of university - industry - government relations. Science and Public Policy, 23(5), 279-286.

Liñán, F., \& Chen, Y. W. (2009). Development and cross - cultural application of a specific instrument to measure entrepreneurial intentions. Entrepreneurship Theory and Practice, 33(3), 593-617.

Liñán, F., \& Fayolle, A. (2015). A systematic literature review on entrepreneurial intentions: Citation, thematic analyses, and research agenda. International Entrepreneurship and Management Journal, 11(4), 907-933.

Liñán, F., Moriano, J. A., \& Jaén, I. (2015). Individualism and entrepreneurship: Does the pattern depend on the social context? International Small Business Journal, 34(6), 760-776.

Lopes, J., Ferreira, J. J., Farinha, L., \& Raposo, M. (2018). Emerging perspectives on regional academic entrepreneurship. Higher Education Policy, 1-29.

March, J. G., \& Olsen, J. P. (2006). The logic of appropriateness. In M. Moran, M. Rein, \& R. Goodin (Eds.), The Oxford handbook of public policy (pp. 689-708). Oxford: Oxford University Press. 


\section{Tatiana Iakovleva and Mette Eriksen Adkins}

McLaughlin, P., Bessant, J., \& Smart, P. (2005). Developing an organisational culture that facilitates radical innovation in a mature small to medium sized company: Emergent findings. Cranfield School of Management Working Paper Series SWP 04/05

Meyer-Krahmer, F., \& Schmoch, U. (1998). Science-based technologies: University industry interactions in four fields. Research Policy, 27(8), 835-851.

Morris, M. H., Kuratko, D. F., \& Cornwall, J. R. (2013). Entrepreneurship programs and the modern university. Edward Elgar Publishing.

Mowery, D., \& Sampat, B. (2005). Universities in national innovation systems. In J. Fagerberg, D. Mowery, \& R. Nelson (Eds.), The Oxford handbook of innovation (pp. 209-239). New York: Oxford University Press.

Oftedal, E. M., \& Iakovleva, T. (2015). Stavanger: From petroleum focus to diversified competence through crisis and consensus. Academic Entrepreneurship-from University Research to Implementation and Commercialization of Innovations - A Comparative Study. https://doi. org/10.4324/9781315737065-11

Oftedal, E. M., Iakovleva, T. A., \& Foss, L. (2018). University context matter: An institutional perspective on entrepreneurial intentions of students. Education + Training, 60(7/8), 873-890. https://doi.org/10.1108/ET-06-2016-0098

Olsen, J. P. (2007). The institutional dynamics of the European university. In P. Maassen \& J. P. Olsen (Eds.), University dynamics and European integration (pp. 25-54). Dordrecht: Springer.

Oosterbeek, H., Praag, M., \& Ijsselstein, A. (2010). Impact of entrepreneurship education on entrepreneurship skills and motivation. European Economic Review, 54(4), 442-454.

Perkmann, M., Tartari, V., McKelvey, M., Autio, E., Broström, A., D’Este, P., Fini, R., Geuna, A., Grimaldi, R., Hughes, A., \& Krabel, S. (2013). Academic engagement and commercialisation: A review of the literature on university-industry relations. Research Policy, 42(2), 423-442.

Pinheiro, R., Normann, R., \& Johnsen, H. C. G. (2017). External engagement and the academic heartland: The case of a regionally-embedded university. Science and Public Policy, 43(6), 787-797. https://doi.org/10.1093/scipol/scw020

Rasmussen, E., Moen, Ø., \& Gulbrandsen, M. (2006). Initiatives to promote commercialization of university knowledge. Technovation, 26(4), 518-533.

Rauch, A., \& Hulsink, W. (2015). Putting entrepreneurship education where the intention to act lies: An investigation into the impact of entrepreneurship education on entrepreneurial behaviour. Academy of Management Learning E Education, 14(2), 187-204.

Saeed, S., \& Muffatto, M. (2012). Conceptualizing role of university orientation: Graduate entrepreneurial intention. In M. Muffatto \& P. Giacon (eds.), Entrepreneurial strategies and policies for economic growth. Italy: Webster.

Sánchez-Barrioluengo, M., \& Benneworth, P. (2019). Is the entrepreneurial university also regionally engaged? Analysing the influence of university's structural configuration on third mission performance. Technological Forecasting and Social Change, 141, 206-218.

Schartinger, D., Rammer, C., Fischer, M. M., \& Fröhlich, J. (2002). Knowledge interactions between universities and industry in Austria: Sectoral patterns and determinants. Research policy, 31(3), 303-328.

Scott, W. R. (2014). Institutions and organizations: Ideas, interests, and identities (4th ed.). Thousand Oaks, CA: Sage.

Soete, L. (1999). The challenges and the potential of the knowledge based economy in a globalised world. Background Paper of the Portuguese Presidency of the European Union. MERIT, Maastricht. 
Solesvik, M., Iakovleva, T., \& Trifilova, A. (2019). Motivation of female entrepreneurs: A cross-national study. Journal of Small Business and Enterprise Development, 26(5), 684-705. Souitaris, V., Zerbinati, S., \& Al-Laham, A. (2007). Do entrepreneurship programs raise entrepreneurial intention of science and engineering students? The effect of learning, inspiration and resources. Journal of Business Venturing, 22(4), 566-591.

Storper, M. (2013). Key to the city: How economics, institutions, social interactions and politics shape development. Princeton, NJ: Princeton University Press.

Tidd, J., Bessant, J., \& Pavitt, K. (2001). Managing innovation integrating technological market and organizational change (2nd ed.). Chichester: Wiley.

Todorovic, Z. W., McNaughton, R. B., \& Guild, P. (2011). ENTRE-U: An entrepreneurial orientation scale for universities. Technovation, 31(2-3), 128-137.

Tolbert, P. S., David, R. J., \& Sine, W. D. (2011). Studying choice and change: The intersection of institutional theory and entrepreneurship research. Organizational Science, 22(5), 1337-1344.

Turker, D., \& Selcuk, S. (2009). Which factors affect entrepreneurial intention of university students? Journal of European Industrial Training, 33(2), 142-159.

Ucbasaran, D., Westhead, P., \& Wright, M. (2006). Habitual entrepreneurs. Hanover: now Publishers Inc.

Valdez, M. E., \& Richardson, J. (2013). Institutional determinants of macro-level entrepreneurship. Entrepreneurship Theory and Practice, 37(5), 1149-1175.

Verheul, I., Stel, A. V., \& Thurik, R. (2006). Explaining female and male entrepreneurship at the country level. Entrepreneurship and Regional Development, 18(2), 151-183.

Welter, F. (2011). Contextualizing entrepreneurship-Conceptual challenges and ways forward. Entrepreneurship Theory and Practice, 35(1), 165-184.

Westhead, P., \& Solesvik, M. Z. (2016). Entrepreneurship education and entrepreneurial intention: Do female students benefit?. International Small Business Journal, 34(8), 979-1003. 


\section{Appendix 6.1 Constructs used in the study}

\begin{tabular}{|c|c|}
\hline Construct/source & Items / Cronbach alpha \\
\hline Entrepreneurial intentions & Cronbach alpha 0.92 \\
\hline $\begin{array}{l}\text { Clarysse et al. (2011), Liñán and Chen } \\
\text { (2009), Krueger et al. (2000), and } \\
\text { Iakovleva and Kolvereid (2009) }\end{array}$ & $\begin{array}{l}\text { I frequently identify opportunities to start up } \\
\text { new businesses } \\
\text { I have very seriously thought of starting a } \\
\text { business } \\
\text { I intend to start a business one day } \\
\text { It is very likely that I will start my own } \\
\text { business in the next } 5 \text { years }\end{array}$ \\
\hline $\begin{array}{l}\text { Industry collaboration intentions } \\
\text { inspired by D'Este and Perkmann (2011) }\end{array}$ & $\begin{array}{l}\text { Cronbach alpha } 0.665 \\
\text { feedback from industry on academic research } \\
\text { information of industry problem } \\
\text { research income from industry }\end{array}$ \\
\hline \multicolumn{2}{|l|}{ Controls $^{1}$} \\
\hline Gender & 1 for male and 0 for female \\
\hline Department & categorical variable \\
\hline Age & ordinal variable \\
\hline Self-employment experience & 1 if yes and 0 if no \\
\hline \multicolumn{2}{|l|}{$\begin{array}{l}\text { University context supportive to } \\
\text { entrepreneurship } \\
\text { adopted from Oftedal et al. } 2018\end{array}$} \\
\hline Regulative dimension & Cronbach alpha 0.936 \\
\hline Financial support licensing & \\
\hline Financial support patenting & \\
\hline Financial supporting starting business & \\
\hline Management recognition starting business & \\
\hline Management recognition patenting & \\
\hline Management recognition licensing & \\
\hline Normative dimension & Cronbach alpha 0.991 \\
\hline Colleagues respect and admire patenting & \\
\hline Colleagues respect and admire licensing & \\
\hline $\begin{array}{l}\text { Colleagues respect and admire starting } \\
\text { business }\end{array}$ & \\
\hline Cognitive dimension & Cronbach alpha 0.951 \\
\hline $\begin{array}{l}\text { I know of and can speak with colleagues } \\
\text { who have licensed ideas }\end{array}$ & \\
\hline
\end{tabular}


Items / Cronbach alpha

I know of and can speak with colleagues who have patented ideas

University context supportive to industry collaboration

Financial support and management recognition for IC

Awareness of and access to colleagues who have IC

${ }^{1}$ We also tried to enter other control variables such as job title, percentage of research that is applied research, whether respondents were permanent or temporary members of staff, experience of licensing, and experience of patenting, but they were not significant and are not included in final regression. 


\title{
7 Student Entrepreneurship Programmes in Higher Education Institutions
}

\author{
Multi-scalar Embeddedness and \\ Heterogeneous Regional Responses
}

\author{
Øyvind Midtbø Berge, Øystein Stave Hovig, \\ and Svein Gunnar Sjøtun
}

\begin{abstract}
Since the 2000s there has been an increasing prevalence of student entrepreneurship programmes in higher education institutions (HEIs). Even though the HEIs have different institutional and regional preconditions for student entrepreneurship, the concrete activities and strategies are often shaped by best practice models derived from successful and wellperforming organizations. Hence, we argue in this chapter that a stronger investigation of how different HEIs interact with the region with regard to student entrepreneurship is needed. With empirical examples, we show how the embeddedness of HEIs in a regional context influences strategies for student entrepreneurship. We discuss the activities and strategies at three different HEIs in the Bergen region regarding how they have been influenced by the dynamic interaction between the HEIs and the regional context. We find that the regional HEIs embed their student entrepreneurship efforts more in networks on different geographical scales. For the Western Norway University of Applied Sciences the regional scale is of more importance, while the national scale is of more importance for the Norwegian School of Economics and the international scale is of more importance for the University of Bergen.
\end{abstract}

\section{Introduction}

Since the 2000s there has been an increasing prevalence of student entrepreneurship programmes in higher education institutions (henceforth HEIs), which are eager to increase their impact within regions through engaging in "third-mission activities" besides research and teaching (Uyarra, 2010). HEIs' organizational structure is shown to be an important determinant for students' 
engagement into entrepreneurship (Åstebro et al., 2012), and a proactive development of an entrepreneurial strategy has become an explicit strategic goal of many HEIs (Bergmann et al., 2016). Due to this more strategic approach towards entrepreneurship HEIs are increasingly setting up infrastructure and engaging in activities that support students in pursuing entrepreneurship, such as education programmes, student incubators, idea competitions, and so on.

However, as student entrepreneurship is a relatively new avenue for many HEIs, concrete activities and strategies are often shaped by best practice models derived from successful and well-performing organizations. ${ }^{1}$ While such models without doubt have many good elements, we believe one should be careful to apply them in an undifferentiated manner across different HEIs and regions. We argue in this chapter that HEIs have different institutional preconditions for student entrepreneurship. More importantly, we also contend that regional conditions can significantly affect HEIs (see Asheim et al., 2011; Benneworth et al., 2017; Karlsen, 2019), for example, the entrepreneurship strategies and activities they engage with in order to increase regional impact.

Our main argument in this chapter is, therefore, that a stronger investigation of how different HEIs interact with the region with regard to student entrepreneurship is needed. The scholarly discussion about entrepreneurship in HEIs has been successful in illuminating HEIs' internal dynamics with regard to entrepreneurship strategies, for example Nelles and Vorley's (2010) concept of "entrepreneurial architecture". However, to the best of our knowledge, it has to lesser extent assessed how the region influences HEIs' strategies for student entrepreneurship, even though the surrounding environment is identified as one of the key factors in HEIs' move towards an entrepreneurial turn (Foss \& Gibson, 2015). The dynamic interaction between HEIs and regional context, or how HEIs are embedded in regional contexts (Hess, 2004), therefore needs to be further unpacked. Thus, the main contribution of this chapter is to illustrate with empirical examples how the embeddedness of HEIs in a regional context influences strategies for student entrepreneurship. We do this by qualitatively exploring student entrepreneurship activities at three different HEIs in the Bergen region in Western Norway. Our research question is this: What are the main strategies and activities for student entrepreneurship in HEIs in the Bergen region in Western Norway, and how have they been influenced by the dynamic interaction between the HEIs and the regional context?

\section{Theoretical discussion}

\section{HEIs and regional embeddedness}

With increased focus on entrepreneurship in HEIs, the term "entrepreneurial turn" has been introduced by Foss and Gibson (2015) to identify the transition that leads HEIs to pursue a "third mission" beyond their core missions of education (first mission) and research (second mission). Different studies have scrutinized variation in how HEIs organize their entrepreneurial turn. 
Trippl et al. (2015) distinguish between a "soft" and a "hard" entrepreneurship model in HEIs. ${ }^{2}$ A lot of the literature on HEIs are oriented towards hard activities, such as spin-offs, patents, and licensing, leading to an understanding of entrepreneurship as commercialization of research (Philpott et al., 2011). In this regard, a hard understanding of student entrepreneurship would imply an orientation towards business idea development, student incubation, and new venture formation. On the contrary, a "soft" model links entrepreneurship to HEIs role in the regional innovation system (RIS) and includes a broader set of initiatives such as cooperation, networking, and learning between actors in HEIs and actors in the knowledge-exploiting production system (Trippl et al., 2015). A soft understanding of student entrepreneurship would include the activities and initiatives encompassed in the hard model but would also go beyond and include initiatives and activities designed to enhance student's innovation and networking capabilities in order to make them more capable to contribute to innovation and entrepreneurship activities in their future career choice. This includes for example students doing innovation projects for regional firms and organizations (e.g., "intrapreneurship"), writing innovation and entrepreneurship-oriented bachelor thesis, and engaging in practice courses and work placement doing innovation projects in firms. In addition, by bringing in the regional dimension in the soft entrepreneurship model, the discussion about HEIs and entrepreneurship is nuanced in several ways. While the hard model assumes that the regional dimension is of no importance in HEIs' entrepreneurial turn, the soft model puts the nexus between HEI and its surroundings in focus and argues that this is of importance in discussions about HEI and entrepreneurship (Arbo, 2019).

The relationship between HEIs and its surroundings has already been explored in several studies, though most have focused on how HEIs contribute to regional development (see, e.g., Arbo, 2019; Karlsen, 2019). Arguing for a dynamically interacting relationship between HEIs and the region, conceived here as composed of regional actors and industry compositions, public support structures, and so on, we find that the literature on embeddedness is of great relevance (Granovetter, 1985; Hess, 2004; Jakobsen et al., 2009; Polanyi, 1968). The origin of the term can be traced back to the seminal writings of Karl Polanyi (1968), who argued that economic practice is deeply integrated with non-economic social and cultural practices and institutions. It has later been "scaled down", for example, starting with the work of Granovetter (1985), who focused on how the (economic) practices of actors should rather be seen as embedded in networks of social relations. In short, embeddedness therefore refers to a non-atomistic view of actors and how they relate to the context in which they find themselves in. Rather than subscribing to viewing actors as rational, mechanistic, and predictable, for example, regarding economic life, the embeddedness perspective argues for seeing such actors as being affected by common culture and institutions, which includes regulative, normative, and cognitive pillars (Scott, 1995). Therefore, an embedded view on actors rejects universal and predictable (economic) action and, instead, posits that context 
heavily affects (but does not determine) how actors will and should act in a given context. Still, this context must constantly be reproduced by embedded actors, ${ }^{3}$ rather than always existing "out there" (Giddens, 1984).

The starting point for our analysis is to understand HEIs as organizations embedded in various ways in the region where they are located and the regional context in which HEIs operate is important for students engaging in entrepreneurship (Åstebro et al., 2012). It is, however, important to acknowledge that, in addition, HEIs are also embedded in other institutional contexts at the national (regulative framework, domestic landscape, and so on) and global level. We therefore understand "regional embeddedness" as the ability for a focal HEI to draw on regional dynamics (Dicken \& Thift, 1992; Jakobsen et al., 2009). As said, several authors have already in various ways engaged with mapping the dynamic interplay between regionally embedded firms/industries and HEIs (see, e.g., Asheim et al., 2011; Benneworth et al., 2017; Karlsen, 2019). Moreover, entrepreneurship research has in recent years also become increasingly concerned with the role played by embeddedness and context (e.g., Høvig, 2018; Zahra et al., 2014). This positioning further implies that student entrepreneurship strategies and activities do not emerge and circulate in a vacuum, but rather that they are enmeshed in regional industrial structures and needs, as well as, importantly, a regional culture for entrepreneurship per se.

However, while this study focuses on the spatial embeddedness of student entrepreneurship strategies and activities at regional HEIs, there is no a priori spatial scale of analysis in the concept of embeddedness (Hess, 2004). As such, in responding to regional contexts HEIs also need to take into account other context as well, which may create tensions and trade-offs (Hüther \& Krücken, 2016). We therefore argue that embedded student entrepreneurship strategies and activities at regional HEIs should be explored further and that regional HEIs potentially should also be seen as being embedded in various extra-regional networks (Jakobsen et al., 2009; Hess, 2004). HEIs are often embedded in complex and dynamic networks spanning several geographical scales but where some networks are dominant over others (see Hess, 2004; see also Fløysand \& Jakobsen, 2011). Some HEIs have a dominant focus on engaging in regional networks, while others have a focus on engaging in global networks. This feature is, partly, a result of policy. Norway has established a binary system of universities (more nationally and globally oriented) and universities colleges (more regionally embedded) (see Normann \& Pinheiro, 2019). This system has convergence towards a unitary (university-based) model in recent years. Thus, while all the case HEIs have a common territorial embeddedness, we argue that their geographies of student entrepreneurship activities and strategies differ; for example, that both regional and extra-regional networks are of importance.

\section{Empirical context, research design, and methodology}

We explore how the embeddedness of HEIs in a regional context influences strategies for student entrepreneurship through a qualitative case study set in 
the Bergen area in Vestland county in Norway (hereafter referred to as "the region"). With approximately 285,000 inhabitants (Statistics Norway, 2020), this region makes up the second largest urban area in Norway. The region hosts several strong and dynamic industries (e.g., oil and gas, marine and maritime industries, media and culture industries, as well as tourism and finance). Several of these industries are organized in industrial clusters through the national cluster development programme, which encourages and stimulates collaborative partnerships between firms, R\&D organizations, and public organizations (Njøs, 2018).

The city of Bergen hosts several HEIs and is a "student city" with more than 30,000 students. The most prominent HEIs are the University of Bergen (UiB), the Western Norway University of Applied Sciences, (HVL) and the Norwegian School of Economics (NHH). These three HEIs make up the empirical cases for this chapter. UiB (est. 1946) is an internationally recognized university with strong research traditions, which is also the most cited university in Norway (Times Higher Education, 2021). In 2019, UiB enrolled 18,000 students, with a high proportion of them graduating at the master's level. $\mathrm{UiB}$ teaches and conducts research within a wide range of disciplines within the natural and social sciences, as well as the humanities, and displays excellence within areas such as marine research, research on climate and energy transformation, as well as research on global challenges. UiB displays a strong international orientation and has become the main hub for the United Nation's sustainability development goal number 14, engaging with "life below water". HVL (est. 1994/2017) is a university college with a professional and working life-oriented profile. HVL is the result of a recent merger (2017) between three regional university colleges in Western Norway. Today, HVL is one of the largest HEIs in Norway with around 16,000 students (8,000 students in the Bergen region) and 3,000 annual graduates. Like most university colleges in Norway, HVL has a long tradition of educating candidates tailored for the regional industries, public service provision, and community life. A high proportion of the students are enrolled in 3-year bachelor programmes, studying to obtain professional competence in order to work as teachers, nurses, and engineers in the regional economy. In later years HVL has strengthened its research activities as part of its strategy of becoming a university with a professional and working life-oriented profile. NHH (est. 1936) is a business school hosting around 3,400 students. NHH engages in teaching and research within several academic fields relating to economics and business administration. $\mathrm{NHH}$ represents international research excellence and has also a strong national role and is often depicted as the first choice for students who want to study business administration in Norway.

Since the turn of the millennium, all three HEIs have become increasingly concerned with third-mission activities such as entrepreneurship. This has happened in parallel with an increased interest in society at large as well as changes in national intellectual ownership laws concerning employees at HEIs (2004). In the Bergen region these events have led to the establishment of the 
technological transfer office (TTO) VIS (2004), which aims to commercialize research-based discoveries on behalf of its HEIs' owners. In addition, several incubators for start-ups have emerged in Bergen during the last decade, both within the boundaries of several of the clusters (e.g., media, finance technology, seafood) and outside of them (e.g., Impact HUB and StartupLab). Additionally, and more recently, attention towards student entrepreneurship has increased in the Bergen region. This may also be seen as part on a more general interest in student entrepreneurship in higher education at large in Norway, expressed for example in the establishment of the Research Council's STUD-ENT funding scheme for student entrepreneurs (Norwegian Research Council, 2018). Student entrepreneurship has also become an important strategy within several HEIs. This has been prominent in all three HEIs in our study, but with considerable variations with regard to organization and degree of regional embeddedness in their entrepreneurial efforts. In the following section, we describe and analyse HEIs' student entrepreneurship efforts and their regional interaction.

Data on this have been based on several sources. We have conducted document analysis of the different HEIs' strategy documents (HVL, 2019; NHH, 2018; UiB, 2019a), as well as analysis of HEIs' course offerings and extracurricular entrepreneurship activities. Before analysing, we conducted and supplemented our analysis with semi-structured interviews with three key informants at the case HEIs. We specifically targeted employees at the HEIs which hold leading positions in developing the HEIs' student entrepreneurship activities. During the interviews, our specific intent was to scrutinize existing courses and extracurricular activities at the case HEIs, its extent and scope, as well as which networks, partnerships, and geographies were of importance in developing student entrepreneurship strategies and activities in the HEIs. The interviews were recorded and subsequently transcribed. All data were collected and analysed in spring 2020. Finally, but importantly, the authors have several years of experience with developing and direct involvement with student entrepreneurship work in the region, as well as insights in other HEIs' engagement in this matter through several collaborative efforts and meetings with these organizations. Thus, we also base our findings on our professional experience and informal conversations with various stakeholders within the case HEIs. This brings some methodological considerations around potential personal biases and internal validity. Efforts were made to reduce such pitfalls by having all three researchers contributing to analyses and interpretation of the data, checking for consistency, as well as looking for other sources of data that support personal interpretations.

\section{Empirical findings}

\section{Strategies and organization for entrepreneurship}

Starting with HVL, we find that its overarching strategy for the period 20192023, titled "Interaction, sustainability, innovation" (HVL, 2019), emphasizes 
entrepreneurship competence as important for its students. The strategy states that HVL "shall train and educate highly competent candidates. The students shall be equipped to become responsible driving forces for innovation and sustainability" (ibid., p. 6). We also find that social dialogue and interaction in both teaching and research activities, a common hallmark for university colleges in Norway, are highlighted as important in developing innovation and entrepreneurship activities. The strategy states that " $R E D$ and innovation [shall be conducted] in interaction with society, with good student involvement" (ibid., p. 7) and that "[t]he principles of responsible innovation shall also govern our dialogue with society and our efforts to improve our own operations and programmes" (ibid., p. 7) and "HVL's professional and working life-oriented profile shall govern the knowledge and expertise we will develop" (ibid., p. 6).

Turning to NHH, we find that the HEI in its overarching strategy for 20182021 "We educate leaders of the future" (NHH, 2018) states that "NHH shall be a driving force for development in business and society, and shall educate people for the purposes of value creation and sustainable development" (ibid., p. 3). We find explicit reference neither to student entrepreneurship nor to student innovation in the strategy. Neither does the HEI allocate specific resources to student entrepreneurship work.

For UiB, in its overarching strategy for 2019-2023 titled "Knowledge that shapes society" (UiB, 2019a), it states that the institution will "[i]n collaboration with society [. . .] enable students and staff to contribute to new processes, products and technology" (ibid., p. 25). This will be approached by "strengthening study programmes within student innovation and entrepreneurship" to "further develop the technology transfer office VIS" and "to establish a "proof of concept' programme for early phase innovation projects" (ibid., p. 25). Social dialogue and interaction on all geographical levels are emphasized, as the strategy states that "[t]hrough local, national and global interaction with our partners in academia, industry and society, we will make knowledge based contributions to the decisions that shape our societies" (ibid., p. 8). These strategies are further concretized through an action plan for innovation and entrepreneurship (HVL, 2019b), which both state the HEIs' aim to "include knowledge of innovation and entrepreneurship in all relevant courses" (ibid., p. 4), "develop more elective, cross-disciplinary innovation and entrepreneurship courses" (ibid., p. 4), and "facilitate for a summer course and investigate the development of a cross-disciplinary entrepreneurship school" (ibid., p. 4). We find that UiB link these activities to "UiB's focus areas or UN's development goals" (UiB, 2019b, p. 4).

\section{Entrepreneurship courses and extracurricular activities}

HVL offers innovation and entrepreneurship courses at undergraduate, graduate, and doctoral levels. These are courses that are largely developed and taught by academic staff. At the undergraduate level, HVL offers the course "Technology Management, Business Administration and Innovation". This course is mandatory and subject-specific for engineers, and similar bachelor's courses that are subject-specific for the educational groups can be found in public health 
studies, social studies, and occupational therapy. HVL students, in particular at the Faculty of Engineering and Science, also have the tradition of writing bachelor thesis for regional firms, focusing on solving issues that are of importance for the regional actors. HVL also has two specific master programmes: "Innovation and Entrepreneurship" (students with engineering background) and "Innovation and Management" (business administration). Both programmes challenge students from both a theoretical and practical perspective, for example, through practice courses where students work with real-life challenges provided by regional actors. In addition, since 2020, HVL has also provided a doctoral programme in "Responsible Innovation and Regional Development", which aims to stimulate research that investigates how innovation can meet social, economic, and environmental challenges in a regional context. In terms of extracurricular activities, HVL has developed and implemented a student entrepreneurship programme "HVL Skape" (est. 2015, renamed in 2019), which is a campuswide initiative aiming to enhance entrepreneurial culture among students. Several entrepreneurship-related events are organized, like idea competitions, seminars, and mentoring services. HVL has since 2015 held a campus-wide idea competition ("HVL Idea championship"), where students are challenged to develop innovations based on regional-specific challenges provided by central case providers from the region. These efforts are supported by a Bergenbased student incubator ("Fabrikken", one FTE staff, established in 2017) to which a number of academic staff contribute.

Turning to $\mathrm{NHH}$, we find that it has a long tradition of providing entrepreneurship courses to its students, and entrepreneurship is implemented in a range of different educational programmes and courses at the HEI. NHH has, since the early 2000s, offered the bachelor course "From idea to business" which aims to give students an introduction to how ideas and opportunities can be developed into solutions with value for users. The course has been a mandatory course for students admitted to the "Norwegian School of Entrepreneurship" ("Gründerskolen"), which is an academic programme offering students entrepreneurship experience by working as interns within high-tech start-ups overseas. ${ }^{4} \mathrm{NHH}$ has also developed a specific major profile in "New Business Development" as part of the 2-year master programme in economics and business administration. The programme draws on NHH's expertise on commercialization, finance, financial management, international business, strategy, human resources, and economics and gives students opportunity to study entrepreneurship from both a theoretical and practical perspective. $\mathrm{NHH}$ also provides other courses related to entrepreneurship, such as courses on venture capital and service design. A common hallmark of entrepreneurshiprelated courses offered at $\mathrm{NHH}$ is that they are focused on the business side of entrepreneurship, such as commercialization processes, strategy, and financial management of start-ups. This corresponds to what one informant described as the practice of $\mathrm{NHH}$ students joining start-ups as business experts instead of being the inventor or founder of the business idea. "Few startups are founded 
by NHH students, but few start-ups are successful without an NHH student on their team," the informant states.

In terms of extracurricular activities, $\mathrm{NHH}$, and in contrast to HVL, does not provide any specific extracurricular entrepreneurship activities to its students or resources to this task. Instead, NHH has a long tradition of giving students responsibility and ownership for extracurricular activities, for example, through Start NHH, a student organization for and by students interested in entrepreneurship. Start NHH engages in different entrepreneurship-related activities such as the annual Venture Cup, a national business plan competition for both master-and bachelor-level students. To some extent, the wider academic community are involved in student-led activities, but this involvement is ad hoc in nature and does not represent a long-term priority or commitment. As one informant states: "The domain [of student entrepreneurship] lacks resources at our institution, it is based on voluntary work."

$\mathrm{UiB}$ has developed and implemented two entrepreneurship courses at the undergraduate level ("Sustainable Innovation" and "Introduction to Innovation and Entrepreneurship in Media City Bergen"), introducing students to methods for innovation, creative processes, and interdisciplinary collaboration through case-based learning. An entrepreneurship course titled "Innovation and Entrepreneurship" has, since 2020, been implemented at the Faculty of Medicine, which aims to "inspire and equip the attendees (medical students) with enough skills and knowledge to broadly know how to commercialize their future research output in academia and in the clinic". A common trait of the entrepreneurship courses at $\mathrm{UiB}$ is that they are generic in nature, introducing students to innovation methodologies and creative processes. Another hallmark is that the teaching is undertaken by external actors and industry experts, with the wider academic community involved to a lesser degree. Administrative staff is key in the development and implementation of relevant courses, as well as giving lectures. This may be because the institution has less internal resources and innovation and entrepreneurship competences to draw upon in their wider academic community. Currently (2020), in terms of internal resources, the organization has allocated approximately one man-year (administrative resource) for managing its innovation activities, linked to the Division of Research and Innovation. Due to the challenge of engaging its various academic communities, UiB has chosen a model where it collaborates via external resources, such as the TTO, in order to do innovation and entrepreneurship activities. This strategy of engaging external resources in this work is also explicitly stated in the action plan (UiB, 2019b). While this strategy has been considered successful in developing the current student entrepreneurship course and activities at the institution in the face of limited resources, it may nevertheless, according to one informant, cause less involvement of the wider academic community in the long run.

In terms of extracurricular student entrepreneurship activities, UiB has launched an on-campus incubator "Innovation Hub" in 2018, which aims to be an arena for informal knowledge exchange and for the development of an entrepreneurial culture at campus, as well as an instrument for mobilizing 
innovative student ideas. The incubator has a sustainability profile, with its activities, such as idea competitions, having an orientation towards finding solutions to societal challenges such as the climate crisis. UiB provides financing and facilities, while the incubator itself is managed and run by students.

\section{Analysis}

\section{Student entrepreneurship programmes and embeddedness}

Our empirical findings given earlier suggest a general push towards student entrepreneurship in all three case HEIs, expressed both in current strategies as in their education activities and extracurricular efforts. However, our findings also suggest that these efforts pan out differently between the HEIs. We find that the case HEIs display considerable variation in terms of geographical orientation in their student entrepreneurship strategies and activities, the resources they draw upon in developing these, and what they consist of. We elaborate on this for each of the case HEIs later.

Starting with HVL, we find that the HEIs have a dominant focus on engaging in regional networks in pursuing student entrepreneurship. This regional embeddedness is expressed in its overarching strategy, referring to "our dialogue with society" (HVL, 2019, p. 7) in the HEIs' efforts to improve programmes, and that "HVL's professional and working life-oriented profile shall govern the knowledge and expertise we will develop" (ibid. p. 6). This is of course not surprising, giving the structure of the Norwegian higher education landscape and the long tradition of university colleges of providing education for regional industries, public service, and community life (Normann \& Pinheiro, 2019). Nevertheless, we find this interweaving between student entrepreneurship strategies and activities and the region to be strong in this case. HVL exhibits close cooperation with regional actors and industry in linking entrepreneurship education to real-life regional cases, thus making entrepreneurial skills broadly relevant among HVL's diverse group of students. The tradition of linking bachelor theses with regional industry actors is a particular telling demonstration of this, which also has led to the emergence of "homegrown" student start-ups, like Bergen Carbon Solutions and Its learning. A regional orientation is also present in extracurricular student entrepreneurship activities, which is exemplified by regional stakeholders providing real-life cases for students to work with in various entrepreneurship practice courses and when student idea competitions are organized to challenge students to develop novel and innovative solutions to region-specific challenges. Thus, HVL "provides" the region with student entrepreneurs but also, and not least, candidates who can solve regional firmor industry-specific challenges for, and together with, regional stakeholders both short-term through, for example, bachelor theses and long-term through graduates finding employment in the regional economy after graduation. ${ }^{5}$ As such, one can argue that HVL employs a "soft" student entrepreneurship model (Trippl et al., 2015) aiming not only to commercialize research through 
student ventures but also to provide students with innovation capabilities in order to improve the RIS itself. An important prerequisite in this regard is the HEIs embeddedness in regional networks, both connected to public support infrastructure (like local government) and the other industrial clusters. Tellingly, these relationships are reciprocal, providing "direction" for student entrepreneurship strategies, activities, and practices, but also provide financial means (and other resources) to run the student entrepreneurship programme.

Turning to $\mathrm{NHH}$, we find that regional network is of lesser importance in influencing and being influenced by the HEIs' student entrepreneurship efforts than the case of HVL. In line with the embeddedness literature (Hess, 2004; Jakobsen et al., 2009; Fløysand \& Jakobsen, 2011), we find that extraregional networks, in particular on a national scale, are dominant over others. Overarching, we find a national orientation expressed through the HEIs aim of graduating students for the national economy and the practice of depicting the school as the first choice for students who want to study business administration in Norway. The interweaving between extra-regional networks, such as national networks, and student entrepreneurship strategies and activities is strong. Graduates often find jobs in large national companies, rather than starting own regional businesses and start-ups based on own innovations. Thus, the output of NHH's student entrepreneurship strategies and activities is not primarily about stimulating entrepreneurship activity in the region but rather equipping graduates with entrepreneurship competence that they can bring into the national business arena. This is also reflected in the fact that students from the HEI rarely were start-up founders but often become "joiners" in other student's start-ups where they contribute to the business side of the projects. This often strengthens the start-up teams and increases their chances of being successful. That student entrepreneurship can also be about stimulating students to join start-up teams, however, is also an important point in this regard. As such, we find elements of both a "hard" entrepreneurship model focusing on commercialization and new venture formation and also a "soft" model where graduates have acquired competence which may improve the innovation capabilities of actors in the RIS.

Finally, turning to $\mathrm{UiB}$, we find that the strategy gives the HEI mandate on local, national, and international levels (UiB, 2019a, p. 8), but that extraregional networks are most prominent in the HEIs' entrepreneurial development (see, again, Hess, 2004; Jakobsen et al., 2009 for a discussion on extra-regional embeddedness). In particular, we find that UiB embeds student entrepreneurship efforts in international and national networks. This is not surprising, given UiB's long tradition of being a strong research university with international networks. Tellingly, the HEIs' student entrepreneurship efforts are often embedded in these networks, expressed for example through the entrepreneurship course "Sustainability Innovation", which are part of European research collaboration partnerships where students work together with peers across Europe. Global and international issues, such as efforts to find solutions to "grand societal challenges" and sustainability issues, rank high on the agenda, 
Table 7.1 HEIs' entrepreneurship activities, strategies, and embeddedness

\begin{tabular}{|c|c|c|c|}
\hline$H E I$ & $H V L$ & $\mathrm{NHH}$ & $U i B$ \\
\hline Activities & $\begin{array}{l}\text { - Entrepreneurship } \\
\text { courses, practice } \\
\text { courses, bachelor } \\
\text { theses, idea } \\
\text { competitions with } \\
\text { regional challenges } \\
\text { - Both courses and } \\
\text { extracurricular } \\
\text { activities developed } \\
\text { and run by } \\
\text { professional staff. }\end{array}$ & $\begin{array}{l}\text { - Entrepreneurship } \\
\text { courses, practice } \\
\text { courses } \\
\text { - Courses } \\
\text { developed and run } \\
\text { by professional } \\
\text { staff. } \\
\text { - Extracurricular } \\
\text { activities } \\
\text { developed and run } \\
\text { by students. }\end{array}$ & $\begin{array}{l}\text { - Technology transfer, } \\
\text { commercialization } \\
\text { of student ideas, } \\
\text { entrepreneurship } \\
\text { courses } \\
\text { - Both courses and } \\
\text { extracurricular } \\
\text { activities developed } \\
\text { and run by } \\
\text { administrative } \\
\text { staff or external } \\
\text { resources (TTO). }\end{array}$ \\
\hline $\begin{array}{l}\text { Entrepreneurship } \\
\text { model/strategy }\end{array}$ & $\begin{array}{l}\text { Soft: Enhancing } \\
\text { innovation } \\
\text { capabilities }\end{array}$ & $\begin{array}{l}\text { Soft/hard: } \\
\text { Promoting a } \\
\text { joiner strategy }\end{array}$ & $\begin{array}{l}\text { Hard: } \\
\text { Commercializing } \\
\text { research }\end{array}$ \\
\hline $\begin{array}{l}\text { Embeddedness } \\
\text { and } \\
\text { geographical } \\
\text { orientation }\end{array}$ & $\begin{array}{l}\text { Regional: solving } \\
\text { tasks for regional } \\
\text { stakeholders (and } \\
\text { help nurturing the } \\
\text { regional innovation } \\
\text { systems) }\end{array}$ & $\begin{array}{l}\text { National: servicing } \\
\text { national big firms } \\
\text { (and supporting } \\
\text { national } \\
\text { innovation } \\
\text { systems) }\end{array}$ & $\begin{array}{l}\text { International: solving } \\
\text { grand challenges }\end{array}$ \\
\hline
\end{tabular}

both within the entrepreneurship courses and with regard to extracurricular activities in the student incubator "Innovation Hub". Thus, UiB orients its strategies and activities towards issues "outside" of the region and do not seem to benefit significantly from regional networks or resources with regard to their student entrepreneurship activities but rather draws upon international resources in their efforts. In terms of entrepreneurship model, we find elements of a "hard" entrepreneurship model (Trippl et al., 2015) present in this case HEI, which could be seen as a result for the tradition of involving the TTO in student entrepreneurship activities instead of engaging the wider in-house academic community but also in light of UiBs national and global mandate and more classic orientation on science.

To sum up, our findings show that the case HEIs embed their student entrepreneurship efforts in networks on different geographical scales: HVL on a regional scale, $\mathrm{NHH}$ on a national scale, and $\mathrm{UiB}$ on an international scale. While, of course, all the HEIs and their student entrepreneurship strategies and activities are embedded in regional, national, and international networks, we argue - and in line with literature - that some geographical scales or networks are dominant over others (Hess, 2004; Jakobsen et al., 2009; Fløysand \& Jakobsen, 2011). Moreover, the HEIs show a broad spectrum of student entrepreneurship models, ranging from "hard" (commercialization of research in $\mathrm{UiB}$ ), to "hybrid" (joiner mentality in $\mathrm{NHH}$ ), to "soft" (enhance innovation capabilities in HVL) approaches. 


\section{Concluding remarks: complementarity and regional re-orientation through Bergen Entrepreneurship Academy?}

The main contribution of this chapter has been to illustrate with empirical examples how the embeddedness of HEIs in a regional context influences strategies for student entrepreneurship. By qualitatively exploring student entrepreneurship activities at three different HEIs in the Bergen region in Western Norway, we find that the HEIs embed their student entrepreneurship efforts in different network, spanning several geographical scales, but where some networks are dominant over others. Thus, our claim is that regional geographical presence per se does not automatically ensure a shared regional embeddedness or a shared culture around stimulating regional industrial development through student entrepreneurship strategies or activities, aligned with regional support structures, networks, or resources. Moreover, it does not ensure crossinstitutional alignment across HEIs, for example, cooperation or knowledge exchange around themes such as student entrepreneurship. Instead, we suggest that the regional context promotes heterogeneous strategy for student entrepreneurship. This observed variation in embeddedness is perhaps unsurprising, given the structure of the higher education landscape in Norway and the binary system of nationally and globally oriented universities and more regionally oriented university colleges. Still, we contend that the HEIs align their student entrepreneurship strategies and activities with these networks, and as such, it has implications for how student entrepreneurship strategies and activities play out in the region.

However, the picture is not static, and we observe some convergence between the HEIs in terms of strategies and ambitions. For example, HVL has ambitions to become a university with a professional and working life-oriented profile in 2023 (HVL, 2019) while UiB currently seeks a stronger regional reorientation, expressed in more active involvement in regional partnerships such as industrial cluster programmes. Following our argument, one would expect that student entrepreneurship efforts would align with new networks and constellations. Therefore, it is telling that recently (2020), the three focal HEIs have decided to join forces in creating a common platform for promoting student entrepreneurship education and activities in the region. This initiative is called "Bergen Entrepreneurship Academy" (BEA) and aims to facilitate for interdisciplinary student entrepreneurship activities across the three HEIs, as well as fostering collaboration with the region through industry clusters, innovation hubs, and alumni networks. As the BEA initiative shows, the three HEIs can potentially be complementary in a stronger regional ecosystem for student entrepreneurship. This can entail mixing the HEIs' various models (hard and soft) with regard to student entrepreneurship in the BEA initiative but also - and simultaneously - activating the HEIs' various student entrepreneurship networks that span different geographical scales. Whether or not this will be become a regional success, however, remains an empirical question. 


\section{Notes}

1 For example, in Norway, NTNU and Nord University are given a national mandate through their Centre of Excellence in Education (Engage) to disseminate results and best practice in entrepreneurship education and extracurricular activities in entrepreneurship.

2 Being ideal types, we believe that real-life examples of student entrepreneurship models in HEIs would consist of elements of both soft and hard entrepreneurship models (e.g., "hybrid" models).

3 As engaging with student entrepreneurship in the case HEIs is a relatively new endeavour, this implies that the actions of key individuals and networks have been important in shaping the strategies and programmes for student entrepreneurship. Thus, questions of "agency" or "institutional entrepreneurship" (Battilana et al., 2009) - for example, studying how purposeful actors ultimately create new institutions which favour student entrepreneurship in HEIs - would be of interest when studying how strategies for student entrepreneurship are being created and carried out in practice in regional HEIs.

4 The programme is an academic cooperation programme involving most HEIs in Norway and is administered by the University of Oslo.

5 A survey conducted in 2018 shows that around three out of four HVL students come from the region, and a corresponding proportion finds a job in the region after completing their education. Correspondingly, only $16 \%$ of $\mathrm{NHH}$ students stay in the region after their studies, and more than half of them take a job in Oslo (Høgestøl \& Bjørnebekk, 2018).

\section{References}

Arbo, P. (2019). Universitet og region - en sammensatt relasjon. In J. P. Knudsen \& T. Lauvdal (Ed.), Geografi, kunnskap, vitenskap. Den regionale UH-sektorens framvekst og betydning (pp. 99-130). Oslo: Cappelen Damm Akademisk.

Asheim, B. T., Smith, H. L., \& Oughton, C. (2011). Regional innovation systems: Theory, empirics and policy. Regional Studies, 45(7), 875-891.

Åstebro, T., Bazzazian, N., \& Braguinsky, S. (2012). Startups by recent university graduates and their faculty: Implications for university entrepreneurship policy. Research Policy, 41(4), 663-677.

Battilana, J. Leca, B., \& Boxenbaum, E. (2009). How actors change institutions: Towards a theory of institutional entrepreneurship. The Academy of Management Annals, 3(1), 65-107.

Benneworth, P., Pinheiro, R., \& Karlsen, J. (2017). Strategic agency and institutional change: Investigating the role of universities in regional innovation systems (RISs). Regional Studies, 51(2), 235-248.

Bergmann, H., Hundt, C., \& Sternberg, R. (2016). What makes student entrepreneurs? On the relevance (and irrelevance) of the university and the regional context for student start-ups. Small Business Economics, 47, 53-76.

Dicken, P., \& Thift, N. (1992). The organization of production and the production of organization: Why business enterprises matter in the study of geographical industrialization. Transactions of the Institute of British Geographers, 17(3), 279-291.

Fløysand, A., \& Jakobsen, S-E. (2011). The complexity of innovation: A relational turn. Progress in Human Geography, 35(3), 328-344.

Foss, L., \& Gibson (Eds.). (2015). The entrepreneurial university. Context and institutional change. Routledge studies in Innovation, Organization and Technology. London: Routledge.

Giddens, A. (1984). The constitution of society: Outline of the theory of structuration. Berkeley and Los Angeles: University of California Press. 
Granovetter, M. (1985). Economic action and social structure: The problem of embeddedness. The American Journal of Sociology, 91(3), 487-510.

Hess, M. (2004). "Spatial” relationships? Towards a reconceptualization of embeddedness. Progress in Human Geography, 28(2), 165-186.

Høgestøl, A., \& Bjørnebekk, A. (2018). Kandidatundersøkelsen 2018 - Fra studier til jobb på Vestlandet. Ideas2evidece-rapport 08:2018

Høvig, Ø. S. (2018). Entrepreneurship facilitation practices in various contexts: Generic characteristics and contextual particularities (PhD thesis). University of Bergen.

Hüther, O., \& Krücken, G. (2016). Nested organizational fields: Isomorphism and differentiation among European universities. In E. Berman \& C. Paradeise (Eds.), The university under pressure (pp. 55-83). Bingley: Emerald Group Publishing Limited.

Jakobsen, S-E., Gammelsæter, H., \& Fløysand, A. (2009). The spatial embeddedness of professional football clubs in Norway. Soccer \& Society, 10(2), 261-279.

Karlsen, J. (2019). En diskusjon om universitetets tredje rolle. In J. P. Knudsen \& T. Lauvdal (Eds.), Geografi, kunnskap, vitenskap. Den regionale UH-sektorens framvekst og betydning (pp. 195-217). Oslo: Cappelen Damm Akademisk.

Nelles, J., \& Vorley, T. (2010). Constructing an entrepreneirual architecture: An emergent framework for studying contemporary university beyond the entrepreneurial turn. Innovative Higher Education, 35(3), 161-176

$\mathrm{Njøs,} \mathrm{R.} \mathrm{(2018).} \mathrm{The} \mathrm{role} \mathrm{of} \mathrm{multilevel} \mathrm{dynamics} \mathrm{and} \mathrm{agency} \mathrm{in} \mathrm{regional} \mathrm{industry} \mathrm{renewal} \mathrm{(PhD}$ thesis). University of Bergen.

Normann, R., \& Pinheiro, R. (2019). Den tredje rollen: Fra distriktshøgskole til universitet. In J. P. Knudsen \& T. Lauvdal (Eds.), Geografi, kunnskap, vitenskap. Den regionale UHsektorens framvekst og betydning (s. 155-175). Oslo: Cappelen Damm Akademisk.

Norwegian Research Council. (2018). Programrapport 2018 - Forskningsbasert nyskaping/ FORNY 2020. Norwegian Research Council.

Norwegian School of Economics. (2018). We educate leaders for the future. NHH Strategy 2018-2021. Norwegian School of Economics.

Philpott, K., Dooley, L., O’Reily, C., \& Lupton, G. (2011). The entrepreneurial university: Examining the underlying academic tensions. Technovation, 31(4), 161-170.

Polanyi, K. (1968). The economy as instituted process. In E. LeClair \& H. Schneider (Eds.), Economic anthropology. New York: Holt, Rinehart and Winston.

Scott, W. R. (1995). Institutions and organizations. Thousand Oaks, CA: Sage.

Statistics Norway. (2020). Population, Norway. www.ssb.no/kommunefakta/bergen

Times Higher Education. (2021). Times Higher Education world university rankings 2021.

Trippl, M., Sinozic, T., \& Smith, H. L. (2015). The role of universities in regional development: Conceptual models and policy institutions in the UK, Sweden and Austria. European Planning Studies, 23(9), 1722-1740.

University of Bergen. (2019a). Knowledge that shapes society. Ocean, Life, Society/Strategy 2019-2022. Bergen, Norway: University of Bergen.

University of Bergen. (2019b). Handlingsplan for innovasjon og entreprenørskap for Universitetet $i$ Bergen 2019-2022. Bergen, Norway: University of Bergen.

Uyarra, E. (2010). Conceptualizing the regional roles of universities, implications and contradictions. European Planning Studies, 18(8), 1227-1246.

Western Norway University of Applied Sciences. (2019). Interaction, sustainability, innovation. Strategy 2019-2023. Bergen, Norway: Western Norway University of Applied Sciences.

Zahra, S., Wright, M., \& Abdelgawad, S. (2014). Contextualization and the advancement of entrepreneurship research. International Small Business Journal, 32(5), 479-500. 


\title{
8 Student Incubators in China
}

\author{
The Cases in Shanghai and Wuhan
}

\author{
Dian Liu
}

\begin{abstract}
This chapter focuses on the impact of environmental contextual characteristics on incubator practice. Environmental contextual characteristics refer to both the organizational character of the host university and the regional features where the university incubator is located, which intertwine and jointly shape the current profile of university incubators. Drawing upon two case studies of incubators in two universities with varying disciplinary strength (science and engineering, and teacher education) in two different cities (Shanghai and Wuhan), this chapter examines management policies and practices of the two student incubators and how such incubator profiles are framed by environmental contextual perspectives. This chapter first demonstrates the entrepreneurship initiative and student entrepreneurship development as background of the generation of university incubators, followed by an introduction to the two cases of university incubators. It then compares the varied incubation policies, structures, and practices in the two cases underpinned by regional characteristics and organizational institutions, supplying empirical evidence for further policy recommendations regarding student incubators and entrepreneurship in China.
\end{abstract}

\section{Introduction}

The construction of student incubators in higher education as the innovation engine is a mirror image of the broad set of government-university-industry interaction in a triple helix context (Etzkowitz, 2002; Etzkowitz \& Leydesdorff, 2000; Etzkowitz \& Zhou, 2017; Mian, 1996). Student incubators at universities worldwide have developed significantly during the past decade, attracting rising number of students and alumni, involving expanding networks from diverse stakeholders, transforming technology and skills into an array of enterprises, and meanwhile relieving the harsh graduate unemployment in the 


\section{Dian Liu}

regional labour market (Etzkowitz, 2003; McAdam et al., 2006; McAdam \& McAdam, 2008; Stal et al., 2016). And China is no exception. To date, almost all higher education institutions in the Chinese context have established diverse forms of incubators to encourage the entrepreneurial activities of both students and staff (such as student incubators, technology parks, entrepreneurial schools, university science, and technology zone), especially after the top-down initiation of "universal innovation and entrepreneurship" in 2014 (State Council, 2015a).

However, despite of the increasing scholarly work on general growth of business incubators and start-ups (Akcomak, 2009), very few empirical studies have been conducted in the Chinese context. There is rising scholarly work in the Chinese literature during recent years ( $\mathrm{Lu} \&$ Etzkowitz, 2008), discussing the theoretical importance of student incubators in alignment with the enhancement of regional innovation level or describing the designing and running of the Chinese student incubators in comparison with incubators in the Western sphere such as the "Stanford-Silicon Valley collaboration" (Cheng et al., 2019; Jongwanich et al., 2014; Kim et al., 2012; Lu, 2008; Matt \& Tang, 2010). Yet little ink has been spilled over the specialties of the student incubators in Chinese universities. Moreover, Chinese incubators do not necessarily employ a unified model. One reason is that economic development in China is rather unbalanced. Developed, coastal regions such as Shanghai can solely contribute a GDP over 10 trillion RMB annually and attract most innovative enterprises and international networks, suggesting rich entrepreneurial activities, business cooperative culture, and behaviour codes as references to incubator practices in the area. However, inland provinces in central and western China endeavour to upgrade their industry to attract more investment and therefore may demonstrate varied regional involvement in incubator activities. Moreover, Chinese higher education highlights itself as a highly hierarchical system (Ying et al., 2017), where top universities are prioritized in terms of financial resources, top-student recruitment, industrial alignment, and alumni networks. This suggests that student incubators in different universities may activate different resources and display diverse models. To date, we know precious little about how the environmental contextual characteristics shape the profile of university incubators, what lessons can be learnt after the top-down government initiative of "universal innovation and entrepreneurship" since 2014, and what timely feedback can be collected to support policy adjustments and incubator preparedness in the future.

This chapter focuses on the impact of environmental contextual characteristics on incubator practice. Environmental contextual characteristics refer to both the organizational character of the host university and the regional features where the university incubator is located, which intertwine and jointly shape the current profile of university incubators. Drawing upon two case studies of incubators in two universities with varying disciplinary strength (science and engineering, and teacher education) in two different cities (Shanghai and Wuhan), this chapter examines management policies and practices of the two 
student incubators and how such incubator profiles are framed by environmental contextual perspectives. This chapter first demonstrates the entrepreneurship initiative and student entrepreneurship development as background of the generation of university incubators, followed by an introduction to the two cases of university incubators. It then compares the varied incubation policies, structures, and practices in the two cases underpinned by regional characteristics and organizational institutions, supplying empirical evidence for further policy recommendations regarding student incubators and entrepreneurship in China.

\section{Entrepreneurship initiation, student entrepreneurship, and university incubators in China: a top-down process}

The knowledge transformation and technology industrialization required in incubation and entrepreneurial activities in the Chinese academic context can be traced back to the 1950s. Even though there were no guideline policies and regulations concerning university-industry collaboration back then, universities would offer technical solutions for industries under request (Zhou, 2008). This is the initial stage of the knowledge and technology transfer in Chinese higher education. From the 1980s, the government has published a series of policies and regulations regarding entrepreneurship in general in the society. Among these, the most cited is the document issued by the State Council: Opinions on Further Efforts Relating to Employment and Entrepreneurship under New Circumstances (State Council, 2015a) (hereafter referred to as Opinions). Measures include building the innovation and entrepreneurship platform at diverse levels (nationally, provincially, and regionally), introducing tax reduction and allowance to entrepreneurs, involving and encouraging more funding and financial sources, to enhance the interpleural service at diverse levels.

Documents targeting knowledge industrialization (or, in some analysis, knowledge or technology commercialization (Wu, 2010)) in higher education have appeared more frequently during the past decade to implement entrepreneurial education in universities and to establish service sectors (known as entrepreneurship and innovation colleges, university incubators, science and technology parks, or innovation centres) to serve the needs of entrepreneurship and innovation activities. Notably, industry was specially targeted by the government from two perspectives. Firstly, it suggests involving experienced entrepreneurs and investors from industry in the entrepreneurial education (such as guest lecturers, presenters, or entrepreneurial tutors). And secondly, the government encourages local societies, companies, organizations, or individuals to contribute to the capital funds or other types of financial support for student entrepreneurs.

The top-down innovation and entrepreneurship initiation in China is driven by two forces - firstly, the need of facilitating the economic transformation from relying heavily on manufacturing to a knowledge-based and innovationled sector. And the university, as a key institution for scientific and technological 


\section{Dian Liu}

achievements, plays a central role in this process. Ever since the Reform and Opening-up from 1978 (Gan \& Zheng, 2009) and the continuous efforts to promote educational and technological innovation, Chinese higher education has gone through significant development in terms of improved research capabilities and academic productivity, with rising expenditures allocated in education and research (Yang et al., 2018). The second driven force is the dramatic growth of the university graduates flowing into the labour market, after the dramatic expansion of Chinese higher education since 1999 (Liu, 2014; Mok, 2016). The number of higher education graduates has risen by $2-5 \%$ annually since 2010, and reached 8.34 million in 2019, leading to heavy burdens in the graduate labour market. To encourage and to facilitate student entrepreneurship has become a necessary choice of relieving the graduate employment pressure (Li et al., 2003; Zhou \& Xu, 2012). Besides emphasizing entrepreneurship in sectors of high technology and innovation, the government also uplifts the entrepreneurship in social service. In 2020, a jointly issued document by seven government departments (including Ministry of Human Resources and Social Security) was published in 2020, namely, Notice on Guiding and Encouraging College Graduates to Work and Start Business in Urban and Rural Communities (Xinhua Net, 2020), which motivates graduates seeking employment or conducting entrepreneurial activities targeting serving household communities.

Under this top-down initiation towards innovation and entrepreneurship, the number of university students involved in or expressing interest in starting up both during and after graduation has increased greatly. A recent report from Renmin University based on a national survey revealed that $26 \%$ of graduates among all surveyed participants would like to be involved in entrepreneurship, while this number was $18 \%$ in 2016 . According to the report, the leading motivation and incentive of the students for becoming involved in entrepreneurship is to seek autonomy and freedom in career and life, followed by economic incentives such as earning money. The number of students who actually started up their own business also rose across the country. The percentage of graduate entrepreneurs has doubled during the past 5 years from 1.6\% in 2011 and remained at around 3\% to date. The report also reveals that graduate entrepreneurship focuses on industrial fields with low thresholds such as accommodation and catering, as well as early-childhood education (private tutoring centres for pre-school children). Despite the increasing economic support at different levels, most graduates received their start-up funding from private networkrelated resources (with 37\% from self-funding, 25\% from partners, and around $10 \%$ from family). Lack of funding remains the biggest challenge for graduates inhibiting starting up immediately. Additionally, the success ratio of student enterprises was rather low. Most of the entrepreneurial activities failed to continue after graduation or after a certain period of graduation (MyCOS, 2015-2019; Renmin University of China, 2019).

Under the requirement of State Council Opinions (State Council, 2015b), student incubators (regardless of varying names such as entrepreneurial park, entrepreneurial valley, innovation park, technology park, university science 
park $^{1}$ ) have been built in almost all higher education campuses, and universities are the main operators of the incubators. Incubators offer service, assisting the transferring and commercialization of research products to students as well as academic faculties. The association between incubation and regional innovation and technological development is confirmed in recent studies. For example, drawing upon a provincial-level panel dataset over the 1997-2009 period together with adopting patents as an indicator of innovative capacity, Jongwanich and colleagues (2014) showed that incubators (science parks) had a significantly positive impact on regional patenting. More importantly, science parks play a key role in coordinating research and development (R\&D) collaboration across various $\mathrm{R} \& \mathrm{D}$ performers within the region and indirectly contribute to upgrading the regional technological ladder.

Student incubators in China are in majority university-owned and operated, where students or graduates within 3-5 years submit applications to the university, and the university selects those with competitive entrepreneurial ideas to be the "incubatees". The successful applicants will then be assisted by the university to fulfil the ideas, consistent with the university arrangement. However, in many cases, student incubators may also have diverse sponsors including government sectors, companies, investors, and other social groups. For example, the municipal government in Wuhan in 2013 established the first 25 incubators covering 4,000 square metres, targeting student entrepreneurship. Successful student applicants can use the facilities for up to 2 years without rent, meanwhile receiving a starting capital of 5,000-20,000 Yuan. Optics Valley Startup Café was established in 2013 in Wuhan by a group of experienced and successful entrepreneurs, aiming at building a hybrid platform and offering incubation and training for university students. The non-university-owned incubators, especially technology incubators, are always in close connection with universities. They regard universities as the source of new technology and actively seek collaboration and endeavour to facilitate knowledge commercialization. The positive consequence of industry-academy cooperation (Guimón, 2013) is supported by research. Chen et al. (2016) examined the influence of cooperation on high-tech firms. On the basis of an investigation of 552 high-tech firms and 56 universities, they found that the high-tech firms can improve the economic situation via cooperation with universities on the platform. Moreover, principal discoveries demonstrate that the economic performance of high-tech firms is positively related to the cooperation projects.

\section{Method: field sites, cases, and participants}

This study is part of the ongoing research on university student entrepreneurship in China, and the chapter presents case studies of two on-campus student incubators conducted in 2018: student incubator of University-S (U-S) at Shanghai (hereafter referred to as U-S incubator) and student incubator of University-W (U-W) at Wuhan (hereafter referred to as U-W incubator). Both $\mathrm{U}-\mathrm{S}$ and $\mathrm{U}-\mathrm{W}$ are top-tier universities in Chinese higher education, which are 
included in either the 985 project $^{2}$ or the 211 project. ${ }^{3}$ They both are under the direct administration of Ministry of Education and receive a large amount of funds annually for research, innovation, and, more recently, entrepreneurship activities. U-S is traditionally strong in science and engineering, while $U-W$ is strong in social science disciplines.

The activities of the two incubators also benefit from the geographic locations: Shanghai and Wuhan. The former city, Shanghai, is recognized as an international centre for finance and innovation (The Global Financial Centres Index 26, 2019). It is also home of the Shanghai Stock Exchange and the Shanghai Free-Trade Zone. The population of Shanghai reached 24.2 million in 2019, and it is the most populous urban area in China. The six largest industries of the city, namely IT, finance, commercial circulation, automotive manufacturing, equipment manufacturing, and real estate, contribute to half the city's GDP (Shanghai Municipal Statistics Bureau, 2014). There are 64 higher education institutions in Shanghai as of 2019 with a higher education population of over half a million, including four 985 project universities. The latter city, Wuhan, is the most populous city in Central China, with over 11 million residents. For decades, the city has been a hub for traditional manufacturing and enterprises for industrial modernization. To date, Wuhan has 3 national development zones, 4 scientific and technological development parks, over 350 research institutes, and 1,656 high-tech enterprises. There are 89 higher education institutions in the city (including two 985 project universities and seven 211 project universities), with a higher education student population of over 1 million.

This study adopts a qualitative case study approach to conduct the investigation of the student incubators, and the incubator (organization) constitutes the level of analysis. In the case studies, visit to the incubators, observation, and documentation were conducted to better understand the entrepreneurial context as well as the activities taking place in the incubators. Additionally, interviews were conducted with both the incubator administrative staff (two at each) and student entrepreneurs (representatives from 10 different teams at each incubator) whose team was selected to reside in the incubators. Questions were asked regarding their experiences, opinions, and reflections about the incubators. Participants were accessed through snowball sampling, and personal privacy and ethnicity were guaranteed during data collection. ${ }^{4}$ Data were analysed following a comparative approach which is further demonstrated in the following text.

\section{Data and analysis: a comparative perspective}

\section{Structure and managerial style of the incubators}

Even though both incubators function to facilitate the student entrepreneurship and hence enhance the innovation and knowledge transfer of the universities, they employ two varying managerial structure and operation models. 
U-W incubator is part of the U-W Entrepreneurship School, which is under the operation of the U-W entrepreneurship company, a wholly owned subsidiary of U-W. The administrative staff of the Entrepreneurship School are both personnel of the firm and also from administrative department of the university. Unlike other schools which offer courses in normal teaching and research, the Entrepreneurship School works on three projects - firstly, to build labs for entrepreneurial training and practice. The completed labs (VR, AI, and 3D printer), however, have limited student participation, as such labs are not open for all and closed most of the academic year. The contact person explains that the maintenance of the labs requires considerable funds and resources, and hence they are not ready for public use yet. The second project is constructing a multi-functional cultural space for student recreation. Facilities at the space include a student cafe, bookstore, souvenir stores, and to-be-constructed campus cinema, which recruit student teams to run the facilities. Although it claims to be innovative, the second project awards limited autonomy to the students to initiate their entrepreneurial ideas but rather to fill the positions offered in the project. The third project is to run the U-W incubator, administrating the application and activities of the student entrepreneurial teams. Early-stage entrepreneurial teams, upon passing the proposal evaluation and presentation, will be offered working tables for a period of 3 months. They will be replaced by other teams if they are unable to register as a firm. The registered firms, upon being selected, will be allocated office area in the school. Notably, in order to reside in an U-W incubator, entrepreneurial teams must meet the requirement demanded by $\mathrm{U}-\mathrm{W}$ : to include the name of the university in the registered names and to allow U-W entrepreneurship company a 5\%-share ownership of the new firms.

The U-W incubator to date has only one full-time staff as a contact person. $\mathrm{He}$ is also an employee from the U-W administration. His major duties are to collect registration information of the incubatees and inform them of relevant regulations and university policies and daily logistics of the incubator (such as assuring that the teams pay electricity bills and rent on time). The micromanagement approach at the U-W incubator partly explains the limited interest in applying for joining the incubator - the number of the teams is kept at a limit of 30, and most of the current teams are in the incubator over years. Occasionally the incubator administration organizes communicative activities between entrepreneurs and students (2-5 activities per academic year). The low frequency of the events and the inconsistent connection between regional industry and the incubator make it challenging to build a continuous communicative rapport, which can function as a resource hub to the student entrepreneurs and teams.

U-S, on the other hand, employs a more decentralized approach in the daily management of the incubator. The U-S incubator is under the administration of the U-S university committee of communist youth league. The incubator basic functions are structured in incubator handbooks, including information about entrepreneurship policies and entrepreneurial activity regulations 
such as company-registration process and tax payment; to provide necessary entrepreneurial facilities such as office rooms, computers, or even labs; to offer financial support such as rent deduction; to award starting capital for successful applicants; and to facilitate the entrepreneurship education and create an innovative and entrepreneurial climate on campus. The daily operation, however, is decentralized to a whole student team from all 28 faculties of the U-S. The student operation team was divided into six groups, responsible respectively for project matching, resource exploration, logistics, activity planning, creative design, and public relations and media connection. In 2017, the operation team was updated and reorganized as the innovation and entrepreneurship service team, which is comprised of a student committee, an innovation department, and an entrepreneurship department (even though the two terms are not distinguished and in most cases are interchangeably used). Besides the aforementioned six groups, more specified groups are added, serving the needs of student entrepreneurs in terms of popularization of science, competition preparation, external communication, and human resources. To date, the service team has 68 students from all over the university. Their serving hours and work at the incubator can be recognized as credits in the U-S system. University administrative departments will not disturb the operation practice of the service team but offer them required resources and support.

It is challenging to reveal the relationship between incubator managerial structure and the efficiency of entrepreneurial activities, due to lack of data at the current stage. However, the micro-management of the U-W incubator seems to have blurred the focus of supplying incubation service into bureaucratic administrative procedures. Reviewing the operating documents of the two incubators, the U-W incubator administration has allocated considerable time and resources to demanding and checking the behaviours of the entrepreneurial teams, such as a minimum three working days at U-W incubator offices per week (those who do not meet will be moved out), timely payment of the rent and electricity expense, and spending two-thirds of the summer in the office. In contrast, the U-S incubator service team has a clearer target to serve the needs and facilitate the core activities of student entrepreneurship. The contrast can be seen in the organized activities of the two incubators. In 2017, the U-S incubator service team organized almost 600 activities (with over $70 \%$ in entrepreneurship seminars, $16 \%$ in competition preparation, resource matching, and team building) and the annual Student Innovation Training Program (SITP) (95\% of the registered participants have passed the evaluation). Over 80 teams have successfully registered as firms. In addition, over 30 teams won competitions at either national or municipal level in the year. The U-W incubator, on the other hand, archived two meetings with the student entrepreneurs and three entrepreneurship seminars in the same year.

The difference of adopting a decentralized approach at the U-S and a micromanaged approach at the U-W can be explained by the varied entrepreneurship circumstances embedded in the two cities. Even though it is debatable whether the city policies contribute to fostering talent and boosting entrepreneurship, 
Table 8.1 Stakeholder groups

\begin{tabular}{|c|c|c|}
\hline & U-S incubator & $U-W$ incubator \\
\hline Government sectors & $\begin{array}{l}\text { Funding source, co-organizer } \\
\text { of activities }\end{array}$ & $\begin{array}{l}\text { Funding source, co-organizer } \\
\text { of activities }\end{array}$ \\
\hline Social enterprises & $\begin{array}{l}\text { Funding source, co-organizer } \\
\text { of activities, speakers in } \\
\text { entrepreneurship seminars }\end{array}$ & $\begin{array}{l}\text { Funding source, speakers in } \\
\text { entrepreneurship seminars }\end{array}$ \\
\hline Investors & $\begin{array}{l}\text { Funding source, co-organizer } \\
\text { of activities, long- } \\
\text { term or short-term } \\
\text { tutors in training } \\
\text { programmes, speakers in } \\
\text { entrepreneurship seminars }\end{array}$ & $\begin{array}{l}\text { Funding source, speakers in } \\
\text { entrepreneurship seminars }\end{array}$ \\
\hline Alumni & $\begin{array}{l}\text { Funding source, co-organizer } \\
\text { of activities, long- } \\
\text { term or short-term } \\
\text { tutors in training } \\
\text { programmes, speakers in } \\
\text { entrepreneurship seminars }\end{array}$ & $\begin{array}{l}\text { Funding source, occasional } \\
\text { tutor in training } \\
\text { programmes, speakers in } \\
\text { entrepreneurship seminars }\end{array}$ \\
\hline Individual entrepreneurs & $\begin{array}{l}\text { Funding source, co-organizer } \\
\text { of activities, long-term } \\
\text { or short-term tutors in } \\
\text { training programmes }\end{array}$ & $\begin{array}{l}\text { Funding source, occasional } \\
\text { tutor in training } \\
\text { programmes, speakers in } \\
\text { entrepreneurship seminars }\end{array}$ \\
\hline Other incubators & Co-organizer of activities & Co-organizer of activities \\
\hline Partners institutions & $\begin{array}{l}\text { Co-organizer of training } \\
\text { programmes and activities }\end{array}$ & $\begin{array}{l}\text { Co-organizer of training } \\
\text { programmes and activities }\end{array}$ \\
\hline
\end{tabular}

Shanghai highlights itself as an entrepreneurship city, featuring in a clear government stance of attracting capital and talents, and stabled neo-liberal entrepreneurial strategies and practices in expanded global connections and market mechanisms (Zheng, 2011). Shanghai outpaces Wuhan in almost all entrepreneurial environment index, including government programmes, research and development transfer, commercial and professional infrastructure, and business behavioural norms (Yang \& Yu, 2007). Comparatively, market reforms proceed more slowly in Wuhan, and bureaucratic procedures remain functional in the society.

\section{Stakeholder involvement}

Stakeholders are involved in the practice of both incubators at diverse levels (as shown in Table 8.1), except that $\mathrm{U}-\mathrm{W}$ incubator relies more on the alumni network to design its innovation training programmes, which take place in a limited way at U-W, while the U-S incubator manages to activate resources from multiple perspectives.

Entrepreneurship in nature requires communal and adaptive efforts in which multiple stakeholders are gathered together to perform valuable service (Shane \& Venkataraman, 2000). This is especially essential in university incubator activities 
where the major actors are all inexperienced entrepreneurs. Stakeholder involvement was stressed by all interviewed student entrepreneurs. During the interview, U-W students regretted the limited activities that involve stakeholders on campus; they also expressed dissatisfaction towards the U-W incubator leadership who demonstrated no concrete strategies and hence no efforts in bringing relevant stakeholders. In contrast, the U-S entrepreneurs appreciated the expanded social network brought by stakeholders and their valuable first-hand experience sharing. In fact, a considerable number of stakeholders were also funders, potential employers, or investors in selective activities. Additionally, the stakeholders contribute to the entrepreneurship education, in both the formal curriculum and informal activities. All these echo literature analysis on the positive impact of stakeholder involvement on entrepreneurial outcomes (Bischoff et al., 2018; Dew \& Sarasvathy, 2007). As reflected by all the U-S entrepreneurs, the U-S incubator seemed to display an ideal benefit-sharing win-win model between incubatees and stakeholders. In this model, stakeholders contribute time in guidance and advice, and capital as seed money to incubate. And in return, the stakeholders get access to innovative entrepreneurial ideas supported by sound knowledge base at the U-S and a chance to invest in advance potential business.

The deepened involvement of stakeholders in the U-S incubator might be partly explained by the geographic location of the incubator. Shanghai as the international finance and trade centre naturally contains more dynamic business networks, creating a spontaneous connection between industry and higher education in knowledge commercialization. Another explanation might be the reputation of the U-S as a 985-project university endorsed by the government, which leads stakeholders to easily trust its qualifications and seek collaborations. In addition, the U-S is strong in STEM disciplines like science and engineering, which are prioritized in current entrepreneurship programmes. In fact, student entrepreneurs from non-STEM disciplines of both universities have expressed the confusion of the role of humanities and social sciences in entrepreneurship and innovation. Some of them started up in low-threshold entrepreneurship such as private tutoring, with limited involvement of high technology. This makes them feel they are "stealing the quota, and are ashamed when seeing other STEM-teams”, as described by one U-W student entrepreneur.

\section{Entrepreneurial mindset readiness of student entrepreneurs}

The general attitudes of student entrepreneurs towards university incubators are rather controversial. On the one hand, all entrepreneurs expressed the appreciation of the entrepreneurship atmosphere on campus, which contributed to the vigour of their campus life and widened network and vision. They also gave positive feedback concerning university efforts in incubation. The following illustration is representative among student entrepreneurs in both universities.

I was dragged into the entrepreneurship trend. . . . I feel like everybody is talking about entrepreneurship overnight, so many entrepreneurial 
activities take place every day, this cannot be imagined years ago, we have caught a good time. ... I also appreciate that I take the opportunity bravely when our teachers send us the registration form. . . I probably will take a totally different career path, going to job fairs, sending CVs and waiting for interviews. ... This brings so many possibilities for us.

On the other hand, most interviewees have not decided on whether to continue with the entrepreneurship after graduation, or to continue with postgraduate study, or to follow a traditional job-seeking path and give up entrepreneurial activities totally. Reasons for the uncertainties are manifold. For the first, universities play an ambiguous role in the share of the ownership of the registered firms. U-W incubator has stated clearly in its guidebook that the U-W would share partially the firms' ownership upon their successful registration. The $\mathrm{U}-\mathrm{W}$ students expressed in the interview that the conflict between registered student enterprises and incubator is unavoidable. Entrepreneurs do not regard the U-W support as worthy of a share of firm ownership, while the incubator presumes that student entrepreneurs should be grateful and pay back after leaving the incubator. At the U-S, the negotiation regarding firm ownership is not shared; however, debates about patent use are voiced out. For the second reason, current guidelines at university incubators appear incomplete, failing to cover diverse aspects that the students care about. For example, students at U-S find no clear regulations concerning detaching the incubator due to patent argument. For the third, students are uncertain about the real capability of surviving in market competitions of their firms. The teams are well protected during the incubation. When the free or cheap office support facilities on campus, university-related funding, and networks are not accessible, are they really qualified as an entrepreneur?

The worries of the student entrepreneurs reflect that current university incubator profile is not yet able to prepare the students with an entrepreneurial mindset. Students are generally adopting a try-out perspective instead of being determined in their entrepreneurial activities. While this exit out of entrepreneurship of university graduates remains a universal problem (Zamfir et al., 2018), the practices of two incubators suggest a possible solution to develop the entrepreneurial mindset of student entrepreneurs in a proper way. That is, universities decentralize the routine management of incubators to student bodies and award a high level of autonomy in their daily practice, while regional industries open to intensive and continuous collaboration, aiming at a mutualbeneficial win-win model.

\section{Discussion and conclusion}

This chapter illustrates the administration, operation, and stakeholder connections of two on-campus student incubators in China. It is found that universities have relevant high autonomy to design the managerial structure and operation model of the incubators, even though the student entrepreneurship and 


\section{Dian Liu}

establishment of student incubators are under the top-down initiation of the government. The chapter highlights that the decentralized, service-oriented model in incubator administration and management facilitates the richness of activities, as well as the productivity of the incubator. Students entrepreneurs are also more motivated in daily practice. On the contrast, the micro-management model will sacrifice the efficiency of incubation and student motivations. This suggests the need of updating the administration logic from managementoriented into service-oriented, not only in incubator administration but also in Chinese higher education administration, given that the on-campus incubator management is also structured in the university administrative system.

The differing performance of the two incubators described in the chapter implies the important role of regional and organizational characteristics in boosting entrepreneurship and innovation - a perspective which is only limitedly examined in current literature. At the regional level, the entrepreneurial environment functions as a contextual foundation, significantly impacting stakeholder involvement, entrepreneurial training, and the incubator entrepreneurial climate both implicitly and explicitly. At the organizational level, instead of passively following the government guidelines with measures such as setting entrepreneurial credits and entrepreneurial apprenticeship/tutoring mechanism, universities are able to actively mobilize resources, design entrepreneurship programmes, and seek cooperation. While regional development exerts more requirements regarding policy inclinations and resource allocation, organizational improvement can be achieved in a more timely way by adopting a neo-liberal, creative, and open-minded approach, involving stakeholders and mobilizing resources. It would be thought-provoking in future research to conduct more case studies in diverse regions and higher education institutions in a hierarchy system in China, to compare their daily practices and structures, to collect effective regional and organizational characteristics, and to offer references to each context.

This chapter also highlights that an entrepreneurial mindset among students is not yet developed, regardless of the government initiatives and "universal entrepreneurship" campaign for years. While the reluctance of the entrepreneurial mindset is a universal issue, a few reasons could be mentioned which lead to the unreadiness of the student entrepreneurial mindsets in the Chinese context. Firstly, the role of higher education in fostering regional innovations is not fully accepted and understood in the current higher education system. The conservative perception of looking at higher education as an educational site offering teaching and learning is still influential. Accordingly, most higher education programmes have limited relevance to the labour market. Curriculum design is still isolated from the enhanced academy-industry alignment oriented towards innovation and entrepreneurship, especially in non-STEM disciplines. In this context, boosting entrepreneurial activities in many universities appears to be quota-filling behaviour, accomplishing tasks demanded in the "mass entrepreneurship" initiative, such as the U-W incubator practice described in the chapter. Secondly, a systematic training programme to develop future 
entrepreneurs as well as entrepreneurial education is needed in incubator practice and the higher education curriculum. Current entrepreneurship training at incubators has been largely outsourced to stakeholders who are experienced in business activities and have connections with the universities. As valid as such individual stakeholder cases are, entrepreneurship training and mindset building demand consistent and sound framework support, both theoretically and pragmatically. Literature confirms the positive association between entrepreneurial education, entrepreneurial mindset, and entrepreneurship intent (Cui et al., 2019). Universities in China have, to date, established a wide variety of entrepreneurial education programmes; the next step is to build a quality system to ensure the qualification and consistency of such programmes and to embed the education in entrepreneurship activities on campus in future endeavours.

\section{Notes}

1 All these names are obtained and directly translated from the university-run incubators in China.

2 Project 985 is a project launched by Chinese government to support the development of the Chinese higher education system. The project involves both national and local governments which allocate large amounts of funding to selected universities to facilitate the academic strength, research productivity, and internationalization. In the latest Academic Ranking of World Universities 2018/19 and the Times Higher Education World University Rankings 2019/20, most of the 39 universities in project 985 are ranked among top 500 universities in the world.

3 Project 211 is a project aiming to improve the research qualification of Chinese universities with research fund allocation and support. During 1996 to 2000 (first phase), approximately US $\$ 2.2$ billion was distributed to selected universities. China has 116 universities which meet the 211 project criteria including scientific qualifications, degree programmes, and research outputs. Project 211 universities train four-fifths of doctoral students and one-third of undergraduates in Chinese higher education. They run over $90 \%$ of the national key laboratories, taking $70 \%$ of scientific research funding. In the latest Academic Ranking of World Universities 2018/19 and the Times Higher Education World University Rankings 2019/20, most of the 39 universities in Project 985 are ranked among top 500 universities in the world.

4 Both incubators own limited space to host entrepreneurial activities. It is therefore not challenging to identify the personal information of the student entrepreneurs, if detailed information about universities or names of the incubators are given. This chapter hence uses abbreviations (U-S, U-W, U-S incubator, and U-W incubator) to refer to the universities and incubators.

\section{References}

Akcomak, S. (2009). Incubators as tools for entrepreneurship promotion in developing countries. UNU-MERIT Working Papers.

Bischoff, K., Volkmann, C. K., \& Audretsch, D. B. (2018). Stakeholder collaboration in entrepreneurship education: An analysis of the entrepreneurial ecosystems of European higher educational institutions. Journal of Technology Transfer, 43, 20-46.

Chen, F., Wu, C., \& Yang, W. (2016). A new approach for the cooperation between academia and industry: An empirical analysis of the triple helix in East China. Science, Technology and Society, 21(2), 181-204. 


\section{Dian Liu}

Cheng, Y., Liu, Y., Fan, W., Yan, Z., \& Ye, X. (2019). Triple helix on globalization: A case study of the China International Nanotech Innovation Cluster. Information Development, 35(2), 272-289.

Cui, J., Sun, J., \& Bell, R. (2019). The impact of entrepreneurship education on the entrepreneurial mindset of college students in China: The mediating role of inspiration and the role of educational attributes. The International Journal of Management Education, online first.

Dew, N., \& Sarasvathy, S. D. (2007). Innovations, stakeholders \& entrepreneurship. Journal of Business Ethics, 74, 267-283.

Etzkowitz, H. (2002). Incubation of incubators: Innovation as a triple helix of universityindustry-government networks. Science and Public Policy, 29(2), 115-128.

Etzkowitz, H. (2003). Innovation in innovation: The triple helix of university-industrygovernment relations. Social Science Information, 42(3), 293-337.

Etzkowitz, H., \& Leydesdorff, L. (2000). The dynamics of innovation: From National Systems and "mode 2" to a Triple Helix of university - industry - government relations. Research Policy, 29(2), 109-123.

Etzkowitz, H., \& Zhou, C. (2017). The triple helix: University - industry - government innovation and entrepreneurship. Abingdon: Routledge.

Gan, C.-H., \& Zheng, R.-g. (2009). An empirical study on change of industrial structure and productivity growth since the reform and opening-up - a test for the structure-bonus hypotheses from 1978 to 2007 in China. China Industrial Economics, 2, 55-65.

Guimón, J. (2013). Promoting university-industry collaboration in developing countries. World Bank, 3, 12-48.

Jongwanich, J., Kohpaiboon, A., \& Yang, C.-H. (2014). Science park, triple helix, and regional innovative capacity: Province-level evidence from China. Journal of the Asia Pacific Economy, 19(2), 333-352.

Kim, H., Huang, M., Jin, F., Bodoff, D., Moon, J., \& Choe, Y. C. (2012). Triple helix in the agricultural sector of Northeast Asian countries: A comparative study between Korea and China. Scientometrics, 90(1), 101-120.

Li, J., Zhang, Y., \& Matlay, H. (2003). Entrepreneurship education in China. Education+ Training, 45(8/9), 495-505.

Liu, D. (2014). Graduate employment in China: Current trends and issues. Chinese Education and Society, 47(6), 3-11.

Lu, L. (2008). Creating knowledge-based innovation in China: The strategic implications of triple helix model. Journal of Technology Management in China, 3(3), 249-263.

Lu, L., \& Etzkowitz, H. (2008). Strategic challenges for creating knowledge-based innovation in China: Transforming triple helix university-government-industry relations. Journal of Technology Management in China, 3(1), 5-11.

Matt, M., \& Tang, M. F. (2010). Management of university incubators in China and in France: A comparative analysis. International Journal of Entrepreneurship and Innovation Management, 11(3), 282-300.

McAdam, M., Galbraith, B., McAdam, R., \& Humphreys, P. (2006). Business processes and networks in university incubators: A review and research agendas. Technology Analysis $\mathcal{E}$ Strategic Management, 18(5), 451-472.

McAdam, M., \& McAdam, R. (2008). High tech start-ups in University Science Park incubators: The relationship between the start-up's lifecycle progression and use of the incubator's resources. Technovation, 28(5), 277-290.

Mian, S. A. (1996). Assessing value-added contributions of university technology business incubators to tenant firms. Research Policy, 25(3), 325-335. 
Mok, K. H. (2016). Massification of higher education, graduate employment and social mobility in the Greater China region. British Journal of Sociology of Education, 37(1), 51-71.

MyCOS. (2015-2019). Chinese college graduates' employment annual report. Beijing: Social Sciences Academic Press (China).

Renmin University of China. (2019). Renmin University-Graduate employment report 2019. Beijing: Renmin University of China.

Shanghai Municipal Statistics Bureau. (2014). Added value of the six pillar industries by years. https://web.archive.org/web/20140304223405/www.stats-sh.gov.cn/sjfb/201103/ 84307.html

Shane, S., \& Venkataraman, S. (2000). The promise of entrepreneurship as a field of research. Academy of Management Review, 25(1), 217-226.

Stal, E., Andreassi, T., \& Fujino, A. (2016). The role of university incubators in stimulating academic entrepreneurship. RAI Revista de Administração e Inovação, 13(2), 89-98.

State Council, China. (2015a). Opinions on further efforts relating to employment and entrepreneurship under new circumstances. www.gov.cn/xinwen/2015-05/01/content_2856034.htm

State Council, China. (2015b). Opinions on deepening the education reform towards innovation and entrepreneurship in higher education. www.gov.cn/zhengce/content/2015-05/13/content_ 9740.htm

The Global Financial Centers Index 26. (2019). www.zyen.com/media/documents/ GFCI_26_Report_v1.0.pdf. Z/Yen (Commercial think-tank in the City of London) and China Development Institute.

Wu, W. (2010). Managing and incentivizing research commercialization in Chinese Universities. The Journal of Technology Transfer, 35(2), 203-224.

Xinhua Net. (2020). Notice on guiding and encouraging college graduates to work and start business in urban and rural communities in 2020. www.gov.cn/xinwen/2020-07/02/content_5523693. htm

Yang, G.-1., Fukuyama, H., \& Song, Y.-y. (2018). Measuring the inefficiency of Chinese research universities based on a two-stage network DEA model. Journal of Informetrics, 12(1), 10-30.

Yang, Y., \& Yu, Y. (2007). Analysis of shanghai entrepreneurial environment and suggestions based on gem model. Journal of Shanghai University of Finance and Economics, 9(2), 82-89.

Ying, Q., Fan, Y., Luo, D., \& Christensen, T. (2017). Resources allocation in Chinese universities: Hierarchy, academic excellence, or both? Oxford Review of Education, 43(6), 659-676.

Zamfir, A. M., et al. (2018). Resilient entrepreneurship among European higher education graduates. Sustainability, 10(8), 2594.

Zheng, Jane. (2011). "Creative industry clusters" and the "entrepreneurial city" of Shanghai. Urban Studies, 48(16), 3561-3582.

Zhou, C. (2008). Emergence of the entrepreneurial university in evolution of the triple helix: The case of Northeastern University in China. Journal of Technology Management in China, 3(1), 109-126.

Zhou, M., \& Xu, H. (2012). A review of entrepreneurship education for college students in China. Administrative Sciences, 2(1), 82-98. 


\title{
9 Aligning University Roles and Strategic Orientations

\author{
When Local Mandates and Global \\ Aspirations Meet
}

\author{
Iyad Abualrub and Rómulo Pinheiro
}

\begin{abstract}
Recent policy developments in Norwegian higher education, aiming to nurture world-class environments, have focused on the need to strengthen teaching quality and research excellence. However, higher education institutions (HEIs) are increasingly under pressure to make local contributions ("impacts"), for example, in the form of job creation, technology transfers, local economic developments, and so on, which result in tensions and dilemmas at multiple levels, not least as regards strategic management. This chapter investigates how universities align education and research on the one hand and how they navigate the tensions between local demands and global aspirations on the other. Firstly, we identify such tensions and dilemmas, and secondly, we investigate how they are being handled with regard to strategic planning (including resource allocation) at both the central (university) and sub-unit (faculty) levels. The study adopts a qualitative case study research design and compares developments at two distinct HEIs located in Norway. The findings suggest that relevance and excellence are intertwined dimensions associated with the multiple pressures facing HEIs. These findings provide critical insights into how the strategies and daily practices of actors at different levels within universities address the demands posed by a dynamic and complex environment.
\end{abstract}

\section{Introduction}

Higher education institutions (HEIs) are under increasing pressure to be more globally competitive on the one hand and to address local and regional needs on the other. Over the last decades, increased emphasis on notions such as "knowledge economy" and "knowledge society", especially in developed countries (cf. Taylor et al., 2008; Temple, 2011), has led policymakers and researchers in higher education $(\mathrm{HE})$ to focus more on the societal roles of 
knowledge institutions, from firms to universities. This expectation is particularly salient for HEIs, which are the primary places where societies acquire and deliver knowledge.

Researchers and policymakers alike have strongly recommended that HEIs must continuously work on strengthening their teaching quality and research excellence (Ramirez \& Tiplic, 2014). Excellence and relevance have become twin concepts in recent academic discourses and policy initiatives (Perry, 2012; Pinheiro, 2016) and are often used as proxy indicators for global competitiveness and local impact. In other words, contemporary debates on HE are centred on the premise that universities and other types of HEIs have multiple purposes and serve various types of "clients" (cf. Pinheiro, 2015). However, implementing this strategic orientation often creates challenges for HEIs, leading to tensions and dilemmas among $\mathrm{HE}$ communities, as pointed out in earlier studies (Benneworth, 2018).

Many of the challenges and tensions that emerge when pressing HEIs to adapt to new policies and changes are connected to the nature of HEIs as organizations and institutions. Firstly, HEIs, particularly traditional universities, are bottom heavy and fragmented or decoupled organizations (Clark, 1983), consisting of diverse internal powers that play a strong role in HEIs' behaviours towards change (Birnbaum, 1988). Such powers include academic tribes with unique cultures and beliefs shaped over time by disciplines and professions that highly influence their views and reactions when faced with changes (Becher \& Trowler, 2001). Secondly, autonomy, academic freedom, and democratic participation are widespread internal values and critical for HEIs' existence, survival, and prosperity. If HEIs and their academic tribes feel that these values might be threatened by external changes, including policy shifts, they are likely to resist them (Olsen, 2007).

Given this backdrop, and the overall aim of the edited volume in addressing the mundane or everyday aspects underpinning HEIs' societal roles, this chapter investigates how internal actors (formal leaders) at two distinct HEIs in Norway make sense of recent developments and strategically accommodate (or do not accommodate) external demands for relevance and excellence. The main questions to be investigated are as follows:

1. How do actors within HEIs conceive of the notions of excellence and relevance, and to what extent are these related to the core functions of teaching and research?

2. What types of strategic efforts do actors within HEIs undertake to address the need to be both excellent and relevant?

3. What types of strategic challenges and tensions do actors within HEIs face, and how are they being addressed if at all?

By investigating these questions in a Nordic HE context, this study aims to improve our current understanding of how different types of HEIs and internal actors negotiate the daily (mundane) tensions associated with having to demonstrate their societal value while catering for the imperative to survive and 
prosper in an increasingly competitive marketplace or sector. In so doing, our findings are relevant to policymakers, university managers, and social science researchers alike. Prior to presenting the empirical findings, the chapter sheds light on the conceptual and methodological underpinnings of this research. This is followed by a discussion and conclusion, including an exposition of the study's main implications in the context of future research.

\section{The Relevance-Excellence Nexus}

The interplay between the roles and functions of HEIs, not least as regards their local obligations and global aspirations, can be assessed in terms of the dichotomous relation between relevance and excellence. Scholars have traditionally considered strategic efforts to increase the relevance and excellence of universities as somewhat mutually exclusive. Within binary HE systems, the characterization (and policy discourses) around teaching or vocationally oriented HEIs versus classic research universities are but one indication of this problematic (cf. Kyvik, 2009). The latter are expected to contribute to global scientific excellence (independently of its direct value for society), whereas the former are seen as having a critical function in transmitting skills and competencies to future (knowledge) workers, as well as providing useful knowledge in the context of problem-solving (Kyvik \& Lepori, 2010). Similarly, in the realm of knowledge production, discussions about basic (mode-1) versus applied (mode-2) research point in a similar direction (Gibbons et al., 1994). Basic or blue-sky research efforts, it is often argued, should first and foremost be geared towards scientific excellence, regardless of whether the knowledge generated may (in the long run) be useful to society. In contrast, more applied research initiatives are thought to contribute, first-hand, towards societal relevance by helping to address current problems facing humankind.

Perry and May (2006) propose a novel way of conceiving of the interplay between relevance and excellence against the backdrop of a globalized, knowledgebased economy and society. Their conceptual starting point is that both the interdependence and contextualization of excellence and relevance are rather complex processes to which little scholarly attention has been given. It is argued that a dichotomous relation between these two aspects is unhelpful, since "excellence can be relevant, and relevance can be excellent, regardless of funding sources or disciplinary areas" (Perry \& May, 2006, p. 76). That being said, several studies report a considerable degree of structural decoupling (Oliver, 1991) between universities' core activities and tasks (Pinheiro \& Young, 2017; Benneworth, 2018), thus making the synergies between relevance and excellence difficult to realize.

In the last couple of years, there has been a concerted effort by governments to devise policy mechanisms that address both excellence and relevance. The EU's Horizon 2020 and the importance attributed to scientific impact are one such manifestation. At the national level, a number of initiatives have been forged with the aim of enhancing the scientific excellence of research groups 
based at universities (Geschwind \& Pinheiro, 2017), while at the same time ensuring that bridges are built between academics and industry in the context of technology transfer and innovation (Cai et al., 2015). Nevertheless, when it comes to universities' third mission or local mandate, as aligned with the "relevance" imperative or logic, there is a general absence of supportive policy frameworks and incentive structures (Pinheiro \& Benneworth, 2018). Moreover, despite an increased emphasis on relevance, universities are increasingly pressured to compete globally, especially in the context of research excellence (Ramirez, 2014; Ramirez et al., 2016; Smeby \& Stensaker, 1999).

\section{Method and Cases}

We applied a most different systems design and comparative case study approach (Yin, 2009) and selected two Norwegian HEIs according to the binary described earlier, namely a more teaching-centred vocational college ("Alpha") and an established, comprehensive, and research-intensive university ("Beta"). In terms of their normative orientations or preferences, and given their historical trajectories and institutional profiles, one would expect actors within Alpha to be keener to demonstrate their local relevance to society and those at Beta to be more willing to prioritize national and global excellence. That said, at the time of data collection, Alpha was actively working to attain the official status of a full-fledged university, whereas Beta was known for its strong technical profile (hard sciences and engineering) and active engagement with external actors, such as regional and national industry, in the context of technology transfers and innovation. Both organizations operate within relatively large urban contexts alongside other knowledge actors such as firms, stand-alone research centres, governmental agencies, and other types of HEIs. The organizations are embedded in regions that rank highest (domestically) in terms of per capita research and development investments, alongside the presence of knowledge and economic clusters of national and global relevance (food production, health services, construction and real estate, energy, financial services, and so on). Geographically, Alpha is more centrally located than Beta, thus having more access to physical and technological hubs and networks. That said, both regions are characterized as highly dynamic, innovative, and ranking high in terms of absorptive capacity, attracting people with high-level skills and competencies (inflow migration) from other areas, nationally and internationally.

In Norway, a traditional binary division emerged (first in the 1960s and then in the 1990s) between different types of publicly funded HEIs. More vocationally oriented university colleges located in more peripheral regions were tasked with catering to the labour market and knowledge needs of their immediate surroundings, while larger and more comprehensive universities were mandated with providing educational training at the national level and knowledge production within the scope of global science and national competitiveness. A nationwide structural reform enacted in the last decade has led to voluntary mergers among providers, resulting in fewer and larger HEIs and a gradual 
erosion of the binary system (Pinheiro et al., 2016b). Moreover, all HEIs in Norway are legally mandated to take into account societal engagement as part of their core missions. Nevertheless, changes resulting from structural reforms in tandem with the strategic ambitions of the remaining colleges to become full-fledged universities have led to increasing ambiguity about the interplay between local goals on the one hand and national and global goals on the other.

A total of 10 semi-structured face-to-face interviews were conducted with actors at HEIs at multiple organizational levels, during two site visits in 2016 and 2017. In each case, the interviewed actors included senior academics and administrative leaders at departments and centres linked to three different faculties within the fields of the social sciences and applied sciences/technology. The interviews were recorded on tape, transcribed verbatim, and analysed following discourse analysis and thematic coding.

\section{Findings}

The key empirical findings are presented in accordance with the three specific dimensions identified in our research questions.

\section{On the Excellence-Relevance Nexus}

When asked what "excellence" in HE means to them, many interviewees pointed immediately to research, emphasizing that excellence in HE means conducting more research; publishing more research articles, especially in wellknown international scientific journals; training and recruiting good researchers; writing good funding proposals; and generating funds nationally, regionally, and internationally. Moreover, the term was associated with the establishment of strong cooperation with a wide range of top (research-intensive) universities around the globe, alongside active participation in academic and research networks and conferences. That said, there were contrasting views and perspectives among respondents across the two HEIs and disciplinary fields. While respondents at Beta highlighted the importance of problem-solving and innovation in the context of societal and industrial needs and expectations, the modus operandi within Alpha was characterized by a classic research ethos centred on publications and graduate training, which accords with its strategic ambition to attain full university status.

Over the last 15 years, we have seen more emphasis on excellence in research, striving towards becoming a [full-fledged] university. . . . We need more research and more publications at the international level.

(Alpha, Senior Administrator, Applied Sciences \& Technology)

Our university is doing excellent research, trying to solve the questions that the industry doesn't have answers to yet. . . . That's what I mean, if you are really working at these questions, I think you are in the excellence 
[camp]. . . . You need to do something that's not just in current research; you need to really take big steps. . . . We want our students to know about the latest research and where the research front is.

(Beta, Senior Administrator, Applied Sciences \& Technology)

As regards teaching, respondents mainly focused on teaching methods, pedagogical skills, and how to engage students in learning and advance their skills in critical thinking and innovation. Research was also mentioned here. Many informants stressed that excellence in teaching also means embracing "research-based teaching" and educating students on research methods and skills at an early stage. A gradual move towards socializing students to develop key skills and competencies, alongside basic knowledge within a field, was also highlighted by some.

With regard to that point [excellence in teaching], we are moving towards innovation and entrepreneurship [skills] and more focus on critical thinking. (Alpha, Senior Academic, Applied Sciences \& Technology)

When talking about this concept [excellence], we must not forget to teach students the basic skills [in their fields].

(Alpha, Senior Administrator, Applied Sciences)

Turning now to "relevance", we noticed that most of the informants started talking about it while they were still explaining their understanding of the term "excellence". For them, excellence in research also means being relevant. This means that research is conducted on topics relevant to current and potential needs, society's problems and interests, and industries and markets, at both the national and international levels. This was also emphasized in the context of teaching. For example, informants identified relevance in teaching as connecting students with what is going on around them both in their country and abroad, while training them to be skilful and competitive in their majors when they enter the job market. Some also indicated that excellence in HE is about being open to discussion, teaching, researching new fields of knowledge, new ideas, anticipating new challenges and problems, and looking at answers even if they do not look completely relevant to the current needs of society and the market. In addition, some referred to difficulties in clearly identifying the future relevance of knowledge being produced today.

Relevance and excellence means that you have international competitiveness with others, you have a global awareness of some issues, like climate change, income inequality, and inclusion of people with disabilities. . . In my opinion, there is too much emphasis here on relevance and too little on excellence because, you know, we have to be relevant for [the surrounding city] and its metropolitan area, which would be relevant for 
employers, for the business sector. But there is not that much focus on excellence and quality of research and publications.

(Alpha, Senior Academic, Social Sciences)

Future employers' points of view will probably be more concerned about relevance than excellence. . . . So, I think that the basic foundation is relevance from an industry point of view.

(Alpha, Senior Academic, Applied Sciences \& Technology)

I have not defined relevance for this department, but the university has defined it for me, so it concerns certain criteria and mainly focuses on the societal and industrial needs in Norway. However, in research, we follow the criteria from the Norwegian Research Council and the EU Research Council for example, and there you find that excellence is the main standard.

(Beta, Senior Academic, Applied Sciences \& Technology)

Some informants emphasized the role of university identity in directing their focus and whether a privileged emphasis should be given to either research or teaching.

We [case HEI] have been initially established for professional [vocational] education; and therefore we often focus on teaching and practical training first. This does not imply that we don't care about research. We do, and we now put more emphasis on it, as we want to be a (fully-fledge) university. It would be good if we could balance between the two: research and teaching. (Alpha, Senior Administrator, Social Sciences)

Our university is a research university, and it is mainly specialized in science and technology. You should, therefore, understand why we tend to focus more on research. Recently, we started paying more attention to teaching and how to improve our professors' teaching skills. The main reason is that due to the mergers we have had with several university colleges, the majority of our students are now BA students, and the majority of our staff is used to focusing on teaching.

(Beta, Senior Administrator, Applied Sciences)

Other informants highlighted the role played by departmental or faculty identity and strategic priorities as key drivers for behaviour. For example, in an interview with one senior academic in applied sciences at Alpha, it was stressed that, historically, the sub-unit has been connected with the domestic health care sector. Research activities and excellence in research are, thus, seen as essential. However, it was emphasized that the department's main task was first and foremost to train students and teach them the best practices and skills required to be a good public servant. The respondent added, "We would 
therefore be interested in research that can advance our ability to improve our teaching and increase its relevance to society."

Another informant (a senior academic in social sciences at Alpha) was sceptical about being too focused on practical skills at the expense of research and believed that excellence in HE mainly means being excellent in research and conducting more of it. It was explained that, in the field in question (social sciences), "the primary aim is to prepare students to be excellent social workers (professionals) and that this requires conducting intensive and continuous research in the field". Finally, an informant associated with the field of technology at Beta emphasized that

for employers, the core issue is to have highly skilled people who are familiar with the basics and the essence of the knowledge in this field on the one hand and who possess strong analytical and research skills on the other.

(Beta, Senior Academic, Applied Sciences)

\section{Daily Practices and Strategic Ambitions}

Organizationally, the interview data revealed a strong focus on providing incentives, promotions, and financial support to academics for conducting and publishing research, as well as attending and organizing conferences with peers. Many informants talked about providing an environment where researchers have more time for research and good-quality labs, technological facilities, welfare services, and so on, in addition to good internships and research and administrative assistants. Informants at the research university (Beta) highlighted these points several times while stating that their organization aims to invest more in them to be more attractive places for researchers and learners. The same was outlined by the university college informants, but they complained that it is often difficult to compete with research universities in generating funds for research and excellence centres and that this can make them less attractive to young, talented researchers. Moreover, it was believed that if, in the near future, they were to become a full-fledged university and focus on issues relevant to the needs of the society and the market, they could increase their competitiveness and thus attract more funding and top researchers.

Some informants from the two case institutions talked about encouraging and facilitating cooperation between different researchers from different departments and centres, as well as between researchers and teachers, by promoting and facilitating the establishment of inter- and trans-disciplinary study groups and programmes. These aspects were repeatedly highlighted as significant tools used for advancing the excellence and relevance of teaching. However, many informants acknowledged that these actions are often undertaken within the teaching rather than the research realm. As stated by a senior administrator from social sciences at Beta, "Incentives, promotions, facilities, and projects provided to researchers and for advancing research are far more numerous than those available for improving teaching and teachers' pedagogical skills." 


\section{Iyad Abualrub and Rómulo Pinheiro}

However, some informants, including a senior administrator from applied sciences at Alpha, indicated that there has recently been an increased focus on further developing teaching skills and improving the quality of teaching. Initiatives and programmes such as teaching improvement programmes, yearly awards for best teachers, excellence and departmental and faculty work, and research groups for advancing education with different academic units were mentioned as pointers of the increasing strategic importance of teaching-related tasks.

The strategic ambitions of the two case organizations mainly included (a) research competitiveness at the international level; (b) active involvement in academic and research cooperative groups and projects with national and international HEIs, markets, and research funding organizations; and (c) advancing teaching and pedagogical methods and learning environments. For the university college (Alpha) informants, these ambitions are mainly driven by the collective goal to become a full-fledged university. For the research university (Beta), the primary reason for these ambitions is to enhance its competitive standing in global university rankings.

We are a research university, and research universities compete among themselves - for students, academic resources, funding for research, for better rankings; . . . in order to survive and win we need to be more competitive and always focus on being more excellent and relevant in what we provide.

(Beta, Senior Administrator, Applied Sciences \& Technology)

As you may know, we are aiming to become a [full-fledged] university. This means more focus on research and excellent research, but it also should include focusing on teaching, which we are very good at.

(Alpha, Senior Administrator, Social Sciences)

\section{Key Challenges and Tensions}

The interview data shed light on two key challenges facing the case HEIs. The first challenge concerns how to measure or assess excellence in teaching. Informants, including administrative leaders and academics in both social and natural sciences, stated that while research excellence can be measured by numbers of publications and citations, excellence in teaching is more difficult to assess. They referred to the limitations associated with relying on students' satisfaction, which is not necessarily connected to excellence in teaching. A common solution mentioned is to combine the surveys on students' satisfaction with teaching with feedback from alumni and their respective employers. However, as indicated by many informants, students' voices and quality assessments have become increasingly important. This has created a tension between academics, who support the aforementioned solution, and central administrative and institutional leaders, who have to abide by governmental regulations to maintain legitimacy and secure needed financial resources. 
The second challenge concerns the rapid changes within the HE sector in the context of recent government-led reforms. These changes demand that academic staff fulfil multiple roles and adapt constantly, which is not always easy to accomplish.

Every decade or so, we merge with new institutions, and each has its own culture, identity, workplace norms, and definition of how to be excellent and relevant in HE. Many [academics] focus on teaching, and we have found it hard to push them to conduct more research. We have also found it hard to convince our own research professors to adapt and learn advanced teaching skills from them [other teachers] that they developed over time. . . We are going to try a new solution: two career tracks: a teaching track and a research track with good incentives for both.

(Beta, Senior Administrator, Applied Sciences)

Everything written in strategies and polices about academic development and enhancing their teaching skills are nice, and many [academics] agree with them; the problem is applying them. Professors who, over the years, have gotten used to teaching in a specific way do not easily accept and adapt to changes. Another issue is that while we want professors to focus on developing their teaching, we also want them to keep doing research. Time and resources are the main challenges here.

(Alpha, Senior Administrator, Applied Science)

In addition, the interviews reveal complaints made by informants, administrators, and academics at both case HEIs about the constant changes in funding policies and research interests by national, regional, and international research and education bodies that HEIs rely on for obtaining research funding. Informants at both case institutions mentioned that part of the solution is to recruit researchers with close relations and contacts with these national and international bodies to better understand the changes that are taking place. Both case institutions were found to encourage their current staff to participate in workshops and conferences focusing on predicting, analysing, and tracing the changes across the HE field, as well as the larger social and economic environment that might impact HEIs.

\section{Discussion and Conclusion}

In Norway, recent changes in the domestic HE landscape, in large part driven by government policy (mergers across the board), have resulted in the erosion of the university - non-university institution binary (Kyvik, 2009). As a result, HEIs are now tasked with multiple roles and functions, all competing for scarce resources (time, funding, and people). This, in turn, creates a dilemma for administrators and academics regarding which tasks to prioritize, under what circumstances, and by whom. Another tension facing internal actors 
pertains to the fact that excellence and relevance discourses have permeated teaching, research, and engagement agendas within HEIs. However, HEIs also face new competitive pressures, both nationally and globally, and are attempting to address these strategically by developing a distinct institutional profile that, among other aspects, encompasses strategic collaborations with a wide variety of external stakeholders such as other HEIs, regional and national actors across the public and private sectors, and civil society (Pinheiro \& Stensaker, 2014).

Berg and Pinheiro (2016) reported that one approach to addressing such conflicting interests, as first suggested by Oliver (1991), involves either decoupling structures or building bridges in the form of embracing hybrid forms of leadership and management that take into consideration specific situations and interests as they manifest themselves on a daily basis. Our data provide evidence of strategic attempts to bridge both teaching and research activities, as well as the logics of (global) excellence and (local) relevance. As pointed out by Perry and May (2006), teaching and research relevance can be excellent and vice versa, thus moving away from the traditional dichotomies associated with functional domains and objectives. That being said, in practice, universities face dilemmas about resource allocation (i.e., people and funding) to key tasks and interest groups. More time spent engaging with external actors comes at the expense of other important activities such as grant writing, publishing, and academic advising. One way in which universities elsewhere have been able to accommodate the various demands of the environment and multiple stakeholders relates to the decoupling of tasks and structures (Oliver, 1991) in the form of separate arrangements for undergraduate and graduate teaching, as well as research, such as dedicated units or centres (Geiger, 2009).

In Northern Europe, the normative commitment towards the teaching and research nexus makes the decoupling strategy impractical. Recent studies from Sweden have revealed that within traditional HEIs, and when faced with competing demands, research agendas often take priority over teaching needs:

While managers seek to secure the participation of senior researchers in education, they often actively prefer to delegate the bulk of teaching activities to less research-active staff. Such strategies seem to reinforce existing patterns of division of labour among academic staff.

(Geschwind \& Broström, 2015, p. 60)

Yet the rise of a strategic research agenda across Europe (the Horizon 2020 programme), stressing both research excellence and social impact, implies that Norwegian HEIs need to devise mechanisms to couple these conflicting goals, as well as the diverging and growing expectations of multiple stakeholders (Benneworth \& Jongbloed, 2010). One of the ways in which HEIs are doing this is by embracing a "responsible agenda" across the board (Sørensen et al., 2019), for example, by involving regional actors in teaching and research tasks through new forms of mutually beneficial collaborations centred on the cocreation of knowledge (Karlsen, 2007). 
Our findings also point to the divide between core functions within HEIs. Excellence is often associated with research and relevance to teaching. Yet recent policy developments focusing on enhancing the research capacity of all HEIs (not only universities), as well as the quality of teaching activities and labour market relevance, have brought to the fore a number of different considerations, thus blurring the traditional distinction between teaching and research on the one hand and "local" and "global" dimensions on the other. HEIs are both locally embedded - that is, regulated by national frameworks and largely funded by the state - and globally oriented, based on scientific networks that span multiple continents and national jurisdictions (Benneworth, 2018). Hence, they need to pay close (strategic) attention to the imperatives of scientific and funding communities alike, both locally and globally.

In conclusion, the findings of this study suggest that, as pointed out by Perry and May (2006) and Perry (2012), relevance and excellence are intertwined dimensions associated with the multiple pressures facing HEIs. Despite different historical trajectories and institutional profiles, HEIs are now exposed to similar and multiple institutional pressures and thus are expected to react accordingly. As they do, they need to come to terms with the internal complexity emanating from the multiplicity of norms, values, knowledge domains, and external stakeholder groups. As all domestic HE systems undergo periods of expansion and contraction (Kyvik, 2009), HEIs the world over face increasing pressures to accommodate a multiplicity of external demands, while having to cope with growing internal complexity and more turbulent technical and institutional environments. One way of accomplishing this is by concentrating resources (economies of scale) and devising more sophisticated internal structures, for example, in the form of mergers between different types of HEIs (Pinheiro et al., 2016b).

Finally, when it comes to the regional roles of HEIs (Pinheiro et al., 2012; Benneworth, 2018), this study demonstrates that traditional conceptions focusing on the dichotomy between global excellence and local relevance are, as first suggested by Perry (2012), rather outdated. In an integrated global economy - where all regions and the actors composing them (firms, universities, local governments, communities, and so on) are exposed to a multitude of local and global events, as well as hegemonic actors and their respective strategic interests (e.g., funders and supranational bodies such as the EU, OECD, and Word Bank) - HEIs' ability to respond rests, to a great degree, on their capacity to first host and, secondly, creatively bridge a multiplicity of tasks, norms, and logics. In so doing, they enhance the growing repository of skills, knowledge, and competencies that are needed to simultaneously address local, regional, national, and global imperatives in ways that foster both their distinct sense of identity and their resilience or adaptability to changing circumstances (for a recent discussion, consult Pinheiro et al., in 2022). 


\section{References}

Becher, T., \& Trowler, P. (2001). Academic tribes and territories: Intellectual enquiry and the culture of disciplines. Buckingham: Society for Research into Higher Education \& Open University Press.

Benneworth, P. (2018). Universities and Regional Economic Development: Engaging with the Periphery. London: Taylor \& Francis.

Benneworth, P., \& Jongbloed, B. (2010). Who matters to universities? A stakeholder perspective on humanities, arts and social sciences valorisation. Higher Education, 59(5), 567-588.

Berg, L., \& Pinheiro, R. (2016). Handling different institutional logics in the public sector: Comparing management in Norwegian universities and hospitals. In R. Pinheiro, F. Ramirez, K. Vrabæk, \& L. Geschwind (Eds.), Towards a comparative institutionalism: Forms, dynamics and logics across health care and higher education fields (pp. 145-168). Bingley: Emerald.

Birnbaum, R. (1988). How colleges work: The cybernetics of academic organization and leadership. San Francisco: Jossey-Bass.

Cai, Y., Zhang, H., \& Pinheiro, R. (2015). Institutionalisation of technology transfer organisations in Chinese universities. European Journal of Higher Education, 5(3), 297-315.

Clark, B. R. (1983). The higher education system: Academic organization in cross-national perspective. Los Angeles, CA: University of California Press.

Geiger, R. L. (2009). Research \& relevant knowledge: American research universities since World War II. Piscataway, NJ: Transaction Publishers.

Geschwind, L., \& Broström, A. (2015). Managing the teaching - research nexus: Ideals and practice in research-oriented universities. Higher Education Research \& Development, 34(1), $60-73$.

Geschwind, L., \& Pinheiro, R. M. (2017). Raising the summit or flattening the agora? The elitist turn in science policy in Northern Europe. Journal of Baltic Studies, 48(4), 513-528.

Gibbons, M., Nowotny, H., Schwartzman, S., Scott, P., \& Trow, M. (1994). The new production of knowledge: the dynamics of science and research in contemporary societies., London: Sage.

Karlsen, J. (2007). The regional role of the university: A study of knowledge creation in the agora between Agder University College and regional actors in Agder. Trondheim: NTNU.

Kyvik, S. (2009). The dynamics of change in higher education: Expansion and contraction in an organisational field. Dordrecht: Springer.

Kyvik, S., \& Lepori, B. (2010). Research in the non-university higher education sector in Europe. Dordrecht: Springer.

Oliver, C. (1991). Strategic responses to institutional processes. Academy of Management Review, 16(1), 145-179.

Olsen, J. P. (2007). The institutional dynamics of the European university. In P. Maassen, \& J. P. Olsen (Eds.), University dynamics and European integration (pp. 25-54). Dordrecht: Springer.

Perry, B. (2012). Excellence, relevance and the construction of regional science policy: Science frictions and fictions in the North West of England. In R. Pinheiro, P. Benneworth, \& G. A. Jones (Eds.), Universities and regional development: A critical assessment of tensions and contradictions (pp. 105-123). Milton Park and New York: Routledge.

Perry, B., \& May, T. (2006). Excellence, relevance and the university: The "missing middle" in socio-economic engagement. Journal of Higher Education in Africa, 4(3), 69-92.

Pinheiro, R. (2015). The role of internal and external stakeholders. In S. Schwartzman, R. Pinheiro, \& P. Pillay (Eds.), Higher education in the BRICS countries: Investigating the pact between higher education and society (pp. 43-57). Dordrecht: Springer. 
Pinheiro, R. (2016a). Assessing change in higher education from the perspective of excellence versus relevance. In N. Cloete, L. Goedegebuure, Å. Gornitzka, J. Jungblut, \& B. Stensaker (Eds.), Pathways through higher education research: A festschrift in honour of Peter Maassen (pp. 37-40). Oslo: University of Oslo.

Pinheiro, R., \& Benneworth, P. (2018). Regional roles of higher education. In J. C. Shin \& P. Teixeira (Eds.), Encyclopedia of international higher education systems and institutions (pp. 1-8). Dordrecht: Springer.

Pinheiro, R., Benneworth, P., \& Jones, G. A. (2012). Understanding regions and the institutionalization of universities. In R. Pinheiro, P. Benneworth, \& G. A. Jones (Eds.), Universities and regional development: An assessment of tensions and contradictions (pp. 11-32). London and New York: Routledge.

Pinheiro, R., Charles, D., \& Jones, G. (2016a). Equity, institutional diversity and regional development: A cross-country comparison. Higher Education, 72(3), 307-322.

Pinheiro, R. Frigotto, L., \& Young, M. (Eds.). (2022). Towards resilient organizations and societies: A cross-sectoral and multi-disciplinary perspective. Cham: Springer Nature.

Pinheiro, R., Geschwind, L., \& Aarevaara, T. (2016b). A world full of mergers: The Nordic countries in a global context. In R. Pinheiro, L. Geschwind, \& T. Aarevaara (Eds.), Mergers in higher education: The experience from Northern Europe (pp. 3-25). Dordrecht: Springer.

Pinheiro, R., \& Stensaker, B. (2014). Strategic actor-hood and internal transformation: The rise of the quadruple-helix university? In J. Brankovik, M. Klemencik, P. Lazetic, \& P. Zgaga (Eds.), Global challenges, local responses in higher education. The contemporary issues in national and comparative perspective (pp. 171-189). Rotterdam: Sense.

Pinheiro, R., \& Young, M. (2017). The university as an adaptive resilient organization: A complex systems perspective. In J. Huisman \& M. Tight (Eds.), Theory and method in higher education research (pp. 119-136). Bingley: Emerald.

Ramirez, F. O. (2014). Accounting for excellence: Transforming universities into organizational actors. In L. Portnoi, V. Rust, \& S. Bagely (Eds.), Higher education, policy, and the global competition phenomenon (pp. 43-58). Basingstoke: Palgrave.

Ramirez, F. O., Byrkjeflot, H., \& Pinheiro, R. (2016). Higher education and health organizational fields in the age of "world class" and "best practices". In R. Pinheiro, L. Geschwind, F. Ramirez, \& K. Vrangbæk (Eds.), Towards a comparative institutionalism: Forms, dynamics and logics across health care and higher education fields (pp. 35-57). Bingley: Emerald.

Ramirez, F. O., \& Tiplic, D. (2014). In pursuit of excellence? Discursive patterns in European higher education research, Higher Education, 67(4), 439-455.

Smeby, J.-C., \& Stensaker, B. (1999). National quality assessment systems in the Nordic countries: Developing a balance between external and internal needs? Higher Education Policy, 12(1), 3-14.

Sørensen, M. P., Geschwind, L., Kekäle, J., \& Pinheiro, R. (2019). The responsible university: Exploring the Nordic context and beyond. Cham: Springer Nature.

Taylor, J., Ferreira, J., Machado, M., \& Santiago, R. (2008). Non-university higher education in Europe. Springer.

Temple, P. (2011). Universities in the knowledge economy: Higher education organisation and global change. London and New York: Taylor \& Francis.

Yin, R. K. (2009). Case study research: Design and methods. London: Sage Publications. 


\title{
10 Emergent Strategies and
} Tensions between Decoupled University Structures and Management Initiatives

\author{
A Case Study of a Strategy Process
}

James Karlsen and Rómulo Pinheiro

\begin{abstract}
This chapter investigates the ways in which a Norwegian university located in a region facing a series of socio-economic challenges devised and implemented a new strategy. More specifically, we examine the dilemmas and tensions faced by university actors in articulating a shared strategic platform bridging internal (university) aspirations with external (regional actors and ministry) demands and expectations. The chapter adopts a historical institutionalist perspective using institutional logics as the conceptual lens against which the case data are interpreted. The findings provide fresh evidence of the complexity associated with strategic processes within highly institutionalized organizations like universities. Strategic orientations were found to adopt emergent rather than deliberative patterns. Challenges associated with the institutionalization of the co-creation of knowledge vision at the University of Agder resulted from the clashes between the different logics and behavioural postures associated with the main actors involved in the strategy process.
\end{abstract}

\section{Introduction}

Traditional conceptions of strategic processes within organizations involve the deliberative and linear nature of the process, with leaders at the top setting a vision and mission and others throughout the organization enacting on a plan to achieve it (Mintzberg, 1978, 1993). Instrumentalist accounts of modern organizations do not take into consideration that actors are bounded by the knowledge they fail to possess, as regards both their internal operations and the external environment (Christensen et al., 2007). In reality, most managers are unaware of, or fail to acknowledge, what they do not know, what Herbert Simon (1991) famously termed as pertaining to "bounded rationality". 
Following this line of thought, Weick (1995) contends that strategy refers to "an after-the-event rationalization by top management of what they (often wrongly) believe their organisation has recently been doing" (cited by Bovaird \& Löffler, 2009, p. 62).

The notion of strategy as pattern (Mintzberg, 1978) is particularly salient in the context of complex organizations that are deeply embedded in highly institutionalized environments, as is the case of universities (see Pinheiro et al., 2016). Firstly, viewing strategy as an (emergent) pattern sheds light on its ex post rather than ex ante nature, that is, focusing on the actual behaviours of actors rather than their predetermined intentions. Secondly, it pays attention to processes of sense-making and enactment (Weick, 1995), the idea that strategy is something organizational actors talk about in attempts to overcome the ambiguity and uncertainty associated with the complex environments in which they operate. Thirdly, a process view on strategy adopts an organic, evolutionary perspective focusing on past behaviour and consequences, rather than on becoming an instrument for shaping future actions.

According to Pinheiro and Young (2017), an emergent view on strategy is part and parcel of the university as a complex, adaptive system that coevolves with its surrounding environment. Co-evolution implies, among other aspects, that causal mechanisms are multifaceted and non-linear. For university managers, this means embracing rather than reducing complexity, thus continuously adapting to changing internal and external environments. In such circumstances, adopting a systemic or holistic view is warranted rather than attempting to isolate the parts to manage them more efficiently. For example, while most strategies within universities refer to their core missions of teaching, research, and societal engagement or outreach, few articulate the ways in which the inner and outer dynamics surrounding each of these functions affect the others and, in turn, the complex interplay between the university and its external environment.

This chapter investigates the ways in which a Norwegian university located in a region facing a series of socio-economic challenges devised and implemented a new strategy. More specifically, we examine the dilemmas and tensions faced by university actors in articulating a shared strategic platform bridging internal (university) aspirations with external (regional actors and ministry) demands and expectations. Hence, in this chapter, we address the following research question:

- What types of internal (university) tensions emerge during the strategy process, and how can these be interpreted in the light of (institutional) theory?

\section{Method and case}

This chapter adopts a historical institutionalist perspective. As a methodological and theoretical tradition within the social sciences, historical institutionalism sheds light on the importance of past events in determining the course of future 
trajectories (Suddaby et al., 2014). Past events create a kind of "anchoring effect", making it difficult for agents to explore alternative patterns of behaviour or choices (Pierson \& Skocpol, 2002).

In accounting for the importance of path dependencies in the behaviour of actors, individually and/or collectively, historical institutionalists refer to the importance of critical events or "junctures" in time (Pierson \& Skocpol, 2002). One way to identify and investigate the role played by critical junctures over time is to resort to process tracing. The latter is a valuable methodological tool for drawing descriptive and causal inferences emerging from diagnostic pieces of evidence. These pieces are organized and re-constructed to provide researchers with a temporal sequence of events underlying a specific social phenomenon (Collier, 2011). The process is initiated with a narrative or "story" substantiated in an accurate timeline listing the sequence of key events or junctures. This is followed by the exploration of causal or salient ideas embedded in the narratives, considering the types of evidence that may confirm or disconfirm such ideas (Collier, 2011, pp. 828-829). Process tracing can be used in both positivist and interpretivist research designs. In the current study, we adopt an interpretivist approach anchored in a case study focusing on strategic (top-down) attempts at enacting structural and cultural change at a mid-size university in Norway.

The context for the study is a mid-size comprehensive university (the University of Agder or UiA) located in southern Norway, a region of approximately 300,000 inhabitants. As part of a far-reaching structural reform in Norway, resulting in several voluntary yet government-supported mergers (Kyvik \& Stensaker, 2013), UiA's board decided in 2013 not to pursue such an endeavour with a university college from the nearby region of Telemark. This, in turn, created a legitimacy dilemma in the eyes of UiA's central administration, which had shifted into a new leadership team shortly following the decision not to merge. The case for this study focuses on the strategy process with the new rectorate facing this situation. Given the importance attributed to path dependencies or historical trajectories, our case builds on the role that major, prior events or antecedents play in future trajectories. Notably, the new rector who was the former Dean of the Technology Faculty was one of the few supportive of the merger, along with UiA's previous rector. This created momentum (pressure) for a more engaging and ambitious strategy process.

Three semi-structured interviews (lasting about 1 hour each) were conducted in the spring of 2020 with key university actors involved with the strategy process at different hierarchical levels: central administration and project management. A variety of internal official documents and minutes were gathered. In addition, we drew upon our intrinsic knowledge of the strategy process due to our direct involvement as participants (period 2017-2019) in the context of the development of internal structures for co-creation. Finally, we used a research diary (Groenewald, 2004) to document all meetings we participated in, and draw upon important datasets from an earlier study (MA thesis, advised by one of the authors) on strategic processes at UiA which encompassed several interviews with key actors across multiple faculties and the central administration (Hassan, 2018). 


\section{Conceptual backdrop: institutional logics}

In contrast to earlier institutional accounts stressing the importance of compliance resulting in uniformity or isomorphism (DiMaggio \& Powell, 1983), the institutional logics' perspective caters to the importance of micro-level dynamics (agency and power) resulting in differentiation and pluralism. A logic is defined as "the socially constructed historical patterns of cultural symbols and material practices, assumptions, values and beliefs by which individuals produce and reproduce their material subsistence, organise time and space and provide meaning to their daily activity" (Thornton \& Ocasio, 1999, p. 804). Logics can be both symbolic representations and material practices that become embedded (taken for granted) over time. Logics act as formal and informal rules shaping agentic behaviour at the meso (organization) and micro (individual) levels.

Despite their salience, logics are both dynamic and historically contingent, evolving and changing in accordance with macro-level (societal) shifts (termed as "institutional orders") in which they are embedded or nested. For example, a participative democratic logic is part and parcel of a political, economic, or social system that puts a premium on individual rights, decentralization of power, accountability, and the rule of law (Fukuyama, 2014). As these institutional orders lose public support and legitimacy, the prevalent logics associated with them gradually decline and are replaced by other logics, linked to the rise of new, alternative institutional arrangements, or orders. The contemporaneous cases of quasi-democratic systems or illiberal democracies, such as those of Russia, Hungary, the Philippines, Venezuela, and so on, are compelling examples. In other words, institutional logics correspond to "the organizing principles of institutions" (Ocasio et al., 2017, p. 511) in the form of both formal and informal rules or norms.

Multiple studies have empirically shown that, as a result of the complex institutional and technical environments in which modern organizations are embedded, agents are faced with the difficult task of having to accommodate a multiplicity of institutional orders and their associated logics (cf. Pache \& Santos, 2013). Often, these orders provide conflicting normative and pragmatic orientations, resulting in internal clashes or tensions. Some organizations resolve such tensions in a form of decoupling either by allowing different subunits to follow a specific logic or by symbolically complying with the logics while retaining their structures and tasks unchanged (Greenwood et al., 2008). There is increasing evidence of the simultaneous accommodation of different logics, resulting in the rise of hybrid forms (Battilana \& Lee, 2014). In such situations, formal leaders play an increasingly important role in mediating the tensions between two or more logics, often resulting in the adaption of hybrid leadership roles or strategies (Berg \& Pinheiro, 2016). Recent studies have shown that actors are able to dynamically (and strategically) balance coexisting logics, maintaining the distinction between the logics while exploiting the benefits associated with their interdependence (Smets et al., 2015), suggesting that institutional complexity can itself become institutionalized and routinely 
Table 10.1 Competing logics within universities

\begin{tabular}{lllll}
\hline $\begin{array}{l}\text { Logics } \\
\text { Key dimension }\end{array}$ & Managerial & Political & Administrative & Collegial \\
\hline $\begin{array}{l}\text { Institutional order } \\
\text { Basis of } \\
\text { legitimacy } \\
\text { Locus of attention }\end{array}$ & Market & State & Bureaucracy & Networks \\
$\begin{array}{l}\text { Means of } \\
\text { enforcement }\end{array}$ & Goal achievement & Accountability & $\begin{array}{c}\text { Rule } \\
\text { following }\end{array}$ & Knowledge \\
\hline
\end{tabular}

Source: Authors' own elaboration

enacted within everyday practice (Greenwood et al., 2011). Table 10.1 presents the key components associated with four logics of relevance to universities as organizations and institutions embedded in a highly institutionalized organizational field (Pinheiro et al., 2016).

\section{Tracing the strategy process}

Following the process tracing methodology sketched out earlier, Figure 10.1 shows the key events underpinning four key phases of the strategy process: (a) the emergence of UiA's new vision, (b) reactions of the faculties towards the vision, (c) the organization of the implementation process, and (d) the implementation of the co-creation laboratory and a course. It is important to note that these identified phases overlap one another and do not necessarily follow a linear fashion. Instead, they represent critical moments or junctures of the strategy process.

\section{Phase I: Emergence of the new vision}

In connection with the preparation of the new strategic plan, the rector established a strategy council for the period of January to July 2016. The council reported to the university board, which was the formal strategy group; it was composed of 16 members representing the following group of actors: staff, students and administration from UiA, and regional actors from the Agder region. In addition, a total of four open workshops targeting UiA staff were held, where specific topics in the realms of teaching, research, internationalization, and engagement were discussed. These workshops provided critical input for the discussion at the council level. The interviewees described the process as good with open discussions about vision and strategic areas. By mid-March 2016, three different proposals of the new vision were advanced by the strategy council; however, none were accepted by the strategy group. The leader of the strategy council, who was also head of department, underlined that the participants were concerned that the strategy had to reflect the university's main functions 


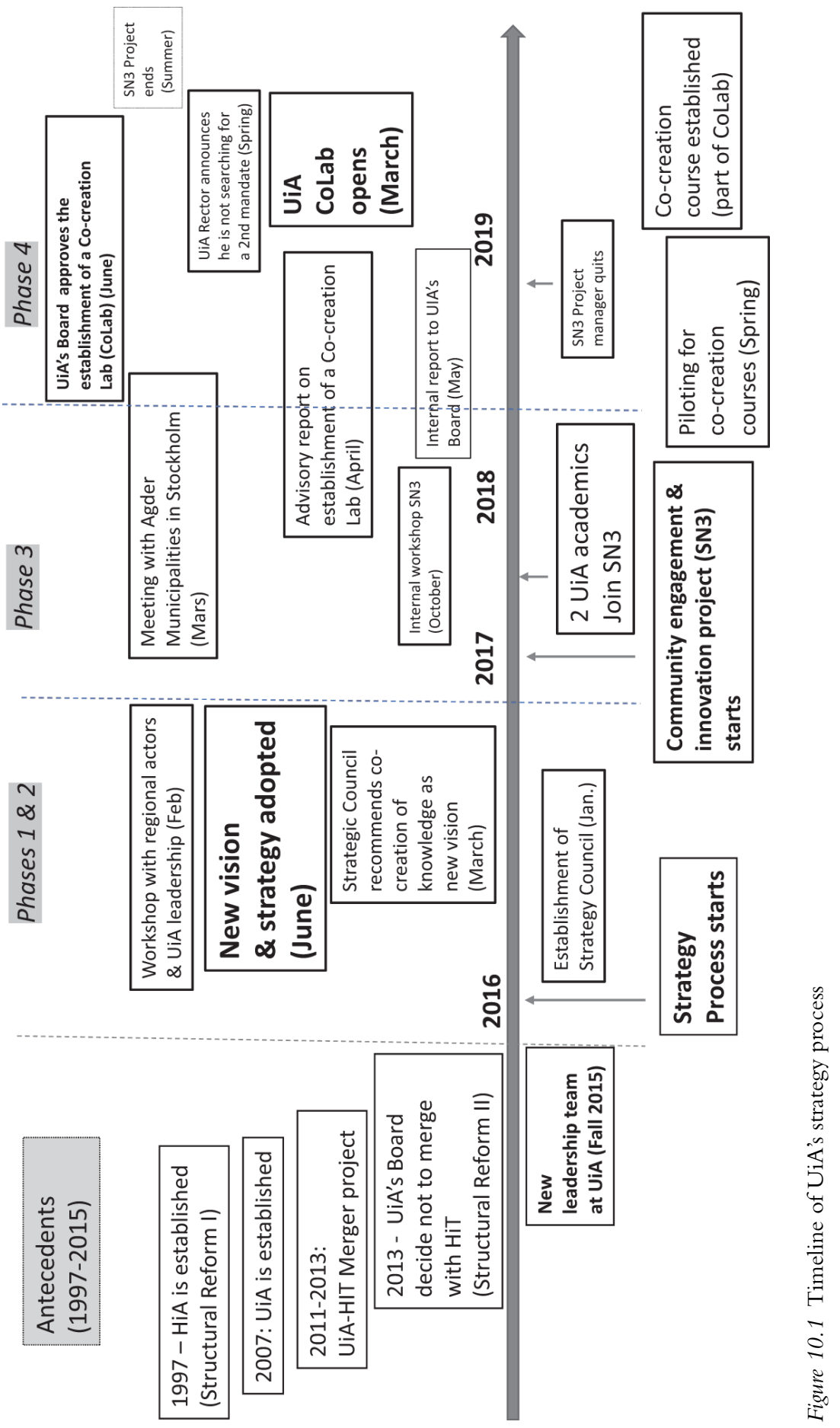


of research, education, and outreach. The latter function was especially important for the external members of the council, who argued that the university should improve their communication with the region. The argument was that there were too many access points to the university, and it was therefore difficult to identify and contact the appropriate person. There should be one access point, the external members argued. As a result, following further discussions, the council proposed the new vision "Co-creation of knowledge" (Samskaping av kunnskap) which emerged as a result of the discussions on integrating research, education, and the connection to the external environment with both the surrounding region and the broader world.

I remember I presented the vision in a meeting at the university where the rector was also present. . . . I thought before I presented it, that samskaping [co-creation] is not a good word in Norwegian. Then I said: "Co-creation in the absence of a better word". For the Rector, it was like turning on a light. He got completely excited. Since then, there has only been co-creation. It was the one thing he [Rector] wanted to bring away from that meeting.

(strategic council member)

According to the same senior member of the council, the vision was created with a focus on the external environment of the university because there was a sense that it should be more open-minded and use the knowledge that already exists in and about the region. The reception of the new vision by UiA academics was mixed, as shown in the next section. As for the regional actors, they reacted rather favourably, as this was perceived as an attempt to engage with the region in a more systematic fashion. After some years of neglect, they argued, and following the transition to a full-fledged university in 2007, UiA was finally re-engaging with the region.

\section{Phase II: Reactions towards the new vision at the faculty level}

The proposal for a new strategic plan was submitted for consultation on 23 May 2016 with two alternatives of the vision: "Co-creation of knowledge" and "Together we create knowledge". In the consultation responses from the faculties, one can see from the internal documents that the vision was met with mixed responses.

The arguments against the vision did not, however, convince the university board. The new vision and strategy were adopted in July 2016. An interview conducted in early 2018 with a faculty director, reported in a previous study, provides the following insight:

He [Director] also points out that the concept of collaboration is used ironically. These may be symptoms of resistance within the faculty, but at the same time, this contributes to the concept being incorporated into the faculty's culture and language 
apparatus. In the long run, it can be assumed that this will help the faculty gain greater ownership of the term.

(Hassan, 2018, pp. 41-42)

\section{Phase III: Organization of the implementation process}

According to UiA's rector at the time, his role was to act as a moderator by keeping everyone focused on the vision and the effective implementation of the strategy. The implementation process of the new strategy was organized differently for the three strategic areas. ${ }^{1}$ The process for the strategic area Community engagement and innovation (internally known as SN3) was anchored in the university director's office, that is, in the main administration of the university. The leader of this process, a former minister of education and politician, was a newly hired senior advisor. He was hired largely because of his political skills and good connections to the political environment in Oslo with the aim of supporting lobbying efforts towards the government and its various agencies, most notably the Ministry of Education and Research. Yet, since lobbying is not necessarily a full-time job, he was given the responsibility of implementing this strategic area, which consisted of two key initiatives: the Co-creation Laboratory and Students' Traineeships, each of which was managed by a project leader. The two project leaders were externally recruited, but they had some previous knowledge about the university. The recruitment of external project leaders to work on implementation of the strategy led to criticism and resistance across the academic heartland, as reported in a previous study.

In the informants' view, the work with the SN-3 focus area has been where the most complications and challenges emerged at departmental, faculty and central level. The informants pointed out that the lack of competence and knowledge of UiA as an organization has been the primary reason why the project has not had the desired progression. It is a widespread problem that external people who are brought in to lead projects in complex organizations where the structures are hybrids of several ideal ways of organizing, often stumble because the organizational culture (different norms and values) are not taken into account well enough.

(Hassan, 2018, p. 85)

\section{Phase IV: Establishment of the Co-Creation Laboratory}

The most complex of the two projects was the establishment of the Co-Creation Laboratory, which encompassed a dedicated unit for coordinating engagement efforts across the board, including interdisciplinary joint teaching activities focusing on addressing the key challenges facing regional actors across the public sector. $^{2}$ In addition to the project leader who was working full-time, two senior academics from the social sciences were brought on board on a part-time basis as key advisors. ${ }^{3}$ The advisors possessed both scientific and practical knowledge on different aspects associated with universities' engagement: regionally, nationally, and internationally. In the interview with the project leader, we asked him about 
the implementation process. He started by arguing that his role was one of being a dialogue facilitator and that he personally did not like the notion of implementation.

He continued by saying that the Co-creation Laboratory was an idea that had been established prior to his assuming of the role, and he wanted to have a process (ongoing dialogue) with the different faculties where the idea could be discussed, concretized, and anchored in the academic heartland. He did not want it in the form of one, two, and three steps (a linear process) but as a co-created laboratory for the whole university. The inspiration for the Co-Creation Laboratory originated from the Openlab in Stockholm, which a delegation from UiA visited in March 2017. ${ }^{4}$ The Openlab is located at the KTH Royal Institute of Technology's campus and is owned and financed not only by KTH but all the higher education institutions (HEIs), municipalities, and other public actors in the Stockholm region. Moreover, inspired by Stanford's University Design School, the Openlab adopts design thinking as its main co-creation method. According to the project manager: "We started too early in the process talking about building a co-creation laboratory and on the location of the new building." If he had had a second chance, the project manager noted, he would have spent more time on the process, especially by engaging academics. In retrospect, it was an administration-driven process. Yet it must be stated that in his earlier visits to some of UiA's faculties, the project manager was not received with open arms, with some academics being rather critical of the entire process. In addition, the former politician tasked with leading the SN3 efforts as project director, to whom the two project managers reported, was not keen on decentralized and informal team-based approaches, preferring instead a more classic command and control orientation based on formal committees and written documents for critical input. During an internal workshop in October 2017, in which the authors of this chapter were also invited to participate, together with the Rector, the SN3 project director, the two project managers, and other key internal actors, the project director started his speech the beginning of the session by stating:

We [participants] should not use the concept Samskapingsverkstedet, ${ }^{5}$ but UiA Co-creating. It should be the aim of the seminar. . . What do we believe can give success? Should we spend more time on workshops? The answer is no! There are three things we are going to work with. The first is an academic project, an interfaculty course, the second an Openlab [referring to the co-creation lab], and the third a website with information about the project.

(Authors' notes from the workshop 31 October 2017)

After the speech by the project director, the rector delivered a speech where, among other things, he argued: "The University of Agder should be easy to collaborate with and be a new and exciting partner in co-creation processes." In the discussion following his speech, the rector underlined that co-creation is a cultural mindset and that everyone at the university is a co-creator.

At the end of the workshop, the time for discussion and deliberation, including what was meant by co-creation and how to co-create knowledge, was over. The time had come for action, that is, the implementation of the decisions 
taken. This strategic stand was supported by the rector who stressed the need to move forward with effective implementation, following half a year or so of project planning dedicated to establishing the vision and selecting the key initiatives. This strategic posture contrasted with that of the project team, which continued to argue for the need to engage with the academic heartland and take a more organic and systemic approach focusing on dialogue and an emerging consensus rather than a top-down implementation centred on timelines and deliverables.

UiA's board approved the creation of the new lab, later to be renamed CoLab. Following the rector's announcement, in the spring of 2019, of his decision not to stand for re-election, both the SN3 director and the remaining project manager left UiA, ${ }^{6}$ marking the completion of the process as such.

\section{Discussion: clashing logics in an emergent strategy process}

Starting with the strategy process, the process tracing analysis shows a pattern gradually moving from idea generation to discussion and the selection of alternatives to implementation, with a multiplicity of decisions taken within each of the key phases. This supports the notion of strategy as a stream of deliberative actions or decisions by the various actors involved, as proposed by Mintzberg (1978, p. 935). The data also show evidence supporting the notion of an emergent strategic process (Mintzberg, 1978), with actors adopting their behaviours in light of emerging circumstances, including earlier decisions and reactions to those decisions by key stakeholders. The deliberative nature of strategic processes within universities results from the historical legacy of the university as a democratic institution (de Boer \& Stensaker, 2007). That said, the amalgamation of multiple disciplinary tribes and professionals (Trowler et al., 2012), and their respective norms and traditions that are embedded in distinct institutional logics, makes the pursuit of "unity of action" (Olsen, 2007) a daunting task. The empirical evidence suggests that, at key moments in the process, key UiA actors, such as the rector or project director, used their privileged or legitimate social standing to enforce or coerce participations to adopt a particular course of action, such as the decision to cease deliberation in the spring of 2018.

The establishment of a temporary (project-based) organization (encompassing a strategic council, project groups, and so on) attests to the deliberative or planned nature of the strategy process at UiA. As Mintzberg and Waters (1985) point out, deliberate and emergent dimensions should be seen as part of a continuum rather than dichotomies per se. The reality is that, in most cases, neither purely deliberate nor purely emergent strategies are realized in practice, despite actors' initial intentions:

It is difficult to imagine action in the total absence of intention - in some pocket of the organisation if not from the leadership itself - such that we would expect the purely emergent strategy to be as rare as the purely deliberate one. 
The structural and cultural complexity inherent to universities as both organizations and institutions (cf. Pinheiro \& Young, 2017) makes it nearly imperative that any planned action by management is conditional on debate and deliberation at multiple levels, as was the case regarding the faculties' reactions to the new vision.

Even though the vision was generated by the strategy council in consultation with multiple stakeholders, it became embodied in the personal figure of the rector, who, as both a representative and symbolic figure, continuously urged internal stakeholders to take bold actions in order to remain competitive in a highly dynamic environment. Stensaker and Benner (2013) contend that universities, particularly newer ones located in less central geographies, as is the case with UiA, have little choice but to engage in innovative efforts to move up competitively in their domestic and international fields. In this respect, we can also detect elements of the entrepreneurial (strategic) orientation as presented by Mintzberg and Waters (1985, p. 260; see also Young \& Pinheiro, 2022). In fact, the idea of a somewhat charismatic and sympathetic foreign-born engineer (the rector) with prior experience in the private sector seemed to have appealed to both internal and external stakeholders. ${ }^{7}$ Such an entrepreneurial orientation (cf. Pinheiro \& Stensaker, 2014a) was found to be adequate given the external pressures for change that ensued following the decision in 2013 not to merge. Hence, it was not surprising that UiA's new vision statement would be outward-oriented, also given the broader changes facing the Norwegian and European HE sectors, with societal engagement and impact ranking high on the government's agenda (Sørensen et al., 2019).

As for the way in which, as a strategic idea, co-creation was both adopted and adapted at UiA, the analysis shows a lack of internal deliberation associated with what it meant (definition), how it was to be applied (practice), and for whom it was intended (audience). Such debates were held at the level of the project team, including students and academic advisors involved with co-creation activities, but they never expanded the idea to encompass other levels of the organization. Rather than approaching co-creation as a longterm cultural shift or mindset, as proposed by the project team, actors close to the central administration adopted a narrower, managerialist approach in the form of co-creation as a means to an end (i.e., repositioning UiA in the national and global marketplace), instead of an end in and of itself. Dialogue, tolerance, and engagement are time-consuming and require a level of tolerance (also in regard to failure) that today's university leaders and administrators are, for the most part, not willing to embrace, partly given the multiple external pressures they face and the need for a speedy and coordinated strategic response (see Pinheiro \& Stensaker, 2014b). UiA's rector played an active and dominant role in initiating and driving strategic change, which is aligned with recent findings from Norway on the role of university management (Frølich et al., 2019). 
Table 10.2 Empirical manifestation of competing logics at UiA

\begin{tabular}{lllll}
\hline $\begin{array}{l}\text { Logics } \\
\text { Key dimensions }\end{array}$ & Managerial & Political & Administrative & Collegial \\
\hline Primary carrier & Rectorate & Project director & $\begin{array}{c}\text { Central } \\
\text { administration }\end{array}$ & $\begin{array}{c}\text { SN3 project } \\
\text { manager and } \\
\text { team }\end{array}$ \\
$\begin{array}{c}\text { Strategic } \\
\text { priority }\end{array}$ & $\begin{array}{c}\text { Implementation } \\
\text { (project } \\
\text { management) }\end{array}$ & $\begin{array}{c}\text { External actors } \\
\text { (regional and } \\
\text { national) }\end{array}$ & $\begin{array}{c}\text { Institutionalization } \\
\text { (structures, } \\
\text { processes, } \\
\text { resources) }\end{array}$ & $\begin{array}{c}\text { Academic } \\
\text { engagement }\end{array}$ \\
$\begin{array}{c}\text { Normative } \\
\text { posture } \\
\begin{array}{c}\text { Temporal } \\
\text { perspective }\end{array}\end{array}$ & Efficiency & $\begin{array}{c}\text { Management } \\
\text { (top-down) }\end{array}$ & $\begin{array}{c}\text { Accountability } \\
\text { Short term }\end{array}$ & $\begin{array}{c}\text { Short term } \\
\text { Culture or ethos } \\
\text { (bottom-up) }\end{array}$ \\
\hline
\end{tabular}

The data point to tensions associated with conflicting logics held by the different actors involved (see Table 10.2). Both the rector and the project director were concerned with a successful or efficient outcome, but their behavioural postures differed based on their social standings, normative beliefs, and past experiences. The rector was keen to adopt efficiency, goal achievement, and (linear) project management, aspects strongly associated with a managerialism logic (see Table 10.1).

In contrast, the project director's experience as a politician, alongside his official mandate, centred on external actors (lobbying), resulted in a behavioural posture where power relations (control) and external accountability (political logic) ranked high on the agenda. Working alongside (embedded in) UiA's administrative bureaucracy which focused on procedural aspects such as budgeting and compliance with internal and external rules and regulations, the project director adopted a traditional top-down orientation. This directly clashed with the more informal, collegial posture adopted by the project team, which was led by a hands-off project manager, and where networking based on trust, knowledge, and respect for different disciplinary cultures and local traditions was centre stage. This long-term orientation associated with an evolving (non-steered) cultural shift within UiA clashed with the short-term focus associated with achieving the milestones and goals of the strategic plan (for a recent discussion on the interplay between culture and resilience in Nordic HE, consult Geschwind et al., 2022). This, in turn, led to the rise of two competing narratives or paradigms on co-creation. The first, linked to the cultural perspective (Christensen et al., 2007) adopted by the project team, approached co-creation as an end in itself (i.e., part and parcel of internal norms, values, and academic identities), whereas the second, subscribed to by UiA's central administration and its formal leaders, the rector included, conceived of co-creation as a tool or instrument (see also Olsen, 2007) for realizing the short-term goals composing UiA's strategy. This clash of distinct logics is illustrated in Table 10.2. 


\section{Conclusion}

This case study, focusing on a mid-size university located in a somewhat peripheral mid-size region in Northern Europe, provides fresh evidence of the complexity associated with strategic processes within highly institutionalized organizations like universities (Pinheiro et al., 2016). As found in earlier studies (Fumasoli et al., 2015; Pinheiro \& Young, 2017), strategic orientations at universities tend to adopt emergent rather than deliberative patterns, reflecting ongoing dynamics set in motion by a multiplicity of forces, many of whom co-evolve with each other, thus questioning the idea of strategy as a linear, rational, and predictable process.

Some of the challenges associated with the institutionalization of the cocreation of knowledge vision at UiA, as the case demonstrates, have resulted from the clashes between the different logics and behavioural postures associated with the main actors involved in the strategy process. Of particular salience in this respect are the observed tensions between short-term, instrumentalistic perspectives focusing on efficiency, top-down management, and external accountability on the one hand, and that of a long-term cultural orientation centred on the norms of collegiality, inclusivity, and internal legitimacy on the other. These clashes illustrate the ongoing tensions between planners and other internal actors responsible for rationalizing and managing university structures and procedures (Ramirez \& Christensen, 2013) and those agents (the implementers, in this case academics) responsible for the task of inhabiting and infusing these same structural arrangements with both (cultural) value and meaning. In so doing, the case points to the growing divide within modern universities, in the Nordics and elsewhere, between leadership/administrative structures and the academic heartland resulting from efforts to modernize or rationalize universities in light of market-based models stressing efficiency, accountability, and responsiveness (Enders et al., 2015).

To conclude, this case study demonstrates, among other aspects, the limitations associated with deliberative action in a university context. It also points to the importance associated with the everyday and informal aspects underpinning university life (academic norms, values, traditions, identities, and so on), which managers need to consider while devising strategic plans aimed at change and adaptation within the context of complex internal and external environments. Future studies, resorting to a larger sample and embracing mixed methods, could bring further clarity on the dynamic interplay between deliberative and emergent processes and behaviours within complex organizations such as universities while taking into consideration internal and external dynamics on the one hand and the coexistence/clash among competing logics and stakeholder demands on the other. More specifically, and when it comes to universities and regional engagement in particular, there is a need to unpack the roles that external actors - within and beyond the surrounding region play in change processes and how they affect both strategic trajectories and short- and mid-term outcomes. 


\section{Notes}

1 These were SN1: Learning and education for the future; SN2: Global mindset (internationalization); and SN3: Community engagement and innovation.

2 Due to space constraints, the focus here is exclusively on the establishment of the cocreation unit, rather than on describing the process that led to the development and establishment of an interdisciplinary master-level course on co-creation titled "Cocreation: Theory and praxis" (details here: www.uia.no/en/studieplaner/topic/SV-420-1).

3 In the interest of transparency, we report here that the two advisors are the authors of this chapter.

4 For information about KTH, see the link: https://openlabsthlm.se/

5 The Norwegian term for "co-creation laboratory" as a social and physical space.

6 It is worth noting that, following divergences and tensions regarding management styles, between the SN3 director and the project leader for engagement and innovation, the latter voluntarily quit UiA in the winter of 2018. The remaining project leader (focusing on traineeships) took over the project, working alongside the two existing academic advisors.

7 Yet, as a caveat, it should be stated that the election in 2015 of the new rector was highly competitive and internally contested, ultimately decided by less than a handful of votes by staff.

\section{References}

Battilana, J., \& Lee, M. (2014). Advancing research on hybrid organizing - Insights from the study of social enterprises. The Academy of Management Annals, 8(1), 397-441.

Berg, L., \& Pinheiro, R. (2016). Handling different institutional logics in the public sector: Comparing management in Norwegian universities and hospitals. In R. Pinheiro, F. Ramirez, K. Vrabæk, \& L. Geschwind (Eds.), Towards a comparative institutionalism: Forms, dynamics and logics across health care and higher education fields (pp. 145-168). Bingley: Emerald.

Bovaird, T., \& Löffler, E. (2009). Public management and governance. London: Routledge.

Christensen, T., Lægreid, P., Roness, P. G., \& Røvik, K. A. (2007). Organization theory and the public sector: Instrument, culture and myth. Milton Park: Taylor \& Francis.

Collier, D. (2011). Understanding process tracing. PS: Political Science and Politics, 44(4), 823-830.

De Boer, H., \& Stensaker, B. (2007). An internal representative system: The democratic vision. In P. Maassen \& J. P. Olsen (Eds.), University dynamics and European integration (Vol. 19, pp. 99-118). Dordrecht: Springer Netherlands.

DiMaggio, P., \& Powell, W. (1983). The iron cage revisited: Institutional isomorphism and collective rationality in organizational fields. American Sociological Review, 48(2), 147-160.

Enders, J., Kehm, B., \& Schimank, U. (2015). Turning universities into actors on quasi-markets: How new public management reforms affect academic research. In D. Jansen \& I. Pruisken (Eds.), The changing governance of higher education and research (Vol. 43, pp. 89-103). Dordrecht: Springer.

Frølich, N., Christensen, T., \& Stensaker, B. (2019). Strengthening the strategic capacity of public universities: The role of internal governance models. Public Policy and Administration, 34(4), 475-493.

Fukuyama, F. (2014). Political order and political decay: From the industrial revolution to the globalisation of democracy. London: Profile Books.

Fumasoli, T., Pinheiro, R., \& Stensaker, B. (2015). Handling uncertainty of strategic ambitions - The use of organizational identity as a risk-reducing device. International Journal of Public Administration, 38(13-14), 1030-1040.

Geschwind, L., Pinheiro, R., \& Stensaker, B. (2022). Organizational persistence in highly institutionalized environments: Unpacking the relation between identity and resilience. 


\section{James Karlsen and Rómulo Pinheiro}

In R. Pinheiro, L. Frigotto, \& M. Young (Eds.), Towards resilient organizations and societies: A cross-sectoral and multi-disciplinary perspective. London: Palgrave.

Greenwood, R., Oliver, C., Sahlin, K., \& Suddaby, R. (2008). The SAGE handbook of organizational institutionalism. London: SAGE Publishing.

Greenwood, R., Raynard, M., Kodeih, F., Micelotta, E. R., \& Lounsbury, M. (2011). Institutional complexity and organizational responses. The Academy of Management Annals, 5(1), 317-371.

Groenewald, T. (2004). A phenomenological research design illustrated. International Journal of Qualitative Methods, 3(3), 42-55.

Hassan, H. (2018). Strategiutøvelse ved universiteter - en kompleks affære. En studie av hvordan Universitetet i Agder har arbeidet med Strategi 2016-2020 Samskaping av kunnskap. [Exercising strategy at universities - a complex affair. A study of how the University of Agder has worked with Strategy 2016-2020 Co-creation of knowledge.] Master thesis in Political science and management, University of Agder, Norway.

Kyvik, S., \& Stensaker, B. (2013). Factors affecting the decision to merge: The case of strategic mergers in Norwegian higher education. Tertiary Education and Management, 19(4), 323-337.

Mintzberg, H. (1978). Patterns in strategy formation. Management Science, 24(9), 934-948.

Mintzberg, H. (1993). Structure in fives: Designing effective organizations. New York: Prentice-Hall.

Mintzberg, H., \& Waters, J. A. (1985). Of strategies, deliberate and emergent. Strategic Management Journal, 6(3), 257-272.

Ocasio, W., Thornton, P. H., \& Lounsbury, M. (2017). Advances to the institutional logics perspective. In Greenwood, R., Oliver, C., Lawrence, T., \& Meyer, R. (Eds.), The SAGE handbook of organizational institutionalism (pp. 509-531). London: SAGE Publishing.

Olsen, J. P. (2007). The institutional dynamics of the European university. In P. Maassen \& J. P. Olsen (Eds.), University dynamics and European integration (pp. 25-54). Dordrecht: Springer.

Pache, A.-C., \& Santos, F. (2013). Inside the hybrid organization: Selective coupling as a response to competing institutional logics. Academy of Management Journal, 56(4), 972-1001.

Pierson, P., \& Skocpol, T. (2002). Historical Institutionalism in contemporary political science. In I. Katznelson \& H. Milne (Eds.), Political science: The state of the discipline (pp. 693721). New York: W. W. Norton \& Company.

Pinheiro, R., Geschwind, L., Ramirez, F., \& Vrangbæk, K. (2016). Towards a comparative institutionalism: Forms, dynamics and logics across the organizational fields of health care and higher education (Vol. 45). Bingley: Emerald.

Pinheiro, R., \& Stensaker, B. (2014a). Designing the entrepreneurial university: The interpretation of a global idea. Public Organization Review, 14(4), 497-516.

Pinheiro, R., \& Stensaker, B. (2014b). Strategic actor-hood and internal transformation: The rise of the quadruple-helix university? In J. Brankovik, M. Klemencik, P. Lazetic, \& P. Zgaga (Eds.), Global challenges, local responses in higher education. The contemporary issues in national and comparative perspective. (pp. 171-189). Rotterdam: Sense.

Pinheiro, R., \& Young, M. (2017). The university as an adaptive resilient organization: A complex systems perspective. In J. Huisman \& M. Tight (Eds.), Theory and method in higher education research (pp. 119-136). Bingley: Emerald.

Ramirez, F. O., \& Christensen, T. (2013). The formalization of the university: Rules, roots, and routes. Higher Education, 65(6), 695-708.

Simon, H. A. (1991). Bounded rationality and organizational learning. Organization Science, 2(1), 125-134. 
Smets, M., Jarzabkowski, P., Burke, G. T., \& Spee, P. (2015). Reinsurance trading in Lloyd's of London: Balancing conflicting-yet-complementary logics in practice. Academy of Management Journal, 58(3), 932-970.

Sørensen, M. P., Geschwind, L., Kekäle, J., \& Pinheiro, R. (2019). The responsible university: Exploring the Nordic context and beyond. Cham: Springer.

Stensaker, B., \& Benner, M. (2013). Doomed to be entrepreneurial: Institutional transformation or institutional lock-ins of "new" universities? Minerva, 51(4), 399-416.

Suddaby, R., Foster, W. M., \& Mills, A. J. (2014). Historical institutionalism. In M. Bucheli \& D. Wadhwani (Eds.), Organizations in time: History, theory, methods (pp. 100-123). Oxford: Oxford University Press.

Trowler, P., Saunders, M., \& Bamber, V. (2012). Tribes and territories in the 21st century: Rethinking the significance of disciplines in higher education. New York: Taylor \& Francis.

Weick, K. E. (1995). Sensemaking in organizations. London: Sage Publications.

Young, M., \& Pinheiro, R. (2022). The post-entrepreneurial University: The case for resilience in higher education. In R. Pinheiro, Frigotto, L., \& Young, M. (Ed.), Towards resilient organizations and societies: A cross-sectoral and multi-disciplinary perspective (pp. 173-193). Cham: Springer International Publishing. 


\title{
11 Towards The Strategic Cooperation Of "Two Worlds" -
}

\author{
University-Local Government \\ Relationships in Warsaw
}

\author{
Anna Dabrowska, Wojciech Dziemianowicz, \\ and Magdalena Cybulska
}

\begin{abstract}
This chapter addresses the issue of the relationships between universities and local governments by asking the research question: (how) can universities contribute to the design and implementation of public policies at the local level?. Within the Warsaw (Poland) case study we provide a comparison of the role of university stakeholders in the process of design and implementation of the current Warsaw Development Strategy (Warsaw 2030) and contrast this with their role in the historical process within the previous strategy (Warsaw 2020). We found substantial differences between the two strategy processes. In the Warsaw 2030 the evidence provided by academics guided the process of decision-making, while during the Warsaw 2020 it was used to cover the independent decision taken by policymakers while giving the illusion of their supportive role. The analysis of both processes also helped identify factors hindering the involvement of universities within the policy process, namely lack of the systemic solutions for cooperation, lack of incentives for academics to put special focus on activities not related to publication results, low understanding of the third mission among academic community, and limited trust between the representatives of the "two worlds".
\end{abstract}

\section{Introduction}

The term "two-worlds" paradox (Hewitt-Dundas et al., 2019) is usually used in the context of university-business collaboration for highlighting the differences in institutional logics and priorities between business and universities. However, in many cases this term could refer as well to the relationships between university and policymakers. Caplan (1979, p. 459), using the "twocommunities" model, explained the gap between researchers and policymakers. He argues that limited understanding and communication between them are 
a natural consequence of representing separate worlds with different and often conflicting values, reward systems, and languages.

Universities, mostly oriented towards international cooperation and global networks, are often placed far beyond the boundaries of the local community. At the same time local and regional authorities expect from universities more and more contribution to economic development (Arbo \& Benneworth, 2007). However, Polish universities still seem to be institutions quite isolated from both the needs of society and the needs of economy, much closer to the ideal of ivory tower than other European higher education institutions (HEIs) (Kwiek \& Szadkowski, 2018). Since the end of the communist era in 1989, the system of HE in Poland has undergone fundamental changes, but the adaptations of Polish universities to new post-communist and market conditions were much slower than adaptations of other public sector institutions and organizations (Kwiek \& Maassen, 2012).

In this chapter, we address the issue of the relationships between universities and local governments by asking the research question: (how) can universities contribute to the design and implementation of public policies at the local level? We investigate with the help of Warsaw (Poland) case study whether the process of creating the city development strategy can be a meeting point between local government (City Hall Warsaw) and university (University of Warsaw) and whether it can be used for building a long-term and multifaceted partnership. We are interested in determinants of successful cooperation, particularly in the role of "human factor" (leaders and other actors) by exploring how individual actors can shape larger systems around them and overcome specific innovation system problems. Within this study we want to provide evidence of the role of university stakeholders in the process of design and implementation of the current Warsaw Development Strategy - Warsaw 2030 (City Hall of Warsaw, 2018) and contrast this with their role in the historical process within the previous strategy - Warsaw 2020 (City Hall of Warsaw, 2005).

The study offers an original perspective on analysing the engagement of universities for two reasons. Firstly, it explores the contribution of universities to the process of design of public policies. Although there have been numerous studies exploring the contribution universities can make to business, there has been less systematic analysis of other kind of relations within the triple helix, namely between universities and government/administration (Fonseca, 2019). Secondly, the focus is on the relations between university and policymakers at the local level. Within the European Union Cohesion Policy Framework of smart specialization (Foray, 2015) the engagement of universities in designing and implementation processes of regional innovation strategies (RIS) has been embedded in policy agendas and made compulsory. The engagement of universities in the process of designing the city's strategies (local level) does not follow the same path - those documents are not required by Polish law, and thus the decision about collaboration between universities and local government is more autonomous, voluntary, and not driven by any external factors. While the process of engagement of universities within RIS is already explored 
by numerous studies (Aranguren \& Magro, 2020; Benneworth et al., 2017; Fonseca, 2019), the involvement at the local level seems to be underexplored.

This chapter comprises the following sections. Firstly, we consider the conceptual backdrop of the phenomenon. Secondly, we describe the methodology of our research and provide the context of our case study. In the next section, we focus on empirical results and compare two policy processes around Warsaw Development Strategies according to the three main phases of policy process: partnership formation, strategy formulation, and strategy implementation. Finally, we come to the discussion part indicating main factors that hinder and stimulate the involvement of universities within the policy process. The limitations of the study and questions for further research are also indicated.

\section{Conceptual backdrop}

The discussion about innovation systems was for a long time dominated by the institutional approach, highlighting the role of such elements as state policy, incubators, science and technology parks, higher education institutions, or other R\&D institutions (Asheim et al., 2011). Less attention was paid to the fact that each organization of the system is composed of different people characterized by a set of features pertaining to human capital (referring to the qualifications and skills of individuals) and social capital (related to such concepts as trust, cooperation networks, and proximity in social groups) (Putnam, 1993). Paying closer attention to the "human factor" allows us to unpack the various categories and roles played by actors in local innovation systems (Sotarauta, 2018; Benneworth et al., 2017).

One of the most challenging roles to be played within the innovation system is to facilitate cooperation between partners, to mobilize them around common goals, and to collectively solve a problem related to the specific territory, what is reflected in the concept of place-based leadership (Hambleton, 2014). The role of a leader (understood as both formal and informal leaders) is related to the skilful mobilization of available resources (e.g., money and/or people) and in managing the organization (or organizations) embedded into the system as well as building relations between different partners (Sotarauta, 2018; Goddard \& Vallance, 2011). It is particularly important in overcoming barriers in relations between universities and local authorities, as demonstrated in earlier studies (Goddard \& Vallance, 2011).

The process of designing and implementing the strategy of any organization, even if it takes place behind "closed doors", does not take place in a vacuum. The organization operates in a complex and dynamic environment, which consists of factors such as demand conditions, production factors, strategies and competition, and the activities of organizations related to and supporting given sectors, as well as public policies (Porter, 2001). This environment of the organization also influences the adopted strategies (de Wit \& Meyer, 2010), and the relations between various entities operating in and creating this environment are often ambiguous (Pinheiro et al., 2018). The actual institutional 
setting understood as both explicit and formalized sets of rules (regulations, laws) as well as informal or tacit sets of rules (habits, social norms, and values) plays a crucial role but is often underestimated (Rodriguez-Pose, 2013; Horlings et al., 2018). Finding an appropriate balance between institutional and individual processes, between structural solutions and charismatic leaders, remains a big challenge (Sotaratuta \& Beer, 2017).

We also want to contribute to already existing theoretical discussion about the engagement of researchers with policymaking, which differs depending on how the researchers want to position themselves amidst policy and how the policymakers want to utilize the academic expertise. At the other hand the evidence provided by academics can be used by policymakers for different purposes and to different extent. According to the concept of evidence-based policymaking the research can be used to guide decisions at all stages of the policy process. However the evidence can also support a predetermined position, cover the decision already taken, or help to avoid criticism for unpopular policy outcomes by sharing responsibility (Trostle, Bronfman, Langer, 1999; Weiss, 1979).

\section{Methodology and case study overview}

\section{Methodology}

To answer the research question, a qualitative approach was employed, which is beneficial over a quantitative approach for obtaining in-depth insight (Yin, 2006). We used the method of comparative case study, useful for dealing with a complex phenomenon within its real-world context. We examined two cases of design and implementation of Warsaw Development Strategies: one within the Warsaw Development Strategy adopted by City Council in 2005 - Warsaw 2020 (City Hall of Warsaw, 2005) and the other within the Warsaw Development Strategy adopted in 2018 - Warsaw 2030 (City Hall of Warsaw, 2018). Using the most similar design for the choice of cases we were able to focus on differences in the two processes while disregarding other knowledge about the cases (Stake, 1995). Moreover, the case study method is also useful because the investigated phenomenon occurs partially in the present (the implementation of Warsaw 2030 (City Hall of Warsaw, 2018) is still in progress) (Yin, 2006).

In our approach, we distinguish three main phases - (a) partnership formation, (b) strategic plan formulation, and (c) strategy implementation - which reflect to the main phases of policy process. Since Warsaw 2030 (City Hall of Warsaw, 2018) is the document currently in force, we cover in our analysis the implementation phase as of June 2020.

The data for this qualitative study are mainly drawn from semi-structured interviews with key actors directly involved with the Warsaw 2020 (City Hall of Warsaw, 2005) and Warsaw 2030 (City Hall of Warsaw, 2018). A total of 19 interviews were conducted between April and June 2020. Some of the 
respondents were involved in both strategic processes. We took into account the perspectives of different stakeholder groups: ${ }^{1}$

- Warsaw authorities and city officials (4 respondents) [described as city officials in interviews];

- Top managers and supporting staff at universities (3) [university representatives];

- University academics directly engaged in the strategy design or implementation (10) [university academics];

- Other stakeholders (2) [other stakeholders]

With the help of in-depth interviews we explore the following aspects: (a) the role of university's stakeholders in the process, (b) the motivation behind the involvement of academics within the process, (c) main determinants facilitating and/or hampering the cooperation between university and local government, and (d) perception of the long-term impact on the cooperation.

In addition, the data collection combines secondary sources in the form of policy documents and reports of both City of Warsaw and HEIs in Warsaw. This allowed for a holistic perspective not only of the outcomes of the processes but most importantly of the nature of the processes themselves. Moreover, using multiple sources of data (interviews and secondary sources) offered the possibility of including different perspectives with the added benefit of triangulation of the results.

\section{Case study overview}

The Law on Higher Education and Science (known as Law 2.0) implemented in 2018 defines the mission of the higher education system in Poland, which is based on "conducting the highest quality education and scientific activity, shaping civic attitudes, as well as participating in social development and creating an economy based on innovation" (art.2). The reforms, aimed at expanding the cooperation of universities with the environment, were launched in 2009 (Kwiek \& Szadkowski, 2018). However, the national research evaluation (being one of the main instruments of science policy in Poland and one of the instruments shaping the directions of HEI's activities) does not create strong incentives for Polish HEIs to put special focus on activities not related to publications results. Thus, despite the changes within Law 2.0, the regional engagement of universities remains a big challenge. The weak level of cooperation between universities and the environment is a problem that Polish HEIs have been struggling with for years (Diagnosis . ., 2009; Kwiek \& Szadkowski, 2018; Antonowicz, 2020). Effective activity of the science sector within the third mission also requires commitment and appropriate attitude of the local government administration. The one in Poland still encounters numerous barriers, including politicizing relations or treating the science sector in an instrumental way (Dąbrowska \& Dziemianowicz, 2011). 
Warsaw is the capital and the largest city of Poland (with over 1.7 million residents within the city and 3 million residents within its metropolitan area). It struggles with specific challenges which include innovation or attracting human capital; therefore, the involvement of universities in the design and implementation of local policy seems to be crucial for the effective development of the city. Warsaw with 64 universities attracts $18 \%$ of all students in Poland (2019, GUS). ${ }^{2}$ The biggest comprehensive university, the University of Warsaw, is one of the largest employers in the city (with over 7,300 staff) and an important source of human capital (40,637 students; every year ca. 9,000 graduates, 70\% of them remain in the capital city region) (Gołdys et al., 2021). Other leading universities in Warsaw are: Warsaw University of Technology (technical profile), Warsaw University of Life Sciences (nature profile), and Warsaw School of Economics (economic profile). All of them are public, government-funded institutions.

Previous studies on relations between universities and Warsaw authorities in the context of engagement in policymaking indicate their apparent and occasional nature. Among the main barriers the following were identified: difficulties in the flow of information, underestimating the role of science in local development or dependence on the political cycle and personal attitude towards such cooperation (Dąbrowska \& Szmigiel-Rawska, 2015).

The local development strategy is not a document required by law; however, Warsaw authorities, similar to other municipalities in Poland, decide to create it because it helps them make crucial decisions. However, in many cases the decision about designing the document is driven by another incentive; when applying for European funds, local governments have had to present the convergence of the prepared projects with the "strategic plans" (Dziemianowicz et al., 2012). That is why local development strategies of some municipalities in Poland are of a facade character ("window dressing") and rarely constitute a real instrument for city management. The level of involvement of external partners in the process of formulating strategic assumptions is very diverse; however, there is a noticeable trend of increasing the degree of participation of various social groups (Dziemianowicz \& Cybulska, 2019).

\section{Comparing the strategy processes: 2020 versus 2030}

\section{Partnership formation}

In the process of building the team responsible for the design of Warsaw 2020 (City Hall of Warsaw, 2005), the important factors in the selection of academics (made by employees of the City Hall responsible for the preparation of the strategy) were good contacts, previous experience in cooperation, and/or the recognized position of the local academic in a given thematic area (such as demography, transportation, and so on).

The process of formulating partnerships took place at two levels. The first was composed of the President's advisers, that is, his close political associates, 
who were also jointly responsible for final management decisions in the following phases. The second can be characterized as a working one; here the key role was played by the Department of Strategy (DoS), in which the strategy preparation process formally took place. DoS's employees encouraged various local academics to create a document that, on the one hand, would diagnose the situation in the city and would provide the basis for formulating strategic objectives, on the other. Invitations to cooperate involved academics from various universities and were individualized. It is important that meetings and discussions took place at the working level, resulting in a draft document. The draft of the strategy was then handed over to the mayor's advisers, and this ended the formal cooperation between the City Hall and academics involved in the process of creating the strategy. The draft strategy was then "politically edited", resulting in changes to it that were not discussed with members of the research team. Ultimately, the names of the involved academics were not even mentioned in the strategy (as co-authors of the document).

After the document was submitted to the politicians, a meeting with academics was organized. Political advisers did not want to discuss with us, but only to inform what kind of changes we needed to do. The changes with which we did not agree and we did not hear any substantive arguments for. . . we did not communicate.

(university academic)

Building partnerships within the Warsaw 2030 (City Hall of Warsaw, 2018) had a slightly different character, although, as a general rule, the city attempted to work with experienced and dedicated academics having prior experience in cooperation with the City Hall. This time, however, the previous "group of advisors" was replaced by a team of experts (from the local science sector), one of whom was the lead expert supervising the process of updating the strategy, alongside three thematic experts responsible for the areas of economy, society, and urban space. The lead expert (local academic) was selected from several proposals. His advantage was experience in strategic cooperation with various levels of regional and local administration, including within Warsaw. The selection of the team of three thematic experts was consulted with the lead expert, and one of the arguments, apart from qualifications, was the assessment of the climate of cooperation with the person concerned.

We wanted to involve people [experts] associated with Warsaw because they are on the spot and know the local conditions well. In addition, we wanted them to be people who had already cooperated with our office. Thanks to this, they could better understand the functioning of the administration while on the other hand we were more at ease about them, we trusted them more. At some stage, we rejected titled professors, and instead looked for academics with knowledge and experience, but also being embedded with normal reality and ordinary people. 
The process of opening up to a wider participation also included the establishment of three working groups ("economy", "society" and "urban space" groups, each composed of 25 people) involving also academics. The recruitment to each group took place in two ways. Half of the working group were partly employees of the local administration in the broad sense (including subsidiaries of the municipal government) and partly people from outside the administration. This group included several academics who had prior experience in designing other strategic documents within administration. The second half of the working group (12 people) was selected in the form of open recruitment. Every Warsaw resident could offer their candidacy by submitting an application form comprising two reference letters from organizations operating in the city, a proposal of the applicant's contribution to the group's work, their idea of activities in their thematic area in an urban context, and an indication of their experience in cooperation for the city.

As a result, the working groups comprised representatives of various universities and scientific institutions from Warsaw. Their motivations for participation in the strategy process usually resulted from scientific interests often related to urban development. Cooperation by designing the strategies gave to the academics the opportunity to impart a more practical and applicative dimension to their work.

\section{Strategic plan formulation}

The two-track process of creating the Warsaw 2020 - at the level of the Office of DoS and the President's Team of Advisors - is described by respondents as "deprived of political support" on the one hand and as a rather "politicized" process on the other (City Hall of Warsaw, 2005). However, the seemingly contradictory terms seem to be justified in a way. On the one hand, the office formally coordinating this process worked in some solitude, because the strategy did not break through to the consciousness of a wider group of officials. This was probably the result of the generally low awareness of the role of strategic management as well as the consequence of the fact that this document, and its designing, was not given a "high political rank" in the office. At the same time, however, the final document was largely shaped by the President's Team of Advisors, where political considerations were decisive.

The strategy needs someone who, on the one hand, can introduce it into the official "bloodstream" and on the other, be the face of the strategy outside the office, emphasizing its high rank. This was lacking in building the Warsaw 2020.

(city official)

The process of creating the Warsaw 2030 (City Hall of Warsaw, 2018) looked rather different in this respect. The strategy was created in a socialized way in cooperation with residents, experts, and local officials. Efforts were made to ensure that the strategy-building process had the right rank, both through 
active participation in the process of one of the vice presidents ("high political legitimacy") and through activities involving representatives of various offices (as working-group participants).

As a result of the approach used in 2004-2005, the influence of academics was limited since, in their assessment, the whole process did not bring the expected results and their work (largely consisting in writing fragments of the document) was not sufficiently utilized. The illegibility and two-foldness of the process as well as designing a strategy that would be shelved were, among others, the primary reasons for waiving participation in the subsequent strategic process.

Representatives of the science sector, like other groups of stakeholders, had a much greater driving force in the process of formulating assumptions for the strategic document adopted in 2018. Work carried out in the working groups concerned the next stages: the vision of Warsaw's development, strategic diagnosis, strategic and operational goals, as well as monitoring indicators (Report on the Strategy work). Participation in the meetings of working groups, debates, consultation meetings, expressing opinions on documents, and paper sessions provided the opportunity to conduct broad discussions and fostered a sense of greater agency.

It is worth emphasizing that the academics participating in the process were perceived in the vast majority of cases as those who took care of not only the appropriate substantive level of the strategy building process but also the culture atmosphere, creative discussion, partnership, and political neutrality. This was possible, among other aspects, because the academics involved adopted the perspective of "a Warsaw resident" and not that of "an important professor".

There were many academics who spoke a very accessible language, listened to people, tried to understand what they were talking about and give it a broader context. This was real added value, it raised the discussion to a higher level.

(university academic)

\section{Policy implementation}

In the case of Warsaw, we can observe a significant change in the approach towards the implementation of the strategy already in its design phase. The Warsaw 2020 (City Hall of Warsaw, 2005) was built through the prism of President Lech Kaczyński’s political programme. The President exerted great pressure for the strategy to include provisions removed from his election programme. The fact that the strategy implementation phase began after the change of local authorities most probably influenced the organization of this process (The mid-term evaluation of the Development Strategy. . ., 2015).

In addition, shortly after the adoption of the strategy, in 2006 the Bureau for European Development and Integration Strategy, responsible for the documentbuilding process, was liquidated, and most of its employees were dismissed (there was no conviction among politicians that the strategy is a continuous 
process, requiring the implementation of planned activities, monitoring, and possible modification). The lack of specific institutional memory was seen as an additional threat to the implementation of the strategy.

Warsaw 2020 was a bit unlucky. There was no office in the agency that would take care of it after it was adopted.

(city official)

In the process of implementing the Warsaw 2020 (City Hall of Warsaw, 2005) no specific assumptions for cooperation with external stakeholders were made. The evaluation summarizing the implementation phase recommended expanding the possibilities and tools for social participation (The mid-term evaluation of the Development Strategy. . ., 2015).

The process of implementing the Warsaw 2030 (City Hall of Warsaw, 2018) is ongoing at the time of writing, in the phase of creating executive programmes for the individual operational objectives. Warsaw President's Plenipotentiary for the city development strategy is in charge of implementing the strategy (appointed by the city mayor in August 2019 as a manifestation of a systemic approach to implementing the strategy). The system is based on the activities of the leading offices (dedicated from among the structures of Warsaw City for specific programmes) and programme coordinators (City development strategy management system, 2019). The Plenipotentiary position is new and is not one of the vice presidents but a person who was the unofficial leader of the entire strategic process on behalf of the office.

Work on individual programmes is carried out separately, but in its assumptions the whole system is based (like the process of formulating strategic assumptions) on cooperation with various stakeholders and social groups. The scientific community is involved, among others, in co-creating the executive programme for the operational objective titled "We inspire the world". The recruitment process of members of the social groups involved in programme shaping was an open one, although invitations were addressed simultaneously to various important institutions, universities included.

At the time of writing, the implementation of the planned cooperation between the City Hall and Warsaw universities faces several barriers, most of which are systemic rather than local. These include (a) the lack of a support system, including promotion, for persons involved in the implementation of the university's third mission; (b) low priority of issues related to the university's third mission in the activities of academics and the organizational units within the university; and (c) poorly developed thinking and strategic management practice, especially at the university. The following accounts are rather illustrative:

Cooperation with the environment appears most often in terms of providing for certain deficiencies/deficits, and not in terms of mission or investment. 
Nevertheless, there is no such strategic thinking in the "university's genetic code", i.e. it is not institutionalized, permanent and therefore relies on the grace or disgrace of a specific person.

(university representative)

An academic participant in the process of implementing the Warsaw 2030 (City Hall of Warsaw, 2018) points to the problem of communication both between scientific units and the Warsaw City Hall and within the science sector itself.

We have a problem ourselves to communicate our needs and expectations, so it is hard to require that these needs be later taken into account at the level of specific programs.

(university academic)

It is worth to emphasize the importance of two dimensions of cooperation between the University of Warsaw and the City of Warsaw regarding the implementation of the Warsaw 2030 (City Hall of Warsaw, 2018). The first dimension is institutional cooperation formalized at the highest level. In the case of Warsaw, the local administration does not want to sign special agreements with individual universities in fear of being accused of favouring one at the expense of others. Establishing the Conference of Rectors of Warsaw Universities, bringing together a total of 21 universities, was supposed to be a chance to organize systematic institutional cooperation. However, experience to date shows that it is rather an organization that finds it difficult to develop joint activities. Another potential solution is the proposal of partial dependence of the university on the local budget (currently it depends on central subsidies and, to a minimal extent, on private financing). However, there is the administration's fear of the universities providing human resources inadequate to the administration's needs and on the other side the university fears losing its independence.

The second dimension of cooperation between the university and the City Hall is an unofficial collaboration in a "human-human" relationship. Paradoxically, this form of building relationships is perceived as more practical, effective, and accepted by university managers as well as local authorities. It is the interested entities - individual administrative employees and individual academics that often initiate and establish contact with each other.

Another way leading to cooperation is a tender procedure in which the academics can also make an offer themselves or be a member of a team from outside the university - for example, a private company. From the academics' point of view, entering into collaboration directly is the most profitable way. Thus, in fact, academics work with numerous offices of the Warsaw City Hall, bypassing the problem that both entities lack a systemic institutionalization towards cooperation. This, in turn, creates a vicious circle, namely no attempts are made to create systemic solutions because the "existing, provisional solutions" 
work. However, such a manner of cooperation is not perceived by the academics themselves as a durable and long-term partnership:

As long as the City needs us, we will be invited to cooperate. But I don't have the feeling that academics have a permanent place in the processes of local politics.

(university academic)

\section{Discussion and conclusions}

Our analysis shows substantial differences between the two strategy processes. The broad scale of inclusion of residents and other stakeholders, including university's representatives, was the main observed difference between the two analysed processes. In Warsaw 2030 (City Hall of Warsaw, 2018), universities representatives were actively involved in every stage of the process of designing the strategy offering substantive and methodological support to working groups. Moreover, their involvement was continued in the implementation phase. It is a very different experience from Warsaw 2020 (City Hall of Warsaw, 2005), when the role of academics was limited to short-term assistance by providing scientific knowledge for the purpose of strategic diagnosis (which was anyway used only to a limited extent), and they were not even fully informed about the final results of the whole process. In the Warsaw 2030 (City Hall of Warsaw, 2018) the evidence provided by academics was guiding the process of decision-making, while during the Warsaw 2020 (City Hall of Warsaw, 2005) it was used rather for different purposes - to cover the independent decision taken by policymakers while giving the illusion of their supportive role (Trostle, Bronfman, Langer, 1999; Weiss, 1979).

The analysis of both processes helps to identify diverse factors that hinder or stimulate the involvement of universities within the policy process, increasing the likelihood to build long-term and multifaced partnerships. One of the observed obstacles for involvement of academics is the lack of systemic solutions for such cooperation. Despite the existence of agreements between universities and local authorities, cooperation is still weak, because there are no strong incentives for academics to put special focus on activities not related to publications results. Moreover, the cooperation with non-scientific community (being regarded as of lower value than "pure science") is not widely recognized by the academic community.

In addition, awareness seems to be missing (especially among university managers) that such solutions are needed. One reason may be rather the low role attributed to universities' third mission in Poland, when the financial dependence of these organizations is related to teaching and research activity (Antonowicz, 2020). The interest in the cooperation of universities with the environment is focused rather on cooperation with business than with the local government (Kwiek \& Szadkowski, 2018) and local communes (Misra \& Pinheiro, 2020), which may contribute to the influence of universities on local development. The second reason may be the fact that universities are facing 
the changes resulting from the increasing competition for resources with other public institutions (Kwiek \& Szadkowski, 2018). The necessity to cooperate with potential competitors (the remaining public sector), as well as cooperation with business, causes the process of erosion of trust in science (Sztompka, 2007). The third is the poorly developed thinking and practice of strategic management (Sułkowski \& Seliga, 2019).

In the absence of a system, ad hoc, practical solutions are sought enabling partners to achieve individual goals. In this case, it is primarily professional support in the process of building and implementing strategies (Warsaw City Hall) and the opportunity to pursue scientific interests in the application dimension (academics). This clearly shows that institutional conditions are important because they normalize and stimulate cooperation. Still, cooperation is primarily determined by the human agency (Fonseca, 2019). And, although an independent academic or a single administration employee, regardless of which level they occupy in the organizational structure, is not enough for cooperation (Goldsmith \& Eggers, 2004), individuals can initiate such cooperation despite everything (Benneworth et al., 2017).

The case of Warsaw shows that the cooperation initiative does not have to be on the side of formal leaders (mayors, leading decision-makers), and this role can also be taken over by informal leaders, often remaining at lower levels of the formal structure (Sotarauta \& Pulkkinen, 2011). It goes in line with the concept of "place-based leadership", stressing that the leadership is not restricted to those in positions of authority (Hambleton, 2014).

It is important to underline the different position in the cooperation between local administration employees and individual academics. The former pursue their goals and objectives of the organization while the latter may find themselves in a conflict between their own interests and the interests of the university (Diagnosis . . ., 2009). However, the activity of an academic in non-university structures must not always have a pejorative meaning for the university itself. Scientists cooperating with the local government are still a resource of the university and can help overcome the barriers to cooperation as regards "fit with regional needs" or "staff orientation" (see Benneworth et al., 2013). Individual cooperation may result in increased trust not only in a narrow social network, but in a broader sense, facilitating cooperation at the institutional level (Putnam, 1993; Young et al., 2018). However, questions remain on whether those people with their grassroots initiatives can permanently change the functioning of entire institutions (Maguire, 2007 following Garud et al., 2007; Benneworth et al., 2017). As Sotarauta and Pulkkinen (2011) indicate, it can be expected that individual activities in narrow social networks may, in the long run, cause changes at the level of the entire system.

This study has several limitations. Firstly, the comparison of both processes is not complete because it doesn't cover the whole implementation phase of the Warsaw 2030 (only until June 2020, City Hall of Warsaw, 2018). Future studies could remedy these limitations by covering the whole implementation phase 
of Warsaw 2030 (City Hall of Warsaw, 2018). It could also be interesting to continue this kind of research within the next policy process around next strategy of Warsaw. The second limitation results from the adopted method, based primarily on in-depth interviews supported by the analysis of existing data. The limited number of interviews and the elapsing time since the start of work on Warsaw 2020 (City Hall of Warsaw, 2005) sometimes resulted in different or even divergent views of the interviewees on the discussed issues. In such cases, our inference had to be particularly careful. The third limitation results from the assumption that the strategy and its implementation are an immanent and important element of development policy. However, in the Polish conditions, political processes and strategic actions are not always the same, and even strategies are "forgotten" just after they are adopted by city councils.

\section{Acknowledgements}

This chapter is a result of two projects:

1 "The role of universities in regional development and building the local innovation system”, Microgrant of University of Warsaw Faculty of Geography and Regional Studies, BOB-661-10/20 (PI: Anna Dąbrowska)

2 "Dualism in commune development in Poland in the context of policies and aspirations of local communities as well as external factors - compared to the chosen communities in EU', funded by Narodowe Centrum Nauki (National Science Centre, Poland), grant number DEC-2018/31/B/ HS4/00260 (PI: Wojciech Dziemianowicz)

\section{Notes}

1 One of the authors of the chapter was involved as a key expert in the process of designing Warsaw 2030. Trying to maintain the objectivity of evaluations, his experience, and knowledge of the process "from the inside" was used as a factor facilitating the interpretation of opinions obtained during in-depth interviews.

2 Own calculations based on data obtained from Statistics Poland.

\section{References}

Antonowicz, D. (2020). Understanding the development of technical universities in Poland. In L. Geschwind, A. Broström, \& K. Larsen (Eds.), Technical universities. Higher education dynamics (Vol. 56, pp. 61-77). Cham: Springer. https://doi.org/10.1007/ 978-3-030-50555-4_5.

Aranguren, M. J., \& Magro, E. (2020). How can universities contribute to regional competitiveness policy-making? Competitiveness Review, 30(2), 101-117. https://doi.org/10.1108/ CR-11-2018-0071.

Arbo, P., \& Benneworth, P. (2007). Understanding the regional contribution of higher education institutions: A literature review. OECD Education Working Papers, 9. OECD Publishing. https://doi.org/10.1787/161208155312. 
Asheim, B., Moodysson, J., \& Tödtling, F. (2011). Constructing regional advantage: Towards state-of-the-art regional innovation system policies in Europe? European Planning Studies, 19(7), 1133-1139. https://doi.org/10.1080/09654313.2011.573127.

Benneworth, P., Charles, D., Hodgson, C., \& Humphrey, L. (2013). The relationship of community engagement with universities' core missions. In P. Benneworth (Ed.), University engagement with socially excluded communities (pp. 85-101). Dordrecht: Springer.

Benneworth, P., Pinheiro, R., \& Karlsen, J. (2017). Strategic agency and institutional change: Investigating the role of universities in regional innovation systems (RISs). Regional Studies, 51(2), 235-248. https://doi.org/10.1080/00343404.2016.1215599.

Caplan, N. (1979). The two-communities theory and knowledge utilization. American Behavioral Scientist, 22(3), 459-470.

City Development Strategy Management System. (2019). [System zarządzania strategią rozwoju miasta]. Załącznik do zarządzenia nr 1277/2019 Prezydenta Miasta Stołecznego Warszawy. z dnia 1 sierpnia 2019 r., https://bip.warszawa.pl/UMBIP/Handlers/GetBlob.asp x?id=1454063\&fName=1277_0108zal.docx.

City Hall of Warsaw. (2005). Development strategy of the Warsaw capital city until 2020. Warszawa. [Strategia Rozwoju Miasta Stołecznego Warszawy do 2020 roku], https://spolecznastrategia.um.warszawa.pl/sites/default/files/strategia_rozwoju.pdf

City Hall of Warsaw. (2018). \#Warsaw2030 strategy. Warszawa. https://um.warszawa. $\mathrm{pl} /$ documents/56602/38746844/\%23Warsaw2030+Strategy.pdf/8845940c-99df-aca41a03-524adafe4f63?t=1639549741334

Dąbrowska, A., \& Dziemianowicz, W. (2011). The innovation-based development experience of polish cities - the role of local administration. Studia KPZK, 141, 153-168.

Dąbrowska, A., \& Szmigiel-Rawska, K. (2015). The local leaders' attitude towards placebased collaboration in the Warsaw metropolitan area. MAZOWSZE Studia Regionalne, 16, 87-107. https://doi.org/10.4335/14.4.827-851(2016).

de Wit, B., \& Meyer, R. (2010). Strategy. Process, content, context. Hampshire: CENGAGE Learning EMEA.

Diagnosis of higher education in Poland. (2009). Warszawa-Gdańsk: Ernst \& Young Business Advisory and Instytut Badań nad Gospodarką Rynkową.

Dziemianowicz, W., \& Cybulska, M. (2019). Participation of local communities in the process of building development strategies - an example of voivodeship's capitals in Poland. Prace i Studia Geograficzne, 64(3), 161-180.

Dziemianowicz, W., Szmigiel-Rawska, K., Nowicka, P., \& Dąbrowska, A. (2012). Planowanie strategiczne. Poradnik dla pracowników administracji publicznej. Warszawa: Ministerstwo Rozwoju Regionalnego.

Fonseca, L. (2019). Designing regional development? Exploring the University of Aveiro's role in the innovation policy process. Regional Studies, Regional Science, 6(1), 186-202. https://doi.org/10.1080/21681376.2019.1584050.

Foray, D. (2015). Smart specialisation: Opportunities and challenges for regional innovation policy (regions and cities). Abingdon-New York: Routledge.

Garud, R., Hardy, C., \& Maguire, S. (2007). Institutional entrepreneurship as embedded agency: An introduction to the special issue. Organization Studies, 28(7), 957-969. https:// doi.org/10.1177/0170840607078958.

Goddard, J., \& Vallance, P. (2011). The civic university and the leadership of place. Newcastle University, UK: Centre for Urban and Regional Development Studies (CURDS).

Goldsmith, S., \& Eggers, W. D. (2004). Governing by network. The new shape of the public sector. Washington, DC: Brookings Institution. 
Gołdys, A., Dąbrowska, A., Pugacewicz, A., \& Wasilewski, D. (2021). Appendix E: University of Warsaw. In R. Tijssen, J. Edwards \& K. Jonkers (Eds.), Regional Innovation Impact of Universities (pp.175-189). Cheltenham, UK, Northampton, MA, USA: Edward Elgar Publishing Limited.

Hambleton, R. (2014). Leading the inclusive city: Place-based innovation for a bounded planet. Bristol: Policy Press.

Hewitt-Dundas, N., Gkypali, A., \& Roper, S. (2019). Does learning from prior collaboration help firms to overcome the "two-worlds" paradox in university-business collaboration? Research Policy, 48(5), 1310-1322. https://doi.org/10.1016/j.respol.2019.01.016.

Horlings, L. G., Roep, D., \& Wellbrock, W. (2018). The role of leadership in place-based development and building institutional arrangements. Local Economy: The Journal of the Local Economy Policy Unit, 33(3), 245-268. https://doi.org/10.1177/0269094218763050.

Kwiek, M., \& Maassen, P. (Eds.). (2012). National higher education reforms in a European context: Comparative reflections on Poland and Norway, higher education research and policy. Frankfurt am Main: Peter Lang.

Kwiek, M., \& Szadkowski, K. (2018). Higher education systems and institutions Poland. In P. Teixeira \& J. Shin (Eds.), Encyclopedia of international higher education systems and institutions. Dordrecht: Springer.

Maguire, S. (2007). Institutional entrepreneurship. In S. Clegg \& J. R. Bailey (Eds.), International Encyclopedia of Organization Studies (pp. 674-678). London: Sage.

Misra, D., \& Pinheiro, R. (2020). Engaging with local communities: Five key lessons that businesses can learn from universities. Industry and Higher Education, 1-5. https://doi. org/10.1177/0950422220966964.

Pinheiro, R., Šima, K., Young, M., \& Kohoutek, J. (2018). University complexity and regional development in the periphery. In R. Pinheiro, M. Young, \& K. Šima (Eds.), Higher education and regional development (pp. 1-20). Palgrave Studies in Global Higher Education. Cham: Palgrave Macmillan. https://doi.org/10.1007/978-3-319-78643-8_1. Porter, M. E. (2001). Porter about competition. Warszawa: Polskie Wydawnictwo Ekonomiczne. Putnam, R. D. (1993). Making democracy work: Civic traditions in modem Italy. Princeton: Princeton University Press.

Report on the strategy work (attachment 1 to \#Warsaw2030 Strategy).

Rodriguez-Pose, A. (2013). Do institutions matter for regional development? Regional Studies, 47(7), 1034-1047. https://doi.org/10.1080/00343404.2012.748978.

Sotarauta, M. (2018). Place leadership for regional innovation, 43. Tampere: Sente Working Papers.

Sotarauta, M., \& Beer, A. (2017). Governance, agency and place leadership: Lessons from a cross national analysis. Regional Studies, 51(2), 210-223. https://doi.org/10.1080/0034 3404.2015.1119265.

Sotarauta, M., \& Pulkkinen, R. (2011). Institutional entrepreneurship for knowledge regions: In search of a fresh set of questions for regional innovation studies. Environment and Planning C: Government and Policy, 29(1), 96-112.

Stake, R. (1995). The art of case study research. Thousand Oaks, CA: Sage.

Sułkowski, Ł., \& Seliga, R. (2019). Profesjonalizacja zarządzania uczelniami w Polsce. In J. Woźnicki (Ed.), Transformacja Akademickiego Szkolnictwa Wyższego $w$ Polsce w okresie 30-lecia 1989-2019. Warszawa: Konferencja Rektorów Akademickich Szkół Polskich.

Sztompka, P. (2007). Zaufanie. Fundament społeczeństwa. Kraków: Wydawnictwo Znak.

The Law on Higher Education and Science, Dz. U. 2018 poz. 1668.

The mid-term evaluation of the Development Strategy of the Warsaw Capital City until 2020. (2015). Warszawa: Agrotec Polska Sp. z o.o. 
172 Anna Dąbrowska et al.

Trostle, J., Bronfman, M., \& Langer, A. (1999). How do researchers influence decisionmakers? Case studies of Mexican policies. Health Policy Plan, 14(2), 103-114. https://doi. org/10.1093/heapol/14.2.103.

Weiss, C. (1979). The many meanings of research utilization. Public Administration Review, 39(5), 426-431. https://doi.org/10.2307/3109916.

Yin, R. K. (2006). Case study methods. In J. L. Green, G. Camilli, \& P. B. Elmore (Eds.), Handbook of complementary methods in education research (pp. 111-122). Mahwah, NJ and London: Lawrence Erlbaum Associates Publishers.

Young, M., Pinheiro, R., \& Šima, K. (2018). Conclusion: University ambiguities and analytic eclecticism. In R. Pinheiro, M. Young, \& K. Šima (Eds.), Higher education and regional development (pp. 191-212). Palgrave Studies in Global Higher Education. Cham: Palgrave Macmillan. https://doi.org/10.1007/978-3-319-78643-8_8. 


\title{
12 Keeping Talents in the Region?
}

\author{
Educational Internships and Their \\ Impact on Regional Development
}

\author{
Laila Nordstrand Berg and Kristin Lofthus Hope
}

\begin{abstract}
This chapter focuses on how internships within higher education contribute to place-shaping and regional development. Especially how employees and students engage with regional partners to develop education by co-creating internship projects. Strategies concerning regional development are set into play when higher education institutions (HEIs), private and public sector collaborate to provide education. The empirical focus is on academic disciplines in Norway that quite recently have established student practice through internships, namely sociology, history, and business administration. We follow up this practice element by analysing the perspective of educational fields and different public and private actors within a regional setting to provide internships for students. The overall research question is this: How do internships contribute to educational and regional development from the perspectives of HEIs and regional actors?
\end{abstract}

\section{Introduction}

In the literature regarding sustainability in place-shaping and regional development, there is an increasing focus on education, as well as economic development, planning and regeneration, health, transport, housing, and security (Collinge et al., 2010). However, as part of their mission, universities are expected to contribute to regional engagement, together with teaching and research (Benneworth \& Fitjar, 2019). Although university ambition and strategy involve forming partnerships with regional actors to develop the region, it is when employees and students engage with the regional partners that the strategies are set into play. Traditionally, university colleges have many collaborative activities with the professional context they educate for. Recently, there is a developing political and societal perception that university education or their programmes lack relevant connectedness to working life (NOKUT, 
2019). Simultaneously, government and higher education institutions (HEIs) underscore that learning by doing is a good learning mechanism for students. In addition, such interaction can provide important feedback to the HEIs to ensure that the education curriculum and content are up to date and coherent with the demands of society (Arbo, 2019). Teacher, nurse, and medical education are typical examples where in-house training is crucial.

This type of practical course element has been rather missing from a range of academic fields. In this chapter, we focus on academic disciplines in Norway that quite recently have established student practice through internships, namely sociology, history, and business administration. We are following up on this practice element by analysing the perspective of organizations, including educational fields and public and private actors within a regional setting, to provide internships for students. As this arrangement is fairly new, we can expect limited knowledge on how to align theoretical knowledge with needs from practical work life, as well as few norms and anticipations of how to develop the internships to improve education and contribute to regional development.

Regions can be considered as territorial places with characteristic natural resources and related knowledge producers. The territories are embedded in specific regional innovation systems (RIS) where local and global resources are flowing (Benneworth \& Hospers, 2007; Cooke, 2005). Such RIS contains networks between private and public actors and civil society where coproduction and innovation can take place (Peer \& Penker, 2016). Locating HEIs has been recognized as a political instrument to spur regional development since the middle of the last century (Peer \& Penker, 2016), and the literature on the role of HEI related to regional development is extensive (Caniëls \& van den Bosch, 2011). HEIs can contribute to coproduction and innovation through employees and students participating in knowledge production (Peer \& Penker, 2016). Internships can contribute to ensuring human capital within regions and building regional coalitions necessary for regional development (Jongbloed, 2010). Nonetheless, there remains no automaticity in development. Regional effectiveness depends on the willingness of regional actors to cooperate (Peer \& Penker, 2016).

Studies focusing on the regional role of HEIs suggest that major challenges, cultural as well as structural, remain (Benneworth, 2018; Pinheiro et al., 2018) and that key tensions exist between core teaching and research tasks and processes of local engagement by academic communities (Benneworth et al., 2017). There is an emerging consensus in the literature that to ensure the sustainability of HEIs' regional mandates one needs to consider both the structural and cultural complexity and the dynamic institutional and technical environments (Goddard et al., 2016). National policy arrangements and their focus on efficiency and global excellence (world university rankings, external funding, and so on) often act as major barriers to local academic engagement (Benneworth et al., 2017). Based on research excellence, HEIs generate income from global actors (Benneworth \& Hospers, 2007), but such strive for excellence can be quite distant to mundane activities within the universities and cooperation 
with regional actors. Based on studies regarding internship and regional development, the focus has mainly been on students from applied sciences in relation to building their skills, for example, self-esteem (Price, 2002). An example of a study relevant to our chapter is conducted by Tovey (2001) who focuses on the positive effects of work life socialization, professionalism, and motivation through experiential learning. In addition, Tindowen et al. (2019) focused on how students developed both hard and soft skills through internships. Benneworth and Fitjar (2019) underline that universities contribute to regional development through graduate employment, the collaboration between university and industry, in addition to policymaking and impacting the RIS. Arguably, regional engagement is not an isolated task but rather interlinked with research and teaching activities at universities. The skills of the graduate may not always match the demands in the region, and therefore the collaboration and communication between the recipient and the supplier of professional knowledge are crucial so that the best match can be obtained.

Less attention has been given to academic fields that do not have a long tradition for internships. We, therefore, aim to fill this gap by studying how the selected academic fields and the regional actors are handling internships to meet regional needs, while simultaneously focusing on educational development. With this background, we are posing the overall research question: How do internships contribute to educational and regional development from the perspectives of HEIs and regional actors?

In the continuation of this chapter, we first give a brief presentation of HEIs in Norway. We thereafter elaborate on our theoretical framework and present design and methodological aspects. The findings of our study are presented separately and thereafter discussed in relation to the theoretical framework in the last concluding section. Avenues for further development and research are suggested.

\section{The Norwegian Higher Educational Landscape}

The study in this chapter was conducted at a regional university college in Norway. The Norwegian educational landscape is dominated by public providers at all levels, and there has been a political drive to strengthen access to higher education in regions with educational systems that date back to the 1950s (Pinheiro et al., 2016). A dual system of centralized universities and regional district colleges was established. This system provided central education to the districts, such as nursing, teaching, public administration, economy, and all kinds of engineering. Following the development in the fields, education and institutions were developed through the 1970s. The dispersed model of organizing was costly and perceived as too fragmented. Reforms were enforced in the 1990s, establishing a binary system of universities and university colleges (Kyvik, 2002). In this process, 98 local colleges merged into 26 public university colleges, and a strong mandate to pursue regional development remains. An aspect underlining the importance of access to higher education across 
geography and socio-economic layers is the funding of the sector. Education at public universities is free of tuition fees, and students are offered stipends and affordable loans for life support. This state stipend and loan arrangement (labelled Lånekassen) was established in 1947 and increased possibilities for students to pursue higher education, independently of the family income (Bjelle, 2019). In the last two decades, the focus has been on facilitating research, innovation, and development between all educational institutions and different regional stakeholders (Gythfeldt \& Heggen, 2013). Based on the structural reform in 2015 (KD, 2014-2015), the HEI landscape once more was re-shaped by mergers. In 2017, the 33 HEIs were reduced to 21 by the establishment of multicampus systems and the gradual erosion of the college sector.

\section{Theoretical Approach}

To improve our understanding of the influence of internships as contributors to educational and regional development, we apply the analytical approach of placemaking. A straightforward way of understanding the concept is to perceive that all human beings create places to live from areas they find themselves (Schneekloth \& Shibley, 1995). Placemaking focuses on the processes between different actors to shape and develop the geographical area they are living in (Pierce et al., 2011). Based on this perspective, regional development relies on the interaction and co-creation between the actors involved (Brandsen et al., 2018). Regional actors can influence education through contact with HEI, and universities contribute to shaping the regions through teaching activities, research, and third-mission activities. We are narrowing our study to teachingrelated activities through internships.

An internship is a learning activity that lasts for a limited period, where the student spends a short period and work on specific projects and tasks during the placement. This part of a study programme can be understood as a placemaking activity where different actors are involved in educating through the work placement activities. These forms of learning experience extend the understanding of involvement, where both actors from working life and university staff contribute to the learning outcome in different ways (Brooks \& Youngson, 2016; Eraut, 2011; Jackson \& Wilton, 2016). Based on the temporary character of this type of education, some students live at the place for a short time, while others stay for a longer period in the region. The footprint of student activities can shape local life, including the educational and leisure side. Students can be actors contributing to place-shaping, but their activities can also create connections between the HEIs and local actors. Over time, this can crystalize networks and systemic properties that can have a placemaking effect. The education of students also influences regional development by supplying professionals to the labour market. The place can be shaped by the networks evolving from the interactions between HEIs and local actors. The HEIs do not have any formal roles regarding the local organizations, but a collaboration through networks can shape microstructures that enable participant 
socialization, influence decision-making, support information flow, create a shared identity, and develop solidarity among the participants (Pierce et al., 2011) within that specific regional setting.

Nonetheless, influencing education and educational content is not straightforward. Groups of students, such as nurses, teachers, and social workers, who have traditionally been learning their skills through practical training share strong professional characteristics (Abbott, 1988). They practise monopoly in their jobs, and educational content development is strongly regulated by both professional organizations and political frameworks. Following this, the influence for regional actors to prompt the curriculum and development of the professions is more limited. The academic fields we study are theoretically more open to influence from external actors as they are not regulated to the same degree by professional organizations or regulative frameworks. This gives an avenue for input from the regional actors.

Education such as business administration, sociology, and history is not so focused on learning practical skills. The learning outcomes are more abstract knowledge that must be interpreted and translated within the organization the academics are working. It makes an avenue for local internship placements to fill the practice with meaning and content that is in line with the needs of the organization or region. This gives an avenue for placemaking in relation to locatedness (of being here). Locatedness is iteratively created through different types of input (Pierce et al., 2011). This can be studied in relation to the following elements: political (e.g., what is to be prioritized regarding needs in the setting), social (e.g., what characterizes this particular location), and managerial input (can take many forms depending on the organizations or actors involved).

On the basis of this theoretical framework, we pose the following questions to guide our analysis:

1 What characterizes the processes of developing internship programmes and what possible effects can be seen on placemaking in the region?

2 How can the development of education through internships benefit the region?

\section{Research Design and Methods}

The data collection for this project has a comparative design (Kvale \& Brinkmann, 2009) where we compared a case from the HEI and a regional case. We selected to perform our study in rural Norway, where placemaking through central institutions and students can be crucial to maintain the population and develop the region. In the selected region, the university has expanded their cooperation with both private and public sectors to develop the practical learning courses and trainee agreements within the new fields. The data are anonymized, safeguarding that the participants could speak freely.

Overall, we interviewed eight participants. Of which, four participants from the HEI case were strategically selected (Thagaard, 2018). We interviewed the programme coordinators from history, sociology, and business administration, 
in addition to a dean responsible for internship programmes. History and sociology have only had internships for a year while the business administration has gradually built their internship programme the last decade, starting as an offering for students who were not able to take a semester abroad where internship programme was part of the course package. The numbers of internships were ranging from 15 to 40 students from the business administration (master students) and sociology (bachelor), while history had fewer than 10 internships a year (bachelor). The selection of regional partners was following a snowballing method (ibid.), where we contacted four partners from private and public sectors who had experience with internship students from these educational groups. The interview guide was structured to ease the comparisons between the cases. The first part of the guide contained questions related to the student groups and the specific workplace (e.g., type of students, how to build the network). The second part related to the collaboration between the actors, how to prepare for internships, how to follow up on students, how difficult situations were handled, feedback between the actors, and impact on keeping students in the region. The interviews lasted from 30 to 60 minutes through the Zoom digital platform.

\section{Empirical Presentation}

The presentation of our empirics is organized according to the two questions posed after presenting the theoretical approach. In question 1, we ask what characterizes the processes of developing the internship programmes and thereafter focusing on the effects of these programmes on the region.

When selecting organizations for their students, the business administration programme draws on previous experience. History and sociology were in the phase where they had to build a network of regional actors who were willing to receive students. This process was initiated by the programme coordinator, who e-mailed public and private actors with an invitation to participate in the internship programmes. Where to employ a historian or business administrator is perhaps more obvious than for sociology. The programme coordinator at sociology underscored that it was a bit challenging to establish an internship network for their students, simply because there was no understanding of this subject within the region. "I had to explain what sociology is". The organizations had difficulties seeing how they could contribute and make use of history and sociology students. The HEI actors therefore stressed that internships were venues where students could employ skills such as analysing according to theories and employing specific methods. Illustrated with a quote from the programme coordinator in history:

We are one of the most distant subjects in relation to the labour market, not educating a profession. This is what we emphasize; to show how our theoretical education can be translated into a practical professional life.

(Programme coordinator history) 
The coordinators received good responses from municipal and private actors, but public actors at the state level were rather reluctant (despite the national push for such engagement within the public sector). To confirm the collaboration, the lecturers contacted the actors to explain, plan and clarify expectations. The establishing process was creative, helping to develop ideas of whom and how to invite participants. As an illustration of how a broad mindset is needed in this process, the programme coordinator from history continues narrating his reflection on the skills and interests of students as well as to find organizations to receive students:

Initially, I did not think of a sports club as the natural choice for a history student, but after thorough considerations, I realized the usefulness of studying this club. [As a Norwegian educational organization] we are obligated to facilitate internships for top athletes, so we came to an arrangement with the club regarding the division between training and internship tasks.

(Programme coordinator history)

This is an illustration of how a history student could develop her educational skills by studying the organization and combining it with a top athlete career. Table 12.1 offers examples of internship placements for the academic fields.

When the contacts were established, the regional partners received a description from the programme coordinators at the university explaining the expected learning outcome for the specific field. This was spacious enough for the regional actors to interpret and fill with relevant tasks. The regional partner likewise made a presentation of their organization and what they could offer the students. In addition, the students participated in this selection process by writing a CV presenting their qualifications, interests, and expectations. The business administration had developed this into a more competitive process where students applied for positions, and the regional actors had to promote their internship project as attractive. Some actor from the private sector was a bit worried for the competitive match-making process where the HEI had supervision over the engagement process. They worried that students would

Table 12.1 Examples of regional internship placements

\begin{tabular}{lll}
\hline Sociology & History & Business administration \\
\hline County administration & Museum & Private businesses \\
Regional development centre & Archive & Oil industry \\
Public and private schools & Sports club & Aquaculture \\
NGO's & & Construction \\
Engineering companies & & Media \\
Newspaper & & Start-ups \\
Sports club & Clusters \\
Refugee centre & Hospital \\
Child protection service & Municipality \\
\hline
\end{tabular}


prefer other projects. Nonetheless, in the end, the programme coordinators decided on where the students were assigned and safeguarded the communication process with the external companies.

To ensure the quality of the internship, both students and regional actors were followed up through the internship programme by the HEI staff. For sociology and history, safeguarding the output was challenging because they lack a tradition of training students to translate their academic expertise into practical work.

The communication between the HEI, regional actors, and students was crucial to ensure a meaningful internship period for both the students and the participating organizations. The most successful students had made a structured plan on what they were going to focus on during their internships.

To receive this type of student programmes also challenged the regional actors. They had to build systems for receiving students, who should be the contact person to the HEI, and how to delegate the practical daily contact with the students. In dialog with the educators, the organizations appointed mentors with responsibilities to follow up on the students - aiming at ensuring the learning outcome and safeguarding the educational contributions for the students. This required both time and resources for the participating organizations.

I have to say, just to sum up . . we find it very positive to have students, but it is demanding. Time and resources. But it is nice to get younger people in . . to plan for families and children, teach them bake potato cakes, slaughter a pig ... so they are getting insight in a variety of museum tasks.

(Museum contact)

This quote illustrates how history students had hands-on experiences in developing a teaching programme for families and children regarding one specific historic time.

Placemaking is not necessarily straightforward; it deals with how to address problematic situations. As the internship programmes were quite new, few serious hurdles were mentioned when we asked how the programme coordinators and the regional actors were handling problematic situations. Irrespectively, in the process of building a network and choosing partners that were suitable to participate in educating students through internships, the programme coordinators had to balance the expectations from the regional actors. Some of them were concerned with "what's in it for me?" They desired specific tasks, analysis, or specific reports from the students. This could conflict with the intention of the internship programme. Therefore, the university actors had to clarify and use the time to communicate the programme intentions to the collaborating regional actors. The programme coordinator from the business administration emphasized that they sometimes were "afraid that students will be exploited as free labour. The students must have sensible tasks to perform and learn from". 
When problems occurred, it was feasible to talk with the actors involved to clarify misunderstandings and expectations. Simultaneously, some organizations turned out to be unsuitable for such teaching activities and were not invited to the next round. The dean emphasized that problems often occurred when the organizations did not give the student relevant tasks.

It is easy to distinguish between good and bad internship places. Ehm . . . if they offer tasks that, in many ways, do not have priority within the organization, the students are often dissatisfied with the internship and learning output. At once the tasks are closer to core tasks of the organization, things that matter, is important, then the internship "goes by itself".

Furthermore, the dean emphasizes that the new programmes have a long way to go to co-create new types of educational programmes and to prepare external organizations to participate in education. The mentors from participating companies teach the students both specific tasks and practical skills, but they also had a responsibility to teach soft skills and socializing with the student, including adjusting students to the demands and norms within the working environment. The students had more theoretical training and influenced how well (or not) the students were prepared for handling real-life working situations. One of the mentors from the public sector addressed a problematic situation with the students. They managed to solve the issue and did not feel the need to contact the programme coordinator. In more difficult situations, the programme coordinators often had a mediator role, as they had to both guide students and balance the expectation of the regional actors.

To address placemaking through locatedness, we focused on what happened concerning the content of the work during internships. We pose the following question: How can the development of education through internships benefit the region?

In line with the statement of the dean, success stories were related to core tasks of the organizations. One of the participants from the private sector stated that their internship student was asked to analyse possibilities regarding application for funding for a new project. The student led and played a prominent role in developing the proposal that resulted in the successful allocation of funds.

We would not have been able to start working with this project so early if the internship student and the mentor had not identified the usefulness of that project. Especially the effort from the student who contributed to the proposal.

(Private company actor)

Other times, the students were working on specific projects (alone or collaborated with employees) where they were elaborating their field of knowledge, or the regional actors could influence the learning for the students.

The participants from HE also gave a few other examples of how the experiences with internships influenced both the quality and content of 
education to meet regional needs. History bachelor received feedback regarding communication; the students had to develop their writing skills in a more popularized manner to be able to communicate to a larger societal audience, which contributed to enhancing the quality of their education. Another aspect was input on the order of when subjects were taught. For example, the coordinator for business administration realized that the students had to learn methods earlier to be able to reflect, discuss, and write their papers and exams but also to include multidisciplinary subjects regarding innovation or digitalization. For sociology, the coordinator realized that a new avenue for teaching was social entrepreneurship and youth gaming. It was also obvious that the internships became an eyeopener for students, reflected in the selection of themes for their bachelor thesis. Here illustrated with a quote from the programme coordinator in sociology:

For the first time, the students are showing an expanded focus for the bachelor thesis. Earlier I felt they were only writing about social media.

(Programme coordinator, sociology)

Regarding research, students learned and experienced academic development that they could also integrate into their bachelor and master thesis projects and were gaining a learning outcome that is highly relevant for the region. Students have an independent opportunity to influence their agenda and development. The internship programme also offered an avenue for research collaborations. Collaborating organizations often had ideas for research but did not have the research competencies and therefore welcomed these networks. Here students could participate through their projects, but the organizations also got connections to researchers within their fields at the HEI and the network that evolved through the internship programme.

One arena for "giving back" to society and share knowledge was seminars arranged in cooperation between the programme coordinator, students, and regional actors. Students were presenting projects from the internship period, but also projects developed in collaboration between the student and mentor. The faculty at the HEI contributed by presenting the latest research within specific fields and as such also influenced the development of the region in the communication with the internship organizations and the network. Presentations from regional actors were also a remedy to enlighten students and lecturers on what is going on in their fields.

Through the interviews with the regional actors (both private and public), it seemed like they were not aware of their possibility to influence curriculum within the master or bachelor programme. They were rather surprised that this was an option. Two of the interviewed highlighted that they did not want to interfere and trusted that the HEI had the competencies to provide education of good quality. The last one said: I kind of do not think that conversation has been initiated [from the HEI] (private company actor). 
Lastly, one important function of the internships was to show the employability of the education. The connection between HEI and the region has been elaborated vastly just by introducing such an internship programme and provided the HEIs with a whole new avenue for collecting information on the relevance of their education. However, there is a task to elaborate the view of students and local actors on how the different educational types can be utilized.

The regional actors also realized the importance of internships for them. It became an avenue to show students the broad aspect of jobs they could provide in different villages and small towns in the districts. The organizations could also recruit good candidates for temporary jobs and had recruited for permanent positions among the students. One of the private actors emphasized that the internships were a nice method to recruit talented people:

Clearly, it is difficult to recruit competent people - and especially when you are a start-up company with limited resources. We must convince talented students to work here, therefor the internship period was nice.

(Private company actor)

Both the public and private regional actors were emphasizing their social responsibility to contribute to education, and an actor from a company with good student reputation said:

It is valuable for students and future employees that they have had an internship period and we can contribute to build career for the students. They sort of get a stamp; "okay, you have worked here" - and that can help them pursuing job opportunities later.

(Private company actor)

\section{Discussion and Conclusion}

A crucial aspect of place-shaping is the people; depopulation, brain drain, and stagnation can be a threat to the development of places, and Norway has had an HEI policy that has been focusing on regions since the 1950s (Pinheiro et al., 2016). The focus of this chapter was to get a deeper understanding of how HEI through student internships can contribute to meet regional needs and, in that way, participate in placemaking and regional development.

Central to the approach of placemaking is how human beings participate in creating places to live from areas they find themselves (Schneekloth \& Shibley, 1995). The main finding of our study is that the connection between HE and regional actors has been vastly elaborated by the introduction of internships. It gives a venue where HEI actors and students can make a footprint in the development of the regions. In addition, the regional actors can participate in the development of education. Some of the local organizations highlighted that all partners during the internship process can contribute to a focus on regional needs and even establish long-term contact for further research 
projects between the HEIs and participating companies. Such initiatives are also in line with the regional policy for Norway where the emphasis recently has also been on developing such cooperations (Gythfeldt \& Heggen, 2013).

The internship programmes are rather new, and the collaboration is in progress. Therefore, the regional actors might not be aware of their role as contributors to education and their possibility to influence the educational content of the curriculum and methods. Another way of viewing this is in the light of jurisdictions (Abbott, 1988). Even if the subjects and disciplines included in this case do not have strong professionalized characteristics regarding specific practical skills, the reluctance of giving input could be interpreted as a lack of knowledge of other academic fields. It could also be interpreted as a wish to respect the responsibility of the university.

The sense of locatedness is central in placemaking (Pierce et al., 2011). The data suggest that the focus on local characteristics was more prominent in the private rather than the public sector. The central task for HEIs has been to provide education to serve the need in the regions, especially to serve a strong public sector. Our findings are in line with the characteristic features of education and how open they are to become influenced by external stakeholders. Education aimed towards teaching children, treating people with illnesses, and assisting unemployed or elderly people are standardized across the country. These services are of a more general character, regulated by professional standards and therefore less due to local characteristics. This also implies that the sectors are embedded in the broader national context of political guidelines for prioritization in addition to the larger professional context. The private sector however is more coloured by regional features, of being here with the natural resources that characterize the specific geographical areas, as fishery and technology in relation to the oil industry. These industries are again embedded in the global market by offering high-quality and specialized products and services.

The programme coordinators were striving to get internships in the regions instead of supporting students to go back to their home regions to do the internship. This could be attributed to the fact that local internships are more practical (to be able to follow up on students and regional actors) and financially efficient (no extra costs for the HEI), but it could also be viewed as a political process (Pierce et al., 2011) and an instrument to serve the surroundings as one of the missions for regional educational institutions (Benneworth \& Fitjar, 2019). Regarding power structures, Pierce et al. (2011) show that powerful actors not necessarily are the most visible ones. This can also be traced in our material. In large organizations, the contact between HEIs and regional actors was centralized to the manager higher in the organization. The managers then distributed the contact to select mentors who are responsible for the students. These mentors were the more visible contacts during the internship period. Thereby, the manager frames where the development could happen (or not), but the mentors also have the power to influence the development (or lack of development) according to the projects the students worked on, whom to meet, and what processes to participate in. 
In addition, the regional actors needed to elaborate on their views regarding how to collaborate with new academic fields. Here the programme coordinators at the universities had a crucial task to work as translators and give examples of how sociologists, for example, could contribute to private businesses or managerial teams in a large public office. The internship programme appeared to have some influence on employability within the region. Signs supporting the employability hypothesis were that students were offered summer jobs at the workplace or opportunity after graduating, especially within businesses where such expertise was new.

The footprint of students in the regions can be both temporary and more stable. Many students stay in the region for only the educational period, but the tendency in Norway is that students stay in the area where they are educated (Gythfeldt \& Heggen, 2013). Nonetheless, even students staying temporarily contribute to placemaking through the networks they participate in during studies, leisure and internships. Some students had a direct impact on what kind of partners were contacted to establish the internships, due to their specific interests and talents. In addition, students developed ideas of what themes to elaborate on through teaching and as research areas for their thesis. In this way, students directly influenced the network between the HEI and the region.

Another aspect of locatedness is to fill practice with meaning (Pierce et al., 2011). This was a bit challenging for the regional actors, but they were receiving guidance from the written framework the course coordinators had developed and communicated to the partners. The frames provided leeway to fill with meaningful tasks. The networks that evolve between the institutions are also an avenue for influencing through new microstructures (ibid.). Such networks are not limited to the new contacts between HEI and regional actors but also have the potential to develop across the region through the seminars where local partners, academics, and students presented their projects they have been working on during the internship.

Our study suggests that it is demanding to establish new internship programmes, but it simultaneously provides new avenues for HEI to contribute to regional development, and the employability of history, sociology, and business administration is broadened (Brooks \& Youngson, 2016). Thereby, the HEIs have elaborated their role as placemakers. In addition, the learning platform for students will be enriched when applying learning by doing and meeting stakeholders from the fields where they potentially can be employed. The input is conversely more underdeveloped, as few of the regional actors suggested improvement to the specific education and the learning outcome. Lastly, the introduction of internships for new academic fields supports the idea of maintaining the population, where students participate to develop the regions.

The understanding of the role of internship as a contributor to educational and regional development is intertwined as all parts influence each other to a certain degree. This knowledge is important to both HEI and regional actors 
who can gain input into their mundane activities. It can provide an avenue to receive input from a broader range of academics and can spur development within organizations as new theoretical and methodological angles can be introduced.

Nonetheless, there are additional questions that need follow-up. The participants in the study had responsibilities regarding the new internship regimes and were all (naturally) very positive about this form of educating students. This study has some limitations. An avenue for further research is to include the following critical aspects: What are we losing by reducing the amount of theoretical education? How do we handle input for new themes if receiving many suggestions, and how will the impact of practice influence the research-based foundation of these education? Teaching and nursing students are prepared with rehearsals and practical skills before entering their internships; therefore, they are not "blank" when stepping into the fields. How well are the students in our study prepared, and is it possible to prepare them? How does this influence their self-efficacy and ability to learn? These questions should be followed up.

\section{References}

Abbott, A. (1988). The system of professions: An essay on the division of expert labor. Chicago and London: The University of Chicago Press.

Arbo, P. (2019). Universitet og region - en sammensatt relasjon. In J. P. Knudsen \& T. Laudal (Eds.), Geografi, kunnskap, vitenskap. Den regionale UH-sektorens framvekst og betydnig (pp. 99-130). Oslo: Cappelen Damm Akademisk/NOASP.

Benneworth, P. (Ed.). (2018). Universities and regional economic development: Engaging with the periphery. Milton Park and New York: Taylor \& Francis.

Benneworth, P., \& Fitjar, R. D. (2019). Contextualizing the role of universities to regional development: Introduction to the special issue. Regional Studies, Regional Science, 6(1), 331-338. https://doi.org/10.1080/21681376.2019.1601593

Benneworth, P., \& Hospers, G. J. (2007). The new economic geography of old industrial regions: Universities as global - local pipelines. Environment and Planning C: Government and Policy, 25(6), 779-802. https://doi.org/10.1068/c0620

Benneworth, P., Pinheiro, R., \& Karlsen, J. (2017). Strategic agency and institutional change: Investigating the role of universities in regional innovation systems (RISs). Regional Studies, 51(2), 235-248. https://doi.org/10.1080/00343404.2016.1215599

Bjelle, T. E. (2019). Om tre små studiestadar $i$ Norge. Sogndal: Høgskulen på Vestlandet.

Brandsen, T., Steen, T., \& Vershuere, B. (2018). Co-production and co-creation: Engaging citizens in the public services. New York and London: Routledge.

Brooks, R., \& Youngson, P. L. (2016). Undergraduate work placements: An analysis of the effects on career progression. Studies in Higher Education, 41(9), 1563-1578. https://doi. org/10.1080/03075079.2014.988702

Caniëls, M. C., \& van den Bosch, H. (2011). The role of higher education institutions in building regional innovation systems. Papers in Regional Science, 90(2), 271-286. https:// doi.org/10.1111/j.1435-5957.2010.00344.x

Collinge, C., Gibney, J., \& Mabey, C. (2010). Leadership and place. Policy Studies, 31(4), 367-378. https://doi.org/10.1080/01442871003723242

Cooke, P. (2005). Regionally asymmetric knowledge capabilities and open innovation: Exploring "Globalisation 2" - A new model of industry organisation. Research Policy, 34(8), 1128-1149. https://doi.org/10.1016/j.respol.2004.12.005 
Eraut, M. (2011). Informal learning in the workplace: Evidence on the real value of workbased learning (WBL). Development and Learning in Organizations, 25(5), 8-12. https:// doi.org/10.1108/14777281111159375

Goddard, J., Hazelkorn, E., \& Vallance, P. (Eds.). (2016). The civic university: The policy and leadership challenges. Cheltenham, UK and Northampton, MA, USA: Edward Elgar Publishing.

Gythfeldt, K., \& Heggen, K. (2013). Hva betyr høgskolene for rekruttering av arbeidskraft til egne regioner? Sokelys på arbeidslivet, 30(3), 235-250. www.idunn.no/spa/2013/03/ hva_betyr_hoegskolene_for_rekruttering_av_arbeidskraft_til_

Jackson, D., \& Wilton, N. (2016). Developing career management competencies among undergraduates and the role of work-integrated learning. Teaching in Higher Education, 21(3), 266-286. https://doi/10.1080/13562517.2015.1136281

Jongbloed, B. (2010). The regional relevance of research in universities of applied sciences. In S. Kyvik, \& B. Lepori (Eds.), The research mission in higher education institutions outside the university sector (Vol. 31). Dordrecht: Springer.

KD. (2014-2015). Strukturreformen. Konsentrasjon for kvalitet - Strukturreformen $i$ universitets- og hoyskolesektoren, Meld.St.18(2014-2015). www.regjeringen.no/no/dokumenter/ meld.-st.-18-2014-2015/id2402377/

Kvale, S., \& Brinkmann, S. (2009). Interviews: Learning the craft of qualitative research interviewing. Angeles, London, New Dehli, Singapore: Sage.

Kyvik, S. (2002). The merger of non-university colleges in Norway. Higher Education, 44(1), 53-72. https://doi.org/10.1023/A:1015561027230

NOKUT. (2019). Kvalitet $i$ praksis - utfordringer og muligheter. Report 16-2019. www. nokut.no/globalassets/nokut/rapporter/ua/2019/kvalitet-i-praksis-utfordringer-ogmuligheter_16-2019.pdf

Peer, V., \& Penker, M. (2016). Higher education institutions and regional development: A meta-analysis. International Regional Science Review, 39(2), 228-253. https://doi. org/10.1177/0160017614531145

Pierce, J., Martin, D. G., \& Murphy, J. T. (2011). Relational place-making: The networked politics of place. Transactions of the Institute of British Geographers, 36(1), 54-70. https://doi. org/10.1111/j.1475-5661.2010.00411.x

Pinheiro, R., Charles, D., \& Jones, G. A. (2016). Equity, institutional diversity and regional development: A cross-country comparison. Higher Education, 72(3), 307-322. https:// doi.org/10.1007/s10734-015-9958-7

Pinheiro, R., Young, M., \& Sima, K. (Eds.). (2018). Higher education and regional development: Tales from Northern and Central Europe. Cham: Palgrave Macmillan.

Price, J. (2002). Developing an undergraduate internship program in applied sociology. Sociological Practice, 4(1), 53-66. https://doi.org/10.1023/A:1017971207369

Schneekloth, L. H., \& Shibley, R. G. (1995). Placemaking: The art and practice of building communities. New York: John R. Wiley \& Sons.

Thagaard, T. (2018). Systematikk og innlevelse: En innforing $i$ kvalitativ metode. Bergen: Fagbokforlaget.

Tindowen, D. J., Bangi, J., \& Parallag Jr, C. (2019). Pre-service teachers' evaluation on their student internship program. International Journal of Learning, Teaching and Educational Research, 18(10), 279-291. https://doi.org/10.26803/ijlter.18.10.18

Tovey, J. (2001). Building connections between industry and university: Implementing an internship program at a regional university. Technical Communication Quarterly, 10(2), 225-239. 


\title{
13 Activist Leadership in the Caribbean
}

\author{
The Case of the University of the \\ West Indies
}

Elin M. Oftedal, Emily Dick-Forde, and Luz Longsworth

\begin{abstract}
This chapter investigates how a cross-national university (the University of the West Indies), in a transitional region such as the Caribbean, implements its third mission. We employ a broad understanding of the third mission as engagement in society including entrepreneurial and innovative efforts. Drawing on the entrepreneurial architecture framework, the chapter discusses how systems, structures, strategy, leadership, and culture form a unique mandate to engage in national, regional, but also international challenges.
\end{abstract}

\section{Introduction}

The activities of educational institutions have been central to improving the quality of life for citizens in communities and societies they serve. Universities, in particular, instigate societal transformation through the quality of its graduates (Paphitis, \& Kelland, 2016) as well as through research-based innovations applied to a range of societal challenges such as climate change (Purcell et al., 2019; Hodgson, 2015). This chapter considers the circumstance of the University of the West Indies (the UWI), which operates in the Caribbean and serves as the lead university to the 17 Small Island Developing States (SIDS) of this region. The UWI presents a unique case for contributing insight to the literature on the extended missions of universities. Moreover, the Caribbean region presents a distinctive context relative to the extant literature, as it is comprised of multiple, geographically disperse nations. This contrasts most studies in the literature on the university-region development nexus, as they most often relate to counties, boroughs, or regions in European nations (see for example Sánchez-Barrioluengo, 2014 and Şerbănică, 2012; Hodgson, 2015). Further, Caribbean SIDS are among the most vulnerable nations to the effects of global financial crises and to climate change, due to their small open economies and their geographical position and configuration (Thomas \& Baptiste, 
2018). These vulnerabilities are amplified by entrenched historical and structural challenges that result from slavery and the subsequent colonial political economy. In this regard, the UWI has taken an activist role to press for, inter alia, reparations to improve developmental outcomes for the people and nations of the Caribbean.

The UWI senior leadership addresses such critical issues as concessionary financing for climate resilience and reparatory justice, which is the legal obligation to repair historical wrongs that resulted from enslavement and extractive colonialism as they take on this activist role with a leadership-driven posture on behalf of the region and in partnership with like-minded regional political leaders. Using a case study approach and the analysis of secondary data, this chapter explores the UWI's extended missions in the Caribbean with its economic, historical, and geographical complexities.

This chapter explores the role of the UWI leadership in fulfilling its mandate across the five elements of a university's architecture (Vorley \& Nelles, 2009) of structure, systems, leadership, strategy, and culture, in the vulnerable and distinctively configured Caribbean region, and the unique roles that the university has been given, some of which it also creates. We ask the question: How is the University of the West Indies organizing itself to fulfil its societal mandate and why?

The chapter begins with a brief outline of the historical, sociopolitical, and economic context. This is followed by theoretical perspectives of third mission and university architecture to support the methodology used in the study. Findings and analysis are presented, followed by concluding statements.

\section{The UWI in Its Historical Sociopolitical and Economic Context}

Linked to its colonial past, the UWI was first a College of the University of London, started in Jamaica in 1948 to provide opportunities for strategically relevant tertiary education in the region and beyond. This focus was initially placed on medical sciences, specifically tropical medicine and public health, which were determined as critical societal needs at the time, both for persons in the region and abroad. This college was the genesis for the UWI Mona Campus Jamaica. The precursor to the second campus of the UWI was established in 1962, as the Imperial College in Trinidad and Tobago, with a focus on tropical agriculture. The Cave Hill Campus was established in 1965, the Open Campus (online delivery) in 2008, and the Five Islands Campus Antigua in 2019. These campuses of the UWI serve a geographically disperse set of nation states through landed and virtual campuses.

The Caribbean is characterized by small to micro island nations with populations ranging from fewer than 50,000 to more than a million residents. The islands provide limited land resources and are in some cases isolated by vast ocean expanses. These nations exhibit small open economies which are highly vulnerable to external financial shocks, and extreme weather events can 
incur devastating losses. The region's economies have recorded consistently low growth and high debt-to-GDP ratios over the past 10 years. These indicators have worsened due to the economic and social impacts of COVID-19, which has amplified the historical markers of outward-looking economies in terms of lost revenues as well as the availability of food and basic goods. The severe effects of the global pandemic on the livelihoods and economic welfare of the region have required the UWI leadership to pivot for new ways to support the region's governments and peoples. This chapter seeks to contribute to a better understanding of the institutionalization of a plurality of roles for universities, specifically the UWI, in the economic and social development of the communities in which they serve, and for climate resilience and reparatory justice for generational equity.

\section{Theoretical Perspective: the Third Mission and Entrepreneurial Architecture - a Survey of the Literature}

Research on the extended missions of universities, conducted largely in European settings, has been bolstered by purposeful, prescriptive, and strategic decisions which require that "higher education policy should have an explicit regional dimension, such as in the Nordic countries, where universities' engagement with the business and the community has been recognised and laid upon as a duty" (Şerbănică, 2012, p. 45). It is notable that regions in this literature refer to counties and boroughs within a single country. Research into this subject continues to expand since the early studies of Burns (2005), Vorley and Nelles (2009) and Boucher et al. (2003).

The roles of universities have evolved to meet the changing demands of society, both economically and culturally, encompassing both economic and societal roles (Vorley \& Nelles, 2008). Such activities are labelled "third mission" and refer to academic activities involving actors outside the "internal university architecture" or formal university, which typically includes the leaders, teachers, technical-administrative and traditional students. Outside actors may include partnerships with other universities, government entities, and business leaders, both local and foreign. As such, universities have the opportunity to be social actors and even connectors of entrepreneurship, innovation, and sustainable development. For example, university-industry links can facilitate vital innovation processes (Mowery \& Nelson, 2004; Agrawal, 2001; McMillan \& Hamilton, 2003).

Third mission conveys broad societal assignments that go beyond traditional teaching and research. Thus, universities can function as societal actors as they perform activities with and within their external communities, emerging as the "regionally engaged universities" described by Chatterton and Goddard (2000). Such universities arise from within regions where the learning process and the dynamic planning approach play significant roles (Holbrook \& Wolfe, 2002). Rothaermel et al. (2007) argues for a narrower university role focusing commercialization on licensing and spin-out activities, since knowledge 
produced at universities can spur industrial innovation (Karlsson \& Wigren, 2012; Bozeman et al., 2013).

Subsequently, theoretical framework articles have strengthened the concepts underpinning the emerging roles of universities beyond their traditional missions (Vorley \& Nelles, 2009). Recent studies offer further insight into the regional engagement mission of universities and especially explore why universities pursue these extra missions (Benneworth \& Fitjar, 2019). Indeed, some studies suggest that external expectations, with the multiple expertise and internal university interests, all contribute to the pursuit of third and fourth missions beyond the traditional focus on the first two missions of teaching and research. Notably, Sánchez-Barrioluengo (2014) concludes from her study that regional characteristics influence the strategies and performance of higher education institutions. That study suggests further that in the knowledge economy there is an expectation from connected societies that universities should lead and even fulfil regional innovation and economic development processes. Boucher et al. (2003) spotlight the importance of independent effects of regional identity in shaping the embeddedness of local universities and identify two university profiles shaped by the surrounding regions. In theorizing the entrepreneurial agenda of universities, Vorley and Nelles (2009) consider that the university's institutionalization of its social and economic engagements is a distinctive function and constitutes the third mission (p. 284-285).

Indeed, Benneworth and Fitjar (2019) spotlight the reality of third-mission expectations, noting especially the "why" question (why universities engaged in third missions). Consequently, some universities assume responsibilities and challenges that seem to surpass their traditional role (Benneworth \& Fitjar, 2019). Indeed, knowledge produced at universities can spur industrial innovation (Karlsson \& Wigren, 2012; Bozeman et al., 2013; Bozeman et al., 2013) and, in some regions, promote social transformations to correct historical injustices. Importantly, the intrinsic role is promoted for universities to provide a context for human development through the shaping of civic-minded graduates with attributes that propel them towards community service, including as leaders for economic and social advancement. This contrasts the instrumental role of producing graduates whose degrees are seen as "currency" that can be "converted to a labour market value" and impacts the price of a university education (Kromydas, 2017, p. 1). This process has the potential to exclude many from accessing higher education and thus deepen inequalities. Universities therefore have particularly important societal roles as they both educate individuals for personal advancement and support knowledge creation through research. A further dynamic is realized as universities serve the particular needs of the societies in which they serve, again reflecting mutual influence between universities and the community/society/nation(s) in which they are located.

With this construction of the third mission, the concept of the "entrepreneurial" university as outlined by Clark (2001) describes such an institution as one that seeks to constantly renew and embrace certain contemporary approaches to engage with its community. Further, the entrepreneurial university lies 
Table 13.1 The elements of the entrepreneurial architecture

\begin{tabular}{|c|c|c|}
\hline $\begin{array}{l}\text { Entrepreneurial } \\
\text { architecture }\end{array}$ & $\begin{array}{l}\text { Description (according to } \\
\text { Nelles \& Vorley, 2009) }\end{array}$ & Examples and link to third mission \\
\hline Structures & $\begin{array}{l}\text { Formal organizational } \\
\text { mechanism of knowledge } \\
\text { exchange such as offices } \\
\text { or departments within the } \\
\text { university }\end{array}$ & $\begin{array}{l}\text { Technology Transfer Offices (TTO) } \\
\text { (narrow view); official positions, offices } \\
\text { linking to a societal engagement; } \\
\text { classes focused on formal third-mission } \\
\text { activities, learning labs with live data/ } \\
\text { problem sets; institutionalizing societal } \\
\text { engagements; establishment of centres } \\
\text { of excellence, and so on }\end{array}$ \\
\hline Systems & $\begin{array}{l}\text { Networks of communication } \\
\text { and coordination; norms } \\
\text { of interaction; embedded } \\
\text { values }\end{array}$ & $\begin{array}{l}\text { Decentralized TTO systems (narrow } \\
\text { view); informal third-mission activities; } \\
\text { initiating societal engagements }\end{array}$ \\
\hline Strategies & $\begin{array}{l}\text { Official formulation about } \\
\text { the third-mission or } \\
\text { organizational goals and } \\
\text { avenues }\end{array}$ & $\begin{array}{l}\text { Strategy documents containing third- } \\
\text { mission goals }\end{array}$ \\
\hline Leadership & $\begin{array}{l}\text { Key leadership roles and } \\
\text { their influence on strategic } \\
\text { decisions }\end{array}$ & $\begin{array}{l}\text { Leadership conceives and spearheads } \\
\text { third-mission activities }\end{array}$ \\
\hline Culture & $\begin{array}{l}\text { Attitudes of individuals } \\
\text { and the value they } \\
\text { place on innovation and } \\
\text { entrepreneurial activities }\end{array}$ & $\begin{array}{l}\text { To what degree third-mission activities } \\
\text { are admired and respected/understood } \\
\text { as such }\end{array}$ \\
\hline
\end{tabular}

within the internal architecture (Vorley \& Nelles, 2008). They call it the university's entrepreneurial architecture (EA) and suggest that the third mission is "caught" within it. EA comprises the institutional, communicative, coordinating, and cultural elements of an organization oriented towards innovation (Vorley \& Nelles, 2008). As such, EA consists of five elements: structures, systems, strategies, leadership, and culture (Burns, 2005). Outlined in Table 13.1, these elements are interrelated and overlapping; however, the presence and coordination of all five are required to secure successful adaptation to the third mission (Vorley \& Nelles, 2008; Foss \& Gibson, 2015). The architectural elements are mutually supportive, and the absence of one aspect may contribute to either a weakness in the third mission or failure to evolve.

This chapter leans on a wide interpretation of the third mission, such as societal engagement, and as such, aims to explore how and why a university might pursue several roles towards building societies on local, national, regional, and international levels, while also providing activist leadership to build climate resilience and pursue justice for historical wrongs in the thrust for a fair economic footing and a sustainable future. Further, this chapter acknowledges the narrow view of the third mission, including research-based innovation and university spin-offs. The EA framework is helpful in describing UWIs approach to 
the third mission. The EA elements will be utilized in part to present the key features of the UWI.

\section{Methodology}

This study formulates its central research question as "how" and suggests a research design that explores EA as a social phenomenon within the UWI from the perspective of the actors involved. Phenomenological studies require researchers to go in depth to access the details of the situation to understand the "reality" (Remenyi, 1998). This chapter is a description of several deep aspects of the role and mandate of the case study university, which has not been studied relative to this literature. Therefore, exploring the UWI's third-mission roles required broad reading of the institution's documents to understand the EA of the UWI. A qualitative approach was used that "explores a real-life, contemporary bounded system" (Creswell, 2013). Multiple data collection and analysis methods were adopted to further develop and understand the case, shaped by context and emergent data (Stake, 1995).

For this study, the UWI presents a university that faces seemingly unique challenges to their mandate, given the region's context. The intrinsic case (Stake, 1995) is used to shed light on the extant theory to reveal "how" the third mission is pursued and to explore why universities might choose to participate in regional development (Benneworth \& Fitjar, 2019).

\section{Data Collection and Analytical Constructs}

A variety of methods were used to collect data for this case. To ensure credibility, these data were drawn from a variety of primary and secondary sources, mainly secondary sources in the form of published reports, including Reports of the Vice Chancellor to University Council. These were sourced from both print and electronic publications including the UWI website. Data collection also included secondary sources on the nature of the institution, its historical background, physical setting, and other institutional and political contextual factors (Stake, 1998). An interpretive or social constructivist approach to qualitative case study research supports a transactional method of inquiry, where the researchers have a personal interaction with the case institution. The second and third authors are employed in the UWI system. Thus, care was taken to balance the authors' knowledge and judgement and simultaneously address issues of reliability and validity. One author sits at the executive leadership level of the UWI and provided valuable insight as well as detailed information on the structure, systems, and culture aspects of the EA. All these inputs were verified against secondary sources for accuracy.

The document studies were accessed using searches on Google Scholar, JSTOR, ScienceDirect, Scopus, and Web of Science, based on the search words: UWI, timeline, structure, system, culture, strategy, third mission. Internal University documents were carefully studied, including all of the Five Year 
Strategic Plan reports (published in 2007, 2012, and 2017) (Strategic plans of the university of the west indies - Google zoeken, n.d.). Further, the authors referenced public reports and releases on the UWI's official website to inform on the different elements of the EA framework in addition to the third-mission activities. The concepts from the EA provide the constructs for analysis.

Primary data were collected through an interview guide with ten openended questions refined by the authors and shared via email with key directors and leaders at the UWI who serve at the campus and executive management levels. The inquiry went out to nine leaders, and three provided written replies while others provided personal interviews and discussions. Quotes from these interviews are shown in the findings section to underline certain issues.

Confirmability is ensured as the interviews were in written form. The first author initiated discussions over topics that seemed unclear. The team of researchers discussed the different dimensions of the EA and how the data correspond with each of the dimensions. For example, for the strategy dimension, we went through strategy documents from the last 20 years discussing the evolution of current third-mission activities. As the study proceeded, several challenging questions were raised, based on the history of the Caribbean region's complex and persistent race relations concerns, the emergent and appealing agenda on reparatory justice, and how these fit into the entrepreneurial university. A triangulation of data informed the research process across secondary published data, primary data from colleagues, and the authors' experiential insight, precipitating an image of the UWI and its EA. Transferability cannot be claimed as this is a single case study. We have assumed dependability of the data, as they were collected from different parts of the region and since the author group has both internal and external viewpoints. Table 13.2 provides an overview of sources for the data collection.

\section{The Case Findings: The University of the West Indies}

In this section we present findings from secondary data and input from leaders in the institution to answer the research question: How is the University of the West Indies organizing itself to fulfil its societal mandate and why? We firstly elaborate on third mission and thereafter on EA.

The understanding of the UWI's participation third-mission activities was informed by both its stated mission, from responses to interviews and from published data. The UWI's mission states: "To advance learning, create knowledge and foster innovation for the positive transformation of the Caribbean and the wider world". The following quote from a key leader at the UWI describes how the main mission supports the third mission.

I firmly believe that The UWI's main mission (and raison d'être) is to transform the social, economic, cultural and political bases/aspects of our societies into developed and sustainable ones where our governments view their roles as being that of development and empowerment of our people. 
Table 13.2 Data sources for third-mission activities and the entrepreneurial architecture

\begin{tabular}{|c|c|}
\hline Dimension & Data source \\
\hline $\begin{array}{l}\text { Third-mission } \\
\text { activities }\end{array}$ & $\begin{array}{l}\text { The UWI's websites, university documents, Reports of the Vice } \\
\text { Chancellor to University Council on third-mission activities, } \\
\text { secondary data such as interviews of leaders in the media. }\end{array}$ \\
\hline Structure & $\begin{array}{l}\text { The UWI's websites, university documents, Reports of the Vice } \\
\text { Chancellor to University Council on third-mission activities, } \\
\text { secondary data such as interviews of leaders in the media. }\end{array}$ \\
\hline System & Authors' knowledge, responses to emailed interview guide. \\
\hline Leadership & $\begin{array}{l}\text { Reports, media releases, and other documents on actions, statements, } \\
\text { and activism of current and former leaders. Research and advocacy } \\
\text { of the Vice Chancellor of the UWI and formalized by regional } \\
\text { political leaders at CARICOM (CARICOM: The Caribbean } \\
\text { Community quasi government mechanism that formalizes and } \\
\text { implements regional collaborations and agreements). }\end{array}$ \\
\hline Strategy & $\begin{array}{l}\text { Strategy documents from } 2007 \text { to } 2022 \text {, strategy-related historical } \\
\text { speeches, and transcript from public interviews. }\end{array}$ \\
\hline Culture & Media releases, discussions with authors embedded in the culture. \\
\hline
\end{tabular}

Another respondent referenced the narrow version of the third mission, such as research-based entrepreneurship and spin-offs. Over the last 5 years, several student incubators have been set up, and there is an active effort to encourage research-based and student-based innovation and entrepreneurship across the campuses.

UWI is involved in innovation, entrepreneurship and business activities and with increasing involvement in all. Entrepreneurship is now a stated addition to our mission and Pro Vice-Chancellor has been given special responsibility to increase our innovation and entrepreneurial activity.

While entrepreneurial action at the UWI has been internally driven, an external assignment to lead on climate change has propelled the UWI into significant action in this regard. The following excerpt captures this assignment (The UWI Selected to Lead Climate Smart World, 2019):

The International Association of Universities (IAU) selected The University of the West Indies (The UWI) as its global leader in the mobilisation of research and advocacy for the achievement of a climate-smart world. The IAU designated The UWI in recognition of the University's decades of world class research on climate change and sustainable development.

Subsequently, several climate change initiatives were launched including the Caribbean Climate Smart Accelerator (Caribbean Climate -Smart Accelerator, n.d.) in which the UWI is a collaborator among 20 other partners such as Virgin Atlantic, the World Bank, and the InterAmerican Development Bank. 
These examples of the UWI's third-mission activities reflect the elements of the EA. In terms of structure, in its early years the UWI followed the traditional teaching and research universities from the British colonial centre. Additionally, as a regional university under colonial rule, state funding has dominated the institution's 70 plus years of operation. However, the UWI's structure has evolved over time, commencing with the extra-mural/outreach units to expand more basic and vocational learning opportunities in the region in the 1960s. This provision of relevant education and training remains within the traditional teaching mission and directly contributes to an improved quality of life for increasingly more regional citizens to access university education and/or to access better job opportunities. From community outreach to global partnerships for centres and satellite campuses, the UWI's current formal structure (see Figure 13.1) shows the strong external linkages and third-mission engagements that have become a part of the structure of the institution.

The UWI's senior leaders are included in high-level meetings of the Caribbean Community (CARICOM), which is an umbrella organization that facilitates collaboration across several issues of governance among the nations of the Caribbean. Article 22 of the Revised Treaty of Chaguaramas, which establishes CARICOM, recognizes the UWI as an associate member of the community. Notably the CARICOM Secretariat hosts the Heads of Government meetings where major decisions are taken on, inter alia, trade, security, foreign affairs, education, and health. The leadership of the UWI is a standing member of this meeting. The CARICOM Commission on Reparations originated from the economic history research of the current vice chancellor of the UWI (Homepage, n.d.). Internally, a Center for Reparations Research established at the Mona Campus explores new avenues to address economic challenges in the Caribbean.

The structure and functioning of the UWI include third-mission activities assigned to senior leaders in the institution. The principals/pro vice chancellors serve as leads. The principal of the Open Campus also has led for UWIGlobal, which includes the State University of New York (SUNY), UWI Center for Leadership and Sustainable Development (CLSD), and partnerships with other universities on nearly every continent for a centre or campus in discipline areas such as information and communication technology. The principal of the Mona Campus, Jamaica, has responsibility for Disaster Risk Management (DRM), which includes integration in curriculum, and for DRM improvement with linkages to regional stakeholders. The principal of the St. Augustine Campus, Trinidad, leads the innovation and entrepreneurial activities for the UWI, with each campus engaged in various innovation and business development activities.

With a decidedly third-mission structure, the UWIs systems, that is, its networks of communication, coordination, norms of interaction, and embedded values, appear to lag somewhat behind a more aggressive external partnerships. While the system appears to be set up for cooperation among the campuses, there are dynamics of competition for resources, which can undermine their common goals. 

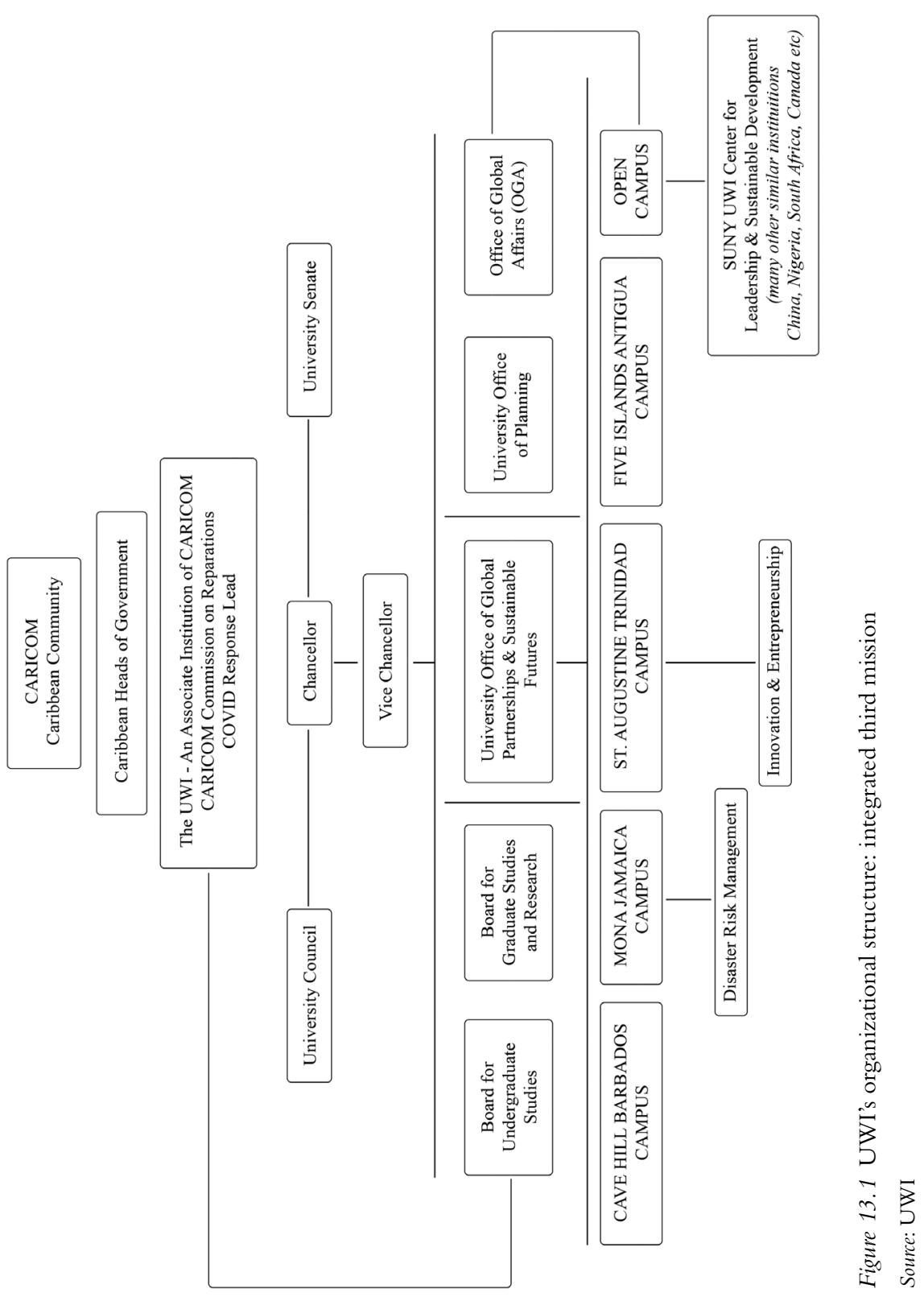
The arrangements for communications with external stakeholders on thirdmission events and operations are yet to integrate with the core activities of The UWI. There are, however, increasing efforts to connect relevant academics and curriculum to such external events. The use of invitations and announcements to engage staff and students on major international achievements, while commendable, has not been measured to assess impact.

Reviews of the UWI's strategy documents include the formal work first published in 1997 to the current Triple A Strategy: Revitalizing Caribbean Development 2017-2022. The strategic focus of the university has necessarily undergone significant developments over the period indicated. The first strategy document was broad in scope. Subsequently, throughout the years the work on strategy became more professionalized and effective. The latest strategy document is a shorter and more specific document outlining the UWIs "Triple A Strategy" of Access, Alignment, and Agility. The strategy makes room for the third-mission activities mainly through the Access objective. Hence, the global outreach is one of the more integrated third-mission activities.

Leadership at the institution influences the extent of third-mission activities and, over the past 5 years, the personal research and life work of these leaders have enriched the external reach of the UWI (Perkins \& Landis, 2020). These leaders and other professors apply their research to the pressing problems of environment, climate change, COVID-19, and the challenges of economic development of the nations of the region. It is in this vein that reparations has emerged as a major strategy to transform the region's efforts at sustainable economic development and includes research, action, and activism (Beckles, 2016).

Additionally, the following interview responses to open-ended questions administered in 2020 by the authors, reveal the diversity of views on the EA dimension of leadership and the UWI:

In terms of leadership, most of the region's Prime Ministers and governmental representatives have UWI degrees, putting the UWI in a dominant position in terms of leadership training.

In 70 years, the university's leadership has moved from colonial to regional at all levels and the original single campus has expanded outward under a broad regional umbrella, while vesting significant degree of autonomy in each campus.

The UWI provides the philosophical leadership for the Caribbean by underscoring our history as enslaved people (we were not slaves; we were enslaved by violently uncivilized nations and people using brutal and superior force), our progress during pre-and post-colonial and independence periods, and the challenges these posed. The UWI does this in a way that other organizations/institutions or politicians are unable to. This leadership covers political, economic, social, cultural and other matters. The UWI Science intervention in the COVID-19 Pandemic crisis is now well-known. PVC Prof. Clive Landis is a household name now. The UWI Science has been loud, ubiquitous and unequivocal. 
As the University of the West Indies is so important to and immersed in Caribbean politics and society, its university culture ubiquitously reflects Caribbean culture. Yet when culture is understood as the attitudes of organization members and the value they place on innovation and entrepreneurial activities, a nuanced approach to perceiving culture seems needed. University culture is rarely discussed, and there is few means of how to capture it. While the information from our respondents was limited, the discussion of culture in our author group concluded that a culture around the third mission is present yet may not be fully integrated in the conversations within the institution. The global thrust may not be embraced by the majority. If this is indeed the case, a change in leadership then might instigate a major shift away from third-mission advances in current areas towards those of the incoming leaders.

Yet both our primary and secondary research revealed several expressions of the UWI as a "culture bearer". The following is a representative quote from the vice chancellor of the UWI in 2018:

Islands are generally expected to be culturally inward-looking. Groups of islands may be more global in their outlook and actions. [The] UWI came into being as an academic world with an identity shaped by ethnic forces and historical circumstances within the colonial ethos of London University in 1948. Thinking globally while being connected to regional roots has been the ideological heartbeat of The UWI as it separated from its colonial scaffold in 1963. The identity of the Caribbean as a crossroad of modernity has shaped the evolution of the University. The UWI in its current strategic cycle is working with global partners and has reached out beyond the Caribbean into the wider world.

(Sir Hillary Beckles)

\section{Analysis and Conclusion}

How is the University of the West Indies organizing itself to fulfil its societal mandate and why? The study of UWI and their approach to the third mission provides us with an example of a university that is under immense pressure and with major challenges ahead. The pressure consists of being a regional project among several highly vulnerable island nations to educate their peoples and meet their common challenges. The large challenges lie, inter alia, in historical inequities and in limited natural resources that are vulnerable to extreme weather events and economic declines, currently made worse by a prolonged pandemic. Looking through the lens of the EA, it becomes evident that the UWI has a clear societal mandate. Through the document analysis, from the interviews and discussions, the third mission commands high focus within the UWI and takes several shapes and forms: Firstly, the UWI is committed to their mandate to meet the diverse regional challenges. The EA is set up to fulfil the demands of the countries to create a competent workforce and to build a common base of knowledge throughout the islands. Further, one sees at the UWI a strategy that evolves profoundly over time. The UWI strategy documents, in particular, 
show the progress over the years, as the university has moved from a broad societal mandate to articulate a narrower understanding of the third mission, innovation, and entrepreneurship.

Also, the leadership has made an impact on the path the university has taken to fulfil its societal mission. While the university's early leaders reflected the colonial reality of this region, later leaders worked to strengthen an independent region. Today, the UWI leadership embraces the role of embodying an "activist university", working to correct the wrongs that have been done towards minorities throughout the colonial history. Overall, the passion of the UWI leadership strongly influences the third-mission activities through intense engagement across the region and within the individual nations it represents.

The extent to which systems and culture integrate these third-mission activities is unclear. In some cases, anecdotal evidence suggests that the sustainability of these third-mission activities may be tenuous when the current leaders inevitably move on and new leaders come forward into these senior roles. Recall Vorley and Nelles (2009) posit that institutionalization of these societal engagements establishes strong evidence of the third mission. Nevertheless, the UWI's existence is rooted in a wide definition of third mission - of being a societal actor that pursues enormous common challenges in the region. Moreover, the case suggests that the UWI also currently embraces the narrow view of the third mission, reflected in an increased effort on research-based and studentbased innovation and entrepreneurship. It is crucial to the region served by the UWI that the university succeeds, inter alia, with its entrepreneurial and innovation drives, thereby increasing the region's economic resilience.

\section{References}

Agrawal, A. (2001). University-to-industry knowledge transfer: Literature review and unanswered questions. International Journal of Management Reviews, 3, 285-302.

Beckles, H. (2016). Professor Sir Hilary Beckles speaks about reparatory justice at Oxford University. Britain's Black Debt: Reparatory Justice and the restoration of "moral nation status". Race and the Curriculum in Oxford Lecture Series. www.youtube.com/watch?v= Zm4NxB9SKfc

Benneworth, P., \& Fitjar, R. D. (2019). Contextualizing the role of universities to regional development: Introduction to the special issue. Regional Studies, Regional Science, 6(1), 331-338.

Boucher, G., Conway, C., \& Meer, E. (2003). Tiers of engagement by universities in their region's development. Regional Studies, 37, 887-897. https://doi.org/10.1080/0034340 032000143896.

Bozeman, B., Fay, D., \& Slade, C. (2013). Research collaboration in universities and academic entrepreneurship: The state-of-the-art. The Journal of Technology Transfer, 38(1).

Burns, P. (2005). Corporate entrepreneurship: Building an entrepreneurial organization. Basingstoke, England: Palgrave Macmillan

Caribbean Climate -Smart Accelerator. (n.d.). Making the Caribbean the world's first climatesmart zone. Retrieved June 1, 2021, from www.caribbeanaccelerator.org/an. Google Scholar. 
Chatterton, P., \& Goddard, J. (2000). The response of higher education institutions to regional needs. European Journal of Education, 35(4). https://doi.org/10.1111/1467-3435.00041

Clark, B. R. (2001). The entrepreneurial university: New foundations for collegiality, autonomy and achievement. Higher Education Management, 13(2), 9-25.

Creswell, J. W. (2013). Qualitative inquiry and research design: Choosing among five approaches (3rd ed.). Washington, DC: Sage.

Foss, L., \& Gibson, D. (Eds.). (2015). The entrepreneurial university: Context and institutional change. London: Routledge.

Hodgson, R. (2015). High-technology entrepreneurship in a university town: The Cambridge story. In Foss \& Gibson (Eds.), The entrepreneurial university: Context and institutional change (1st ed.). London: Routledge.

Holbrook, A., \& Wolfe, D. (2002). Knowledge clusters and regional innovation: Economic development in Canada. Vancouver, BC, Canada: Centre for Policy Research on Science and Technology, Simon Fraser University.

Homepage. (n.d.). Caribbean reparations commission. Retrieved June 1, 2021, from https:// caricomreparations.org/

Karlsson, T., \& Wigren, C. (2012). Start-ups among university employees: The influence of legitimacy, human capital and social capital. Journal of Technology Transfer, 37, 297-312

Kromydas, T. (2017). Rethinking higher education and its relationship with social inequalities: Past knowledge, present state and future potential. Palgrave Communications, 3(1). https://doi.org/10.1057/s41599-017-0001-8

McMillan, G. S., \& Hamilton, R. D. (2003). The impact of publicly funded basic research: An integrative extension of Martin and Salter. IEEE Transactions on Engineering Management, 50(2), 184-191.

Mowery, D. C., \& Nelson, R. R. (Eds.). (2004). Ivory tower and industrial innovation: University - industry technology before and after the Bayh - Dole Act. Stanford: Stanford University Press.

Nelles, J., \& Vorley, T. (2009). Constructing an entrepreneurial architecture: An emergent framework for studying the contemporary university beyond the entrepreneurial turn. Innovative Higher Education, 35(3), 161-176. https://doi.org/10.1007/s10755-009-0130-3

Paphitis, S., \& Kelland, L. (2016). The university as a site for transformation: Developing civic-minded graduates at South African institutions through an epistemic shift in institutional culture. Education as Change, 20. https://doi.org/10.17159/1947-9417/2016/906.

Perkins, A. K., \& Landis R. C. (2020). Ethics amidst COVID-19: A brief ethics handbook for Caribbean policymakers and leaders. https://uwi.edu/covid19/sites/covid19/files/Ethics\%20 Amidst\%20COVID-19_\%20A\%20Brief\%20Ethics\%20Han\%20-\%20Anna\%20Kasafi\%20 Perkins\%20R\%20\%20Clive\%20Landis.pdf

Purcell, W. M., Henriksen, H., \& Spengler, J. D. (2019). Universities as the engine of transformational sustainability toward delivering the sustainable development goals: "Living labs" for sustainability. International Journal of Sustainability in Higher Education, 20(8), 1343-1357. https://doi.org/10.1108/IJSHE-02-2019-0103

Remenyi, D., Williams, B., Money, A., \& Swartz, E. (1998). Doing research in business and management: An introduction to process and method. London: Sage.

Rothaermel, F. T., Agung, S. D., \& Jiang, L. (2007). University entrepreneurship: A taxonomy of the literature. Industrial and Corporate Change, 16(4), 691-791. CrossRefGoogle Scholar

Sánchez-Barrioluengo, M. (2014). "Turning the tables”: Regions shaping university performance. Regional Studies, Regional Science, 1(1), 276-285. https://doi.org/10.1080/ 21681376.2014.964299 


\section{Elin M. Oftedal et al.}

Şerbănică, C. (2012). Best practices in universities' regional engagement: Towards smart specialisation. European Journal of Interdisciplinary Studies, 4(2), 45-55.

Stake, R. E. (1995). The art of case study research. Thousand Oaks, CA: Sage.

Stake, R. E. (1998). Case studies. In N. K. Denzin \& Y. S. Lincoln (Eds.), Strategies of qualitative inquiry. Thousand Oaks, CA: Sage. [Google Scholar]

Strategic plans of the university of the west indies - Google zoeken. (n.d.). Strategic Plan for the University of the West Indies. Retrieved June 1, 2021, from www.google.com/ search?client $=$ firefox-b-d \&q $=$ strategic + plans + of + the + university + of + the + west + indies

The UWI selected to lead climate smart world. (2019, February 12). Campus News. https:// sta.uwi.edu/news/releases $/$ release.asp?id $=21881$

Thomas, A., \& Baptiste, A. K. (2018). Knowledge, perceptions, concerns, and behaviors to climate change - the Caribbean context: An introduction. Journal of Environmental Studies and Sciences, 8(1), 39-41. https://doi.org/10.1007/s13412-017-0462-5.

Vorley, T., \& Nelles, J. (2008). (Re)Conceptualising the academy: Institutional development of and beyond the Third Mission. Higher Education Management and Policy, 20(3), 109-126.

Vorley, T., \& Nelles, J. (2009). Building entrepreneurial architectures: A conceptual interpretation of the Third Mission. Policy Futures in Education, 7(3). 


\title{
14 Universities and Regions
}

\author{
New Insights and Emerging \\ Developments
}

\author{
Laila Nordstrand Berg, Elisa Tomas, Tatiana Iakovleva, \\ Rómulo Pinheiro, and Paul Benneworth
}

\begin{abstract}
In this concluding chapter, the editors take stock of the empirical findings across the cases and levels of analysis and link the empirical evidence to the analytical framework presented in Chapter 2. In so doing, we revisit the interplay between macro, meso, and micro dimensions of the environments as well as the temporality in which higher education institutions (HEIs) operate, which, taken together, help shape the mundane (everyday) or routine behaviours of actors within HEIs. The editors conclude by suggesting that the empirical evidence and conceptual insights advanced in this volume represent a needed first step, yet more needs to be done (future studies) to further unpack how the dynamic process associated with the everyday university-region interplay plays out in practice, and how it can be successfully managed and sustained over time.
\end{abstract}

\section{Introduction}

This book's starting point, as described in Chapter 1, is to consider the various processes by which university knowledge is made available and actionable by being taken up by and shaped in concert with regional actors. The primary focus of analysis is the micro-scale of individual agency (knowledge actor) and the ways in which university interactions with societal partners shape local contexts for actionable knowledge. As indicated at the onset and elaborated further in Chapter 2, the book's aim is not simply to map out the diversity among case institutions, engagement mechanisms, and regional contexts. The aim is also to use that diversity to advance a novel conceptual/analytical framework for unpacking the everyday engagements of university-regions, considering the dynamic, complex, and co-evolving interplay between (a) key social agents and institutions, (b) the contexts in which they are embedded, and (c) the historical trajectories and strategic ambitions underpinning context-specific social arrangements and interactions that are mediated by temporal and 
spatial dimensions. In this concluding chapter, we take stock of the empirical findings across the cases and levels of analysis and link the empirical evidence to the analytical framework presented in Chapter 2.

The cases presented in this book provide a picture of how the interplay between macro, meso, and micro dimensions of the environments as well as the temporality in which HEIs operate help shape the mundane or routine (everyday) behaviours of actors within HEIs. As presented earlier, the macro environment refers to the extent to which the everyday engagements or interactions of university-regions are mediated by macro-level systems (broader context) - political, economic, social, cultural, and so on - at the regional, national, and global levels (e.g., national/regional science and innovation systems, government policy, world rankings). The meso environment refers to the sets of established (routine-like) and emerging daily practices and mechanisms material, symbolic, informal, and so on - that characterize everyday life, including relationship networks and interpersonal relations. The microenvironment refers to the actions and behaviours of individuals and institutions at multiple levels aimed at either maintaining or changing the institutional (rules) and organizational (structures) settings underpinning their work.

The macro environment is exogenous because agents at the micro level often have limited power to change it. Social, cultural, and institutional arrangements determine how the "gatekeepers" of resources as well as the power holders impact agents and their behaviours (Brush et al., 2009). Meanwhile, the meso environment includes links between the macro forces and the micro level through intermediate institutions and structures. Meso institutions include occupational networks and business associations (Brush et al., 2009) that might have a significant impact on the behaviours of HEIs. Hence, the actions of key agents at the micro level have an impact, albeit indirectly, on the macro- and meso-level structures, not only the other way around. We illustrate below how the different dimensions comprising the analytical framework presented in Chapter 2 manifest empirically throughout the book and the individual case contributions later. Although we analyse these levels separately, the empirical materials provide support for important linkages across the levels and the time dimension, regarding past, present, and future scenarios, which is cutting through all levels. The discussion, by touching upon the correspondence between the macro, meso, and micro levels (plus the temporality), shows how policy and strategy (and other elements of the macro and meso levels) enable the agency of university actors (micro level).

\section{Socio-cultural arrangements: the macro level}

When analysing the different contributions of this book, there are differences in how the case HEIs are embedded in national and regional contexts and the types of opportunity structures that influence local developments (Edelman et al., 2016). We provide examples of how such opportunity structures allow for an interaction between agents and the institutional context. The historical scene, which includes but is not limited to the political embeddedness (Pfeffer \& 
Salancik, 2003), is clearly important to the way in which the case HEIs relate to their local and national surroundings. Starting with the Polish case (Chapter 11, Dąbrowska et al.), the HEI is embedded in a post-communist era, where universities still operate as ivory towers geared more towards academic values, and the focus on market conditions is lower than in other sectors. The universities are therefore isolated from societal needs, including their role in the local/ national economy. The Polish case study reflects an attempt to develop the connection between the university sector and local government agencies to devise strategies and plans for regional economic development in the next decade. The tension between communist and market approaches is also a central feature of the Chinese case (Chapter 8, Liu). In this case, efficiency was hampered by the focus on hierarchy and control based on the communism approach, while the adoption of a market logic and service orientation was found to be far more efficient in both the establishment and operation of student incubators.

Another post-era that provides opportunities for influencing development is the chapter on the Caribbean (Chapter 13, Oftedal et al). The case university is not only a multicampus HEI but also a multinational one, consisting of universities in the 17 small-island nations composing the Caribbean region. The islands are still rebuilding from the colonization and slavery period in addition to struggling with the local effects of climate change, financial crisis, and more recently COVID-19. The university is a central actor in the effort to rebuild the region and is not only required to manage the various political and economic conditions from different governments; central actors in the university are also working as political activists to promote new ideas and initiatives geared towards socio-economic development. The evidence from the case suggests that the university's structure, strategy, and core activities reflect a mixture of embeddedness in political (across nations), cultural (across islands), social (across networks), and cognitive (expressed in, for example, political activism) elements (Kloosterman et al., 1999; Pfeffer \& Salancik, 2003).

In a society with a low degree of trust in government, the role of local universities can be crucial for the development of a region (Gunasekara, 2006), as described in the case from Brazil (Chapter 4, Faccin et al.). When a region that had been well developed experienced economic stagnation and decline, combined with low levels of trust in central authorities, joint collaborations between universities and private and public actors were established, boosting the regional economy. This can be seen as a bottom-up approach to political embeddedness as a means to improve living conditions in the region as well as a social embeddedness approach (Granovetter, 2005) involving the proactive efforts of a network of local actors or a regional coalition (Pinheiro \& Normann, 2017; Thomas \& Asheim, 2022).

In peripheral or less-developed ("thin") regions (for recent accounts, see Benneworth, 2018; Pinheiro et al., 2018), HEIs can contribute to the development of the local economy by providing education and research that supports regional needs and participating in third-mission activities and innovative projects. The local actors are building and engaging in networks that influence social embeddedness (Granovetter, 2005). The example from Italy (Chapter 5, 
Tomasi et al.) is illustrative of how the development of knowledge networks brings together local actors from different parts of the economy; for example, students and university actors come together to develop projects to boost the economy and contribute to a more sustainable society. This peripheral dimension is also central in two of the chapters from Norway (Chapter 3, Berg \& Yttri, and Chapter 12, Berg \& Hope). Still, the focus here is less on thirdmission activities and more on educational efforts to provide the peripheral region with professionals and keep students from moving away after graduating, thereby influencing social embeddedness (Granovetter, 2005).

The other Norwegian cases in the book were found to be responsive to the opportunity structure resulting from political embeddedness (Pfeffer \& Salancik, 2003) through reforms and a governmental push to increase focus on thirdmission activities, co-creation, and entrepreneurship. Examples of this are given by Karlsen and Pinheiro (Chapter 10), Berge et al. (Chapter 7), and Iakovleva and Adkins (Chapter 6). The chapter from Abualruband and Pinheiro (Chapter 9) problematizes this push from central government to be both exceptional in teaching and research and relevant in relation to universities' local and global aspirations.

Hence, a pattern seems to emerge from our empirical material: in countries with low governmental influence over universities, the role of the university as an active agent in regional and national development is rather prominent, not only in terms of providing teaching and research but also the high focus on the third mission of regional engagement. However, this picture is blurrier in the cases of Norway and China, where local initiatives towards third-mission activities can be categorized as strategic responses by the actors involved to governmental policies and incentive structures. That being said, in the case of Norway (but not exclusively), such strategic efforts at the macro (policy) and meso (university strategy) levels are mediated by existing structural and cultural barriers at the level of the academic profession and/or a given knowledge domain. Existing professional incentive structures are still geared towards the core activities of teaching and research, particularly the latter, rather than local engagement per se, as found in earlier studies (Balbachevsky, 2008; Pinheiro, 2012; Benneworth et al., 2017).

In Table 14.1, the chapters are organized according to the government's influence on the mundaneness of HEIs' activities (high versus low) as well as

Table 14.1 Mapping the volume's empirical contributions

\begin{tabular}{|c|c|c|c|}
\hline & & HEIs' locus of attention & \\
\hline & & Internal orientation & External orientation \\
\hline \multirow[t]{2}{*}{$\begin{array}{l}\text { Government } \\
\text { influence }\end{array}$} & High & Norway Chapters 7, 11 & $\begin{array}{l}\text { Norway Chapters } 4,5,8,10 \\
\text { China Chapter } 9\end{array}$ \\
\hline & Low & Poland Chapter 3 & $\begin{array}{l}\text { Brazil Chapter } 6 \\
\text { Italy Chapter } 12 \\
\text { The Caribbean Chapter } 13\end{array}$ \\
\hline
\end{tabular}

Source: Authors' own 
the orientation of HEIs' activities (internal versus external with regional stakeholders) or locus of attention.

\section{Mundaneness: the meso level}

As indicated at the onset, mundaneness, as applied to the analytical framework presented in Chapter 2, manifests in three distinct levels: institutionalization processes, materiality and practice, and leadership. We tackle each of these aspects below as empirically demonstrated in the case stories.

\section{Institutionalization of mundaneness}

Scott's three institutional pillars (Scott, 2008) reflect three different logics and ways of considering how work becomes mundane. The regulative pillar refers to regulations and legal frameworks that exist at a societal level, independent of the particular organizations. Such regulation must be interpreted and implemented by the members of the organization to become a part of the mundane work. Within institutions, templates for actions are developed as well as regulative mechanisms to enforce them. This is an influence that goes both ways, as actions also influence the institutions (Lawrence et al., 2009). Different logics can motivate application of the alternative ways of acting (e.g., an instrumental logic is prominent in relation to regulations). The members of an organization act in an instrumental way to avoid losing legitimacy and even to avoid punishment. The normative pillar reflects precisely this: the norms and values that are dominating and influencing behaviour in daily life. Such values can originate, for example, in professional norms or academic fields and consist of (informal) instructions regarding how to behave and perform within the organization. Here the logic of appropriateness (March \& Olsen, 2011) is prominent: What is appropriate to do in this situation? Such norms become institutionalized and are not necessarily reflected on a daily basis. The last pillar, the cultural cognitive pillar, is based on how the members cognitively perceive the cultural surroundings and how this is interpreted and integrated in the organization in a way that it is taken for granted (Scott, 2008). Culture becomes a part of the identity of the members and is influenced by traditions and common perceptions of how to act and how to perceive the social reality where the organization operates. The logic of orthodoxy - "this is how we have always done this" - regulates the mundane activities from this perspective.

In relation to the daily activities and mundane life that unfolds between HEIs and regional actors, we apply the three institutional pillars (Scott, 2008). The relevance of an institutional framework is addressed by Iakovleva and Adkins (Chapter 6) in their chapter on different types of entrepreneurship and university - industry collaboration. They point to the fact that activities within the university are affected by the regulative framework. Projects and collaborative initiatives that receive incentives from the university are more easily institutionalized (Berger \& Luckmann, 1966; DiMaggio \& Powell, 1983; Scott, 
2008) and become an integral part of the mundane activities within the university. Examples of this are joint research projects between the university and industry. New initiatives, such as start-ups, licensing, and patenting, have not become institutionalized to the same degree and could benefit from an increase in incentives to boost university-research collaboration.

Similar findings are described in the Polish case (Chapter 11, Dąbrowska et al.). The Polish university sector seems decoupled from the needs of society and the development of surrounding regions, and the level of cooperation with local authorities is weak. This can be linked to few incentives for academics to pursue such activities as a regulative tool but also seen in the light of the cultural pillars and logic of orthodoxy (Scott, 2008), where such non-scientific activities are regarded to have less value than "pure science". Individual scientists who are cooperating with local governments can help to build trust between academia and surroundings, and in turn such activities can facilitate cooperation at an institutional level, which, in the long run, can contribute to changing the system.

Another chapter that illustrates how demanding it is to introduce new elements into a highly institutionalized organization, as a university, is Chapter 10 (Karlsen and Pinheiro). The authors study the efforts to develop a new university strategy and the establishment of a co-creation lab where academics, students, and regional actors from the public and private sectors can co-create solutions and entrepreneurial activities for the region. The process to establish this lab was characterized by a clash of logics on the part of the different actors involved. This chapter illustrates that, even if the regulative framework is provided by central actors at the university - in this case a new vision statement - the various implementers follow different institutional logics (Battilana \& Lee, 2014; Thornton \& Ocasio, 2008). This, in turn, affects university norms and culture, resulting in clashes and tensions, thus making cultural change a daunting task, even in the context of a relatively young university. The professional norms underpinning academic tasks and roles diverge from those emanating from managerial and politico-administrative-based models at the level of the central administration and leadership, and this clash can contribute to the growing divide between the leadership and academics within the university on the one hand and internal and external stakeholders on the other (for an earlier discussion, see Berg \& Pinheiro, 2016).

Another aspect is that it takes time to institutionalize (Berger \& Luckmann, 1966) new initiatives. As Abualrub and Pinheiro (Chapter 9) point out, (Norwegian) academics are exposed to simultaneous demands to deliver relevant and high-quality teaching to the region while striving for research excellence and global competition. This results in a divided focus for the academics, who may struggle to meet the increasing demands from multiple actors. If the academics are constantly exposed to new inputs regarding how to improve teaching and research, new routines are not routinized, and they fail to become a part of what is taken for granted and mundane. When institutionalized in this way, one does not spend much time reflecting on how things should be done, and that frees more time for other activities. The institutionalization of activities 
that seem to have a similar focus - as in the case of student entrepreneurships (Chapter 7, Berge et al.) - can take very different forms. By comparing cases from three different universities in a Norwegian region, student entrepreneurship activities were found to reflect characteristic features of the universities (one with a regional focus, one with a national focus, and the last with a global focus), and this focus seems to be institutionalized into what the students were doing through their internships.

Taking mundane activities for granted in the context of a changing political and economic environment can also contribute to decline and closure of the educational institution, as illustrated in the case of teacher education in Western Norway (Berg \& Yttri, Chapter 3). Even though local actors were successful in building a solid teaching programme that was seen as benefiting the region and became an institutionalized part of the university's culture, new government-mandated reforms emphasizing research and a more global competitive focus challenged the logic of orthodoxy, resulting in the need to merge with other HEIs to survive as an educational organization.

\section{Materiality and practice}

Mundane activities are often made visible through materiality (Buse et al., 2018), and mundane work is often influenced by material practices related to "things" such as our technical environment, computers, and programmes. The aspect of practice includes a relationship between actors' competencies, ongoing dynamics and processes, the relation to the material side and embodied, tacit knowledge, and routine activities (Buse et al., 2018). "Know-how" and "craft knowledge" enable or hinder daily activities. In light of such mundane activities, examples of how the interaction involving local actors can contribute to regional development can be found in several of the chapters in this book. This is particularly the case for students' involvement with engagement or third-mission activities that are tightly coupled with teaching. In the chapter by Berg and Hope (Chapter 12), the authors focus on history students interning at a museum. The students were learning the craft and developing know-how on the museum sector by performing mundane activities. In the chapter from Italy (Chapter 5, Tomasi et al.), the university applies experiential learning, where students work together with local actors and in that way receive different types of knowledge in relation to food, wine, agriculture, and tourism. Such material actions can foster innovation and rural development, and they also contribute to the students' employability. This was explicitly expressed by actors in the Norwegian case (Chapter 12, Berg \& Hope); after the internships, the students reported having learned "material practices" that could be used for holiday jobs and even permanent job positions.

Mundane activities are interconnected with spatiality, temporality, and practice (Buse et al., 2018). The way agents design and physically organize their social and physical work influences their mundane activities. The locations can vary from physical organizational buildings to informal spaces in and between 
organizational boundaries. Departments that are located close to each other often influence the development of social networks and trusted organizations, as they are easier to access than those located in more remote settings.

The most prominent example of spatiality in our book is the university in the Caribbean (Chapter 13, Oftedal et al.). This university is situated not only in different locations but also across many different island nations, thus being exposed to multiple regulative environments. The spatiality element can be seen as an advantage regarding the mission of universities to provide education to the population in the scattered region and develop third-mission activities. The Caribbean university has built a clear structure to support this and shared responsibilities for different areas among different campuses. This can also be challenging due to large physical distances and internal competition regarding what needs to be in focus, but the university can also assume a bold role by giving advice on development regarding difficult issues across the different countries. Spatiality and geography can also be seen as an advantage in regional development, as actors from different locations can provide networks across a larger area. For example, the three universities in the Brazilian case (Chapter 4, Faccin et al.) or the two campuses at Norway's UiA (Chapter 10), through emerging practices, link up to different actors in the region, including public agents, civil society, and private companies. The universities can have legitimacy and act as a catalyst in regions where trust in national and local authorities is low. By establishing such networks, underpinned by trusting collaborations among local actors, both formal and informal contacts can become part of mundane activities that have the potential to boost the regional economy. In other areas, bottom-up network arrangements in the form of regional coalitions (Pinheiro \& Normann, 2017) may be efficient means to reach regional development goals in the absence of stable, efficient, and trustworthy governmental agencies.

\section{The mundaneness of leadership}

Hierarchies and power relations also regulate practice and influence the mundane (Buse et al., 2018). Turning our gaze towards the managerial side of the organization, the differences in what leaders do compared to what employees do are not remarkable (Alvesson \& Sveningsson, 2003). Mundane activities are mostly neglected in the literature on management and leadership studies. Nevertheless, performing administrative tasks, chatting with employees, listening to them, gossiping, and creating a good working atmosphere are considered as important mundane activities of leaders, and the significance of leadership may be more linked to such activities than broad strategies and changes (Alvesson \& Sveningsson, 2003). Such mundane activities, it is argued, are given extraordinary meaning as they are performed by managers.

Our studies do not cover mundane activities such as the small talk to employees (Alvesson \& Sveningsson, 2003), but the cases from China (Chapter 8, Liu) and Norway (Chapter 10, Karlsen \& Pinheiro) illustrate how micromanagement as a mundane activity hinders development, not least going against professional norms centered on academic freedom and autonomy. Finally, the case 
of Brazil (Chapter 4, Faccin et al.) illustrates the importance of leadership and local coalition building in processes of regional engagement aimed at fostering socio-economic impact.

\section{Agency: the micro level}

The book emphasizes the analysis of the roles played by universities' different agents in engaging with their surrounding regions. Although universities, as organizations, are expected to contribute to regional growth, in practice the engagement with external actors is undertaken by individual academics or research groups. The authors of the book chapters discuss how different university agents perform their ordinary activities engaged with "regional agents" because universities' engagement is context-specific and contingent on agency. We view agentic behaviour as a structuration process, including iterative, projective, and practicalevaluative behaviours (Emirbayer \& Mische, 1998). While iterative behaviour reflects routinized patterns in an organizational context, projective behaviour generates possible future trajectories of action that are creatively reconfigured on the basis of the actors' hopes, fears, and desires for the future. Finally, practicalevaluative behaviour reflects the capacity of actors to make practical and normative judgments regarding alternative trajectories of action in response to emerging demands and dilemmas alongside the ambiguities of evolving situations. In this way, agents both are affected by and help shape the structural conditions through their actions and experiences (Battilana \& D'Aunno, 2009).

It is the agent who mindfully deviates from existing paths to establish new practices that will, over time, create new routines (Garud \& Karnøe, 2003; Steen, 2016). In this book, some of the chapters investigate how new paths emerge instead of others and how this process is influenced by actors' habitual activities. As pointed out by Steen (2016), actors respond to changes and influence the contexts in which they operate. Yet, at the same time, as outlined by institutional scholars regarding the dilemmas of embedded agency (Battilana \& D'Aunno, 2009), local actors are often socially conditioned to accept their institutional and organizational contexts as natural or given, thus restricting their room to manoeuvre when attempting to change such conditions.

There is a considerable variety of practices analysed in the book that form the mundaneness of universities' regional engagement. For example, Iakovleva and Adkins (Chapter 6) explore how academics contribute to knowledge transfers to the region. Through iterative behaviours, such as joint research projects, academics are able to reinforce already established routines. At the same time, some academics demonstrate projective behaviours and engage in entrepreneurial activities, which are less rooted in traditional teaching and research associated with academic jobs. Another example of projective behaviours can be found in Chapter 11, (Dąbrowska et al.), which describes the behaviour of representatives of the university who actively participated with residents and other stakeholders to design the Warsaw Development Strategy 2030. Chapter 12 (Berg \& Hope) describes practical-evaluative behaviours of programme coordinators who initiated 


\section{Laila Nordstrand Berg et al.}

partnerships with regional actors to institutionalize internship programmes. The actions of these university agents fit well within the concept of "entrepreneurial agency" (Garud \& Karnøe, 2003), which is explained by the complementarity of knowledge and practices from universities and external partners: each actor possesses incomplete knowledge, and thus all must collaborate to harness specific and complementary knowledge with the goal of delivering value to the region.

Agents within HEIs include students as well as academics. Faccin et al. (Chapter 4) tell a story that includes students as representatives of the university in key activities, such as network mobilization and project management, working together with external stakeholders to transform the region into an ecosystem conducive to entrepreneurship and innovation. Whether students originate from the same region in which the university is located or they stay in the region after graduation, they contribute to regional path creation. This is an example of practical-evaluative behaviours. Creating a new path is the result of collective rather than individual agency, and the actors are embedded in these paths at the same time as they shape them, fostering structural change (Garud \& Karnøe, 2003; Steen, 2016).

University agents may act as change agents when they enable structural change both within the university and across the regional economies, acting as “academic entrepreneurs" (Bercovitz \& Feldman, 2008). Some case studies, such as the ones reported by Tomasi et al. (Chapter 5) and Oftedal et al. (Chapter 13), show that the regional role of the university is dependent on people, and therefore the potential for regional change is dependent on individual actors as well. This is understandable, given that local agents have ties with social and economic networks in their home regions, which allows them to understand and draw from the region's capabilities to develop engagement activities contributing to regional development (Pinheiro et al., 2017; Neffke et al., 2018).

University agents are responsible for engagement activities, but often these activities are not transformed into daily routines. If engagement activities are not embedded into the university's habitual actions, including a tight coupling with core teaching and research tasks, the potential positive effects for both the region and the university are very fragile in the long run (cf. Pinheiro et al., 2015). The empirical insights emanating from many of the chapters in the book offer important lessons about how universities could better institutionalize their regional engagement. Attention should be paid to the degree of coupling between core and third-mission activities. Critical local agents, and the informal social networks (both local and global) in which they are deeply embedded, need to be both recognized and rewarded accordingly if such efforts are to become sustainable (institutionalized) in the long run across the institutional fabric (formal and informal or cultural structures) of universities.

\section{Temporality}

Temporality, in this book, is seen as a meta-dimension that embraces the interlink among the three levels forming universities' regional engagement: the 
macro level of sociocultural arrangements, the meso level of mundaneness, and the micro level of agency. In this book, we have investigated the importance attributed to temporal dimensions (Buse et al., 2018) - past events, present conditions, and future scenarios with strategic aspirations - as well as the complex and dynamic interplay between them.

Past events, internal and external to universities, such as mergers or failed mergers and public reforms, create pressure for new ways for universities to connect with regional actors. For example, the case discussed by Karlsen and Pinheiro (Chapter 10) shows that the university established a new strategic vision as a response to governmental reforms in Norway and changing national and global institutional and operational environments. The same applies to another Norwegian case study (Chapter 3, Berg \& Yttri), in which the university adapted its teachers' education programs following external decisions that led to three university colleges merging into one university. External pressures, especially top-down decisions from governmental agencies, are clearly seen as reasons over time that drove universities closer to their regions or at least that changed the way universities engaged with regional actors in Norway.

This was also seen in the Chinese case (Chapter8, Liu). China has had a long history of institutionalization of a bureaucratic way of working, and it takes time to change such path dependency (cf. Krücken, 2003). This is evident in the establishment of university incubators in two provinces, where one continued the historically established path while the other took a new route and developed a more market-oriented approach. The market-oriented case has flourished compared to the more bureaucratic case, which struggles to implement successful student entrepreneurship. If actors in the Chinese incubator context manage to institutionalize the new approach, it could potentially influence the development of incubators throughout the entire country in the future. However, the clash of institutional logics (cf. Greenwood et al., 2010) between the deeply institutionalized tradition of strong (top-down) state control and the need for more decentralized marketand network-based arrangements and mechanisms may make this a daunting task for both universities and regional actors. Norway, and the Nordic countries more generally, may serve as an important benchmark in this respect, as they are able to combine strong state-centred regulative frameworks with high levels of university autonomy and other policy instruments that are conducive to the adoption of more informal (networks) and dynamic market-based arrangements at the local level (see Sørensen et al., 2019).

It is different, however, when one analyses universities in countries where the government does not exert such a strong role, as in the cases of Brazil, the Caribbean, and Italy. Chapter 4 (Faccin et al.) reports a case study in Brazil, where the universities decided to lead a movement together with other actors to revitalize the regional ecosystem and develop an environment in which entrepreneurship and innovation could flourish. The present socio-economic context of the region and past experience influenced the leaders' intentionality and efforts (Lawrence et al., 2009). The history of the region justified the 


\section{Laila Nordstrand Berg et al.}

actions, while the past relationships of universities with several stakeholders gave the universities the necessary legitimacy to take a leadership position. Future expectations about regional ecosystem renewal influenced the actors' intentionality, explaining their goal-oriented actions (Buse et al., 2018).

In the Caribbean islands, Chapter 13 (Oftedal et al.) investigates the case of the University of the West Indies, which illustrates the importance of temporality. Due to past practices over decades in the region, the university identifies itself as an "activist university", where senior leadership propels the university's societal mission. Additionally, the example from Italy (Chapter 5, Tomasi et al.) shows the history of the relationship of the university with regional actors, where the initiative from the university and internal agents led to the creation of knowledge networks. Throughout the book, it is rather clear how time, as a meta-dimension, unifies several elements that form the mundane embeddedness of universities in the region.

The following findings from our case studies are not set in stone, but they indicate that changes born from universities' internal initiatives take longer to materialize into institutionalized change when compared to pressure exerted in a top-down manner. However, by analysing the cases of these three countries (Brazil, the Caribbean, and Italy) one can clearly see that the main driver is individuals at the university, stressing the role of agency as a critical component in institutionalizing new ways of regional engagement, as illustrated in previous studies (Benneworth et al., 2017). People take their time to create and establish strong ties with regional partners, with the good of their region in mind. This highlights the overarching reach of temporality over the macro level of embeddedness, the meso level of mundaneness, and the micro level of agency.

Some chapters have explored the evolution of their case studies over time, such as the examples of Berge et al. (Chapter 7) and Dąbrowska et al. (Chapter 11). The temporally embedded process of social engagement relies on habits from the past to imagine the future, while contingencies of the present contextualize how this transformation will occur (Emirbayer \& Mische, 1998). The present challenges the past in one of the case studies presented by Abualrub and Pinheiro (Chapter 9). The university has a long history of meeting regional needs through vocationally oriented educations, but this is being challenged by external pressure from multiple stakeholders to also focus on global competition, excellence, and future relevance. Actors within the university struggle to balance excellence in teaching (connected to a historical commitment to this task) with fostering research quality while competing with larger national and global players. The case presented by Iakovleva and Adkins (Chapter 6) shows a relatively new university struggling with past arrangements. It takes time to establish new routines and support structures to develop into an entrepreneurial university with a greater focus on innovation, and current (and future) development is hampered by an absence of a holistic approach.

We can clearly see that the future scenarios of the case studies are shaped by path dependence, which considers not only past relationships of universities and regional actors but also universities' profiles, internal dynamics, and 
organizational cultures (for a discussion, see Krücken, 2003). Nevertheless, as universities are also active in leading regional change, future aspirations are being developed and may become routinely embedded into universities' third mission in the future. In Norway (Chapter 7, Berge et al.), for example, three universities decided to join forces and create a common platform for promoting student entrepreneurship education and activities in the region. In that case, the sense of security supported by tacit rhythms and rituals (Buse et al., 2018) is being shaken by intentionality as a part of universities' institutional work (Lawrence et al., 2009).

Another example of a university's effort to change its traditions and increase its future regional impact is presented in Chapter 12 (Berg \& Hope), showing how actors adjust their actions and evaluate current possibilities (Araujo \& Harrison, 2002) to improve student internship. With the aim of keeping students in the region in the future, the university gained experience from previous established networks (e.g., from the business administration bachelor) to establish new programmes such as sociology and history. As affirmed by Araujo and Harrison (2002), path dependence differs from determinism when agents are aware of their ability to change the course of events. A university's agents may create new paths, and the efficacy of their choices is temporally dependent.

In short, the diversity of accounts associated with the case studies presented in this book attests to the complexity of university-region interactions, lending support to the analytical framework advanced at the onset of the volume in Chapter 2 (Pinheiro et al.). Moving forward, future studies could deepen our understanding of the complex ways in which macro, meso, and micro dimensions interact to produce dynamic and non-linear outcomes (at both the level of the universities and that of the regions) that can be neither predicted nor steered or regulated by any single entity or individual. The ability of regions and universities to adapt to emerging circumstances, including structural shocks and crisis, is a function of the ways in which local knowledge ecosystems, both formal and informal, emerge and are nurtured over time in the context of existing and new or emerging institutional arrangements. This occurs alongside the intentional actions of key local agents, more often than not working together in the form of regional coalitions (Pinheiro \& Normann, 2017) that, in an increasingly digitally mediated world, cut across traditional conceptions of time, space, and social relations.

\section{Concluding thoughts}

We started this volume by pointing to the wicked issue of university engagement in regional development. So far, there has been a focus on "happy family stories" of ambitious regional development coalitions that have had visible impacts in the form of successful spin-offs or clusters of industrial actors attached to such universities. Through this volume, we emphasized that it is equally important to shed light on the "everyday" engagements of universities through the lens of mundaneness, where actors such as academics and students contribute to the development of the regions in which they are located 
through their daily actions and practices. There are many ways in which university knowledge agents can build connections with regional partners, and this book provides various examples of such mundane activities in different countries.

The evidence presented in this volume across different countries and contexts suggests that mundaneness matters. However, we need to convert it from a normative concept into a practical approach whose benefits are clear and which encourages relevant policies to facilitate HEI-regional engagement. In particular, the idea of agent behaviours and temporality, which enable structural changes in the organizational context, might be of interest. It is always individuals who are behind the changes, and the inclusion of multiple stakeholder views and insights (democratic deliberation and/or co-creation) is important. At the same time, it is not always clear what events or actions in particular result in positive or negative changes. In other words, it is much harder to measure the effects of mundaneness in comparison to traditional "hard" measures like the number of patents and/or licences.

Therefore, in order to enable the positive effects of mundaneness on HEIregion interactions, there is a need for a framework and guidelines around how to build such effects. We have been working in this book with four key dimensions: macro, meso, and micro environments, and temporality. This not only has aided our analysis but could also offer a template for understanding mundaneness. We propose (and explore in Chapter 2) a model of mundaneness that might be helpful for further unpacking this complex process.

Making interactions between HEIs and regional actors happen is about managing the contestable nature of behaviours - the trajectory is always a product of social shaping forces. For any change in actors' behaviour and for the establishment of new routines, there should be scope for moving the walls of an established trajectory. Nevertheless, in practice, there are multiple obstacles some of which are more susceptible than others to policy intervention, whether at a state or organizational level.

One area where there is considerable scope for fostering successful HEIregion interactions is in designing a supportive regulative environment. This could include proper incentive systems, which can stimulate such cooperative activities, and encourage the development of cognitive skills to support joint research projects and cooperative activities with various regional stakeholders to facilitate positive social outcomes. It takes time to build and foster norms of behaviour, but once this is done, the supportive collaborative culture can reinforce itself, creating mundaneness processes. Policies might include training and empowering university staff to take initiatives to interact with regional actors through a spectrum of activities and social arrangements. There might be considerable scope for using rewards to help set and shape the direction of such activities, privileging interactions that demonstrate a high degree of social impact. Finally, regarding social capital as a critical factor, it is important to note that regional and national initiatives can include the development of organizational networks that include HEIs, industry, government agencies as 
well as civic society groups, which aim to make HEI-region interactions less time- and resource-demanding for each individual actor.

With regard to future research directions in the field, while we are confident that this volume offers a valuable contribution to the ongoing debates and literature on the role of HEIs in regional development, there are some points that have been raised but not explored in-depth in the book. These might well constitute a valuable future research agenda in this important field. As demonstrated by some of the cases included in this volume, everyday routines in HEIs revolve around teaching and research activities, including fund-raising, quality assurance, and challenges imposed by the changes in global development, such as the recent COVID-19 pandemic. It should be acknowledged that interaction with regional actors and knowledge transfer is not a separate and isolated activity; rather it should be seen, as illustrated in many cases in this volume, as an integrative part of everyday HEI tasks and routines. We have stressed the importance of individuals and mundaneness processes to the role of HEIs in regional development, but more needs to be done to further unpack how the process of mundaneness can be successfully managed and sustained over time. This includes, inter alia, addressing the following queries, preferably using comparative and longitudinal research designs based on mixed methodologies: Who are the internal and external agents who might participate and orchestrate those processes? What outcomes can be expected, and how can these outcomes be assessed and quantified? Who benefits from engagement, under what circumstances and why? What types of new tensions and dilemmas emerge, and how do they affect teaching and learning as well as knowledge production, diffusion, and co-creation? We hope that researchers in the field will examine these and other related aspects.

\section{References}

Alvesson, M., \& Sveningsson, S. (2003). Managers doing leadership: The extra-ordinarization of the mundane. Human Relations, 56(12), 1435-1459.

Araujo, L., \& Harrison, D. (2002). Path dependence, agency and technological evolution. Technology Analysis \& Strategic Management, 14(1), 5-19. https://doi.org/10.1080/ 09537320220125856

Balbachevsky, E. (2008). Incentives and obstacles to academic entrepreneurship. In S. Schwartzman (Ed.), University and development in Latin America: Successful experiences of research centres (pp. 23-42). Rotterdam: Sense.

Battilana, J., \& D'aunno, T. (2009). Institutional work and the paradox of embedded agency. In T. Lawrence, R. Suddaby, \& B. Leca (Eds.), Institutional work: Actors and agency in institutional studies of organizations (Vol. 31, pp. 58). Cambridge: Cambridge University Press.

Battilana, J., \& Lee, M. (2014). Advancing research on hybrid organizing - Insights from the study of social enterprises. The Academy of Management Annals, 8(1), 777-799.

Benneworth, P. (2018). Universities and regional economic development: Engaging with the periphery. London: Taylor \& Francis. 


\section{Laila Nordstrand Berg et al.}

Benneworth, P., Pinheiro, R., \& Karlsen, J. (2017). Strategic agency and institutional change: Investigating the role of universities in regional innovation systems (RISs). Regional Studies, 51(2), 235-248. https://doi.org/10.1080/00343404.2016.1215599

Bercovitz, J., \& Feldman, M. (2008). Academic entrepreneurs: Organizational change at the individual level. Organization Science, 19(1), 69-89. https://doi.org/10.1287/orsc. 1070.0295

Berg, L. N., \& Pinheiro, R. (2016). Handling different institutional logics in the public sector: Comparing management in Norwegian universities and hospitals. In R. Pinheiro, F. Ramirez, K. Vrabæk, \& L. Geschwind (Eds.), Towards a comparative institutionalism: Forms, dynamics and logics across health care and higher education fields (pp. 145-168). Bingley: Emerald.

Berger, P. L., \& Luckmann, T. (1966). The social construction of reality. London: Penguin Books.

Brush, C., de Bruin, A., \& Welter, F. (2009). A gender-aware framework for female entrepreneurship. International Journal of Gender and Entrepreneurship, 1(1), 8-24.

Buse, C., Martin, D., \& Nettleton, S. (2018). Conceptualising "materialities of care": Making visible mundane material culture in health and social care contexts. Sociology of Health \& Illness, 40(2), 243-255.

DiMaggio, P., \& Powell, W. (1983). The Iron Cage revisited: Institutional isomorphism and collective rationality in organizational fields. American Sociological Review, 48, 147-160.

Edelman, L. F., Manolova, T., Shirokova, G., \& Tsukanova, T. (2016). The impact of family support on young entrepreneurs' start-up activities. Journal of Business Venturing, 31(4), 428-448.

Emirbayer, M., \& Mische, A. (1998). What is agency? American Journal of Sociology, 103(4), 962-1023. https://doi.org/10.1086/231294

Garud, R., \& Karnøe, P. (2003). Bricolage versus breakthrough: Distributed and embedded agency in technology entrepreneurship. Research Policy, 32(2), 277-300. https://doi. org/10.1016/S0048-7333(02)00100-2

Granovetter, M. (2005). The impact of social structure on economic outcomes. Journal of Economic Perspectives, 19(1), 33-50.

Greenwood, R., Díaz, A. M., Li, S. X., \& Lorente, J. C. (2010). The multiplicity of institutional logics and the heterogeneity of organizational responses. Organization Science, 21(2), 521-539. https://doi.org/10.1287/orsc.1090.0453

Gunasekara, C. (2006). The generative and developmental roles of universities in regional innovation systems. Science and Public Policy, 33(2), 137-150. https://doi.org/10.3152/ 1471543067817791187

Kloosterman, R., Van Der Leun, J., \& Rath, J. (1999). Mixed embeddedness: (In)formal economic activities and immigrant businesses in the Netherlands. International Journal of Urban and Regional Research, 23(2), 252-266. https://doi.org/10.1111/1468-2427.00194

Krücken, G. (2003). Learning the "new, new thing": On the role of path dependency in university structures. Higher Education, 46(3), 315-339. https://doi.org/10.1023/ a:1025344413682

Lawrence, T. B., Suddaby, R., \& Leca, B. (2009). Institutional work: Actors and agency in institutional studies of organizations. Cambridge: Cambridge University Press.

March, J. G., \& Olsen, J. P. (2011). The logic of appropriateness. In C. Boix \& S. C. Stokes (Eds.), The Oxford handbooks of political science, public policy, comparative politics. Oxford: Oxford University Press. 
Neffke, F., Hartog, M., Boschma, R., \& Henning, M. (2018). Agents of structural change: The role of firms and entrepreneurs in regional diversification. Economic Geography, 94(1), 23-48. https://doi.org/10.1080/00130095.2017.1391691

Pfeffer, J., \& Salancik, G. (2003). The external control of organisations: A resource-dependence perspective. Stanford, CA: Stanford Business Books.

Pinheiro, R. (2012). In the region, for the region? A comparative study of the institutionalisation of the regional mission of universities. ( $\mathrm{PhD}$ dissertation). Oslo: University of Oslo.

Pinheiro, R., Benneworth, P., \& Jones, G. A. (2015). Beyond the obvious: Tensions and volitions surrounding the contributions of universities to regional development. In L. Farinha, J. Ferreira, H. Lawton-Smith, \& S. Bagchi-Sen (Eds.), Handbook of research on global competitive advantage through innovation and entrepreneurship (pp. 150-172). Hershey, PA: IGI.

Pinheiro, R., \& Normann, R. (2017). Agency, networks and complexity: The many roles of academic institutions in regional development coalition building. EKONOMIAZ. Revista vasca de Economía, 92(2), 68-85.

Pinheiro, R., Normann, R., \& Johnsen, H. C. G. (2017). External engagement and the academic heartland: The case of a regionally-embedded university. Science and Public Policy. 43(6), 787-797. https://doi.org/10.1093/scipol/scw020

Pinheiro, R., Young, M., \& Sima, K. (2018). Higher education and regional development: Tales from Northern and Central Europe. Cham: Palgrave.

Scott, W. R. (2008). Institutions and organizations. Los Angeles, London, New Delhi, Singapore: Sage Publications.

Sørensen, M. P., Geschwind, L., Kekäle, J., \& Pinheiro, R. (2019). The responsible university: Exploring the Nordic context and beyond. Cham: Springer Nature.

Steen, M. (2016). Reconsidering path creation in economic geography: Aspects of agency, temporality and methods. European Planning Studies, 24(9), 1605-1622. https://doi.org/ 10.1080/09654313.2016.1204427

Thomas, E., \& Asheim, B. T. (2022). Entrepreneurial ecosystems, learning regions and the role of universities. In C. I. Fernandes, M. Ramirez-Pasillas, \& J. J. Ferreira (Eds.), The role of universities and their entrepreneurial ecosystems in advocating sustainability (pp. 11-24). Berlin: De Gruyter. ISBN: 9783110670165. https://doi.org/10.1515/9783110670219-002

Thornton, P., \& Ocasio, W. (2008). Institutional logics. In R. Greenwood, C. Oliver, S. K. Andersen, \& R. Suddaby (Eds.), Handbook of organizational institutionalism. CA: Sage. 


\section{Index}

Note: Page numbers in italics indicate a figure and page numbers in bold indicate a table on the corresponding page. Page numbers followed by " $n$ " indicate a note.

\section{Lisbon Agenda (EU) 2}

absorptive capacity 129

Abualrub, Iyad 7, 126, 206, 208, 214

academic cultures 88

academic engagement 80

academic entrepreneurs 212

academic freedom 127

activist leadership, in Caribbean

188-200, 214

Adkins, Mette Eriksen 6, 75, 206, 211, 214

Agder, 32; see also University of Agder (UiA)

agency 109n3; embedded 20;

entrepreneurial 17, 212; in regional

engagement 17-18; see also micro

(agency) level

agora event 63, 66, 69

Agritur-Aso association 6, 59, 62-63, 64-67

Aleffi, Chiara 5, 58

Alliance for Innovation project 46, 47-50

Arizona State University 69

asset orchestration 44,55

autonomy 127

Bayh-Dole Act 76

BEA see Bergen Entrepreneurship Academy (BEA)

Benneworth, Paul 1, 4, 9, 11, 76, 175, 191, 203

Bergen, Norway 100

Bergen Carbon Solutions 105

Bergen Entrepreneurship Academy (BEA) 108

Bergen University College 35

Berge, Øyvind Midtbø 6, 96, 206, 209, 214
Berg, Laila Nordstrand 1, 4-5, 8-9, 11, 26, 136, 173, 203

Bertella, Giovanna 5, 58, 60

Bologna intergovernmental process 31

bounded rationality 140

Brazil, innovation ecosystems in 42, 205

capabilities, seizing 45; sensing; reconfiguring 46, 47; sensing $46,47,50$, 51,54

CAPs see community-academic partnerships (CAPs)

Caribbean 205; activist leadership in 188-200; implementing third mission 8; shared responsibilities 210

Caribbean Climate Smart Accelerator 195

Caribbean Community (CARICOM) 196

CARICOM see Caribbean Community (CARICOM)

Cave Hill Campus 189

Cavicchi, Alessio 5, 58

Center for Leadership and Sustainable Development (CLSD, UWI) 196

China, student incubators in 111-123, 205, 213

civic universities 60,68

climate change 188, 195, 198

co-creation 148, 206; of knowledge

(Samskaping av kunnskap) 7-8, 136, 146;

laboratory 144, 147-148, 208; at UiA 150

co-evolution 141

co-funding possibilities 6

collaboration: at Agritur-Aso association and UNIMC 60-61, 64-67; industry 88, 95; inter-organizational 80

commercialization, of research-based innovations $76-77,81,85-88$ 
community-academic partnerships (CAPs)

60-61, 68

community of practice $(\mathrm{CoP}) 60$

competitions 78,97

competitive funding regimes 13

conversion 29

$\mathrm{CoP}$ see community of practice $(\mathrm{CoP})$

COVID-19 pandemic 189, 198, 217

"craft knowledge" 16, 209

critical junctures 29, 35-36, 36, 142

cultural capital 5, 58

cultural-cognitive dimension 16,77 , 78-79, 86, 94, 207

Cybulska, Magdalena 8, 156

Dąbrowska, Anna 8, 156, 214

democratic participation 127

Dick-Forde, Emily 8, 188

displacement 29

drift 29

dual model, of education 30-31

dynamic capabilities 5, 50; Alliance for

Innovation project $47-50$; applied to universities 43-46; boost stage 51-54, 52,53 ; and innovation ecosystems $41-55$; reconfiguration 45,50 ; seizing 45 , 49; sensing 44, 47-49; theoretical view 44

Dziemianowicz, Wojciech 8, 156

early-childhood education 114

ecosystem orchestration 44, 55

education, 26, 97, 174; see also higher education institutions (HEIs)

Edulingua in San Severino Marche 69

embedded agency 20

embeddedness, of HEIs 97-99

employability 183, 185

engaged universities 41-42, 76, 77, 89; building 86-87; regionally 190

entrepreneurialism/entrepreneurial 2; activities, in industry collaboration 82 ; agency 17, 212; apprenticeship/tutoring 122; architecture 8, 97, 190-193, 192; credits 122 ; intentions $81,83,84,88$, 94; mindset, of students 120-121; orientation 150; turn 97

entrepreneurial university 76-77, 191; building 85-86; transformation to 77-80 entrepreneurship 206; initiative 7, 113, 122; university support for 78 environmental contextual characteristics 6-7, 112

European Credit Transfer System 31

European Union (EU) 2
European Union Cohesion Policy

Framework 157

evidence-based policymaking 159

excellence, and relevance 127-129, 208;

daily practices and strategic ambitions

133-134; key challenges and tensions

134-135;

experiential learning 59, 60

Faccin, Kadígia 5, 41

face-to-face interaction 59

Ferrara, Concetta 5, 58

Ferretti, Roberto 62

Five Islands Campus Antigua 189

From Idea to business course 103

gender differences 85

global competitiveness 127

global pipelines 59

goals/objectives 79

Google Scholar 193

government-university-industry interaction 111

hard entrepreneurship model 98, 106

Harvard Business School 87

HEIs see higher education institutions (HEIs)

Hernes Commission 31

higher education, development in Norway 30-32

higher education institutions (HEIs) 2,

4, 126; daily practices and strategic ambitions 133-134; embeddedness $6,12-13$; excellence and relevance 126-137; and internships 173-186; macro (societal forces) level 12, 204-207; meso (mundaneness) level 12, 204, 207-211; micro (agency) level 12, 204, 211-212; regional relationships 9; socio-cultural context 12-14; strategic planning 7 ; tensions and dilemmas 7, 13, 127, 134-135; see also student entrepreneurship

HI see historical institutionalism (HI)

historical institutionalism (HI) 28-30, 35, 142

Hope, Kristin Lofthus 8, 173, 209

Høvig, Øystein Stavø 6, 96

"human-human" relationship 166

HVL see Western Norway University of Applied Sciences (HVL)

Iakovleva, Tatiana 1, 4, 6, 9, 11, 75, 203, 206, 211, 214

idea competitions 97 
Imperial College in Trinidad and Tobago 189 industrial collaboration $82,84-85,87$, 94, 113

in-house training 174

Innovation and Entrepreneurship course 103, 104

Innovation and Management course 103

innovation ecosystems 5, 158; defined 43; dynamic capabilities to boost $41-55,50$; reconfiguration 45,50 ; seizing 45,49 ; sensing 44, 47-49; stages 51-54, 52, 53

Innovation Hub 104, 107

institutional entrepreneurship 109n3

institutional logics 143-144, 149, 213

institutional work 14-17

InterAmerican Development Bank 195

International Research Institute of Stavanger (IRIS) 84

internships 8, 209, 212; Norwegian educational landscape 175-176; placements through 179; regional placements 179

inter-organizational collaboration 80

Introduction to Innovation and Entrepreneurship in Media City Bergen course 104

IRIS see International Research Institute of Stavanger (IRIS)

Italy 58-70, 205-206

iterative agent $19-20$

joint research projects 6

JSTOR 193

Kaczyński, Lech 164

Karlsen, James 7, 140, 206, 213

know-how 16, 209

knowledge networks: Agritur-Aso association 6, 59, 62-63; background context 61-63; enhancement of "rural buzz" 59; role of universities 60-61; in rural areas 59-60, 61; theory 59-61; University of Macerata 59, 61-62; in

Valley (Marche Region, Italy) 58-70

Kretschmer, Caroline 5, 41

\section{Latin America 41}

Lavandaso festival 63, 68

Law on Higher Education and Science (Law 2.0) 160

layering 29

leadership structures 17

licensing 87, 208

linear regression analysis 83

Lisbon Agenda (2000) 2

Li Tajuli pilusi festival 63, 68
Liu, Dian 6, 111

loan arrangement 176

local government, and university

relationships 8, 156-169

locatedness 177

logics, within university 143-144, 144

Longsworth, Luz 8, 188

loop effect 12, 19

macro (societal forces) level 12, 204-207

managerialism logics 151

Marche in your suitcase event 63, 65, 66, 69

materiality 16

meso (mundaneness) level, 12, 204,

207-211; see also mundaneness

micro (agency) level 12, 204, 211-212

Mjøs Commission 31

Mona Campus Jamaica 189, 196

monetary rewards 78

mundaneness 2, 12; agency/agents

in regional engagement 17-18;

institutionalization of 14-17, 207-209;

integrative framework 19-22, 20; of

leadership 210-211; materiality and

practice 209-210; socio-cultural context 12-14; temporality $12,18-19$

national networks 106

network orchestration 44, 54

New Business Development course 103

NHH see Norwegian School of Economics (NHH)

Nordland, Eva 33

normative dimension 15-16, 77, 78-79, 86, 94, 207

Norway 206; Bergen region 100; educational landscape 175-176; higher education 30-32; Sogndal village 5, 27, 28; University of Stavanger 80; vocationally oriented university college 129

Norwegian School of Economics (NHH) 100-101, 102; entrepreneurship courses and extracurricular activities 103-104; and regional embeddedness 106

Norwegian School of Entrepreneurship (Gründerskolen) 103

Oftedal, Elin M. 8, 188, 212

Openlab in Stockholm 148

opportunities, sensing/shaping 44-45

Optics Valley Startup Café 115

organizational improvement 122

organizational (social) life 15-16 
Pacto Alegre project 49

Participatory Action Research approach 63 partnership formation 159

patenting 2, 87, 208

path dependencies 19, 29, 213; and determinism 18, 215; importance of 142; past events patterns 38

Paviotti, Gigliola 5, 58

person-to-person interactions 80

petroleum engineering 80

Piceno Laboratory on Mediterranean Diet 64

Pinheiro, Rómulo 1, 4, 7, 9, 11, 13, 126, 136, 140, 141, 203, 206, 208, 213, 214

place: place-based leadership 46, 158, 168; place-shaping 173,183

placemaking 176-177, 180, 181, 183

placements, through internship 179

Poland see Warsaw (Poland)

political logics 151

Pontifical Catholic University of Rio Grande do Sul (PUCRS) 46

Porto Alegre 42, 47

practical evaluation 20

practices 16, 133-134, 209-210

primary education $26-27$

process tracing 142; co-creation

laboratory 147-149; new vision emergence 144-146; organization of implementation 147; reactions at faculty level 146-147

professional schools 30

projectivity 20

PUCRS see Pontifical Catholic University of Rio Grande do Sul (PUCRS)

Quality Reform 31

reconfiguration, of internal assets 45

region/regional: development 8,173 ; embeddedness 97-99, 105-108; engagement 3,4

regional innovation system (RIS) 98, 106, 112, 157, 174, 191

regulative dimension $15,77,78,86$, 94, 207

relevance see excellence, and relevance research: excellence 2 ; research-based entrepreneurship 195; research-based teaching 131

resource allocation 7, 122, 136

Responsible Innovation and Regional Development course 103

RIS see regional innovation system (RIS) "rural buzz" 65; in area 68-69; in classroom 68; enhancement of 59; global pipeline 69

rural teacher education: analysis, critical junctures, and modes of change 35-37; changes and continuities in development of 26-38; higher education in Norway 30-32; historical institutionalism 28-30; regional needs and national policies 32-35; Sogn og Fjordane 32-35

Salata event 63, 70

ScienceDirect 193

science parks, 2, 16, 115

Scopus 193

self-esteem 175

Shanghai 112, 115-116

SIDS see Small Island Developing States (SIDS)

Silicon Valley 87

Sjøtun, Svein Gunnar 6, 96

Small Island Developing States (SIDS) 188

smart specialization 2

social embeddedness 206

social reality 79

societal engagement 192

socio-economic challenges 7

soft entrepreneurship model 98, 105-106

Sogndal, Norwegian village 5, 27, 28

Sogndal Teacher School 33-34

Sogn og Fjordane county 27, 28, 32-35, 37

spatiality 16,210

specialized schools 30

spin-offs 2, 87, 195

stakeholder, involvement in student incubators 119-120

Stanford-Silicon Valley collaboration 112

Start NHH 104

start-ups 208

State Council Opinions 113, 114

St. Augustine Campus, Trinidad 196

stipend 176

Stjernø Commission 31

Stord/Haugesund University College 35

strategic leadership 44

strategic plans 7, 161; formulation and implementation 159; Warsaw 156-169

strategy as pattern notion 141

strategy process: co-creation laboratory 147-149; institutional logics 143-144; new vision emergence 144-146; organization of implementation 147; reactions at faculty level 146-147; 
tracing 144-149; see also University of Agder (UiA)

structuration theory 19

student entrepreneurship 6, 96-109, 113-115, 209; analysis 105-107;

Bergen Entrepreneurship Academy 108; development 7; and extracurricular activities 102-105; regional embeddedness 97-99, 105-107; strategies and organization 101-102

STUD-ENT funding scheme 101 student incubators 97; 211 in Chinese universities 111-123; construction of 111-112; entrepreneurial mindset of students 120-121; entrepreneurship initiation 113-115; environmental contextual characteristics 6-7, 112; stakeholder involvement 119-120; structure and managerial style 116-119; student entrepreneurship 113-115; and university incubators 113-115

students: entrepreneurial mindset of 120-121; traineeships in UiA 147; see also internships

Sustainable Innovation course 104, 106 sustainable tourism $5,58,67$

teacher education 27; evolution of 29; in Norway 30-32; regional needs and national policies 32-35; see also rural teacher education

Technology Management, Business Administration and Innovation course 102-103

technology transfer office (TTO Valide) 80-81, 101

Telemark region 32, 142

temporality 12, 18-19, 212-215

temporary (project-based) organization 149 territorial embeddedness 99

tertiary education 32

third mission 1, 6, 100; academic engagement with industry $75-89$; activities 206; engaged university 86-87; and entrepreneurial architecture in UWI 190-193, 195, 197; entrepreneurial university $85-86$; findings $82-85$; future research 89;

Thomas, Elisa 1, 4, 5, 9, 11, 41, 44, 203

Tomasi, Sabrina 5, 58, 212

Triple A Strategy: Revitalizing Caribbean Development 2017-2022 198

TTO Valide see technology transfer office (TTO Valide)
UFRGS see Universidade Federal do Rio Grande do Sul (UFRGS)

UiA see University of Agder (UiA)

$\mathrm{UiB}$ see University of Bergen (UiB)

UNIMC see University of Macerata (UNIMC)

UNISINOS see Universidade do Vale do Rio dos Sinos (UNISINOS)

universal entrepreneurship campaign 122

universal innovation and entrepreneurship initiative 112, 114

Universidade do Vale do Rio dos Sinos (UNISINOS) 46

Universidade Federal do Rio Grande do Sul (UFRGS) 46

universities: aligning roles and strategic orientations 126-137; as constrainer of transformative process $77-80$; contributions to society 2 ; culturalcognitive dimension $16,77,78-79,86$, 94, 207; and entrepreneurship 78, 81, 86, 94-95; excellence and relevance 128; incubators 7,213 ; industry collaboration 88, 95; logics within 143-144, 144; normative dimension 15-16, 77, 78-79, 86, 94, 207; regulative dimension 15, $77,78,86,94,207$; role of $60-61$; science park 115 ; temporality $12,18-19$, 212-215; see also third mission

university-local government relationships 8, 156-169, 205; conceptual backdrop 158-159; partnership formation 161-163; policy implementation 164-167; strategic plan formulation 163-164

University of Agder (UiA) 142; co-creation laboratory 147-149; co-creation of knowledge vision (Samskaping av kunnskap) 146, 152; institutional logics 151; strategy process 144-149, 145; students' traineeships 147; “Together we create knowledge" vision 146

University of Bergen (UiB) 100, 102; entrepreneurship courses and extracurricular activities 104-105; and regional embeddedness 106-107

University of Macerata (UNIMC) 6, 59, 61-62; agri-food marketing course 66, 68; Edulingua in San Severino Marche 69

University of Oslo 30

University of Stavanger 80

University of the West Indies (UWI) 188-189, 214; activist leadership in Caribbean 188-200; Center for 
Leadership and Sustainable Development (CLSD) 196; Five Year Strategic Plan 193-194; historical, sociopolitical and economic context 189-190; Open Campus 196; third mission and entrepreneurial architecture 190-193, 195, 197

UWI see University of the West Indies (UWI)

Venture Cup 104

Vintage festival 63, 70

Virgin Atlantic 195

vocational college 129

vocational training 34

Warsaw 2020 strategy plan 161, 165

Warsaw 2030 strategy plan 162-163, 165, 211
Warsaw (Poland) 8, 205; development strategies 157-158, 162-165, 211; university-local government relationships 156-169

Web of Science 193

Welsh case study 60

Western Norway University of Applied Sciences (HVL) 35, 37, 100-102; entrepreneurship courses and extracurricular activities 102-103; and regional embeddedness 105-106

Wine Hackathon 65-66

World Bank 195

Wuhan 115-116, 119

Yttri, Gunnar 5, 26 


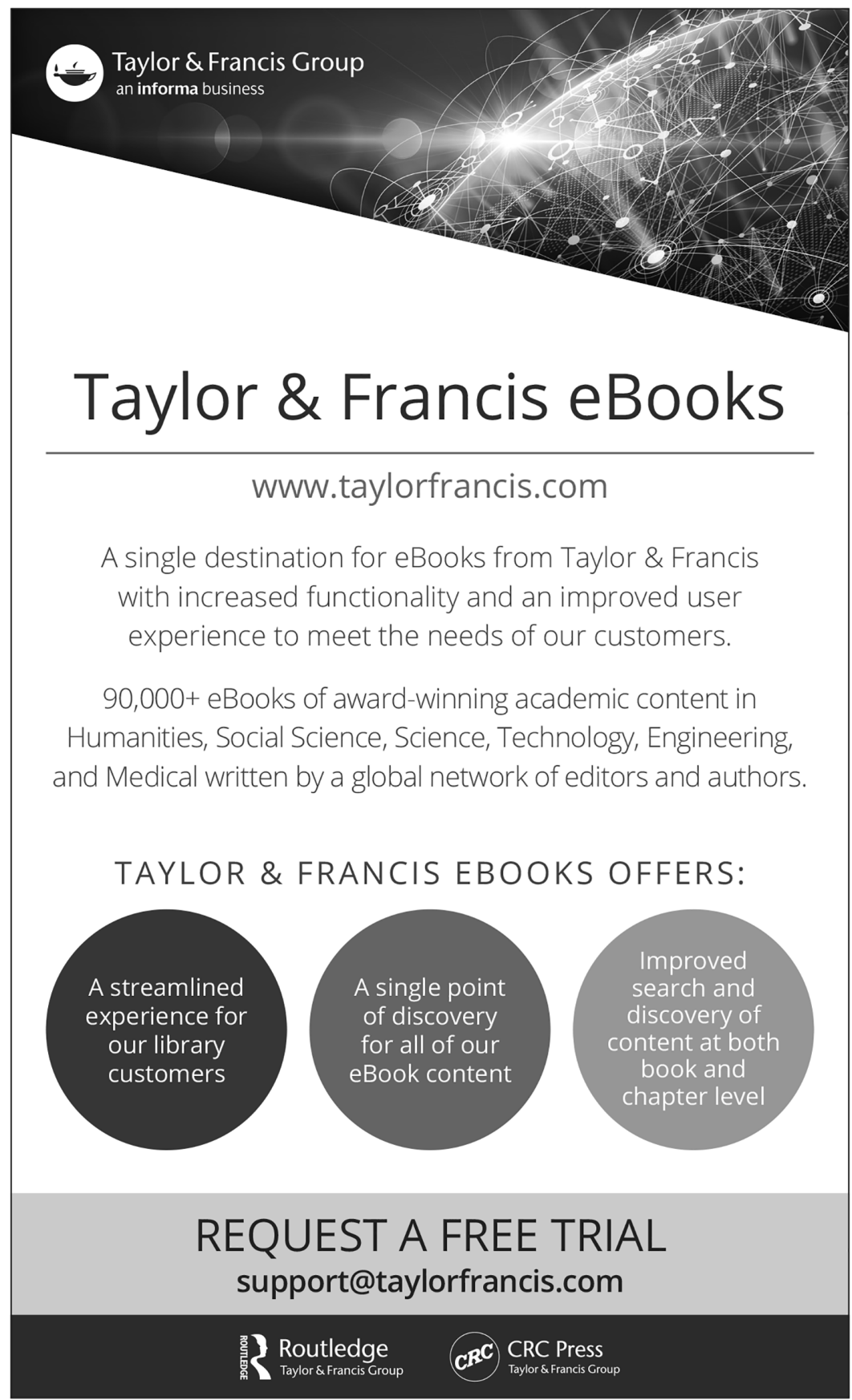

